\title{
Evaluation of the Nutrition-sensitive Features of the Fourth Phase of Ethiopia's Productive Safety Net Programme
}

Guush Berhane, Jenna Golan, Kalle Hirvonen, John Hoddinott, Sunny Kim, Alemayehu Seyoum Taffesse, Kibrewossen Abay, Thomas Assefa, Yetmwork Habte, Mehari Hiluf Abay, Bethelem Koru, Fanaye Tadesse, Haleluya Tesfaye, Abdulazize Wolle, and Feiruz Yimer 


\section{CONTENTS}

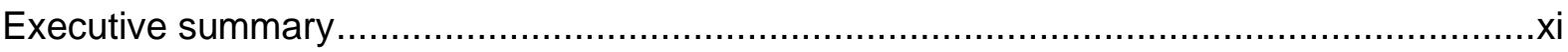

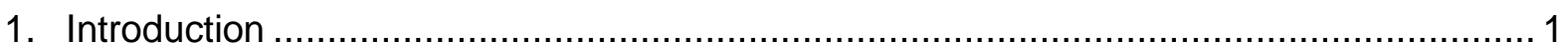

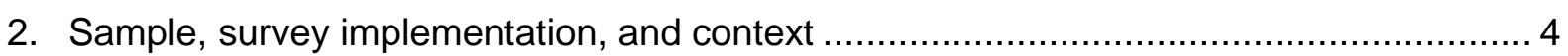

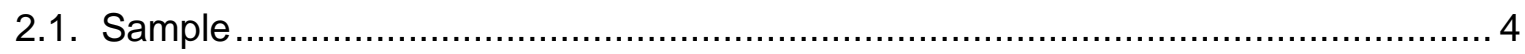

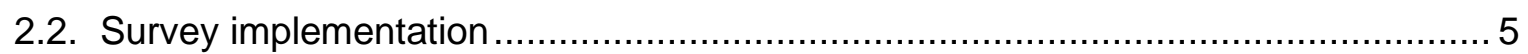

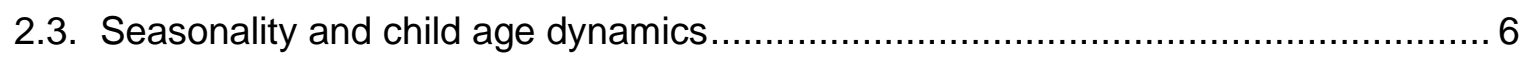

3. Household characteristics: access to resources, food security, and livelihoods.............. 9

3.1. Household characteristics ................................................................... 9

3.2. Food security, storage and consumption sources........................................... 12

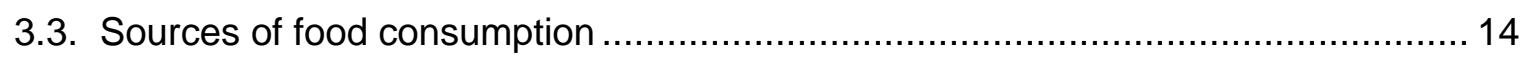

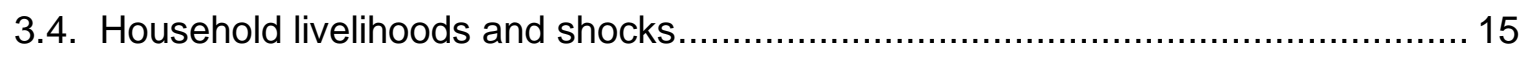

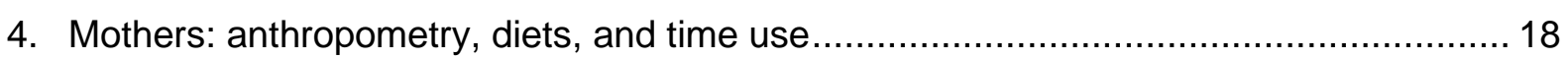

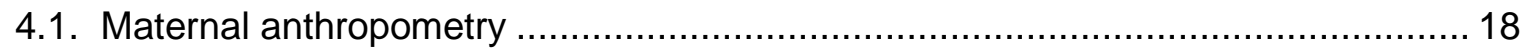

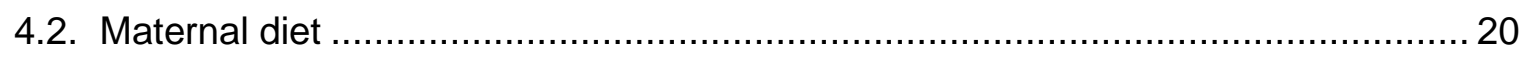

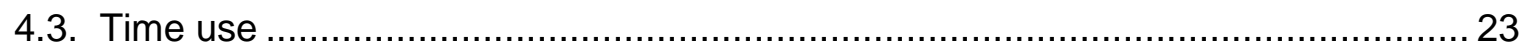

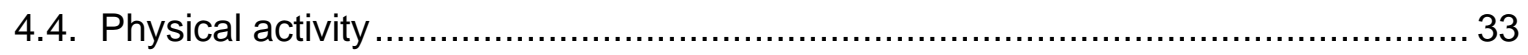

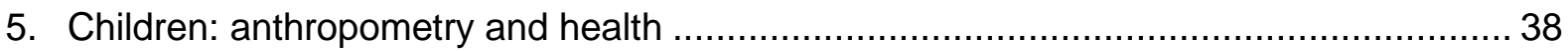

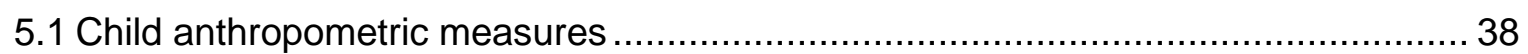

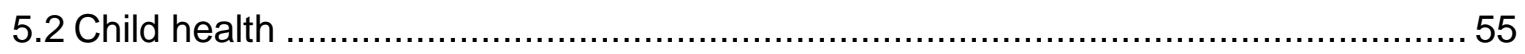

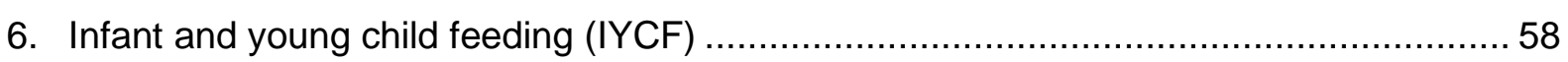

6.1. Knowledge and attitudes on infant and young child feeding ............................... 58

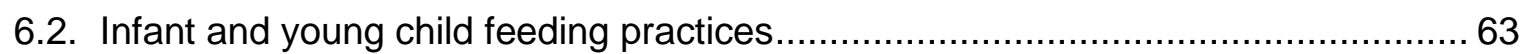

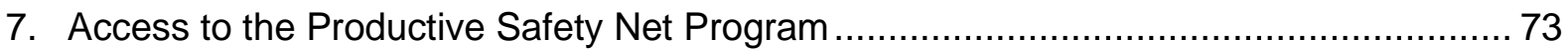

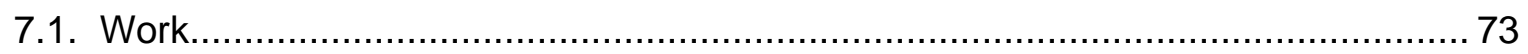

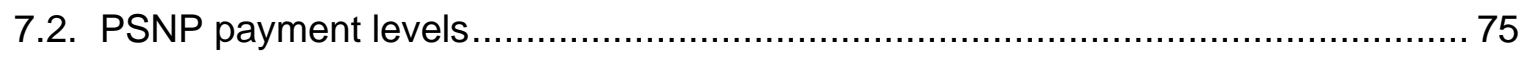

7.3. Protections for pregnant and lactating mothers benefitting from PSNP................. 76

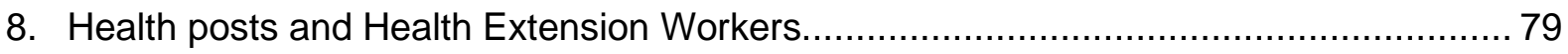

8.1. Health Extension Workers and health post characteristics ................................. 80

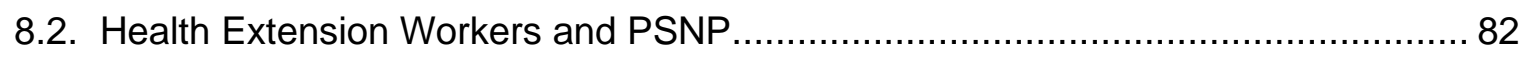

8.3. Workload, job satisfaction, and stress of Health Extension Workers....................... 88

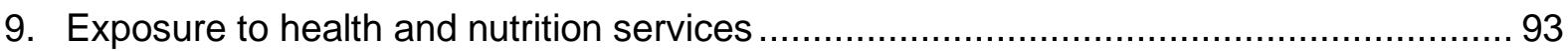

9.1. Exposure to antenatal care services among mothers with children less than 6 months of age.

9.2. Contact with Health Extension Workers and exposure to nutrition services among mothers with children 6 to 23 months of age........................................................ 96

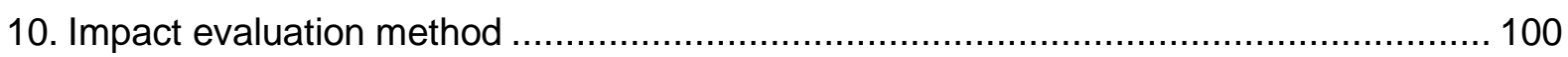

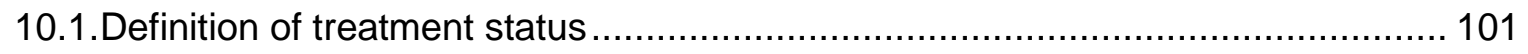

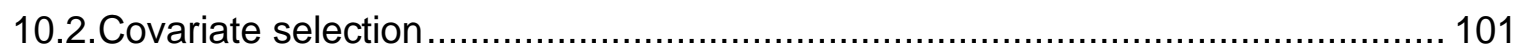

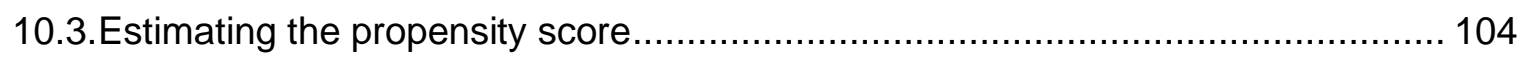

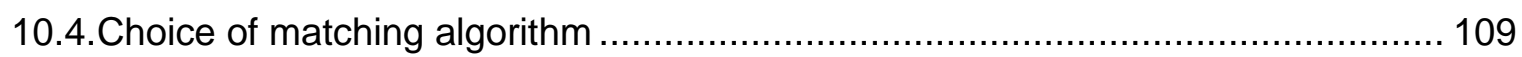

11. Impacts of nutrition-sensitive interventions of PSNP ........................................ 110 
11.1.Impacts on mothers

11.2.Impacts on maternal infant and young child feeding (IYCF) knowledge, attitudes,

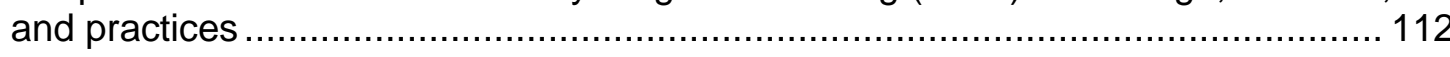

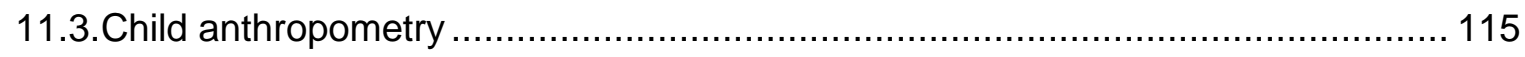

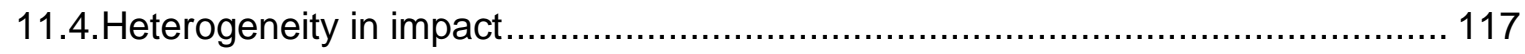

11.5. The impact of PSNP-4 on the level of nutrition outcomes ............................... 117

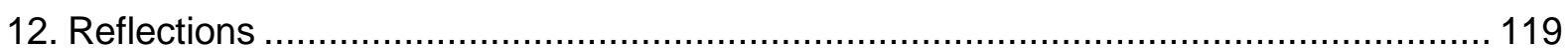

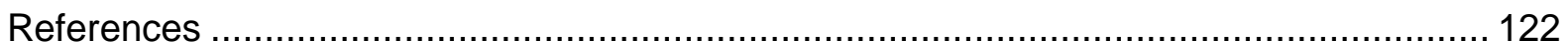

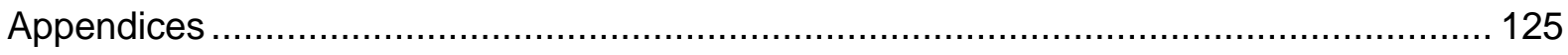

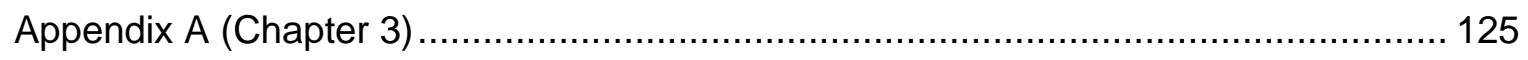

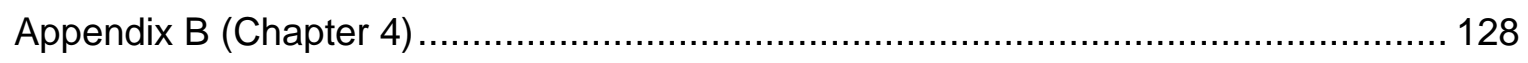

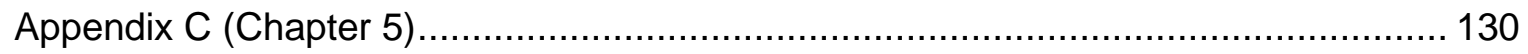

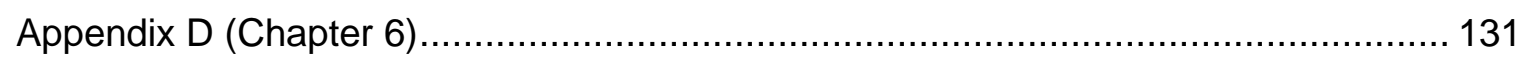

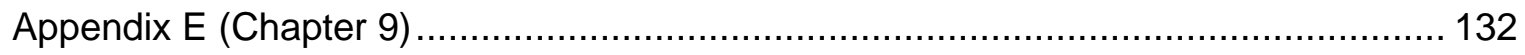




\section{TABLES}

Table 1.1. Research questions covered and the sample used to answer them ................... 3

Table 2.1. Sample size in March and August 2017 and 2019....................................... 5

Table 3.1. Index child and household characteristics by PSNP status, 2017 and $2019 \ldots \ldots . .9$

Table 3.2. Access to health posts, electricity, mobile phones and markets by region and

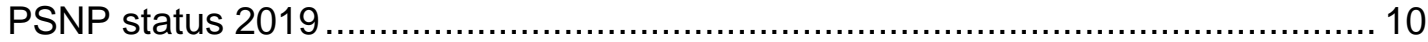

Table 3.3. Source of drinking water by region and PSNP status, $2019, \%$ of households.... 10

Table 3.4. Housing and living quality by region and PSNP status, 2019, \% of households.. 11

Table 3.5. Hygiene conditions and practices by region and PSNP status, $2019, \%$ of

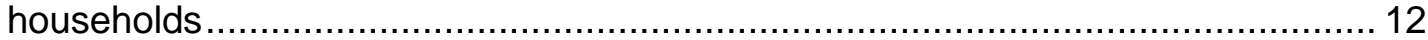

Table 3.6. Food gap in the last 6 months, by survey round and PSNP status ................... 12

Table 3.7. Mean food gap (in months) in the last six months, by region and PSNP status .. 13

Table 3.8. Share of households with cereals in storage in March and August 2019, by region

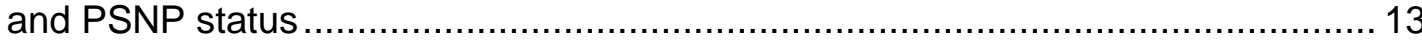

Table 3.9. Share of households with pulses in storage in March and August 2019, by region

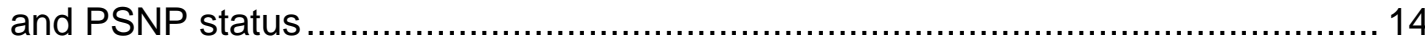

Table 3.10. Mean amount (in kg) of cereals in storage in March and August 2019, by region

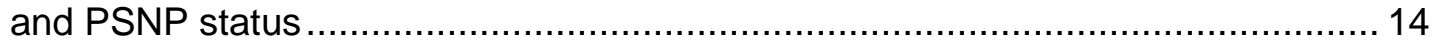

Table 3.11. Primary sources of food consumption by month and PSNP beneficiary status . 15

Table 3.12. Land operated, livestock assets, and engagement in nonfarm activities .......... 16

Table 3.13. Crop shocks and reported consequences............................................... 17

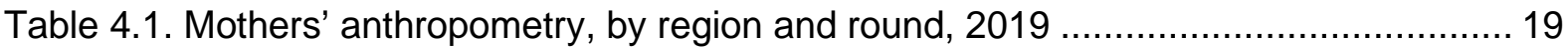

Table 4.2. Mothers' anthropometry by PSNP beneficiary status and round, $2019 \ldots \ldots \ldots \ldots . . .19$

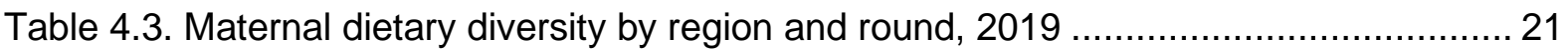

Table 4.4. Mothers' dietary diversity by PSNP beneficiary status and round .................... 22

Table 4.5. Mother's dietary diversity by household religion and round .............................. 23

Table 4.6. Percent of mothers that participated in specific activities during the previous day,

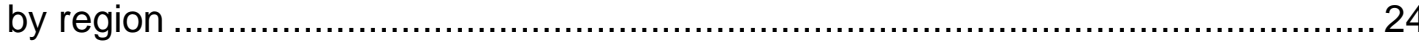

Table 4.7. Percent of mothers that participated in specific activities during the previous day, by PSNP beneficiary status and survey round ................................................. 25

Table 4.8. Consolidation of time use categories ......................................................... 26

Table 4.9. Mothers' time use (minutes and percent of total), by round .............................. 26

Table 4.10. Mothers' time use (minutes) when child not present, by round ....................... 29

Table 4.11. Amount of time (minutes) mothers spent with child, by age of index child........ 31

Table 4.12. Indicators of physical activity disaggregated by season and region ................. 34

Table 4.13. Indicators of physical activity disaggregated by season and PSNP status ........ 35

Table 4.14. Activities during minutes spent at vigorous exertion level disaggregated by

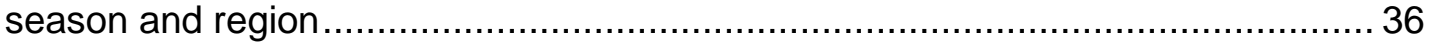

Table 4.15. Percent of vigorous time spent in different activities ..................................... 37

Table 5.1. Child measurement records with biologically implausible values, by anthropometric indicator and survey round, percent

Table 5.2. Mean length-for-age z-score and stunting prevalence of index children 6 to 23 months of age, by survey round and beneficiary status ................................... 46

Table 5.3. Mean length-for-age z-score and stunting prevalence of index children 6 to 23 months of age, by survey round and sex of the child 
Table 5.4. Mean length-for-age z-score and stunting prevalence of index children 6 to 23 months of age, by survey round and child age

Table 5.5. Mean weight-for-length z-score and wasting prevalence of index children 6 to 23 months of age, by survey round and beneficiary status

Table 5.6. Mean weight-for-length z-score and wasting prevalence of index children 6 to 23 months of age, by survey round and sex of the child

Table 5.7. Mean weight-for-length z-score and wasting prevalence of index children 6 to 23 months of age, by survey round and child age

Table 5.8. Mean MUAC and acute malnutrition prevalence of index children 6 to 23 months of age, by survey round and beneficiary status.

Table 5.9. Mean MUAC and acute malnutrition prevalence of index children 6 to 23 months of age, by survey round and sex of the child.

Table 5.10. Mean MUAC and acute malnutrition prevalence of index children 6 to 23 months of age, by survey round and child age....

Table 5.11. Mean weight-for-age z-score and underweight prevalence of index children 6 to 23 months of age, by survey round and beneficiary status 54

Table 6.1. Perceptions on when to start breastfeeding by PSNP status, percent of mothers58

Table 6.2. Perceptions on when to start breastfeeding by region, percent of mothers ......... 59

Table 6.3. Perceptions on when to stop exclusive breastfeeding by PSNP status, percent of mothers

Table 6.4. Perceptions on when to stop exclusive breastfeeding by region, percent of mothers

Table 6.5. Correct responses to questions about complementary feeding practices, by round and PSNP status, percent of mothers responding correctly .............................6 60

Table 6.6. Average complementary feeding knowledge percentage score, by PSNP status and region.

Table 6.7. WHO recommended IYCF indicators related to breastfeeding and introduction of complementary feeding, by year and by PSNP status

Table 6.8. WHO recommended IYCF indicators related to breastfeeding and introduction of complementary feeding, by year and by region

Table 6.9. WHO recommended IYCF indicators related to quality and quantity of complementary feeding, by PSNP status

Table 6.10. WHO recommended IYCF indicators related to quality and quantity of complementary feeding, by region....

Table 6.11. Number of food groups consumed in the past 24 hours among index children, by age group and PSNP status

Table 6.12. Percent of children consuming animal source foods by round, PSNP status, region, and household religion....

Table 6.13. Dietary diversity score, minimum dietary diversity prevalence, and minimum acceptable diet prevalence based on eight food groups

Table 7.1. Mean days worked on PSNP Public Works between Tir and Nehasse EC2011, by month and region

Table 7.2. Individuals by type who worked on PSNP, Tir to Nehasse EC2011 .................. 74

Table 7.3. Total days worked on PSNP between Tir and Nehasse EC2011, by sex........... 74

Table 7.4. Mean value of payments (birr) received between Tir and Nehasse EC2011, by region and type

Table 7.5. Distribution of number of payments received between Tir and Nehasse EC2011,

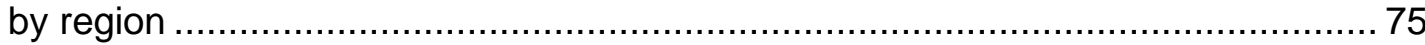

Table 7.6. PSNP protections during pregnancy for women in PSNP households ............... 77 
Table 7.7. PSNP protections post-pregnancy for women in PSNP households .................. 78

Table 8.1. Health Extension Worker characteristics, by region, 2019 ............................. 80

Table 8.2. Health post characteristics, by region, 2017 and 2019 ................................... 81

Table 8.3. Undertaking specific activity and assessment of time spent on it, by activity group, 2019, percent of Health Extension Workers reporting ...................................... 82

Table 8.4. Health Extension Workers reporting membership in Kebele Food Security Task

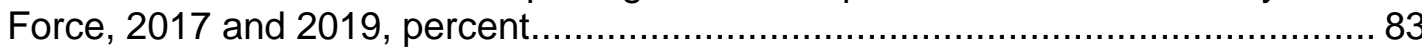

Table 8.5. Health Extension Workers reporting membership in Kebele Appeals Committee,

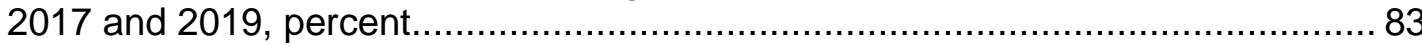

Table 8.6. Interactions of Health Extension Workers with HDAs, DAs, and Social Workers, 2019

Table 8.7. Days of PSNP training received, by region, 2019, percent of HEWs.................. 85

Table 8.8. Hours worked by Health Extension Workers per day by activity and region, 2017

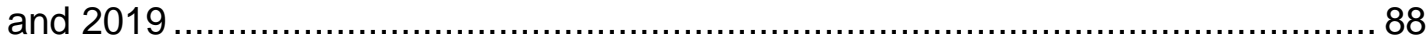

Table 8.9. Perceptions of change in workload, by region, 2019.................................... 89

Table 8.10. Self-confidence, job motivation, and job satisfaction of Health Extension Workers, all regions, 2017 and 2019, percent

Table 8.11. Overall job satisfaction of Health Extension Workers, all regions, 2017 and 2019,

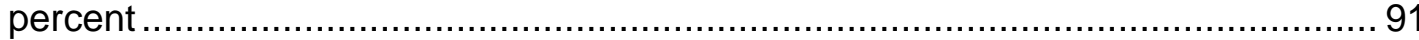

Table 8.12. Mean stress score by dimension/subscale among Health Extension Workers, by region and year

Table 8.13. Health Extension Workers emotional exhaustion, personal accomplishment, and depersonalization, by region and year, percent .......................................... 92

Table 9.1. Use of antenatal care services by PSNP status, 2017 and 2019 ..................... 93

Table 9.2. Use of antenatal care services by region, 2017 and 2019 ............................... 94

Table 9.3. Exposure to nutrition information from HEWs or HDAs in the past three months by PSNP status, 2017 and 2019

Table 9.4. Exposure to nutrition information from other sources in the past three months by

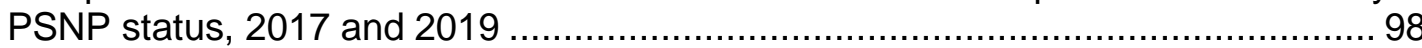

Table 9.5. Exposure to nutrition information from other sources in the past three months by

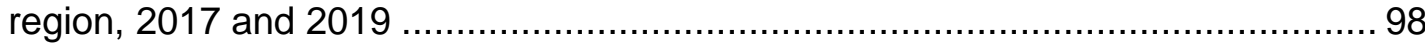

Table 9.6. Children 6 to 23 months of age exposure to growth monitoring and promotion in the past three months by PSNP status, percent ........................................... 98

Table 9.7. Children 6 to 23 months of age exposure to growth monitoring and promotion in

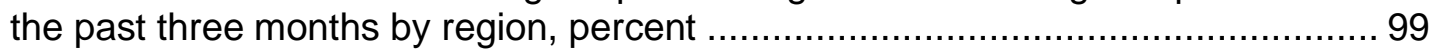

Table 10.1. Covariates used to estimate the propensity score ..................................... 102

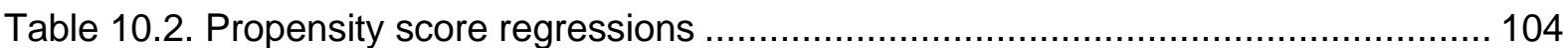

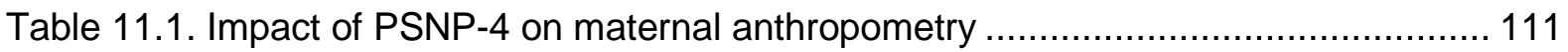

Table 11.2. Impact of PSNP-4 on maternal dietary diversity........................................ 111

Table 11.3. Impact of PSNP-4 on women's workload (year 2019 only) ............................ 112

Table 11.4. Impact of PSNP-4 on women's time use for their own activities and childcare 112

Table 11.5. Impact of PSNP-4 on maternal complementary feeding knowledge score ...... 113

Table 11.6. Impact of PSNP-4 on dietary diversity, children aged 6 to 23 months............ 113

Table 11.7. Impact of PSNP-4 on meal frequency, children aged 6 to 23 months ............ 114

Table 11.8. Impact of PSNP-4 on minimum acceptable diet and consumption of animal sourced foods, children aged 6 to 23 months .................................................. 114

Table 11.9. Impact of PSNP-4 on hygiene practices in the household ........................... 115 
Table 11.10. Impact of PSNP-4 on chronic undernutrition, children 6 to 23 months of age 116

Table 11.11. Impact of PSNP-4 on acute undernutrition, children 6 to 23 months of age .. 116

Table 11.12. Impact of PSNP-4 on weight for age and underweight prevalence, children 6 to

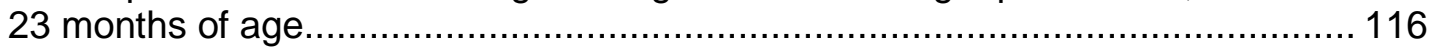

Table 11.13. Impact of PSNP-4 on levels of child and maternal nutrition outcomes, cross

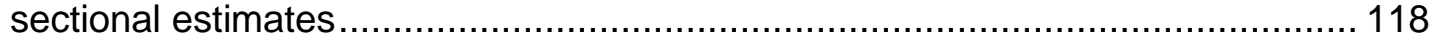

Table A1. Index child and household characteristics by region 2017 and $2019 \ldots \ldots \ldots \ldots \ldots . \ldots . \ldots . \ldots . .125$

Table A2. Hygiene conditions and practices by region and PSNP 2017 ....................... 125

Table A3. Food gap in the last 6 months, by survey round and PSNP status, 2017 ......... 125

Table A4. Mean Food gap (in months) in the last six months, by region and PSNP status 126

Table A5. Share of households with cereals in storage in March and August 2017, by region

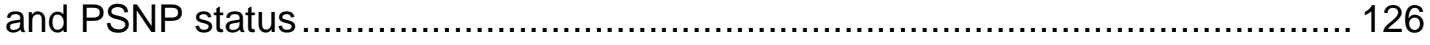

Table A6. Share of households with pulses in storage in March and August, by region and

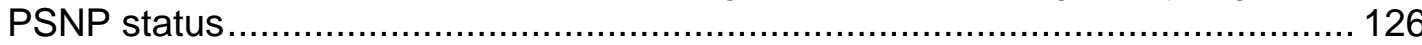

Table A7. Mean amount (in kg) of cereals in storage in March and August, by region and PSNP status................................................................................... 126

Table A8. Primary sources of food consumption by month and PSNP beneficiary status,

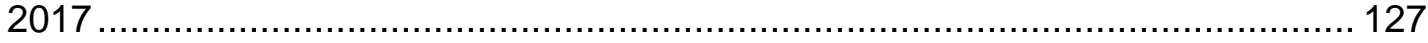

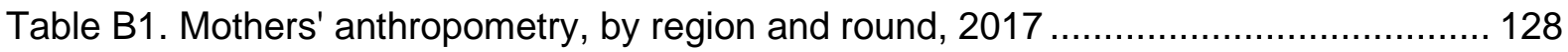

Table B2. Mothers' anthropometry by PSNP beneficiary status and round, 2017 ............. 128

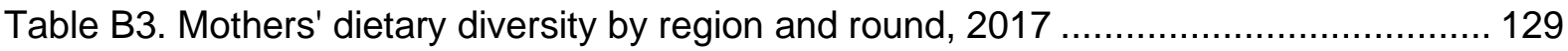

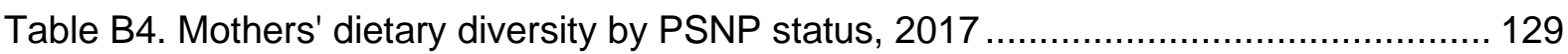

Table C1. Anthropometric indicators, children 6 to 23 months of age, by region ............... 130

Table C2. Fever, diarrhea and ARI prevalence, children 6 to 23 months of age, by region,

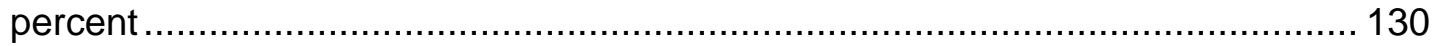

Table D1. WHO recommended core infant and young child feeding (IYCF) indicators ...... 131

Table E1. Whether the same Health Extension Worker was interviewed in both 2017 and

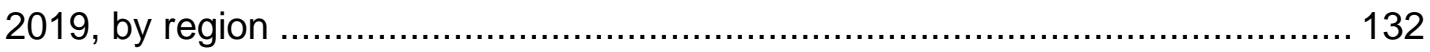

Table E2. Health Extension Worker characteristics, by region, 2017 ........................... 132

Table E3. Percent of Health Extension Workers reporting undertaking specific activity and their assessment of time spent on activity, by activity group............................. 133

Table E4. Interactions of Health Extension Workers with HDAs, Development Agents, and

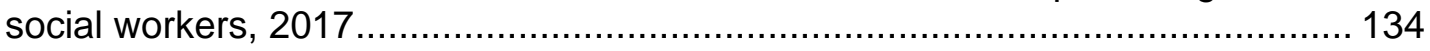

Table E5. Length of PSNP training for Health Extension Workers, by region, 2017, percent

Table E6. Perceptions of change in workload of Health Extension Workers, 2017, by region

Table E7. Frequencies in the experience of 22 feelings related to occupation burnout among all Health Extension Workers across the four regions, 2017, percent 136

Table E8. Frequencies in the experience of 22 feelings related to occupation burnout among all Health Extension Workers across the four regions, 2019, percent 137 


\section{FIGURES}

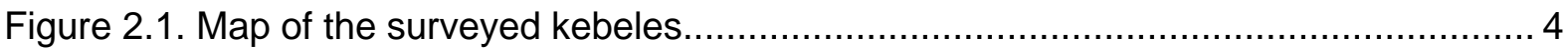

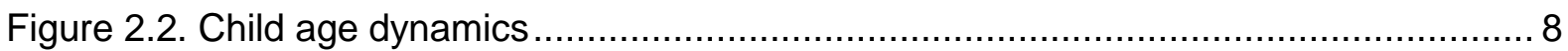

Figure 3.1. Primary sources of food in the last six months March and August 2017 and 2019)

Figure 4.1. Relationship between maternal BMI and child's age .................................. 20

Figure 4.2. Mothers' time use, March 2019, by region................................................. 27

Figure 4.3. Mothers' time use, August 2019, by region............................................... 27

Figure 4.4. Mothers' time use, by PSNP status, survey round, and activity ...................... 28

Figure 4.5. Mothers' time use (minutes) when child not present, by region, March 2019 .... 29

Figure 4.6. Mothers' time use (minutes) when child not present, by region, August 2019... 30

Figure 4.7. Mothers' time use (minutes) when child not present, by PSNP status and survey

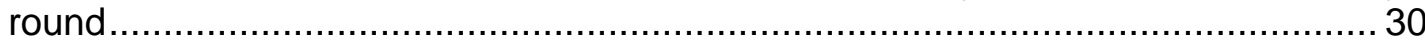

Figure 4.8. Mothers' time spent on active childcare, by age of index child and region, March 2019

Figure 4.9. Mothers' time spent providing active childcare, by age of index child and region, August 2019

Figure 4.10. Mothers' time spent on active childcare, by age of index child, PSNP status and

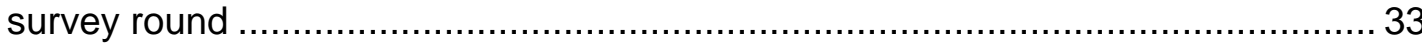

Figure 5.1. Child age distributions for the full sample, March 2017 and March 2019 .......... 40

Figure 5.2. Child age distributions by survey round ................................................... 40

Figure 5.3. Length for age distributions by survey round .......................................... 42

Figure 5.4. Full length for age distributions by survey round in 2017 and $2019 \ldots \ldots \ldots \ldots \ldots . . . . . . .43$

Figure 5.5. Stunting prevalence in PSNP and non-PSNP households by survey round...... 43

Figure 5.6. Simulation exercise: alternative stunting thresholds .................................... 44

Figure 5.7. Relationship between length-for-age z-score and child's age in months........... 45

Figure 5.8. Weight for length distributions by survey round ....................................... 48

Figure 5.9. Wasting prevalence in PSNP and non-PSNP households by survey round....... 48

Figure 5.10. Mid-upper arm circumference distributions by survey round......................... 50

Figure 5.11. Severe and moderate acute malnutrition prevalence based on MUAC in PSNP and non-PSNP households by survey round ................................................. 51

Figure 5.12. Prevalence of acute malnutrition based on WHO definition, children 6 to 23 months of age, by survey round and PSNP status........................................ 54

Figure 5.13. Prevalence of fever among children 6 to 23 months of age, by survey round and PSNP status.

Figure 5.14. Prevalence of diarrhea among children 6 to 23 months of age, by survey round

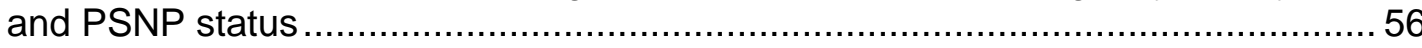

Figure 5.15. Prevalence of acute respiratory infection (ARI) among children 6 to 23 months

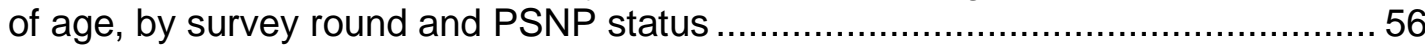

Figure 5.16. Relationship between illness risk and child age ......................................... 57

Figure 6.1. Mean complementary feeding knowledge score among caregivers in PSNP households, by survey round, percentage score .............................................. 61

Figure 6.2. Relationship between complementary feeding knowledge score and mother's age

Figure 6.3. Relationship between complementary feeding knowledge score mother's level of education 
Figure 6.4. Prevalence of age-appropriate breastfeeding practices and introduction of complementary feeding, PSNP households.

Figure 6.5. Prevalence of age-appropriate complementary feeding practices, PSNP households.

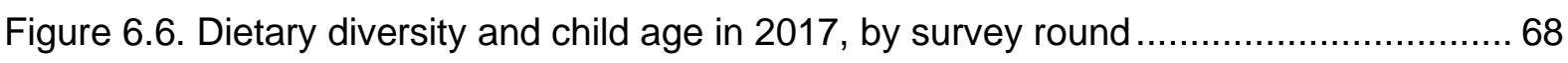

Figure 6.7. Dietary diversity and child age in 2019, by survey round ............................... 68

Figure 6.8. Distribution of children's dietary diversity scores in August 2019, PSNP households

Figure 6.9. Percent of children consuming zero food groups and child's age, PSNP households in August 2019

Figure 6.10. Intake of seven food groups in the past 24 hours among index children age 6 to 23 months in PSNP households, by survey round

Figure 7.1. Percent of individuals by type who worked on PSNP between Tir and Nehasse EC2011, by region.

Figure 7.2. Mean value of payments (birr) received between Tir and Nehasse EC2011, by month and region

Figure 8.1. Percent of HEWs who received training on PSNP implementation in the last 12 months, by region, 2017 and 2019

Figure 8.2. Percent of HEWs who ever received training on Timed and Age-Appropriate Messaging for infant and young child feeding, by region, 2017 and 2019.

Figure 8.3. When should a pregnant woman stop working in public works? - HEW responses (\%) by training status

Figure 8.4. When should a new mother return to Public Works? - HEW responses (\%) by training status....

Figure 8.5. What is the arrangement for PSNP households with a malnourished child under five years old? - HEW responses (\%) by training status.

Figure 9.1. Contact with Health Extension Workers and health post or health center visits in the past three months, by PSNP status, 2017 and $2019 .$.

Figure 10.1. Common support graphs. 108 


\section{ABBREVIATIONS AND DEFINITIONS}

$\begin{array}{ll}\text { ARI } & \text { Acute respiratory infection } \\ \text { BCC } & \text { Behavior Change Communication } \\ \text { BMI } & \text { Body Mass Index } \\ \text { CAPI } & \text { Computer-assisted personal interviewing } \\ \text { DA } & \text { Development Agent } \\ \text { DHS } & \text { Demographic and Health Survey } \\ \text { EC } & \text { Ethiopian calendar } \\ \text { FANTA } & \text { USAID's Food and Nutrition Technical Assistance III Project (FANTA) } \\ \text { FAO } & \text { Food and Agriculture Organization of the United Nations } \\ \text { GPAQ } & \text { Global Physical Activity Questionnaire } \\ \text { LAZ } & \text { Length for age z-score } \\ \text { HDA } & \text { Health Development Army } \\ \text { HEW } & \text { Health Extension Worker } \\ \text { IFPRI } & \text { International Food Policy Research Institute } \\ \text { Index child } & \text { A child under 24 months of age whose household was interviewed } \\ \text { IYCF } & \text { Infant and Young Child Feeding } \\ \text { kebele } & \text { Sub-district-level administrative unit } \\ \text { MAD } & \text { Minimum Acceptable Diet } \\ \text { MDD-W } & \text { Minimum Dietary Diversity - Women } \\ \text { MET } & \text { metabolic equivalent } \\ \text { MUAC } & \text { Mid-Upper Arm Circumference } \\ \text { PIM } & \text { Program Implementation Manual } \\ \text { PSNP } & \text { Productive Safety Net Program } \\ \text { SD } & \text { standard deviation } \\ \text { SNNP } & \text { Southern Nations, Nationalities, and Peoples' Region } \\ \text { TLU } & \text { Tropical Livestock Unit } \\ \text { WAZ } & \text { Weight for age z-score } \\ \text { WHO } & \text { World Health Organization } \\ \text { WLZ } & \text { Weight for length z-score } \\ \text { woreda } & \text { District-level administrative unit } \\ & \end{array}$




\section{EXECUTIVE SUMMARY}

This study assesses progress in the implementation of the nutrition-sensitive interventions of the fourth phase of Ethiopia's Productive Safety Net Programme (PSNP-4) and its impact on: (1) the pathways underpinning children's nutritional status; and (2) the roles it plays in reducing the malign effect of seasonality on the nutritional status of women and pre-school children. The analysis is based on four rounds of household survey data, conducted in March and August 2017 (baseline) and March and August 2019 (endline). These surveys focused on households with a child less than 24 months of age (index child) and his/her mother (index mother). In 2017 and 2019, the survey teams visited more than 2,500 households in 264 kebeles in 88 PSNP woredas in the Amhara, Oromia, SNNP, and Tigray regions.

\section{Household and caregiver characteristics (Chapter 3)}

In PSNP households, an average mother of the index child is 29 years old while an average father (or male caregiver) is 37 years old. About 90 percent of households in the sample are male-headed. Education levels are extremely low - for example, in March 2017 only 14 percent of the mothers and 13 percent of the fathers in PSNP households reported having been to school. An average PSNP household has about six members. Smallholder agriculture forms the main source of livelihoods, with the average household operating a hectare of land and owning 3 Tropical Livestock Units. An average household reported a food gap of 1.2 months, a food gap being the period during which the household was not able satisfy its food needs over the last 12 months. Hygiene conditions in these localities are poor. More than half of the households had animal feces on their compounds and about half of the households reported defecating in the open. For more than 40 percent of households, the main source of drinking water is open and unprotected spring, lake, or rainwater. It takes about an hour to fetch water in these localities.

\section{Maternal anthropometry, diets, energy expenditure and time use (Chapter 4)}

The average index mother had a body mass index (BMI) of $20 \mathrm{~kg} / \mathrm{m}^{2}$. In 2019, the change in the mean BMI was marginal between March and August, the share of underweight $\left(B M I<18.5 \mathrm{~kg} / \mathrm{m}^{2}\right)$ mothers increased from 24 percent in March to 30 percent in August. This change was largely driven by the decline in the number of mothers who had recently given birth - all mothers re-visited in August had already given birth by March when first visited. In each survey round, only about 3 percent were categorized as overweight or obese $\left(>25 \mathrm{~kg} / \mathrm{m}^{2}\right.$ ). The average mid-upper arm circumference (MUAC) was $24 \mathrm{~cm}$. Based on a $21 \mathrm{~cm}$ MUAC cutoff, between 7 and 8 percent of mothers were acutely malnourished in 2019. Maternal diets are extremely monotonous. On a dietary diversity score scale of 0 to10, the average caregiver consumed foods from less than three food groups in 2019 and only about 6 percent met the minimum dietary diversity for women (MDD-W) of five food groups. There was some improvement since 2017.

Analysis of time use in 2019 revealed that mothers divide their time between childcare and cooking, which take nearly 50 percent of their total time. In March 2019, time spent on personal care and leisure was between 20 and 25 percent of total available time. Time allotted for food production related activities, e.g., farming, increased considerably in August 
at the expense of time devoted to child and personal care. This also became evident in the analysis of energy expenditure, which considerably increased in August.

\section{Child anthropometry and health (Chapter 5)}

Chronic undernutrition rates among children 6 to 23 months of age in PSNP localities are high. Depending on the survey round, between 39 and 45 percent of the children in PSNP households were categorized as short for their age, or stunted. This is a considerably higher share than the national stunting prevalence of 33 percent for children in the same age range. Considerable fluctuations in stunting prevalence were also documented across the survey rounds, possibly because of the large number of children just below or above the stunting threshold. Measures of acute undernutrition are also relatively high with distinct seasonal patterns. Irrespective of whether weight-for-length or MUAC is the indicator being used, acute undernutrition prevalence was considerably higher in the postharvest season (March) compared to the lean season (August).

Analysis of child health indicators revealed that child illness risk remains high in these localities. In each round, nearly one-third of children were reported to have experienced a recent bout of fever. The share of children that had a recent episode of diarrhea was also high ranging between 23 and 32 percent, depending on the survey round. The risk of acute respiratory illnesses was lower than fever and diarrhea, but was found to be higher in the postharvest season (March) compared to the lean season (August).

\section{Infant and child feeding (Chapter 6)}

Knowledge and practices of age-appropriate breastfeeding practices are high with more than 70 percent of children less than 6 months of age being exclusively breastfed. In contrast, knowledge and practices regarding complementary feeding are extremely poor. In each survey round, less than 5 percent of the children age 6 to 23 months consumed a diet that is considered acceptable by World Health Organization standards. Child diets, in particular, are extremely monotonous with the average child consuming foods from two or fewer food groups. There are also widespread misconceptions and delays in providing complementary food in a young child's diet.

\section{Access to PSNP (Chapter 7)}

Overall, the average PSNP household worked 76.7 days on PSNP over the eight-month PSNP Public Works period each year. Mean days worked was highest in SNNP, lowest in Oromia, and about the same in Amhara and Tigray. Mean days worked in each month between January and August varied across regions. The public works are mainly carried out by household heads, and by extension, males. Across all regions, mean payments were 3,648 Birr (approx. 126 USD) per household for the whole Public Works season. Cash accounted for 73 percent of the value of all Public Works payments.

Of the 812 mothers who reported to have been pregnant after January 2018, 28 percent were working on PSNP Public Works. Among those, 59 percent stopped working after they learned they were pregnant, an improvement of 31 percent from the 2017 baseline, while 12 percent continued to work until giving birth, which is an improvement from the 20 percent that continued to work at baseline. More than half of pregnant women that stopped working on PSNP Public Works were advised to do so by a Health Extension Worker, which is quite an improvement from the 30 percent at baseline. However, 29 percent of women reported 
they were discouraged from stopping work by the Community Food Security Taskforce. Moreover, in 26 percent of the households, other household members put in more PSNP Public Work days after the mother stopped working, with these percentages being essentially unchanged from 2017. After giving birth, 36 percent of women resumed working on Public Works at, on average, about 5.1 months after delivery - this despite the PSNP-4 Program Implementation Manual stating that they should not do so until 12 months after giving birth.

\section{Health posts and Health Extension Workers (Chapter 8)}

Health Extension Workers (HEW) are the frontline cadre of workers implementing the nutrition-sensitive components of PSNP. Most HEWs have post-secondary education and are from the woreda in which they work, so they are well-qualified and familiar with the communities they serve. HEWs work nearly every day of the month, working long hours every day, and carry heavy client caseloads - depending on the year, between 27 and 36 pregnant women and between 104 and 132 children aged under 24 months per HEW. The health posts in which they work are equipped with rudimentary facilities - only 21 percent have electricity, 42 percent have a flush or VIP latrine, and 40 percent have piped water. More than half (58 percent) do not have a height board for measuring children's height and 13 percent do not have a scale for measuring children's weight.

The percentage of HEWs who received training on PSNP implementation in the last 12 months increased from 25 to 62 percent between 2017 and 2019. This increase was observed in all regions. However, regional disparities in access to PSNP training remain marked, ranging in 2019 from 85 percent in Tigray to 45 percent in SNNP. Training matters: Untrained HEWs (those who did not receive PSNP training in the last 12 months) are much more likely to give incorrect responses regarding the transition of pregnant and lactating women to temporary Direct Support arrangements for PSNP households with a malnourished child under five years old. However, there is also evidence that key messages that should have been delivered during this training were either not conveyed or not retained.

Most HEWs perceive that their workload is "too much". Eighty percent of HEWs reported that their workload in the last 12 months had increased to such an extent that they had added 1 to 2 additional work hours per day to keep up with this increased workload,. While these responses are found in all regions, they are especially pronounced in Tigray. This increasing workload may be affecting the mental health of HEWs. In 2019, 34 percent showed signs of medium or high levels of emotional exhaustion; 50 percent provided responses consistent with medium or high levels of reduced levels of personal accomplishment; and 54 percent showed signs of medium or high levels of depersonalization. A reduced sense of personal accomplishment among HEWs was apparent between 2017 and 2019.

\section{Exposure to health and nutrition services (Chapter 9)}

One of the key intervention areas of the nutrition-sensitive PSNP-4 is increasing exposure to health and nutrition services through incentivizing mothers and training HEWs. Considering this, between the 2017 and 2019 survey rounds a trend of increased exposure to facilitybased care, particularly at the heath center or hospital, was observed among mothers with children less than 2 years of age. More mothers reported that they were exposed to 
antenatal care, delivered their child at a healthcare facility, and visited the local health center in the last 3 months. However, exposure to community-based care delivered by HEWs and Health Development Army staff and nutrition-specific interventions - particularly nutrition counseling during pregnancy or in the last 3 months among mothers with children 6 to 23 months of age, or any growth monitoring - fell over time across all regions. Exposure to nutrition information from food demonstrations and community conversations or gatherings, however, increased significantly among both PSNP and non-PSNP mothers over time and across all regions.

\section{Impact of nutrition-sensitive PSNP-4 on maternal and child outcomes (Chapters 10 \& 11)}

Statistical matching methods combined with a difference-in-difference approach was used to assess the impact of PSNP-4 on various nutrition and hygiene outcomes: mother's diet; mother's anthropometry; mother's workload and time use for their own activities and childcare; maternal infant and young child feeding knowledge, attitudes, and practices; child anthropometry; and hygiene conditions in the home. None of the impact estimates reported were statistically different from zero. This indicates that PSNP-4 nutrition-sensitive interventions did not lead to improvements in nutrition and hygiene related outcomes. Limited implementation of the nutrition-sensitive provisions may explain these disappointing findings. 


\section{INTRODUCTION}

The Productive Safety Net Programme (PSNP) is the Government of Ethiopia's principal social protection program. Beginning in 2005, PSNP has focused on reducing food insecurity and household asset depletion in the face of shocks while at the same time making use of labor during slack periods to build essential community assets and address environmental degradation. PSNP operates in drought-prone woredas (districts) in Ethiopia which historically have been dependent on food aid. At its core, PSNP provides six months of public works employment to its clients with a small number of individuals, primarily elderly and disabled persons, receiving unconditional transfers called Direct Support. Depending on location, payments are received in cash or in-kind, principally grain. The fourth phase of PSNP seeks to benefit approximately 8 million Ethiopians, making it one of the largest social protection programs in sub-Saharan Africa. Careful biannual evaluations of PSNP since 2006 have shown that the program has improved household level food security and helped protect assets (Berhane et al 2011; 2015). These evaluations also show that participation in PSNP had no impact on pre-school nutritional status as measured by height-for-age, weight-forheight, or weight-for-age z-scores (Berhane et al. 2016). A limitation of this work, however, is that data were not available on the inputs that affect children's nutritional status and so the impact of PNSP (or lack thereof) on the pathways that lead to improved nutrition among preschoolers is not known. Further, data was not collected that would allow analysis of the impact of PSNP on women's nutritional status.

The absence of impact of PSNP on children's nutritional status informed the design of PSNP-4 with the goal of making the program more nutrition-sensitive (GFDRE 2014b). PSNP-4 is designed to facilitate linkages with health and nutrition services. Female PSNP participants who are pregnant or lactating are temporarily moved from the Public Works component of the program to the temporary Direct Support. PSNP-4 introduces nutrition-related soft conditionalities or "coresponsibilities". One key co-responsibility is that women are encouraged to attend antenatal care and child visits postpartum. The transition to Direct Support reduces women's workload and allows more time for infant and young child feeding and care. Women participating in Public Works are expected to attend nutrition behavioral change communication (BCC) sessions. To encourage attendance, participation in BCC is counted as part of their Public Works labour requirement. Nutrition-sensitive public works are carried out to improve aspects of physical infrastructure relevant to addressing undernutrition, including the construction of latrines, health posts, and childcare centers; the development of homestead and kitchen gardens; and support to the production of foods needed for children's diets, such as animal source foods. Potential conflicts between women's time use on childcare during implementation of public works is temporarily addressed through the temporary provision of childcare centers.

An important aspect of PSNP-4 is that it is designed to be a systemic response to complex challenges of reducing food insecurity, improving livelihoods, and improving health and nutrition outcomes while at the same time contributing to broader national goals, such as the Climate Resilient Green Economy envisaged in 2011 and the National Nutrition Programme (GFDRE 2014a). These goals are to be achieved through food or cash transfers and nutrition counselling. The implementation of the nutrition and health interventions of PSNP are to be carried out through the collaborative efforts of three-line ministries - the Ministry of Agriculture and Natural Resources, the Ministry of Health, and the Ministry of Labour and Social Affairs. The PSNP-4 Project Implementation Manual (PIM) outlines the expected coordination at local levels between the Development Agent (DA) of the Ministry of Agriculture (technical support for planting, etc.) and the Health Extension Worker (HEW) of the Ministry of Health (and, in some instances, the Health Development Army (HDA)), who will provide the necessary behavior change communication (BCC) activities to ensure that newly developed nutrition-sensitive infrastructure is valued and used. The 
combination of infrastructure and BCC are expected to lead to improved hygiene and sanitation, increased proximity between lactating mothers and their children, and increased access to diverse foods with necessary micronutrients (GFDRE 2014b). The DA will link Direct Support beneficiaries to the same services by coordinating nutrition and health awareness raising and skill training services. Co-responsibilities also are attached to these activities.

The theory of change in the design of PSNP-4 is consistent with the vision of nutrition-sensitive interventions described in Black et al (2013). First, PSNP transfers enable households to acquire more food. Second, the BCC intervention in-built into the program nudges caregivers toward achieving a healthy and more diverse diet for their children. Third, nutrition-sensitive public works that directly invest in nutrition and health infrastructure and promote nutrition-sensitive foods enhance the effectiveness of nutrition and health interventions. Fourth, a systemic approach to addressing food and nutrition insecurity challenges makes it possible for program interventions to be efficient and long-lasting.

In 2016, IFPRI was tasked by the Bill and Melinda Gates Foundation to assess the impact of the nutrition-sensitive features of PSNP-4. ${ }^{1}$ More specifically, the objective was to gain a better understanding of (1) the pathways underpinning children's nutritional status; and (2) how to reduce the malign effect of seasonality on the nutritional status of women and pre-school children.

The current document is the final report on the evaluation of the nutrition-sensitive features of PSNP-4. The analysis is based on four rounds of household surveys, conducted in February/March and August/September in both 2017 and 2019. In each survey round, the survey teams visited more than 2,500 households in 264 kebeles in 88 PSNP woredas in Amhara, Oromia, SNNP, and Tigray regions. In the August survey rounds, the teams also visited health posts in these localities and interviewed HEWs stationed at the health posts.

Table 1.1 lists the research questions addressed in this report along with the sample or subsample used to answer them.

This report has 12 chapters. Chapter 2 describes the sample used for the analysis and discusses the survey implementation and context. Chapter 3 reports on basic household characteristics of the sample. Chapters 4 provides an analysis of mothers' anthropometry, diets, and time use. In Chapter 5 , we assess children's anthropometry and health status, while Chapter 6 focuses on infant and young child feeding (IYCF) practices. Chapter 7 provides a brief overview of households' access to the PSNP program, mothers' PSNP workload, and the protection pregnant and lactating women had from participating in the PSNP Public Works component. Chapter 8 focuses on the HEWs - their work environment; their interaction with PSNP; and their job satisfaction, stress, and workload. In chapter 9, we assess caregivers' exposure to health and nutrition services.

These nine chapters set the scene for the impact evaluation. In chapter 10, we describe the method we use to assess the impact of PSNP-4 on the outcomes listed in Table 1.1. Chapter 11 then provides and discusses the impact estimates. Finally, Chapter 12 provides a synthesis of this report.

\footnotetext{
${ }^{1}$ Nutrition is considered a minor component in the larger biannual PSNP evaluations that focus on assessing the core program components related to food security and livelihoods. Therefore, given the complexities and intensive data requirements to assess these new PSNP-4 nutrition interventions, a separate in-depth study of the nutrition sensitive PSNP-4 seemed necessary. This report complements the 2016 and 2018 PSNP-4 baseline and midline reports (Berhane et al. 2016a, 2016b; Berhane, Hirvonen, and Hoddinott 2016; Berhane et al. 2019; Berhane et al. 2019) that provide a thorough assessment of PSNP processes and outcomes in early 2016 and in 2018.
} 
Table 1.1. Research questions covered and the sample used to answer them

\section{Research Question}

1 How does participation in PSNP-4 affect the inputs into the nutritional status of children aged 6-23 months? These inputs include:

a. Minimum dietary diversity (as defined by WHO)

b. Minimum meal frequency (as defined by WHO)

c. Minimum acceptable diet (as defined by WHO)

d. Consumption of animal source foods

e. Hygiene conditions in the home

f. Maternal knowledge and attitudes regarding care practices affecting the nutritional status of children aged 6-23 months

Index children 6 to 23 months old Index children 6 to 23 months old Index children 6 to 23 months old Index children 6 to 23 months old Households with index children 6 to 23 months of age

Households with index children 6 to 23 months of age

g. Antenatal care and access to health services when the mother is pregnant All mothers and access to nutrition services and postnatal care after giving birth

2 How does participation in PSNP-4 affect women's diet as measured by the Mothers of index children 6 to 23 FANTA/FAO Minimum Dietary Diversity-Women indicator?

3 How do these inputs and indicators vary seasonally? months of age

Index children 6 to 23 months of age and their mothers

4 How does participation in PSNP-4 mitigate the effects of seasonality on inputs into the nutritional status of children and the diets of mothers?

Index children 6 to 23 months of age and their mothers

5 If PSNP-4 has relatively limited impacts on these inputs, does that reflect weaknesses in demand, challenges associated with supply and/or implementation, the absence of complementary non-PSNP resources needed for child nutrition or some combination of these?

6 Does PSNP-4 improve the nutritional status (height and weight) of preschool children?

7 Does PSNP-4 lead to changes in women's BMI?

8 How does participation in PSNP-4 prevent seasonal reductions in weight and BMI?

Index children 6 to 23 months of age and their mothers

Index children 6 to 23 months of age

Mothers of index children 6 to 23 months of age

Mothers of index children 6 to 23 months of age

Mothers of index children 6 to 23 months of age non-PSNP activities? How does it affect women's time use for their and infant/childcare? Does this differ by women's age and relationship to the household head?

10 Does the choice of transfer modality, magnify or attenuate the impact of PSNP on nutrition inputs and outcomes?

This has not been addressed as there was limited in-kind transfers. Food transfers accounted for only 5 percent of transfers in 2017 and 6 percent in 2019.

Source: Authors' compilation. $\mathrm{WHO}=$ World Health Organization . 


\section{SAMPLE, SURVEY IMPLEMENTATION, AND CONTEXT}

This chapter describes the sample (Section 2.1), survey implementation (Section 2.2) and the context, particularly seasonality and child age dynamics (Section 2.3).

\subsection{Sample}

This study is based on a stratified sample in the four highland regions of Ethiopia in which PSNP operates. We randomly selected 88 PSNP woredas located in Amhara, Oromia, SNNP, and Tigray regions. After woreda selection, we randomly selected three rural kebeles from these woredas and one enumeration area from each kebele. ${ }^{2}$ Figure 2.1 maps the surveyed kebeles.

Figure 2.1. Map of the surveyed kebeles

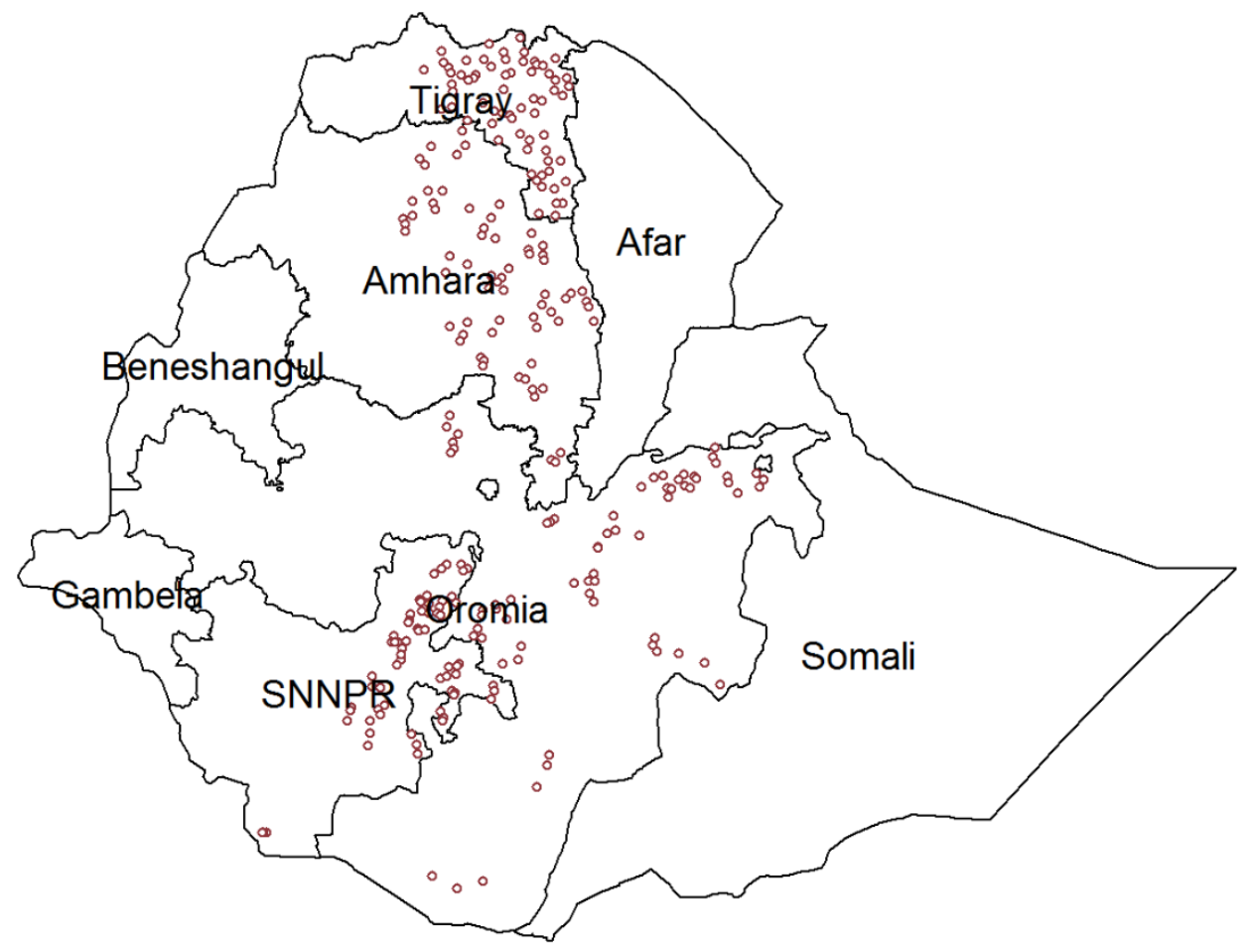

Source: Authors' compilation.

We then randomly selected 10 households from each enumeration area. Household eligibility was two-fold. First, a household was eligible to be selected only if they had a child less than 24 months of age. Second, a household was eligible if it was benefitting from PSNP or was poor but not selected into PSNP. The latter non-beneficiary households serve as control households in this study. Poverty status was determined using a subjective poverty measure in which households were asked to place themselves on to a poverty ladder that has 7 rungs. The first rung represented the very poorest households in the village and the highest $\left(7^{\text {th }}\right)$ rung, the very richest households in the village. Control households were chosen from the bottom four rungs of the ranking. ${ }^{3}$ Roughly half of the households are treatment, i.e., PSNP beneficiaries, and the other half control, i.e., poor non-PSNP households.

This procedure yields a sample of 2,640 households with a young child. Borrowing from the Demographic and Health Surveys (DHS), we refer to this child as the index child and the mother as the mother of the index child.

\footnotetext{
2 These woredas, kebeles and enumeration areas are the same as those which were selected for the main evaluation of PSNP-4. ${ }^{3}$ Our previous work in Ethiopia shows that this poverty ladder is well correlated with other (more objective) welfare measures: durable asset levels, livestock holdings and self-reported food security.
} 
Surveys took place in March and August 2017 (baseline) and March and August 2019 (endline). Table 2.1 shows the sample size in each survey round. In March 2017, the survey teams interviewed 2,635 households with a child under 24 months of age. In August 2017, we re-visited these same households. This time, the children were approximately 6 months older; that is, aged 6 to 29 months. The survey teams successfully re-interviewed 2,569 of the 2,635 households interviewed in March, for an attrition rate of 2.5 percent.

Table 2.1. Sample size in March and August 2017 and 2019

\begin{tabular}{llccccccc} 
& & $\begin{array}{c}\text { Full } \\
\text { sample }\end{array}$ & PSNP & Non-PSNP & Amhara & Oromia & SNNP & Tigray \\
\hline 2017 & March & 2,635 & 1,058 & 1,577 & 661 & 652 & 660 & 662 \\
& August & 2,569 & 1,006 & 1,561 & 637 & 641 & 651 & 640 \\
& Attrition (\%) & 2.5 & 4.9 & 1.0 & 3.6 & 1.7 & 1.4 & 3.3 \\
\hline $\mathbf{2 0 1 9}$ & March & 2,626 & 1,086 & 1,540 & 666 & 650 & 660 & 650 \\
& August & 2,550 & 1,061 & 1,489 & 651 & 617 & 647 & 635 \\
& Attrition (\%) & 2.9 & 2.3 & 3.3 & 2.3 & 5.1 & 2.0 & 2.3 \\
\hline
\end{tabular}

Source: Authors' compilation

In March 2019, we repeated the survey exercise. ${ }^{4}$ We randomly selected 10 households (PSNP and non-PSNP) with a child less than 24 months of age and re-visited them in August 2019. Starting with a sample of 2,626 households in March, we successfully re-interviewed 2,550 households in August for an attrition rate of 2.9 percent.

Attrition in both years is mainly due to three factors. First, the August round took place during the rainy season, so some households were absent from their regular locations either due to farmrelated migration or other reason. Second, a few kebeles in the Oromia region could not be visited in August because of civil unrest at the time. Third, the death of the index child or the index mother also contributed to this attrition. Overall, the attrition rate is very low and unlikely to bias our sample.

\subsection{Survey implementation}

In terms of survey implementation, 18 to 22 survey teams, each composed of 5 or 6 members, took part in the survey that took for about a month to complete for each round. Pre-programmed electronic questionnaires, using computer-assisted personal interviewing (CAPI) software, were administered using notebook computers. The CAPI questionnaires contained a series of in-built data quality checking mechanisms to ensure good quality data. Intensive training was given to supervisors and enumerators in all rounds. The training was conducted by senior Central Statistical Agency statisticians who were supported by the IFPRI team and by supervisors hired by BST Survey Solutions, a local survey company.

For all rounds, enumerator training was organized in three parts.

- The first part focused on the conceptual aspects of the questionnaires. Trainers discussed the content as well as the way each question needed to be probed in order to arrive at an acceptable response from the respondent.

- The second part was focused on the CAPI programming design. This element of the training allowed supervisors and enumerators to understand how the program worked as well as ensured the quality of the coding of the CAPI program. This latter effort served to further improve the questionnaire and to crosscheck the consistency of the CAPI programming against the original paper questionnaires. Data collection and transfer protocols were also part of this section of the training program.

\footnotetext{
${ }^{4}$ Due to delays in the implementation of the nutrition sensitive PSNP-4, our endline surveys were moved from 2018 to 2019.
} 
- Third, the enumerators, with their supervisors, were also carefully trained by a qualified nurse on taking anthropometric measurements - height or length, weight, and mid-upper arm circumference (MUAC) - from children or their mothers. This training took half day in the first round and a full-day in the latter three rounds. Dedicated anthropometric enumerators, mostly female, were deployed in all rounds but more vigorously in the latter three rounds. Special attention was paid to probing about the age of the index child to ensure accuracy. Probing technique protocols were developed on which enumerators were carefully trained. In addition, enumerators were given printouts of the key local calendar events over the past 2 years prior to the surveys.

The last stage of the training was a field pilot to reinforce what was learnt during training as well as for detecting any remaining errors in the CAPI program. We believe all these efforts helped improve the quality of the data obtained.

In all rounds, data were collected using two types of questionnaires: a household questionnaire and a price survey to implement at local markets. The household questionnaire was used to collect the main data used in this report. The supervisors were responsible for carrying out the market surveys in order to collect detailed local price information. The teams also visited health posts and conducted brief interviews with HEWs in the survey kebeles in both August rounds.

Thanks to the use of electronic data collection methods, backup data was received by email from each supervisor almost every day. Feedback on data quality could be provided the enumeration teams almost in real time. All data were compiled shortly after the last interview took place. Raw data were exported to Stata after which data cleaning and analysis were performed. The survey teams were assisted by Central Statistical Agency branch offices in making contacts with woreda officials and with other logistical assistance. These branch offices also lent key survey tools, including the heightllength and weight measurement kits. UNICEF-Ethiopia provided MUAC measurement kits for the survey.

Some of the fieldwork took place during a period of civil unrest that started in August 2016. Fortunately, these events did not affect the implementation of our surveys, except in a few kebeles during the August 2017 and August 2019 rounds.

\subsection{Seasonality and child age dynamics}

We end this chapter by highlighting issues related to seasonality and child age dynamics.

\subsubsection{Seasonality in Ethiopia and the timing of the surveys}

Food production in Ethiopia is largely based on rain-fed smallholder agriculture. This results in considerable seasonal variations in local food availability and prices (Hirvonen, Taffesse, and Worku 2016; Gilbert, Christiaensen, and Kaminski 2017). Moreover, infection risks co-move with seasons. Together, changes in seasonal food availability and infection risks then lead to seasonal energy stress and undernutrition (Branca et al. 1993; Ferro-Luzzi et al. 2001; Maleta et al. 2003; Vaitla, Devereux, and Swan 2009; Abay and Hirvonen 2017), possibly resulting in considerable fluctuations in child acute malnutrition rates across seasons (Baye and Hirvonen 2020). Considering this, it is important to assess how seasonality affects the nutritional status of women and pre-school children and the role of PSNP in mitigating these impacts.

Much of the highland areas of Ethiopia have two rainy seasons. The small rainy season (belg) normally takes place between March and May and the main rainy season (meher) between June and October. Meher is by far the most important season out of the two with more than 90 percent of the total crop production in the country taking place during this season (Taffesse, Dorosh, and Gemessa 2012). The main harvesting season broadly takes place between October and December 
in the highlands of Ethiopia. Between December and February, the harvest is then stored or sold at local food markets.

In addition to seasonality in food production, religion also plays an important role in shaping diets, especially for the Orthodox Christians who comprise 44 percent of the Ethiopian population (Central Statistical Agency [Ethiopia] 2010). The Ethiopian Tewahedo Orthodox Church year has a number of fasting periods during which devout Orthodox Christians follow a vegan diet by refraining from consuming meat or other animal products, e.g., milk, butter. With 55 days, Lent is the longest fasting period, typically taking place between February and April. Other important fasting periods occur in August (16 days) and before the Ethiopian Christmas in December and January (40 days).

Against this background, our March surveys took place in the post-harvest season characterized by drier conditions but better food availability and higher incomes due to the recent harvest. While this is a slack season when it comes to agricultural activities, PSNP households are busy working in the PSNP public works sites. Public works under PSNP mostly take place between January and June. PSNP households also receive their payments in cash or food during this period. In both 2017 and 2019, the March survey overlapped almost completely with the Lent fasting period. While very young children are exempted from fasting, previous research indicates that fasting reduces the availability of animal source foods in households and in local food markets (Kim et al. 2018).

In contrast, the August surveys took place in the lean season when the meher rains fall. In most areas, PSNP public works as well as PSNP payments have stopped by August. Households are busy with agricultural activities. They have lower incomes and savings compared to the post-harvest season. In rural areas, energy intakes at the household level fall during the lean season while dietary diversity improves as affordable vegetables become available (Hirvonen et al. 2016). In both years, the August surveys partly overlapped a two-week fasting period.

\subsubsection{Child age dynamics}

Another important feature of our surveys relates to child age dynamics.

The first two years of life are a critical period in child growth and development during which growth faltering accelerates and many children in Ethiopia become short for their age, or stunted (Golan et al. 2019). In the first six months after birth, the World Health Organization (WHO) recommends that children be exclusively breastfed. When children turn six months, breastmilk is no longer sufficient to support their growth and development, and, thus, children need to be introduced to complementary foods. Because of limited gastric capacity, these foods need to be highly nutritious and provided frequently. Moreover, because children's immune systems are still developing during this age, they need to live in a safe and supportive environment characterized by improved water, sanitation, and hygiene and good access to health services for timely treatment.

Given this highly dynamic period in children's growth and development, it is important that we carefully consider the age of the children when we construct our anthropometric and dietary outcomes. Figure 2.2 illustrates the age dynamics across the four survey rounds. In each March round, we started with a sample of households with a child under 24 months of age. In August, these children are approximately 6 months older. To make sure that the outcomes are comparable across survey rounds, we restrict the August sample to children between 6 and 23 months of age (unless otherwise stated). ${ }^{5}$ This means that we ignore the children under 6 months of age in the March rounds and children 24 to 29 months of age in the August rounds.

\footnotetext{
${ }^{5}$ Outcomes related to exclusive breastfeeding practices are calculated for children under 6 months of age.
} 
Figure 2.2. Child age dynamics

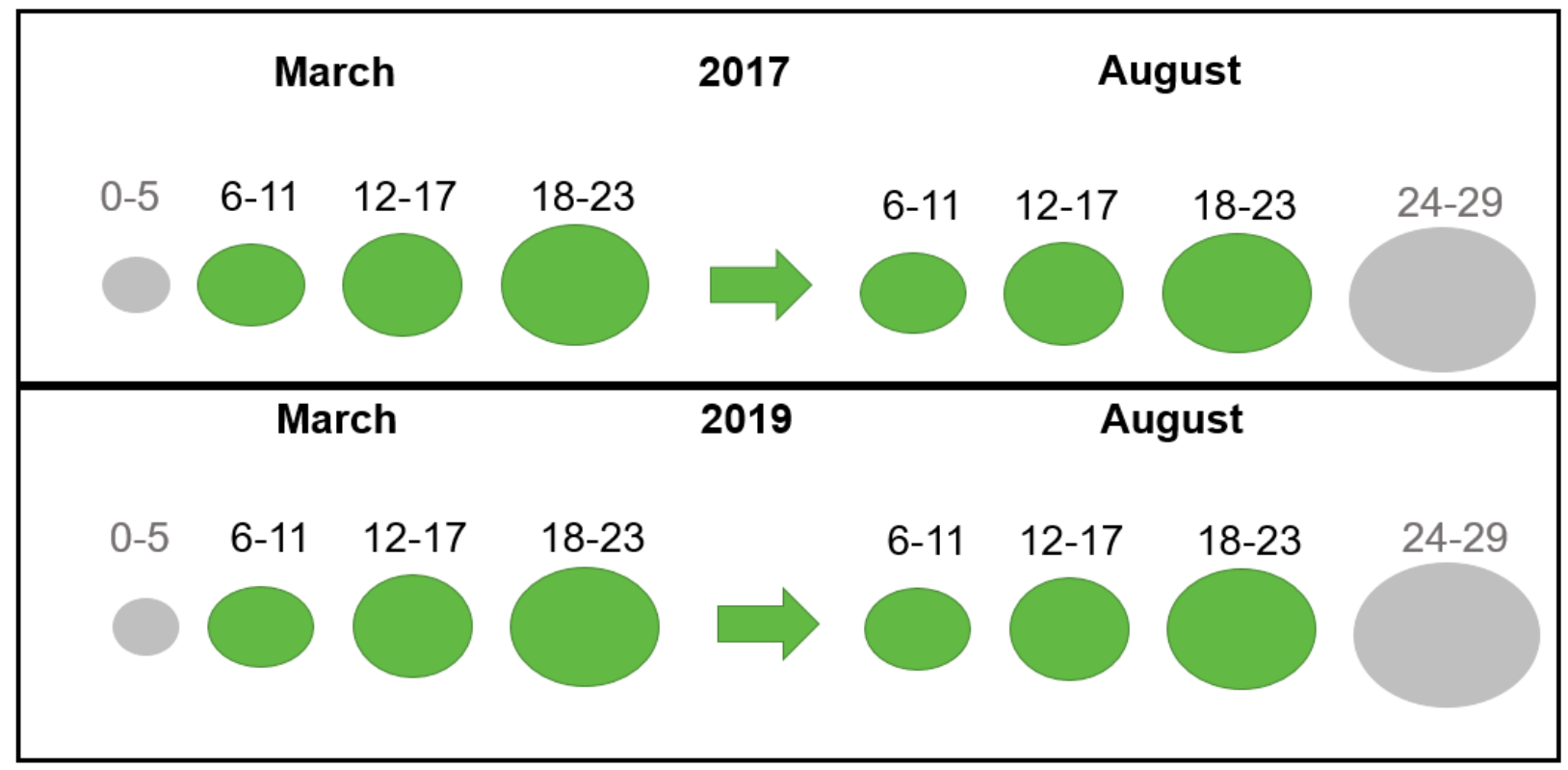

Source: Authors' compilation.

Note: Each circle represents a child age cohort. For most outcomes reported in this study, we do not consider the youngest children (under 6 months of age) in March rounds and oldest children in the August rounds (24 to 29 months of age). These age-cohorts are marked with grey circles. 


\section{HOUSEHOLD CHARACTERISTICS: ACCESS TO RESOURCES, FOOD SECURITY, AND LIVELIHOODS}

This chapter briefly describes basic household characteristics.

\subsection{Household characteristics}

Table 3.1 reports child and household level characteristics by PSNP status in 2017 and 2019. In both years, about 90 percent of households in the sample were male-headed. In PSNP households, the average index mother is 29 years old, while the average father (or male caregiver) is 37 years old. The mean household size is six members, with negligible regional differences (Table A1 in the Appendix A). Education levels are poor. Many of the mothers (55 percent) and fathers (44 percent) have not gone to school and for those that attended school, the average schooling years is only about 3 years. The average index child was 11 months old of age in both March rounds. The index child sample is balanced across sexes.

Table 3.1. Index child and household characteristics by PSNP status, 2017 and 2019

\begin{tabular}{|c|c|c|c|c|c|c|}
\hline & \multicolumn{3}{|c|}{ March 2017} & \multicolumn{3}{|c|}{ March 2019} \\
\hline & All & non-PSNP & PSNP & All & non-PSNP & PSNP \\
\hline Household is male headed & 0.89 & 0.92 & 0.85 & 0.90 & 0.92 & 0.91 \\
\hline Index child is male & 0.50 & 0.50 & 0.50 & 0.52 & 0.52 & 0.51 \\
\hline Index child's age in months & 11.48 & 11.52 & 11.41 & 10.85 & 10.72 & 11.02 \\
\hline \multicolumn{7}{|l|}{ Age categories: } \\
\hline $0-6$ months $(\mathrm{N}=620)$ & 0.24 & 0.23 & 0.24 & 0.27 & 0.28 & 0.27 \\
\hline 6-11 months $(\mathrm{N}=690)$ & 0.26 & 0.27 & 0.25 & 0.27 & 0.26 & 0.29 \\
\hline $12-17$ months $(\mathrm{N}=728)$ & 0.28 & 0.27 & 0.29 & 0.24 & 0.27 & 0.22 \\
\hline $18-23$ months $(\mathrm{N}=589)$ & 0.22 & 0.23 & 0.22 & 0.20 & 0.19 & 0.22 \\
\hline 24 months $(\mathrm{N}=8)$ & 0.00 & 0.00 & 0.00 & 0.00 & 0.01 & 0.00 \\
\hline Mother's age (in years) & 28.83 & 28.45 & 29.40 & 28.97 & 28.20 & 30.06 \\
\hline Mother's education (in years) & 0.87 & 0.95 & 0.74 & 2.42 & 2.64 & 2.12 \\
\hline Mother has not gone to school & 0.83 & 0.81 & 0.86 & 0.55 & 0.51 & 0.60 \\
\hline Father/caregiver's age (in years) & 37.11 & 36.51 & 38.05 & 37.42 & 36.06 & 39.45 \\
\hline Father/caregiver's education (in years) & 1.26 & 1.47 & 0.93 & 3.09 & 3.45 & 2.55 \\
\hline Father has not gone to school & 0.84 & 0.82 & 0.87 & 0.44 & 0.38 & 0.51 \\
\hline Household size & 5.77 & 5.73 & 5.83 & 5.73 & 5.54 & 6.00 \\
\hline
\end{tabular}

Source: Authors' compilation.

The survey teams collected latitude/longitude coordinates at households, health posts, and markets. Using these data, Table 3.2 reports households' access to health posts, markets, and towns by region and PSNP status. The average household in the sample is located about $2.5 \mathrm{~km}$ from their kebele health post. Travel to the nearest food market takes 80 minutes, on average. ${ }^{6}$ Many of the PSNP localities can be considered remote; the mean distance to the nearest town of 50,000 people is nearly $200 \mathrm{~km}$.

Table 3.2 also reports on households' access to electricity and mobile phones. Thirty-six percent of households have access to electricity, while 49 percent own a mobile phone or are connected to a mobile service provider.

\footnotetext{
${ }^{6}$ Headey et al. (2019) uses the baseline data to analyze how child diets are correlated with households' access to these food markets and prices of nutritious foods in these markets.
} 
Table 3.2. Access to health posts, electricity, mobile phones and markets by region and PSNP status 2019

\begin{tabular}{lccccccc} 
& \multicolumn{3}{c}{ non- } & & & & \\
& All & PSNP & PSNP & Amhara & Oromia & SNNP & Tigray \\
\hline Distance (in km) to health post & 2.4 & 2.4 & 2.4 & 2.7 & 3.1 & 1.3 & 2.5 \\
Distance (in minutes) to nearest market & 80 & 80 & 80 & 90 & 111 & 35 & 85 \\
$\begin{array}{l}\text { Distance (in km) to nearest town of } \\
\quad 198\end{array}$ & 198 & 198 & 168 & 147 & 250 & 226 \\
$\quad \begin{array}{l}50,000 \text { people } \\
\text { Household has access to electricity (\%) }\end{array}$ & 36.2 & 38.6 & 32.9 & 30.9 & 38.6 & 33.1 & 42.3 \\
Owns a mobile phone (\%) & 49.0 & 54.4 & 41.3 & 45.0 & 50.9 & 45.8 & 54.1 \\
\hline
\end{tabular}

Source: Authors' compilation using locational information.

For more than 40 percent of households, the main source of drinking water is from an open and unprotected spring, a river, a lake, or rainwater (Table 3.3). Piped water either in dwelling, in compound, or outside the compound is accessible for about 30 percent of the households in all regions (but 36.5 percent for SNNP). During the rainy seasons, it takes on average about an hour to fetch water. This figure is higher in Oromia (about 1.5 hours) and lower in Tigray (about 47 minutes). Average time needed to fetch water is shorter in the dry seasons (by about 11 minutes), possibly because some nearer dry season sources are inaccessible during the rainy season. However, the main sources of drinking water remain largely the same in both the dry and the rainy seasons, with some increases in access to water from rainwater and open springs during the rainy season.

Table 3.3. Source of drinking water by region and PSNP status, $2019, \%$ of households

\begin{tabular}{|c|c|c|c|c|c|c|c|}
\hline & All & $\begin{array}{c}\text { non- } \\
\text { PSNP }\end{array}$ & PSNP & Amhara & Oromia & SNNP & Tigray \\
\hline \multicolumn{8}{|c|}{ Main source of drinking water during rainy season } \\
\hline Piped into dwelling & 0.5 & 0.5 & 0.6 & 0.0 & 0.8 & 0.5 & 0.9 \\
\hline Piped into compound/yard & 1.9 & 2.0 & 1.8 & 0.6 & 0.0 & 1.4 & 5.8 \\
\hline Public tap outside compound & 28.4 & 28.6 & 28.3 & 27.0 & 21.8 & 36.5 & 28.5 \\
\hline Protected/covered well & 12.9 & 11.8 & 14.5 & 9.2 & 4.3 & 7.7 & 30.3 \\
\hline Protected spring & 16.3 & 17.5 & 14.7 & 20.6 & 15.1 & 19.8 & 9.8 \\
\hline Open/unprotected spring & 23.3 & 23.4 & 23.0 & 27.5 & 30.6 & 20.0 & 15.0 \\
\hline River/lake/pond/stream/dam & 14.9 & 14.2 & 15.8 & 14.6 & 22.5 & 13.1 & 9.5 \\
\hline Rainwater & 1.4 & 1.5 & 1.2 & 0.6 & 4.3 & 0.5 & 0.2 \\
\hline Other & 0.3 & 0.5 & 0.1 & 0.0 & 0.6 & 0.6 & 0.0 \\
\hline \multicolumn{8}{|c|}{ Main source of drinking water during dry season } \\
\hline Piped into dwelling & 0.6 & 0.5 & 0.6 & 0.0 & 0.6 & 0.3 & 1.4 \\
\hline Piped into compound/yard & 2.0 & 2.0 & 2.0 & 0.6 & 0.0 & 1.2 & 6.2 \\
\hline Public tap outside compound & 29.0 & 29.2 & 28.7 & 27.2 & 24.5 & 36.9 & 27.6 \\
\hline Protected/covered well & 13.5 & 12.5 & 14.9 & 9.8 & 4.6 & 8.2 & 31.2 \\
\hline Protected spring & 17.2 & 18.8 & 14.9 & 22.1 & 16.6 & 20.6 & 9.5 \\
\hline Open/unprotected spring & 23.8 & 23.5 & 24.3 & 27.3 & 34.0 & 19.4 & 14.7 \\
\hline River/lake/pond/stream/dam & 12.9 & 12.3 & 13.8 & 12.8 & 17.2 & 12.3 & 9.4 \\
\hline Rainwater & 0.2 & 0.2 & 0.2 & 0.3 & 0.5 & 0.0 & 0.0 \\
\hline Other & 0.8 & 1.0 & 0.5 & 0.0 & 2.0 & 1.1 & 0.0 \\
\hline \multicolumn{8}{|c|}{ Time (in $\min$ ) to fetch water and return: } \\
\hline In rainy season & 63.8 & 61.0 & 67.9 & 49.9 & 97.6 & 62.1 & 46.5 \\
\hline In dry season & 53.1 & 52.2 & 54.3 & 44.3 & 79.3 & 43.9 & 45.2 \\
\hline
\end{tabular}

Source: Authors' compilation.

The quality of houses and living condition is similar across regions and PSNP status (Table 3.4). Most houses have a corrugated metal (49 percent) or thatched roof (44 percent). Floors are of earth (78 percent) or cow dung (18 percent). In general, most houses are in moderate or good condition 
with little damage. On average, 49 percent of houses do not have windows. The most common window type is wooden doors or shutters. Finally, only 16 percent of mothers reported to have cultivated a homestead garden in the past 12 months prior to the interview. This percentage is highest in SNNP (28 percent), and lowest in Oromia (7 percent). The higher percentage of households with homestead gardens in SNNP could possibly be because of more favorable climatic conditions due to the bimodal rainfall patterns there, better access to food markets in which to sell these products (see Table 3.2), or the tradition of growing enset (Hirvonen and Headey 2018).

Table 3.4. Housing and living quality by region and PSNP status, $2019, \%$ of households

\begin{tabular}{|c|c|c|c|c|c|c|c|}
\hline Housing Quality & All & $\begin{array}{c}\text { non- } \\
\text { PSNP }\end{array}$ & PSNP & Amhara & Oromia & SNNP & Tigray \\
\hline \multicolumn{8}{|l|}{ Roof type: } \\
\hline Thatched roof & 44.0 & 41.2 & 47.9 & 51.7 & 44.2 & 59.4 & 20.9 \\
\hline Corrugated metal roof & 48.6 & 52.3 & 43.5 & 48.0 & 52.5 & 38.6 & 55.3 \\
\hline Mud/sand/stone & 6.0 & 4.9 & 7.6 & 0.0 & 0.2 & 0.3 & 23.3 \\
\hline Plastic sheeting & 1.4 & 1.6 & 1.1 & 0.3 & 3.2 & 1.7 & 0.5 \\
\hline Floor type: & & $\%$ & & & & & \\
\hline Earth & 77.6 & 77.8 & 77.3 & 68.8 & 92.0 & 78.5 & 71.5 \\
\hline Cow dung or cow dung mixed with soil & 18.1 & 17.3 & 19.2 & 29.6 & 6.8 & 16.8 & 18.9 \\
\hline Concrete/stone/cement & 3.6 & 4.4 & 2.6 & 1.2 & 0.8 & 3.1 & 9.4 \\
\hline Tile/bricks & 0.1 & 0.0 & 0.2 & 0.2 & 0.0 & 0.0 & 0.2 \\
\hline Bamboo /wood & 0.6 & 0.5 & 0.6 & 0.2 & 0.5 & 1.7 & 0.0 \\
\hline Window type: & & $\%$ & & & & & \\
\hline Glass & 0.3 & 0.4 & 0.2 & 0.3 & 0.3 & 0.3 & 0.3 \\
\hline Plastic & 0.6 & 0.6 & 0.6 & 0.3 & 0.3 & 1.4 & 0.6 \\
\hline Wooden doors or shutters & 29.9 & 34.5 & 23.4 & 33.5 & 28.5 & 47.2 & 10.8 \\
\hline Windows are not covered & 10.8 & 10.1 & 11.9 & 10.1 & 7.4 & 8.2 & 17.6 \\
\hline No windows & 49.4 & 44.9 & 55.6 & 47.6 & 61.4 & 41.8 & 46.7 \\
\hline Corrugated iron sheets & 8.7 & 9.3 & 7.9 & 8.1 & 2.2 & 0.8 & 23.6 \\
\hline Dwelling condition: & & $\%$ & & & & & \\
\hline Very good condition, no damage & 15.2 & 17.3 & 12.2 & 16.8 & 12.3 & 13.5 & 18.0 \\
\hline Good condition, slightly damaged & 23.1 & 26.2 & 18.7 & 25.5 & 16.3 & 22.9 & 27.4 \\
\hline Moderate, little bit damaged & 39.5 & 37.3 & 42.5 & 35.1 & 37.5 & 40.0 & 45.2 \\
\hline Bad shape, major damage & 16.4 & 14.4 & 19.3 & 19.1 & 22.3 & 16.5 & 7.9 \\
\hline Very poor state & 5.9 & 4.9 & 7.3 & 3.5 & 11.5 & 7.1 & 1.5 \\
\hline Homestead garden in last 12 months & 15.8 & 15.4 & 16.5 & 15.3 & 7.2 & 28.5 & 12.4 \\
\hline
\end{tabular}

Source: Authors' compilation.

The hygiene conditions in these localities are poor (Table 3.5). Only 51 percent of households have access to toilet - typically a traditional pit latrine. This percentage is higher in SNNP (82 percent) and lowest in Tigray (30 percent). There is garbage, animal feces, and human feces in 61 , 57 , and 12 percent of compounds, respectively. More than 97 percent of mothers reported to have washed their hands the day before the interview - but only 42 percent used soap. 
Table 3.5. Hygiene conditions and practices by region and PSNP status, $2019, \%$ of households

\begin{tabular}{lccccccc} 
& All & $\begin{array}{c}\text { Non- } \\
\text { PSNP }\end{array}$ & PSNP & Amhara & Oromia & SNNP & Tigray \\
Access to proper toilet & 51.1 & 52.7 & 48.7 & 46.6 & 45.0 & 82.3 & 30.3 \\
Human feces in the compound & 11.9 & 11.9 & 11.8 & 7.8 & 22.0 & 7.4 & 9.9 \\
Animal feces in the compound & 57.2 & 56.3 & 58.4 & 77.5 & 57.3 & 34.6 & 60.3 \\
Garbage in the compound & 61.1 & 58.7 & 64.5 & 78.6 & 58.0 & 54.8 & 53.8 \\
Mother washed hands yesterday & 97.6 & 97.5 & 97.7 & 98.3 & 97.1 & 98.4 & 96.5 \\
--- with soap & 42.2 & 43.8 & 39.8 & 33.1 & 32.4 & 58.2 & 44.9 \\
\hline
\end{tabular}

Source: Authors' compilation.

\subsection{Food security, storage and consumption sources}

This section reports the changes in the food security, storage, and consumption sources between the March and August rounds of the 2019 surveys. The same results for the March and August rounds of the 2017 surveys are provided in Appendix A. The evidence provided in this section helps set the scene on the seasonality of food security, storage, and sources of consumption between the post-harvest and the lean seasons.

\subsubsection{Food security}

We measure food security using a subjective indicator called food gap - the number of months the household was not able to satisfy its food needs in the 12 months preceding the survey. This is the main food security indicator used in PSNP evaluations and is generated from the respondent's direct response to the question. Given that we visited the households twice in a year, we report the food gap over a 6-month period.

Table 3.6. Food gap in the last 6 months, by survey round and PSNP status

\begin{tabular}{|c|c|c|c|c|c|c|}
\hline & \multicolumn{3}{|c|}{ March 2019} & \multicolumn{3}{|c|}{ August 2019} \\
\hline & All & Non-PSNP & PSNP & All & Non-PSNP & PSNP \\
\hline Mean food gap, months & 1.18 & 1.02 & 1.41 & 1.26 & 1.17 & 1.39 \\
\hline \multicolumn{7}{|c|}{ Distribution of food gap (\%): } \\
\hline Zero months & 48.4 & 54.0 & 41.0 & 50.0 & 53.0 & 46.1 \\
\hline 1 month & 16.1 & 15.2 & 17.3 & 11.8 & 12.1 & 11.2 \\
\hline 2 months & 18.3 & 16.8 & 20.5 & 18.2 & 16.4 & 20.7 \\
\hline 3 months & 10.1 & 8.7 & 12.1 & 10.4 & 9.5 & 11.6 \\
\hline 4 months & 3.5 & 3.3 & 3.9 & 4.7 & 4.7 & 4.6 \\
\hline 5 months & 0.7 & 0.8 & 0.6 & 1.5 & 1.4 & 1.6 \\
\hline 6 months & 2.9 & 1.8 & 4.6 & 3.5 & 3.0 & 4.2 \\
\hline Total & 100 & 100 & 100 & 100 & 100 & 100 \\
\hline
\end{tabular}

Source: Authors' compilation.

Table 3.6 reports the comparative distribution of the food gap measure in months between PSNP and non-PSNP households in the six months prior to March 2019 and to August 2019. Two important takeaways from this table are:

- For the full sample, the average food gap slightly increased between March (1.2 months) and August (1.3 months). While the average food gap is slightly higher for PSNP than for non-PSNP households, trends between the two seasons suggest that it slightly declined for PSNP households but slightly increased for non-PSNP households. This is expected given that PSNP transfers bridge some of the seasonal gaps for PSNP households. 
- Consistent with this result, we see that between March and August of 2019, the share of households that reported zero months of food gap during the previous six months slightly increased (by about 5 percentage points) for PSNP households, but remained almost the same for non-PSNP households. Taking the same seasons in 2017, the increase of share of households reporting zero food gap was substantial with an increase by about 18 percentage points between March 2017 and August 2017 (see Appendix A).

Table 3.7 reports average food gap disaggregated by regions. Overall, we see that in both seasons, the average food gap for the full sample is higher in Oromia and SNNP than in Amhara and Tigray. Moreover, between March 2019 and August 2019, the average food gap for the full sample slightly decreased for Amhara and Tigray but slightly increased for Oromia and SNNP. And, for all regions and seasons, the average food gap is generally higher for PSNP than for non-PSNP households.

Table 3.7. Mean food gap (in months) in the last six months, by region and PSNP status

\begin{tabular}{|c|c|c|c|c|c|c|}
\hline \multirow[b]{2}{*}{ Region } & \multicolumn{3}{|c|}{ March 2019} & \multicolumn{3}{|c|}{ August 2019} \\
\hline & All & non-PSNP & PSNP & All & non-PSNP & PSNP \\
\hline Amhara & 0.98 & 0.76 & 1.27 & 0.83 & 0.69 & 0.99 \\
\hline Oromia & 1.47 & 1.29 & 1.83 & 1.76 & 1.61 & 2.06 \\
\hline SNNP & 1.47 & 1.31 & 1.72 & 1.95 & 1.76 & 2.24 \\
\hline Tigray & 0.81 & 0.65 & 0.99 & 0.57 & 0.47 & 0.67 \\
\hline All & 1.18 & 1.02 & 1.41 & 1.26 & 1.17 & 1.39 \\
\hline
\end{tabular}

Source: Authors' compilation.

\subsubsection{Food storage}

In this section, we look at changes in storage levels between March and August. Typically, households store either cereals, which are high in calories but not in other macro or micro nutrients, or pulses, which have a relatively high protein content. Given differences in nutritional values between these two food groups, these are treated separately.

Table 3.8 shows the percent of households that reported having cereals in storage for the most recent survey year, 2019 (figures for 2017 are given in Appendix A). In March 2019, more than half of the households had cereals in store, while in August this share had dropped by 23 percentage points. Similar trends were observed in 2017, but the fall in storage was 9 percentage points lower. Regional disaggregation reveals that Amhara and Tigray have the highest share of households with cereals in storage during both seasons.

Table 3.8. Share of households with cereals in storage in March and August 2019, by region and PSNP status

\begin{tabular}{lcccccc}
\multicolumn{3}{c}{ Region } & All & March 2019 & \multicolumn{3}{c}{ August 2019 } \\
Amhara & 0.86 & 0.82 & 0.88 & 0.45 & 0.42 & 0.48 \\
Oromia & 0.39 & 0.39 & 0.40 & 0.25 & 0.17 & 0.29 \\
SNNP & 0.27 & 0.23 & 0.29 & 0.21 & 0.25 & 0.19 \\
Tigray & 0.62 & 0.56 & 0.66 & 0.33 & 0.30 & 0.36 \\
\hline All & 0.54 & 0.53 & 0.55 & 0.31 & 0.29 & 0.33 \\
\hline
\end{tabular}

Source: Authors' compilation.

Table 3.9 reports on storage for pulses. Only 15 percent of households had pulses in storage in March 2019. This compares to 10 percent in March 2017. In August 2019, this dropped to seven percent, compared to 5 percent in August 2017 (see Appendix A). There is little difference between 
PSNP and non-PSNP households. Pulses in storage are more common in Amhara relative to the other regions.

Table 3.9. Share of households with pulses in storage in March and August 2019, by region and PSNP status

\begin{tabular}{|c|c|c|c|c|c|c|}
\hline \multirow[b]{2}{*}{ Region } & \multicolumn{3}{|c|}{ March 2019} & \multicolumn{3}{|c|}{ August 2019} \\
\hline & All & PSNP & non-PSNP & All & PSNP & non-PSNP \\
\hline Amhara & 0.36 & 0.33 & 0.37 & 0.11 & 0.10 & 0.12 \\
\hline Oromia & 0.03 & 0.03 & 0.03 & 0.04 & 0.04 & 0.05 \\
\hline SNNP & 0.06 & 0.04 & 0.07 & 0.07 & 0.06 & 0.07 \\
\hline Tigray & 0.15 & 0.14 & 0.16 & 0.03 & 0.02 & 0.05 \\
\hline All & 0.15 & 0.15 & 0.15 & 0.07 & 0.06 & 0.08 \\
\hline
\end{tabular}

Source: Authors' compilation.

Table 3.10 reports the average amount of cereal in storage. The average household in the sample had $150 \mathrm{~kg}$ of cereals in storage in March 2019. By August 2019, this had fallen to $75 \mathrm{~kg}-\mathrm{a}$ 50 percent drop in the amount of cereal in storage. On average, non-PSNP households have more cereals in storage than PSNP households. Average cereal stocks in storage are largest in Amhara and Tigray. Stored amounts fell considerably by August in all regions except SNNP, where the stored amounts remain more stable for PSNP households. (Given the low share of households that have pulses in storage, we do not report the average amounts of pulses in storage.)

Table 3.10. Mean amount (in kg) of cereals in storage in March and August 2019, by region and PSNP status

\begin{tabular}{lcccccc} 
& \multicolumn{3}{c}{ March 2019 } & \multicolumn{3}{c}{ August 2019 } \\
\multicolumn{1}{r}{ Region } & All & PSNP & non-PSNP & All & PSNP & non-PSNP \\
Amhara & 243.4 & 187.5 & 288.6 & 96.9 & 98.5 & 95.6 \\
Oromia & 122.1 & 95.9 & 135.7 & 73.7 & 23.7 & 99.2 \\
SNNP & 74.16 & 74.3 & 74.1 & 44.8 & 73.9 & 26.3 \\
Tigray & 156.81 & 128.7 & 181.6 & 86.7 & 88.2 & 85.3 \\
\hline All & 149.73 & 125.5 & 166.9 & 75.7 & 75.1 & 76.2 \\
\hline
\end{tabular}

Source: Authors' compilation.

\subsection{Sources of food consumption}

This section focuses on whether the sources of food consumed by households vary by season. A unique feature in our dataset is that it enables us to see the seasonality in sources of the foods consumed. Figure 3.1 reports the main sources of foods consumed by the household in the six months preceding the four survey rounds. We see that the proportion of households that reported 'own production' as the main source of food consumed by the household was slightly higher for the harvest and post-harvest seasons (September to February) than for the lean seasons (March to August). 'Purchases' and 'PSNP transfers' become important during the lean seasons. Compared to 2017, households reporting 'transfers from other government and NGO' as a primary source of food appear to decline in 2019. Except for PSNP transfers, the differences in 'other transfers' between PSNP and non-PSNP households are negligible. In both 2017 and 2019, 5 to 6 percent of households reported PSNP transfers (both Public Works and Direct Support) as the primary sources of food consumed. This increases to about 10 percent in the lean season, i.e., March to August. 
Figure 3.1. Primary sources of food in the last six months March and August 2017 and 2019)

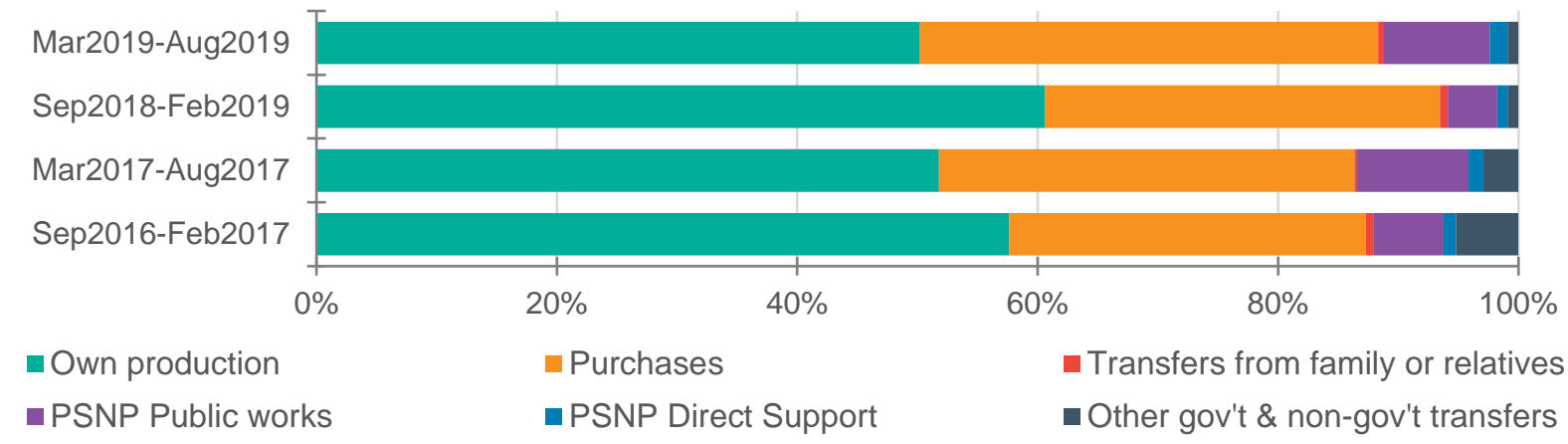

Source: Authors' compilation.

Table 3.11 further disaggregates the primary sources of food consumed by PSNP and nonPSNP households, but only for the six months between March 2019 and August 2019. To simplify the discussion, we also grouped primary sources into three categories: own production, PSNP, and other sources. PSNP captures transfers received through Public Works or Direct Support, while the other sources category refers to food purchases using cash from different sources other than PSNP (e.g. salary, income from own-businesses, other non-PSNP related aid). These sources are presented separately in Figure 3.1.

Table 3.11. Primary sources of food consumption by month and PSNP beneficiary status

\begin{tabular}{|c|c|c|c|c|c|}
\hline & \multicolumn{3}{|c|}{ PSNP households (\%): } & \multicolumn{2}{|c|}{ Non-PSNP households (\%): } \\
\hline & $\begin{array}{c}\text { Own } \\
\text { production }\end{array}$ & PSNP & Other sources & $\begin{array}{c}\text { Own } \\
\text { production }\end{array}$ & Other sources \\
\hline March 2019 & 53.9 & 19.2 & 26.9 & 68.5 & 31.5 \\
\hline April 2019 & 47.2 & 24.7 & 28.1 & 64.5 & 35.5 \\
\hline May 2019 & 39.0 & 29.1 & 31.9 & 58.9 & 41.1 \\
\hline June 2019 & 36.4 & 31.8 & 31.9 & 53.1 & 46.8 \\
\hline July 2019 & 33.6 & 25.2 & 41.1 & 49.2 & 50.8 \\
\hline August 2019 & 33.7 & 18.0 & 48.2 & 47.8 & 52.2 \\
\hline
\end{tabular}

Source: Authors' compilation.

Note: PSNP transfers refers to transfers received through Public Works or Direct Support. Purchase captures non-PSNP related money which has been used to purchase consumption foods, which includes gifts and transfers from family, relatives and neighbors as well as transfers from governmental and non-governmental organizations

In March 2019, 54 percent of PSNP households reported their own production as the primary source of the food they consumed, while 19 percent reported PSNP as their primary source. The remaining 27 percent reported relying primarily on other sources. In contrast, nearly 70 percent of non-PSNP households reported relying primarily on their own production in March, while 30 percent reported depending on other sources. Moving towards the lean season, we see that the role of own production decreases steadily for both groups. In August, only 34 percent of PSNP households and 48 percent of non-PSNP households reported to have relied primarily on their own food production. Nearly 20 percent of PSNP households reported to have relied mainly on food or cash payments received through PSNP. Other sources were reported by 48 and 52 percent of PSNP and nonPSNP households, respectively.

\subsection{Household livelihoods and shocks}

This section provides some descriptive evidence characterizing households' livelihoods: land, livestock, and whether the household is engaged in non-farm activities. Moreover, given the areas targeted by PSNP are characterized by frequent shocks, we also provide statistics describing the extent to which the survey households reported income shocks. 
Table 3.12. Land operated, livestock assets, and engagement in nonfarm activities

\begin{tabular}{lcccccc} 
& \multicolumn{3}{c}{ March 2017} & \multicolumn{3}{c}{ March 2019} \\
\multicolumn{1}{c}{ Indicators of livelihoods } & All & PSNP & $\begin{array}{c}\text { Non- } \\
\text { PSNP }\end{array}$ & All & PSNP & $\begin{array}{c}\text { Non- } \\
\text { PSNP }\end{array}$ \\
\hline Operated land area (in hectares) & 0.9 & 0.9 & 0.9 & 1.2 & 1.5 & 1.1 \\
Land area less than 0.5ha & 36.4 & 37.4 & 35.6 & 34.3 & 34.5 & 34.2 \\
Land area between 0.5ha and 1ha & 34.0 & 34.2 & 33.9 & 31.9 & 32.1 & 31.8 \\
Is the household active in farming & 90.7 & 90.7 & 90.7 & 88.2 & 89.6 & 87.1 \\
Tropical Livestock Unit (TLU) & 3.1 & 2.6 & 3.5 & 3.3 & 2.8 & 3.7 \\
Changes in TLU from two years ago & 1.7 & 1.6 & 1.8 & -0.2 & -0.3 & -0.2 \\
Any household member contacted DA & 29.5 & 31.2 & 28.3 & 25.4 & 29.1 & 22.9 \\
Household has taken a loan & 21.7 & 20.4 & 22.6 & 37.4 & 40.4 & 35.2 \\
Household engaged in business activity & 10.7 & 7.9 & 12.6 & 12.8 & 11.9 & 13.4 \\
Any household member participated in & 15.4 & 18.1 & 13.5 & 21.1 & 22.2 & 20.3 \\
$\quad$ wage employment & & & & & & \\
\hline
\end{tabular}

Source: Authors' compilation.

Table 3.12 reports households' land operated, ownership of livestock assets, and involvement in nonfarm activities. The key takeaways can be summarized as follows.

- About 90 percent of households in our sample are active in smallholder farming - doing their farming activities by themselves, with close to 12 percent of them doing some additional petty businesses and 20 to 22 percent being involved in off-farm wage employment in 2019 . The percentage of households that reported to have participated in own-businesses and offfarm wage employment slightly increased between 2017 and 2019.

- $\quad$ The average land area operated by these households ranged between 0.9 hectares in 2017 and 1.2 hectares in 2019. On average, PSNP households in 2019 operated 0.4 hectare more land than did non-PSNP households. Overall, about 34 percent of sample households in 2019 operated less than 0.5 hectare of land, while about 32 percent operated between 0.5 and 1.0 hectares. Changes between the two years and differences between PSNP and nonPSNP were negligible.

- Average livestock ownership ranged between 3.1 Tropical Livestock Units (TLU) in 2017 and 3.3 TLU in 2019. ${ }^{7}$ This shows a slight increase in livestock ownership between the two years for all households. In addition, in contrast to land operated, on average, non-PSNP households owned more livestock than PSNP households -0.9 TLUs more in both years.

- Between 2017 and 2019, the percentage of households contacted by extension agents declined by about 5 percentage points. However, PSNP households are more likely to be contacted by extension agents than are non-PSNP households. In contrast, the percentage of households that have taken loans from financial sources increased by about 15 percentage points between 2017 and 2019. This increase seems to be due to more PSNP households receiving loans in 2019 than in 2017. This may be associated with improved access to credit in 2019 made available through the livelihoods component that is built into the design of PSNP-4.

Livelihood shocks are part of life in PSNP localities. Given that a majority of households rely on crop production (Table 3.12) for their livelihoods, we now turn to looking at the prevalence of loss of crop income due to shocks related to crop production, such as drought, crop disease, lack of key farm-animals, illness of key labor, or lack of hired labor. Table 3.13 presents a summary of these

7 Tropical Livestock Units are livestock numbers converted to a common unit. Conversion factors are: cattle $=0.7$, sheep $=0.1$, goat $=$ 0.1 , pig $=0.2$, chicken $=0.01$. 
occurrences among our sample households in the last rainy (Meher) season and over the last three years.

Table 3.13. Crop shocks and reported consequences

\begin{tabular}{|c|c|c|c|c|c|c|}
\hline \multirow[b]{2}{*}{ Shocks, losses incurred and receipt of transfers } & \multicolumn{3}{|c|}{ March 2017} & \multicolumn{3}{|c|}{ March 2019} \\
\hline & All & PSNP & $\begin{array}{l}\text { Non- } \\
\text { PSNP }\end{array}$ & All & PSNP & $\begin{array}{l}\text { Non- } \\
\text { PSNP }\end{array}$ \\
\hline \multicolumn{7}{|l|}{ In the last Meher season: } \\
\hline Crop suffered from (drought, birds, weed, disease....) & 62.8 & 62.3 & 63.2 & 17.3 & 17.7 & 17.1 \\
\hline Crop suffered from lack of oxen/ploughing animal & 13.2 & 14.4 & 12.4 & 3.9 & 4.8 & 3.3 \\
\hline $\begin{array}{l}\text { Crop suffered from illness of farmer or household } \\
\text { member }\end{array}$ & 4.9 & 5.7 & 4.4 & 1.4 & 1.7 & 1.3 \\
\hline Crop suffered from lack of outside labor & 3.1 & 2.9 & 3.2 & 0.8 & 0.7 & 0.8 \\
\hline Household received transfers & 3.3 & 2.8 & 3.6 & 10.6 & 10.5 & 10.7 \\
\hline \multicolumn{7}{|l|}{ In the last three years: } \\
\hline $\begin{array}{l}\text { Shocks affecting overall household livelihoods (e.g., } \\
\text { floods, erosion, frosts, hail, storage losses, lack of } \\
\text { access to inputs, input price shocks, output prices } \\
\text { shocks, illness, divorce, ...) }\end{array}$ & 39.1 & 38.2 & 39.7 & 35.7 & 36.3 & 35.3 \\
\hline Shocks resulted in loss of productive assets & 10.1 & 8.9 & 10.9 & 16.9 & 17.2 & 16.8 \\
\hline Shocks resulted in reduction of consumption & 21.9 & 19.8 & 23.3 & 36.7 & 38.4 & 35.4 \\
\hline
\end{tabular}

Source: Authors' compilation.

Note that the last two rows are asked for the last three years and given the last round survey took place after two years of the first, part of the responses given for the last year in 2017 is also covered in the 2019 responses.

In general, the percentage of households that reported occurrence of all kinds of shocks are higher in 2017 than in 2019. For example, 63 percent of households in 2017 (as opposed to 17 percent in 2019) reported their crops suffered from droughts, crop diseases, or other shocks. In addition, illness of key farm labor was 4 percentage points higher in 2017 than in 2019. For all shocks, the difference between PSNP and non-PSNP households is negligible. However, the proportion of private transfers received to help the household cope from a shock experienced in the previous Meher season increased from 3 percent in 2017 to 11 percent in 2019.

When asked about overall shocks, including input and output price shocks, suffered over the last three years, a little more than a third of the households reported they suffered either of the listed shocks in 2017 and 2019, but with a slight decrease in 2019. The adverse effects of these shocks seem to vary between the two years, however. In 2017, about 10 percent of households reported that these shocks led to a loss of productive assets while about 22 percent reported that they led to reduction in consumption. In 2019, these figures increase to 17 percent and 37 percent, respectively. However, the differences with regard to shocks between PSNP and non-PSNP households is marginal in both years. 


\section{MOTHERS: ANTHROPOMETRY, DIETS, AND TIME USE}

This chapter reports on indicators of wellbeing of the mothers of index children, including maternal anthropometry, diet diversity, time use, and physical activity and workload. An element of the design of the fourth phase of PSNP is increasing the impact of the program on maternal nutrition. This phase also has a strengthened focus on gender equity. Anthropometry, diet diversity, and physical activity are important for understanding the impact of PSNP on maternal nutritional status.

Anthropometry and diet diversity were measured in all survey rounds.

Understanding maternal time use is important for increasing the impact of the program on household nutritional status and for improving gender equity. The time use module of the household questionnaire was initially piloted during the August 2017 round. Physical activity is measured by the Global Physical Activity Questionnaire (GPAQ) (WHO 2012). This module was added to the survey during the 2019 survey rounds.

\subsection{Maternal anthropometry}

Maternal nutritional status is assessed through anthropometric measurements taken on the mothers of the index children. Height, weight, and mid-upper arm circumference (MUAC) measurements were taken at each round of data collection. Body mass index (BMI) was calculated on all nonpregnant women. A BMI less than $18.5 \mathrm{~kg} / \mathrm{m}^{2}$ is considered underweight, between $18.5 \mathrm{~kg} / \mathrm{m}^{2}$ and $25 \mathrm{~kg} / \mathrm{m}^{2}$ is considered healthy, and above $25 \mathrm{~kg} / \mathrm{m}^{2}$ is considered overweight or obese. MUAC classifications for this analysis are based on the $21 \mathrm{~cm}$ cut-off to detect acute malnutrition. These cutoffs follow recommendations from the World Food Programme for Ethiopia and Sphere for selection of pregnant women at risk during emergencies (Ververs et al. 2013).

Data on these measures from the 2017 survey rounds are found in Appendix Tables B1 and B2. In the 2017 survey, there was no difference in anthropometry between the two seasons. As can be seen in Table B1, there were some regional variation in BMI and MUAC, but there were no differences in each region between the two seasons. Table B2 shows that there were no differences in BMI and MUAC between PSNP beneficiary status or season.

Table 4.1 provides statistics on the anthropometric measurements collected in the two rounds of 2019. The sample for these measurements is the mothers of the index children. In March 2019, across the full sample, the average BMI was $20.2 \mathrm{~kg} / \mathrm{m}^{2}$. This dropped to $19.7 \mathrm{~kg} / \mathrm{m}^{2}$ during August 2019. In contrast to the 2017 survey data, this decrease in BMI was seen in every region. The average BMI in August 2019 was the same as in 2017. The average BMI in March 2019 was higher than in 2017. The decrease in BMI from March 2019 and August 2019 was also different from the change in child anthropometry, which is explored in more detail in Chapter 5.

During both survey rounds, women in Tigray had the lowest average BMI. Corresponding to the drop in BMI, there was an increase in women that were classified as underweight. The largest increase in women that were considered to be underweight was in Amhara, where prevalence increased from 24.5 to 33.0 percent of respondents.

Few respondents were classified as overweight or obese. In March 2019, 3.3 percent of respondents were overweight or obese. In August, this had dropped to 2.4 percent. While Oromia and SNNP had the highest percentage of respondents classified as overweight during both rounds of data collection, these percentages were still very low.

Unlike BMI, there was no change in MUAC and there was less variation in the average MUAC across regions. The average MUAC was $24 \mathrm{~cm}$. In contrast to the BMI-based classifications, there was a slight decrease in the share of women that were classified as acutely malnourished using their MUAC measurements. In March 2019, 7.6 percent of women were acutely malnourished 
according to their MUAC, while in August 2019 it was 7.0 percent. Oromia was the only region where the share of women classified as acutely malnourished increased. There was almost no change in Amhara and SNNP. In Tigray, the share of women classified as acutely malnourished decreased from 12.7 to 9.8 percent. Tigray was also the only region where the percent of women with a MUAC greater than $23 \mathrm{~cm}$ increased.

Table 4.1. Mothers' anthropometry, by region and round, 2019

\begin{tabular}{|c|c|c|c|c|c|c|c|c|c|c|}
\hline & \multicolumn{5}{|c|}{ March 2019} & \multicolumn{5}{|c|}{ August 2019} \\
\hline & Amhara & Oromia & SNNP & Tigray & $\begin{array}{l}\text { All } \\
\text { regions }\end{array}$ & Amhara & Oromia & SNNP & Tigray & $\begin{array}{l}\text { All } \\
\text { regions }\end{array}$ \\
\hline Number of observations: & 662 & 645 & 648 & 658 & 2,613 & 646 & 613 & 618 & 641 & 2,518 \\
\hline Body mass index $\left(\mathrm{kg} / \mathrm{m}^{2}\right)$ & 20.1 & 20.5 & 20.8 & 19.5 & 20.2 & 19.6 & 19.9 & 20.2 & 19.3 & 19.7 \\
\hline \multicolumn{11}{|l|}{ BMI categories (percent): } \\
\hline $\begin{array}{l}\text { Underweight } \\
\left(<18.5 \mathrm{~kg} / \mathrm{m}^{2}\right)\end{array}$ & 24.5 & 21.6 & 14.0 & 37.0 & 24.4 & 33.0 & 26.2 & 20.8 & 39.3 & 30.0 \\
\hline $\begin{array}{l}\text { Normal weight } \\
\left(18.5-25 \mathrm{~kg} / \mathrm{m}^{2}\right)\end{array}$ & 73.1 & 74.4 & 81.5 & 60.7 & 72.3 & 65.3 & 70.7 & 76.3 & 58.6 & 67.5 \\
\hline Overweight (> $25 \mathrm{~kg} / \mathrm{m}^{2}$ ) & 2.5 & 4.0 & 4.5 & 2.3 & 3.3 & 1.8 & 3.1 & 2.9 & 2.1 & 2.4 \\
\hline Height (cm) & 156.4 & 158.0 & 157.4 & 157.4 & 157.2 & 156.4 & 158.0 & 157.4 & 157.2 & 157.3 \\
\hline $\begin{array}{l}\text { Mid-upper arm } \\
\text { circumference (cm) }\end{array}$ & 23.7 & 24.5 & 24.4 & 23.3 & 24.0 & 23.4 & 24.0 & 24.3 & 23.5 & 23.8 \\
\hline \multicolumn{11}{|l|}{ MUAC categories (percent): } \\
\hline Less than $21 \mathrm{~cm}$ & 9.7 & 3.7 & 3.3 & 12.7 & 7.6 & 9.5 & 5.0 & 3.6 & 9.8 & 7.0 \\
\hline Between 21 and $23 \mathrm{~cm}$ & 31.7 & 23.9 & 23.4 & 35.2 & 28.6 & 37.2 & 26.8 & 23.7 & 32.9 & 30.3 \\
\hline More than $23 \mathrm{~cm}$ & 58.6 & 72.4 & 73.3 & 51.1 & 63.8 & 53.3 & 68.1 & 72.8 & 57.3 & 62.7 \\
\hline
\end{tabular}

Source: Authors' compilation.

Note: BMI was not calculated for 86 pregnant mothers in March 2019 and 150 pregnant mothers in August 2019.

Table 4.2 disaggregates women's anthropometric status by PSNP beneficiary status. BMI and MUAC measurements were similar for both non-beneficiaries and PSNP beneficiaries -there were only slight decreases in both groups. Between the two rounds, there was a larger increase in the women classified as undernourished according to their BMI in the non-beneficiary group than there was in the beneficiary group. Additionally, the share of women that were classified as being acutely malnourished according to MUAC between the two time-points was very similar in the nonbeneficiary group. In the beneficiary group, however, this share decreased between March and August.

Table 4.2. Mothers' anthropometry by PSNP beneficiary status and round, 2019

\begin{tabular}{lcccc} 
& \multicolumn{2}{c}{ March 2019} & \multicolumn{2}{c}{ August 2019} \\
& Non-PSNP & PSNP & Non-PSNP & PSNP \\
\hline Number of observations: & 1,534 & 1,079 & 1,471 & 1,047 \\
Body mass index $\left(\mathrm{kg} / \mathrm{m}^{2}\right)$ & 20.2 & 20.1 & 19.8 & 19.7 \\
BMI categories (percent): & & & & \\
Underweight $\left(<18.5 \mathrm{~kg} / \mathrm{m}^{2}\right)$ & 23.1 & 26.3 & 29.4 & 30.9 \\
Normal weight $\left(18.5-25 \mathrm{~kg} / \mathrm{m}^{2}\right)$ & 73.6 & 70.5 & 68.0 & 66.9 \\
Overweight $\left(>25 \mathrm{~kg} / \mathrm{m}^{2}\right)$ & 3.4 & 3.2 & 2.7 & 2.1 \\
Height $(\mathrm{cm})$ & 157.5 & 157.0 & 157.5 & 156.9 \\
Mid-upper arm circumference $(\mathrm{cm})$ & 24.1 & 23.9 & 23.8 & 23.8 \\
MUAC categories (percent): & & & & \\
Less than 21 cm & 7.0 & 8.5 & 6.9 & 7.2 \\
Between 21 and $23 \mathrm{~cm}$ & 28.3 & 29.0 & 29.6 & 31.2 \\
More than 23 cm & 64.7 & 62.5 & 63.5 & 61.6 \\
\hline
\end{tabular}

Source: Authors' compilation. 
The increase in the underweight prevalence in the August round is largely driven by the fact that in the March rounds, a sizable share of the women had recently given birth, while in the August rounds all index children are at least 6 months of age. Figure 4.1 shows how women's BMI falls rapidly after delivery as measured by the index child's age.

\section{Figure 4.1. Relationship between maternal BMI and child's age}

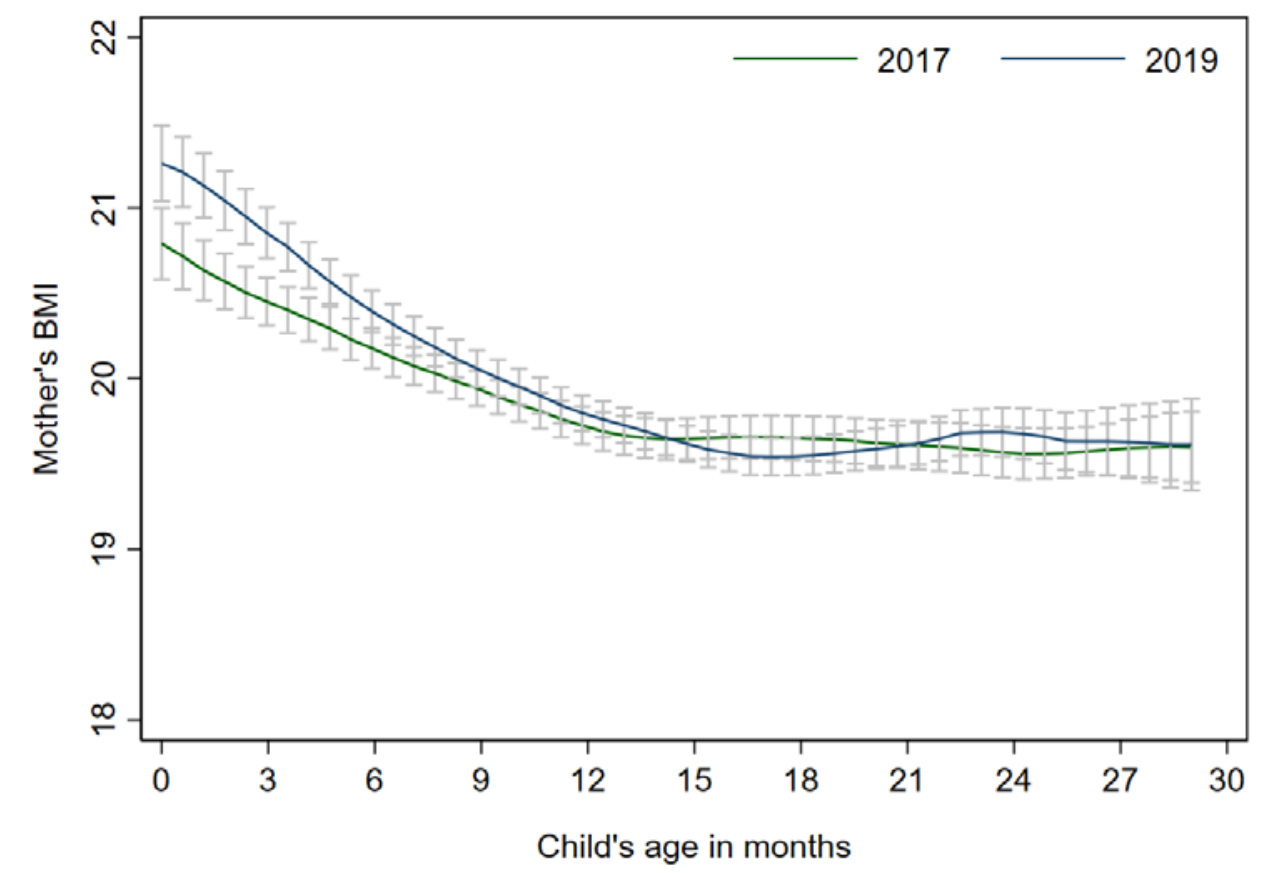

Source: Authors' compilation.

Note: Local polynomial regression. The vertical grey bars represent $95-\%$ confidence intervals.

\subsection{Maternal diet}

Dietary diversity was measured on the mothers of the index children by asking them about their food consumption in the 24 hours prior to the interview using a listing of food items. We grouped the mothers' food consumption into 10 food categories: all starchy staple foods; beans and peas; nuts and seeds; dairy; flesh foods; eggs; vitamin a-rich dark green leafy vegetables; other vitamin a-rich vegetables and fruits; other vegetables; and other fruits (FAO and FHI-360 2016). This yields a dietary diversity score ranging from 0 to 10 . The Minimum Dietary Diversity for Women (MDD-W) is met if the mother consumed from five or more food groups during the 24-hour window.

Table 4.3 reports the results between the two seasons in 2019, disaggregated by region. Overall, the dietary diversity score remained the same in the two rounds. The average mother consumed foods from between 2.7 (August) and 2.8 (March) food groups. There were slight decreases in dietary diversity in Amhara and SNNP between the two survey rounds. These low dietary diversity scores result in few women consuming the minimum dietary diversity requirement - only 6 percent of the mothers of index children had sufficiently diverse diets to meet the MDD-W. This value remained relatively unchanged between the two rounds. 
Table 4.3. Maternal dietary diversity by region and round, 2019

\begin{tabular}{|c|c|c|c|c|c|c|c|c|c|c|}
\hline & \multicolumn{5}{|c|}{ March 2019} & \multicolumn{5}{|c|}{ August 2019} \\
\hline & Amhara & Oromia & SNNP & Tigray & All & Amhara & Oromia & SNNP & Tigray & All \\
\hline $\begin{array}{l}\text { Number of } \\
\text { observations: }\end{array}$ & 666 & 650 & 650 & 660 & 2,626 & 645 & 650 & 617 & 624 & 2,536 \\
\hline $\begin{array}{l}\text { Dietary Diversity } \\
\text { Score (max } 10 \text { food } \\
\text { groups) }\end{array}$ & 2.8 & 2.7 & 2.9 & 3.0 & 2.8 & 2.5 & 2.7 & 2.6 & 3.1 & 2.7 \\
\hline MDD-W (percent) & 2.6 & 6.0 & 9.4 & 5.8 & 5.9 & 2.2 & 4.9 & 9.5 & 6.0 & 5.6 \\
\hline \multicolumn{11}{|l|}{$\begin{array}{l}\text { Food groups } \\
\text { (percent): }\end{array}$} \\
\hline $\begin{array}{l}\text { All starchy staple } \\
\text { foods }\end{array}$ & 99.7 & 94.5 & 96.5 & 98.9 & 97.4 & 99.8 & 94.3 & 79.8 & 99.7 & 93.5 \\
\hline Beans and peas & 91.7 & 51.1 & 30.8 & 80.9 & 63.9 & 83.5 & 45.9 & 22.4 & 80.9 & 58.7 \\
\hline Nuts and seeds & 4.1 & 4.6 & 0.9 & 3.2 & 3.2 & 1.7 & 1.0 & 2.2 & 2.8 & 1.9 \\
\hline Dairy & 3.8 & 37.4 & 18.6 & 4.1 & 15.8 & 4.3 & 44.1 & 27.6 & 8.2 & 20.7 \\
\hline Flesh foods & 6.9 & 2.3 & 4.3 & 9.2 & 5.7 & 4.8 & 2.9 & 10.6 & 10.5 & 7.2 \\
\hline Eggs & 3.2 & 2.0 & 2.8 & 6.2 & 3.5 & 2.0 & 2.4 & 5.3 & 8.7 & 4.6 \\
\hline $\begin{array}{l}\text { Vit. A-rich dark } \\
\text { green leafy vegs. }\end{array}$ & 2.7 & 7.5 & 50.6 & 10.6 & 17.7 & 5.8 & 11.2 & 49.4 & 13.5 & 19.8 \\
\hline $\begin{array}{l}\text { Other vitamin A-rich } \\
\text { vegetables \& fruits }\end{array}$ & 1.1 & 2.3 & 13.4 & 3.9 & 5.1 & 3.7 & 6.2 & 11.4 & 2.9 & 6.0 \\
\hline Other vegetables & 62.9 & 67.4 & 56.6 & 75.0 & 65.5 & 46.8 & 60.9 & 47.3 & 75.3 & 57.6 \\
\hline Other fruits & 1.4 & 5.2 & 11.7 & 3.3 & 5.4 & 1.2 & 2.9 & 7.1 & 6.2 & 4.3 \\
\hline
\end{tabular}

Source: Authors' compilation.

Note: MDD-W = Minimum Dietary Diversity-Women.

These numbers are slightly higher than those reported in 2017 (see Appendix Tables B3 and B4). In 2017, mothers consumed between 2.2 (March) and 2.4 (August) food groups. Only 1.8 percent of women achieved MDD-W in both seasons in 2017. Similar to the 2019 data, the main food groups consumed were starchy staples, beans and peas, and other vegetables. The percentage of women that consumed beans and peas and other vegetables increased on average from 2017 to 2019. There was a large increase in percent of women who consumed vitamin-A rich dark green leafy vegetables during data collection in March - in 2017, 9.3 percent of respondents had consumed them in the past 24-hours compared to 17.7 percent in 2019.

The composition of the diet changed between March 2019 and August 2019. Starchy staple foods were the most frequent food group consumed in both seasons. However, in March, the second most reported consumed food group was other vegetables, while in August, beans and peas were the second most reported food group to be consumed. However, there was a slight decrease in the consumption of both of these food groups.

While overall consumption was low, there was an increase in the percent of women who consumed animal sourced foods (dairy, flesh foods, and eggs) and vitamin A-rich dark green leafy vegetables between the two time points. This is expected due to the seasonal availability of some foods. In August, there is improved access to leafy vegetables and animal feed (grass).

Consumption of other fruit, nuts and seeds, and other vitamin A-rich vegetables and fruits was low in both seasons.

While there were minimal differences in dietary diversity scores between regions, there were regional differences in the percent of women that were achieving minimum dietary diversity (MDD-W). SNNP had the highest percentage of women meeting the minimum diet diversity at 9.5 percent, which remained unchanged between the two rounds. Amhara and Tigray remained relatively unchanged between the two rounds, while Oromia saw a decrease in the percent of women meeting minimum dietary diversity recommendations. Amhara had the lowest percentage of women meeting minimum dietary diversity at both time points with less than 3 percent of women 
consuming five or more foods groups. In Amhara, starchy staple foods, beans and peas, and other vegetables were the most frequently reported foods groups consumed. The consumption of other food groups was very low with fewer than 7 percent of women reporting having consumed them in the previous 24 hours.

Dairy consumption was much higher in Oromia than any other region. In March, while 37.4 percent of women in Oromia reported consuming dairy, the next highest region was SNNP with 18.6 percent. In August, the percent of women consuming dairy was 44.1 percent in Oromia and 27.6 percent in SNNP. Consumption of vitamin A-rich vegetables was highest in SNNP in both March and August.

Table 4.4 shows dietary diversity between the seasons disaggregated by PSNP beneficiary status. The dietary diversity score was similar between the two groups and remained unchanged across seasons. The percent of women achieving minimum dietary diversity was lower in the PSNP beneficiary group than in the non-beneficiary group at both time points, and this pattern remained unchanged between the two seasons. Starchy staple foods, beans and peas, and other vegetables were the most commonly food groups that the women reported to have consumed. Changes in other food groups over time were comparable between women in PSNP and non-PSNP households with the exception of flesh foods. In August, more non-beneficiaries reported consuming flesh foods than in April. Among PSNP beneficiaries, the percent remained unchanged.

\section{Table 4.4. Mothers' dietary diversity by PSNP beneficiary status and round}

\begin{tabular}{lcccc} 
& \multicolumn{2}{c}{ March 2019} & \multicolumn{2}{c}{ August 2019} \\
& non-PSNP & PSNP & non-PSNP & PSNP \\
Number of observations: & 1,540 & 1,086 & 1,481 & 1,055 \\
Dietary Diversity Score (max 10 food groups) & 2.9 & 2.7 & 2.8 & 2.7 \\
MDD-W (percent) & 7.1 & 4.1 & 6.7 & 4.1 \\
Food groups (percent) & & & & \\
All starchy staple foods & 97.8 & 96.9 & 93.2 & 94.0 \\
Beans and peas & 63.4 & 64.5 & 58.0 & 59.6 \\
Nuts and seeds & 2.9 & 3.7 & 2.4 & 1.3 \\
Dairy & 17.3 & 13.8 & 22.9 & 17.6 \\
Flesh foods & 5.1 & 6.5 & 7.8 & 6.4 \\
Eggs & 3.7 & 3.3 & 4.7 & 4.5 \\
Vitamin A-rich dark green leafy vegetables & 19.3 & 15.6 & 21.0 & 18.1 \\
Other vitamin A-rich vegetables and fruits & 5.6 & 4.4 & 6.3 & 5.6 \\
Other vegetables & 68.1 & 61.9 & 59.3 & 55.3 \\
Other fruits & 6.2 & 4.2 & 4.8 & 3.7 \\
\hline
\end{tabular}

Source: Authors' compilation.

Note: $M D D-W=$ Minimum Dietary Diversity-Women.

Table 4.5 disaggregates the seasonal dietary diversity data by religion. We suspect some of the regional differences in dietary patterns regarding animal sourced foods, especially dairy, seen in Table 4.3 can be contributed to the Orthodox fasting season that took place during the fieldwork in March and over part of the August survey. In March, 27.6 percent of respondents reported that they had been fasting the previous day; while in August 21.1 percent reported that they were fasting. Additionally, consumption of animal sourced foods may have increased after fasting broke in the middle of the August survey. The proportion of Orthodox Christian households is highest in Amhara and Tigray, which may explain why consumption of animal sourced foods in those regions is lower.

As expected, women in Orthodox households reported consuming less animal sourced foods than women living in Muslim or Protestant households. In March, consumption of dairy was much lower in Orthodox households than in other households. In August, consumption of dairy had increased in all households, but still remained much lower in Orthodox households. Consumption of 
flesh foods and eggs was low in all households. However, it was higher in Orthodox households than in Muslim or Protestant households in March. In August, a comparable percentage of women in Muslim households reported consuming flesh foods.

Table 4.5. Mother's dietary diversity by household religion and round

\begin{tabular}{lcccccc} 
& \multicolumn{7}{c}{ March $\mathbf{2 0 1 9}$} & \multicolumn{3}{c}{ August 2019 } \\
& Orthodox & Muslim & Protestant & Orthodox & Muslim & Protestant \\
Number of observations: & 1,265 & 840 & 455 & 1,238 & 810 & 434 \\
$\begin{array}{l}\text { Dietary Diversity Score (max 10 food } \\
\text { groups) }\end{array}$ & 2.8 & 2.8 & 2.9 & 2.8 & 2.8 & 2.6 \\
MDD-W (percent) & 4.5 & 5.2 & 11.6 & 3.8 & 6.0 & 10.1 \\
Food groups (percent) & & & & & & \\
All starchy staple foods & 99.2 & 96.5 & 96.0 & 99.5 & 92.8 & 78.8 \\
Beans and peas & 82.6 & 54.6 & 34.5 & 77.5 & 48.5 & 27.6 \\
Nuts and seeds & 3.2 & 4.5 & 1.3 & 2.2 & 1.1 & 2.5 \\
Dairy & 4.7 & 26.0 & 22.6 & 7.4 & 33.5 & 30.0 \\
Flesh foods & 7.4 & 4.4 & 3.5 & 7.8 & 8.0 & 3.2 \\
Eggs & 4.7 & 2.4 & 2.9 & 5.1 & 3.8 & 4.8 \\
Vitamin A-rich dark green leafy vegs. & 8.8 & 15.4 & 46.6 & 12.3 & 16.8 & 47.5 \\
Other vitamin A-rich vegetables \& fruits & 3.0 & 3.9 & 13.6 & 3.4 & 5.8 & 13.8 \\
Other vegetables & 66.6 & 71.1 & 56.0 & 59.5 & 63.0 & 46.1 \\
Other fruits & 2.9 & 3.5 & 14.9 & 4.0 & 3.0 & 8.1 \\
\hline
\end{tabular}

Source: Authors' compilation.

Note: MDD-W = Minimum Dietary Diversity-Women.

\subsection{Time use}

Data on maternal time use was collected using a specially designed 24-hour recall module. Because this is a time-consuming module to implement, these data were collected from approximately half of the mothers interviewed for this evaluation: 1,297 mothers in March 2019 and 1,255 mothers in August 2019. Mothers were selected for inclusion into this module using cluster randomization at the level of the woreda.

The respondents were asked what they did the previous day starting an hour prior to sunrise and ending an hour after sunset, resulting in 840 minutes of data collection per day. To make recall easier, the day was broken into half hour increments. For each increment, participants were asked to select a primary activity, a secondary activity, and whether or not a child under the age of three was with them. It is standard in time use questionnaires to ask about both a primary and a secondary activity because a respondent might be undertaking more than one activity at a time or because an activity took up a portion of the time frame but not all of it, resulting in two activities taking place during the same time frame. When both a primary and secondary activity was listed, each activity was considered to take up 15 minutes of time. For each activity, the respondents were asked their perceived exertion level, information which was used for analysis on physical activity.

If the respondent reported having a child with them, they were asked if they were providing passive or active care of the child. Passive care is defined as having been present, but the respondent was not interacting with the child. For example, the child might be sleeping or playing on its own. Care was considered to be active care if the mother was interacting with the child - for example, she was feeding, playing with, or trying to soothe the child. If a mother responded that she was providing active care to a child in addition to a primary and secondary activity, each activity was considered to have taken up ten minutes or her time. Based on pilot tests conducted in July 2017 , enumerators coded these responses into one of 28 different categories. 
Table 4.6 shows the percent of mothers who responded that they had participated in a particular activity the previous day, disaggregated by region. The percent of participants who reported participating in PSNP activities and attending nutrition sessions in the previous 24 hours was low in all regions. (This is consistent with the results on participation in PSNP activities found in chapter 7.) SNNP had the highest percentage of mothers reporting to have participated in PSNP activities the previous day, but this was only 1.6 percent.

Table 4.6. Percent of mothers that participated in specific activities during the previous day, by region

\begin{tabular}{|c|c|c|c|c|c|c|c|c|c|c|}
\hline & \multicolumn{5}{|c|}{ March 2019} & \multicolumn{5}{|c|}{ August 2019} \\
\hline & Amhara & Oromia & SNNP & Tigray & All & Amhara & Oromia & SNNP & Tigray & All \\
\hline $\begin{array}{l}\text { Number of } \\
\text { observations: }\end{array}$ & 334 & 320 & 317 & 326 & 1,297 & 328 & 307 & 561 & 317 & 1,255 \\
\hline $\begin{array}{l}\text { Caring for children or } \\
\text { other } \mathrm{HH} \text { members }\end{array}$ & 100.0 & 99.1 & 100.0 & 99.7 & 99.7 & 99.7 & 99.0 & 99.3 & 99.4 & 99.3 \\
\hline Preparing food & 91.3 & 90.3 & 92.7 & 88.3 & 90.7 & 97.3 & 94.1 & 98.0 & 93.4 & 95.7 \\
\hline Eating and drinking & 98.2 & 97.2 & 99.1 & 99.7 & 98.5 & 99.4 & 96.4 & 99.3 & 99.4 & 98.6 \\
\hline Personal care & 72.8 & 61.6 & 58.7 & 45.4 & 59.7 & 58.2 & 49.2 & 52.8 & 39.4 & 50.0 \\
\hline Sleeping & 59.9 & 73.4 & 77.9 & 67.8 & 69.6 & 70.7 & 68.7 & 79.9 & 52.1 & 67.7 \\
\hline Resting or ill & 53.3 & 57.2 & 64.4 & 41.7 & 54.0 & 53.0 & 58.0 & 63.7 & 37.5 & 52.9 \\
\hline Own crop production & 2.4 & 5.0 & 13.6 & 2.5 & 5.8 & 33.8 & 15.3 & 23.8 & 27.8 & 25.3 \\
\hline $\begin{array}{l}\text { Crop production for } \\
\text { others }\end{array}$ & 0.3 & 0.9 & 1.3 & 0.3 & 0.7 & 1.8 & 5.2 & 2.6 & 1.6 & 2.8 \\
\hline Caring for own livestock & 20.7 & 24.7 & 30.0 & 16.3 & 22.8 & 23.5 & 30.6 & 42.2 & 19.6 & 28.8 \\
\hline $\begin{array}{l}\text { Caring for someone } \\
\text { else's livestock }\end{array}$ & 0.6 & 1.3 & 1.6 & 0.6 & 1.0 & 0.0 & 2.6 & 1.3 & 0.3 & 1.0 \\
\hline Time at the market & 4.5 & 8.8 & 16.1 & 9.2 & 9.6 & 7.9 & 6.5 & 15.2 & 6.6 & 9.0 \\
\hline Own business activities & 1.2 & 3.4 & 3.5 & 4.9 & 3.2 & 0.6 & 2.9 & 2.3 & 5.7 & 2.9 \\
\hline Non-PSNP wage work & 0.3 & 0.0 & 0.6 & 1.2 & 0.5 & 0.0 & 0.0 & 0.3 & 4.4 & 1.2 \\
\hline PSNP activities & 0.9 & 0.0 & 1.6 & 0.9 & 0.8 & 0.0 & 0.0 & 0.0 & 0.0 & 0.0 \\
\hline $\begin{array}{l}\text { Attending PSNP } \\
\text { nutrition sessions }\end{array}$ & 0.6 & 0.6 & 0.0 & 0.6 & 0.5 & 0.6 & 0.0 & 0.0 & 0.6 & 0.3 \\
\hline Domestic work & 66.8 & 71.3 & 65.6 & 65.6 & 67.3 & 64.6 & 74.3 & 72.9 & 55.5 & 66.7 \\
\hline $\begin{array}{l}\text { Gathering fuelwood or } \\
\text { fetching water by self }\end{array}$ & 38.3 & 50.9 & 54.9 & 29.4 & 43.3 & 36.6 & 50.2 & 56.1 & 25.9 & 41.9 \\
\hline $\begin{array}{l}\text { Gathering fuelwood or } \\
\text { fetching water with } \\
\text { help }\end{array}$ & 7.2 & 7.2 & 6.9 & 9.2 & 7.6 & 5.5 & 9.8 & 5.6 & 2.5 & 5.8 \\
\hline Walking or traveling & 6.9 & 11.9 & 12.0 & 7.4 & 9.5 & 4.6 & 8.8 & 10.6 & 6.3 & 7.5 \\
\hline School or homework & 0.9 & 0.3 & 0.0 & 2.1 & 0.8 & 0.0 & 0.0 & 0.0 & 4.4 & 1.1 \\
\hline Religious activities & 7.8 & 8.1 & 9.8 & 12.6 & 9.6 & 10.1 & 9.8 & 8.9 & 14.5 & 10.8 \\
\hline Community activities & 3.6 & 4.4 & 2.2 & 8.3 & 4.6 & 3.7 & 1.0 & 3.0 & 2.8 & 2.6 \\
\hline Time with families & 38.3 & 55.9 & 54.6 & 27.3 & 43.9 & 41.8 & 44.3 & 53.8 & 28.7 & 42.0 \\
\hline Socializing & 18.6 & 9.4 & 11.0 & 18.7 & 14.5 & 16.2 & 10.4 & 19.8 & 8.8 & 13.8 \\
\hline $\begin{array}{l}\text { Watching TV or } \\
\text { listening to radio }\end{array}$ & 1.5 & 1.3 & 1.3 & 2.5 & 1.6 & 0.9 & 0.3 & 0.7 & 0.3 & 0.6 \\
\hline Other leisure activities & 0.3 & 0.3 & 0.0 & 0.9 & 0.4 & 1.2 & 0.7 & 1.7 & 0.6 & 1.0 \\
\hline Other activities & 3.3 & 1.9 & 3.2 & 3.4 & 2.9 & 3.0 & 1.3 & 5.0 & 2.5 & 2.9 \\
\hline
\end{tabular}

Source: Authors' compilation.

Unsurprisingly, almost all women in all regions reported that they had participated in caring for children or other household members, preparing food, and eating or drinking during both the dry and the rainy season. Also, unsurprisingly, there was a large increase in crop production between the dry season and the rainy season. The largest increase was seen in Amhara and Tigray where 2.5 percent of women reported participating in their own crop production in March, but this increased to 33.8 and 27.8 percent, respectively, in August. Participation in crop production during 
the rainy season was lowest in Oromia where only 15.3 percent of respondents reported participating. Assisting others in their crop production was low in all regions in both March and August. Caring for own livestock increased slightly from 22.8 percent in March to 28.8 percent in August. This may reflect the increase in available grazing land during the rainy season in August. There was also an increase in the percent of women participating in wage work during the rainy season compared to March. This was entirely driven by women in the Tigray region where 4.4 percent of respondents engaged in wage work.

Table 4.7 shows the percent of women who participated in an activity in the previous 24 hours disaggregated by season and PSNP beneficiary status. Only 1.7 percent of respondents in the beneficiary group engaged in PSNP activities and only 0.6 percent had attended the nutrition sessions in March 2019.

Table 4.7. Percent of mothers that participated in specific activities during the previous day, by PSNP beneficiary status and survey round

\begin{tabular}{|c|c|c|c|c|}
\hline & \multicolumn{2}{|c|}{ March 2019} & \multicolumn{2}{|c|}{ August 2019} \\
\hline & non-PSNP & PSNP & non-PSNP & PSNP \\
\hline Number of observations: & 646 & 651 & 636 & 619 \\
\hline Caring for children or other household members & 99.7 & 99.7 & 99.2 & 99.5 \\
\hline Preparing food & 90.6 & 90.8 & 96.4 & 95.0 \\
\hline Eating and drinking & 98.8 & 98.3 & 99.1 & 98.2 \\
\hline Personal care & 59.6 & 59.8 & 52.4 & 47.5 \\
\hline Sleeping & 70.1 & 69.1 & 67.8 & 67.7 \\
\hline Resting or ill & 54.8 & 53.3 & 53.1 & 52.7 \\
\hline Own crop production & 5.6 & 6.0 & 22.3 & 28.4 \\
\hline Crop production for others & 1.1 & 0.3 & 3.6 & 1.9 \\
\hline Caring for own livestock & 23.8 & 21.8 & 30.0 & 27.5 \\
\hline Caring for someone else's livestock & 1.4 & 0.6 & 1.1 & 1.0 \\
\hline Time at the market & 10.5 & 8.6 & 9.1 & 8.9 \\
\hline Own business activities & 2.5 & 4.0 & 3.1 & 2.6 \\
\hline Non-PSNP wage work & 0.8 & 0.3 & 1.4 & 1.0 \\
\hline PSNP activities & 0.0 & 1.7 & 0.0 & 0.0 \\
\hline Attending PSNP nutrition sessions & 0.3 & 0.6 & 0.3 & 0.3 \\
\hline Domestic work & 69.3 & 65.3 & 69.8 & 63.5 \\
\hline Gathering fuelwood or fetching water by self & 43.7 & 42.9 & 44.3 & 39.4 \\
\hline Gathering fuelwood or fetching water with help & 7.9 & 7.4 & 6.4 & 5.2 \\
\hline Walking or traveling & 10.5 & 8.4 & 7.1 & 7.9 \\
\hline School or homework & 0.9 & 0.8 & 1.3 & 1.0 \\
\hline Religious activities & 9.9 & 9.2 & 10.7 & 11.0 \\
\hline Community activities & 4.0 & 5.2 & 3.0 & 2.3 \\
\hline Time with their families & 44.0 & 43.8 & 44.0 & 39.9 \\
\hline Socializing & 13.0 & 16.0 & 13.5 & 14.1 \\
\hline Watching TV or listening to radio & 2.3 & 0.9 & 1.1 & 0.0 \\
\hline Other leisure activities & 0.2 & 0.6 & 0.8 & 1.3 \\
\hline Other activities & 2.8 & 3.1 & 2.0 & 3.9 \\
\hline
\end{tabular}

Source: Authors' compilation.

There was a larger increase in the share of PSNP index child mothers who said they spent time in crop production than for non-PSNP mothers. Engaging in crop production activities or caring for livestock for someone else was low for both groups, but it was higher for non-beneficiaries then for beneficiaries. There was a decrease in the percent of women who spent time on personal care in both groups between March and August. There were also decreases in the percent of women who spent time walking or traveling and engaging in community activities. There was a decrease in the 
percent of PSNP beneficiaries that were engaged in their own business activities from March to August. The decreases in such activities were likely in response to respondents needing to participate in crop production activities in August.

To make it easier to see patterns in these data, we consolidate the results of Tables 4.6 and 4.7 into eight categories: caring for children, adults or elderly household members; cooking or eating; food production or procurement; income generating activities; domestic activities; traveling or walking; personal care; and leisure and other activities. Table 4.8 explains which activities are consolidated into each category.

\section{Table 4.8. Consolidation of time use categories}

\begin{tabular}{ll}
\hline Child, adult, or elder care & Income generating \\
\hline Listed as a primary or secondary activity & Wage work \\
Reported providing active care to their child & Own business activities \\
\hline Food specific & PSNP activities \\
\hline Time spent cooking or preparing food & Attending PSNP nutrition session \\
\hline Time spent eating or drinking & Domestic activities \\
\hline Personal care & Domestic activities \\
\hline Sleeping & Fetching water/ fuel wood \\
Resting or ill & Otherl leisure \\
Showering/ bathing & School/ homework \\
\hline Procuring food & Religious activities \\
\hline Crop production for themselves or others & Community activities \\
Crop production others & Time with their families \\
Tending to their own livestock & Socializing \\
\hline Tending to someone else's livestock & Watching tv or listening to radio \\
Time at market & Other leisure activities \\
\hline
\end{tabular}

Source: Authors' compilation.

Table 4.9 shows the total number of minutes on average that mother spent on each category during the previous day. (Recall the time use module is set up so that it allocates these time use categories across 840 minutes daily.) There were decreases in the amount of time spent in most categories between March 2019 and August 2019. The largest decrease seen is on childcare, which decreased by an average of 45.4 minutes between the dry and the rainy season. The only category that increased was time spent on activities associated with the procurement of food.

Table 4.9. Mothers' time use (minutes and percent of total), by round

\begin{tabular}{lrrrr} 
& \multicolumn{2}{c}{ March 2019} & \multicolumn{2}{c}{ August 2019 } \\
& Percent of & & $\begin{array}{c}\text { Percent of } \\
\text { total }\end{array}$ \\
Childcare & 219.7 & 26.2 & 174.3 & 20.8 \\
Cooking/ eating & 209.4 & 24.9 & 200.5 & 23.9 \\
Food production & 56.0 & 6.7 & 141.6 & 16.9 \\
Income & 10.6 & 1.3 & 9.0 & 1.1 \\
Domestic activities & 124.6 & 14.8 & 122.0 & 14.5 \\
Traveling/ walking & 9.6 & 1.1 & 8.9 & 1.1 \\
Personal care & 115.5 & 13.8 & 98.5 & 11.7 \\
Leisure/ other & 94.4 & 11.2 & 85.2 & 10.1 \\
Total & 840.0 & 100.0 & 840.0 & 100.0 \\
\hline
\end{tabular}

Source: Authors' compilation. 
Figure 4.2 shows the total number of minutes that mothers spent in different categories during March 2019 disaggregated by region. Mothers in Amhara spent the most time on childcare, while mothers in Oromia spent the least time. Mothers in Oromia spent the most amount of time in domestic activities and personal care. Mothers in SNNP spent the most time on food production activities.

Figure 4.2. Mothers' time use, March 2019, by region

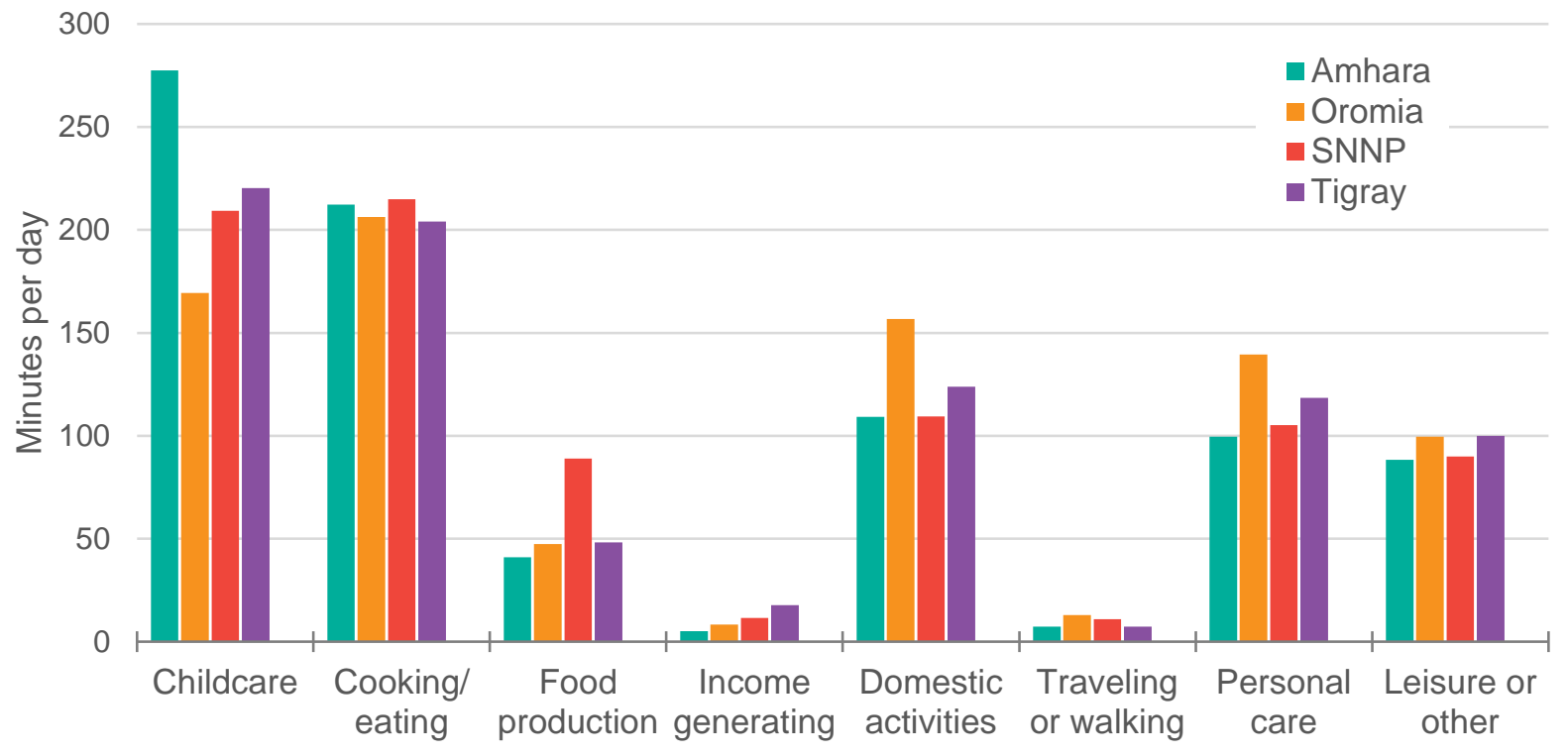

Source: Authors' compilation.

Figure 4.3 shows the amount of time that mothers spent on different time use categories during August 2019 disaggregated by region. In all regions except Oromia, there was a decrease in the amount of time spent on childcare relative to March. However, mothers in Amhara still spent the most time caring for their children and other family members. Time spent in food production and procurement activities increased in all regions. Mothers in Amhara spent less amount of time on cooking and eating than mothers in other regions, likely due to the amount of time spent on food production activities.

Figure 4.3. Mothers' time use, August 2019, by region

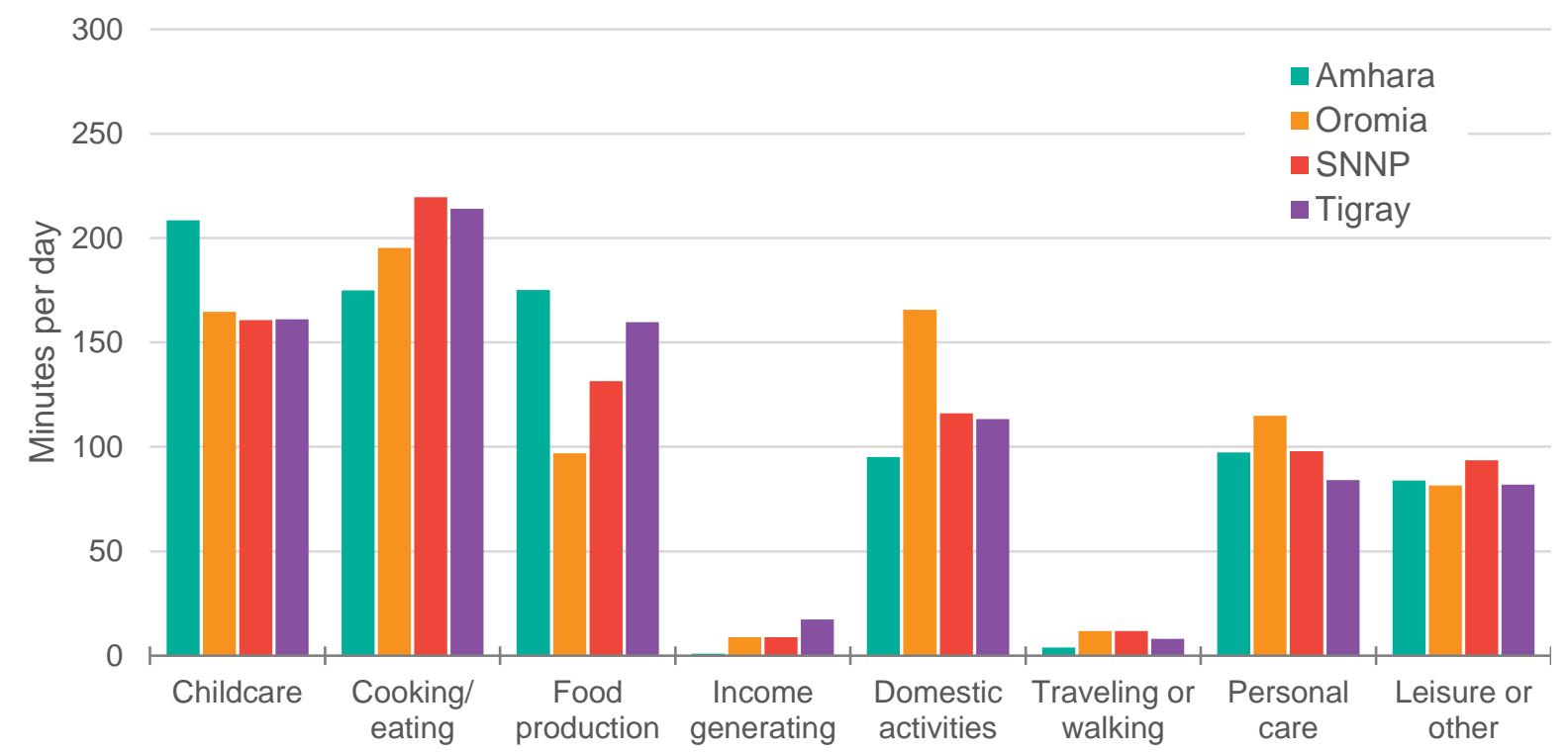

Source: Authors' compilation. 
Figure 4.4 shows the amount of time that women spent in each time use category disaggregated by PSNP beneficiary status and survey round. The amount of time that women spent on childcare decreased between March 2019 and August 2019. In March 2019, mothers in PSNP beneficiary households spent more time on childcare than did mothers in non-beneficiary households.

However, in August 2019, the two groups spent the same amount of time on childcare, as a result of PSNP beneficiary mothers experiencing a greater decrease in the amount of time spent on childcare. There were also slight decreases between March 2019 and August 2019 in the time spent cooking or eating, on personal care, and on leisure or other activities. There were slightly larger decreases in PSNP beneficiary households compare to non-beneficiary households. The decrease in time spent on these activities were likely due to the large increase in time spent on food procurement activities. There was an increase in both groups, however a larger increase was seen in PSNP beneficiary households.

\section{Figure 4.4. Mothers' time use, by PSNP status, survey round, and activity}

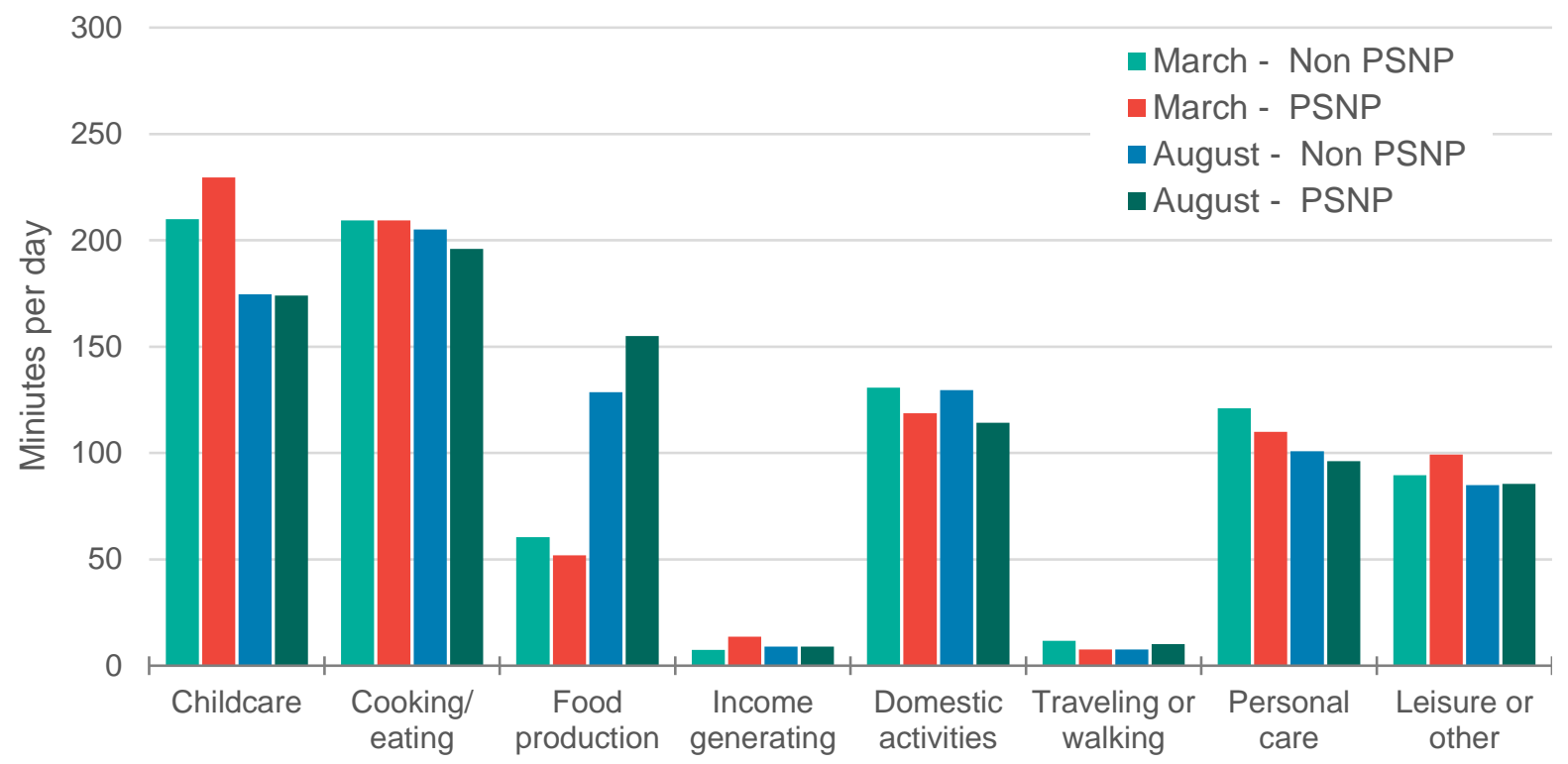

Source: Authors' compilation.

Figures 4.2, 4.3, and 4.4 suggest that mothers are spending less time on childcare when they increase their time spent on food production activities. However, it is possible that women still have their children with them when they are engaged in these activities. Table 4.10 and Figures 4.5, 4.6, and 4.7 shows how women spend their time when their children were not present.

Table 4.10 shows the total amount of time that women spent without a child under the age of 3 years, disaggregated by time use category and survey round. The total amount of time women spent without their children increased by an average of 40 minutes in August 2019 compared to March 2019. In March 2019, the largest amount of time women spent without a child present was while they were engaged in domestic activities. In contrast, in August 2019, the largest amount of time women spent without a child present was while they were engaged in food production activities. 
Table 4.10. Mothers' time use (minutes) when child not present, by round

\begin{tabular}{lrc} 
& $\begin{array}{c}\text { March } \\
\mathbf{2 0 1 9}\end{array}$ & $\begin{array}{c}\text { August } \\
\mathbf{2 0 1 9}\end{array}$ \\
Cooking/ eating & 38.1 & 32.8 \\
Food production & 44.2 & 98.2 \\
Income & 6.4 & 7.1 \\
Domestic activities & 71.1 & 65.7 \\
Traveling/ walking & 7.4 & 7.5 \\
Personal care & 28.5 & 24.1 \\
Leisure & 30.0 & 29.8 \\
\hline Total & 225.7 & 265.2 \\
\hline
\end{tabular}

Source: Authors' compilation.

Figure 4.5 shows mothers' activities when their child is not present disaggregated by region during March 2019. Unsurprising given Figure 4.2, women in Amhara spent the least amount of time with their children. The average total amount of time that mothers spent without their children was similar in other regions. For mothers in Amhara, time spent without their children was divided among all categories. Mothers in Oromia spent the most amount of time without their children engaged in domestic activities. Mothers in SNNP spent the most amount of time when their child was not present engaged in food production activities. Mothers in Tigray spent the most amount of this time cooking or eating or in domestic activities.

Figure 4.5. Mothers' time use (minutes) when child not present, by region, March 2019

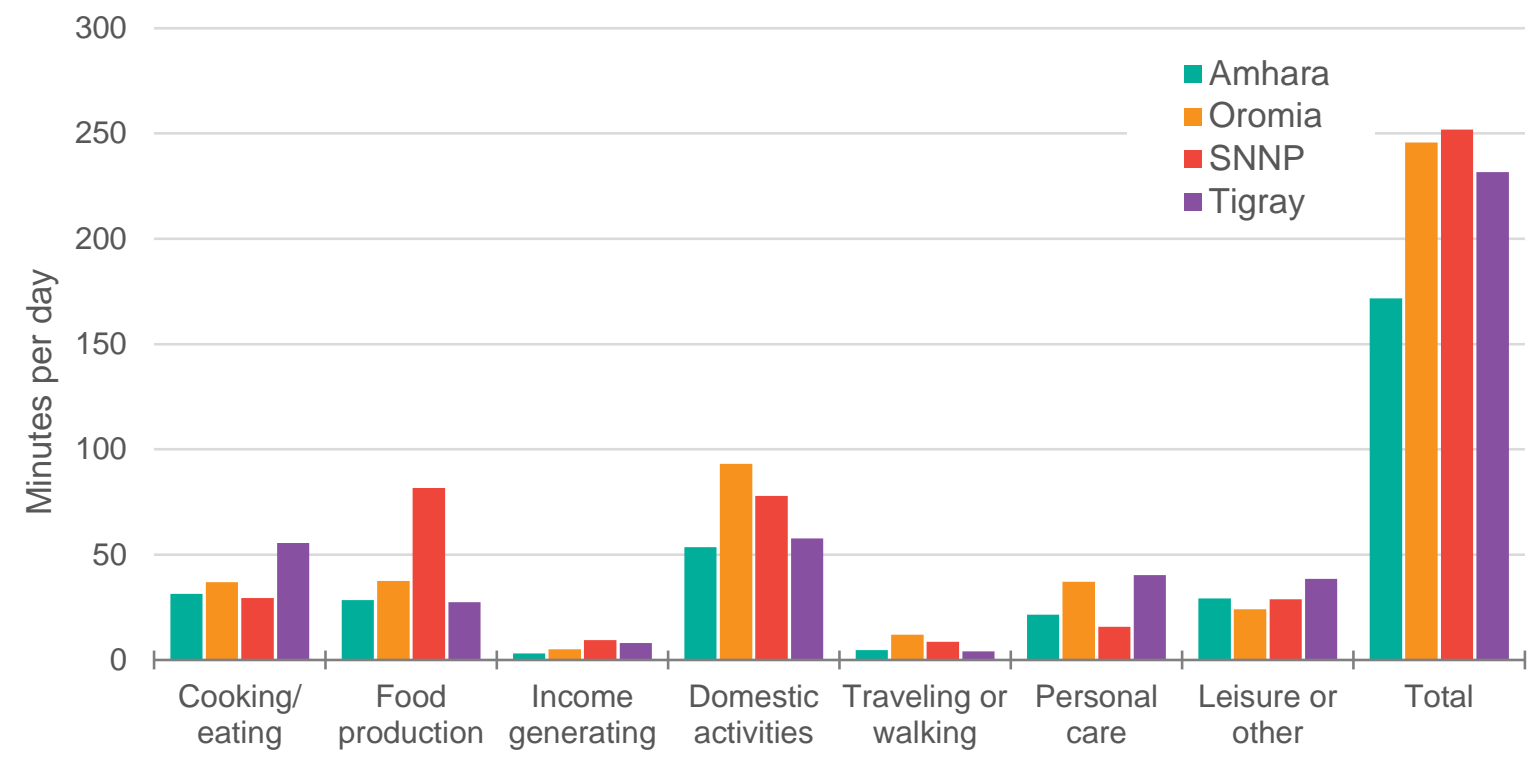

Source: Authors' compilation.

Figure 4.6 shows the time that mothers spent in different time use categories when a child was not present during the August 2019 survey round, again disaggregated by region. Comparing Figure 4.5 to 4.6, in all regions, the amount of time spent without their children increased between March 2019 and August 2019, with the exception of Tigray. The largest increase in time spent without children was in Amhara. In August 2019, mothers in all regions except Oromia spent the majority of their time without a child on food production. In Oromia, the majority of time mothers spent without their child was on domestic activities. Mothers in SNNP spent the most amount of time without their children, whereas mothers in Tigray spent the least amount of time without their children. Mothers spent very little time on income generating or activities or traveling or walking without a child. 
Figure 4.6. Mothers' time use (minutes) when child not present, by region, August 2019

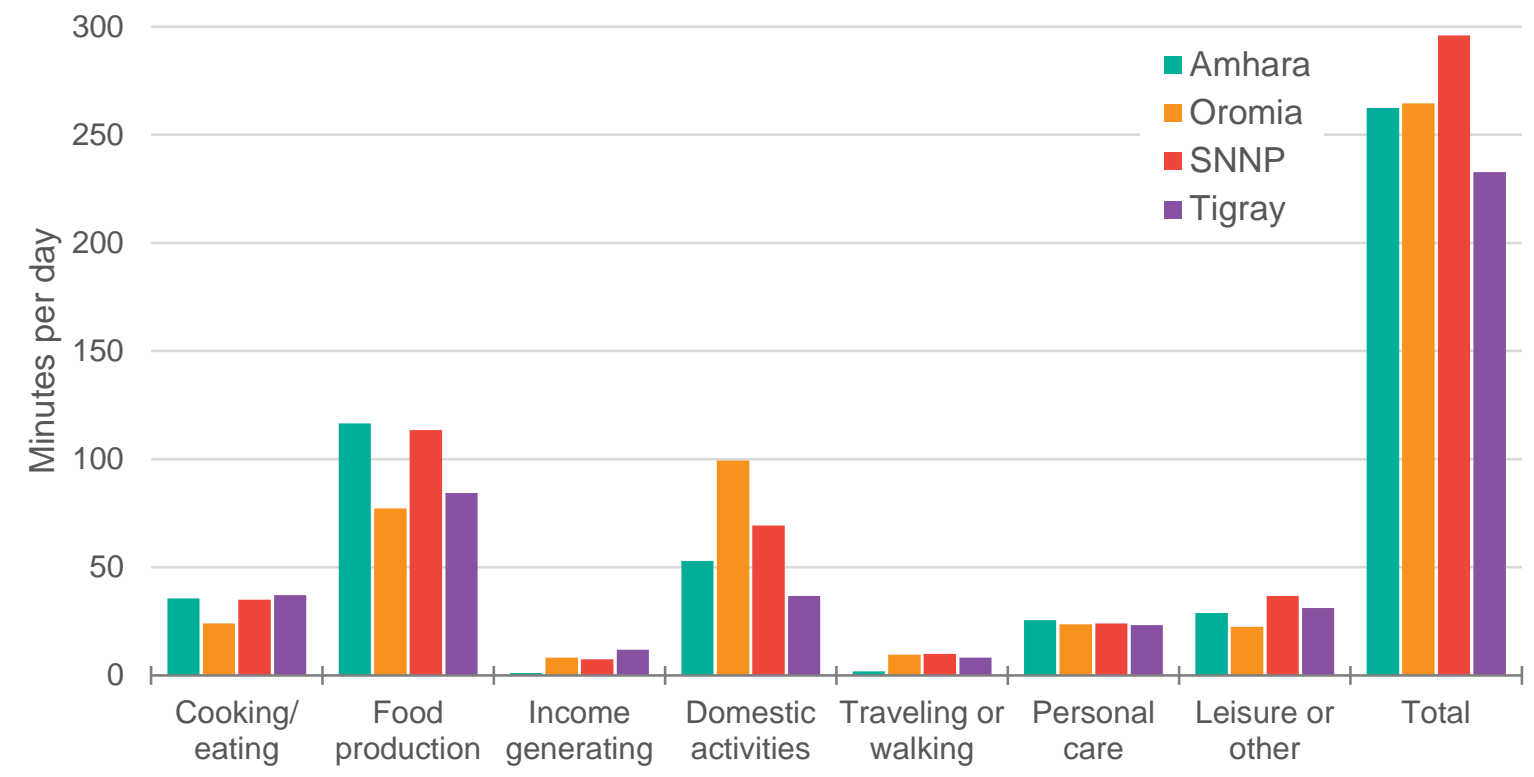

Source: Authors' compilation.

Figure 4.7 shows the amount of time mothers spent in time use categories without their children disaggregated by PSNP beneficiary status and survey round. Both beneficiaries and nonbeneficiaries increased the amount of time spent without their children between March 2019 and August 2019 with PSNP beneficiaries experiencing the larger increase. In March 2019, both groups spent most of their time without children engaged in domestic activities. In August 2019, they spent most time without their children on food production activities. For mothers living in households participating in PSNP, there was a slight decrease in the amount of time they spent without their children on domestic activities between March 2019 and August 2019.

Figure 4.7. Mothers' time use (minutes) when child not present, by PSNP status and survey round

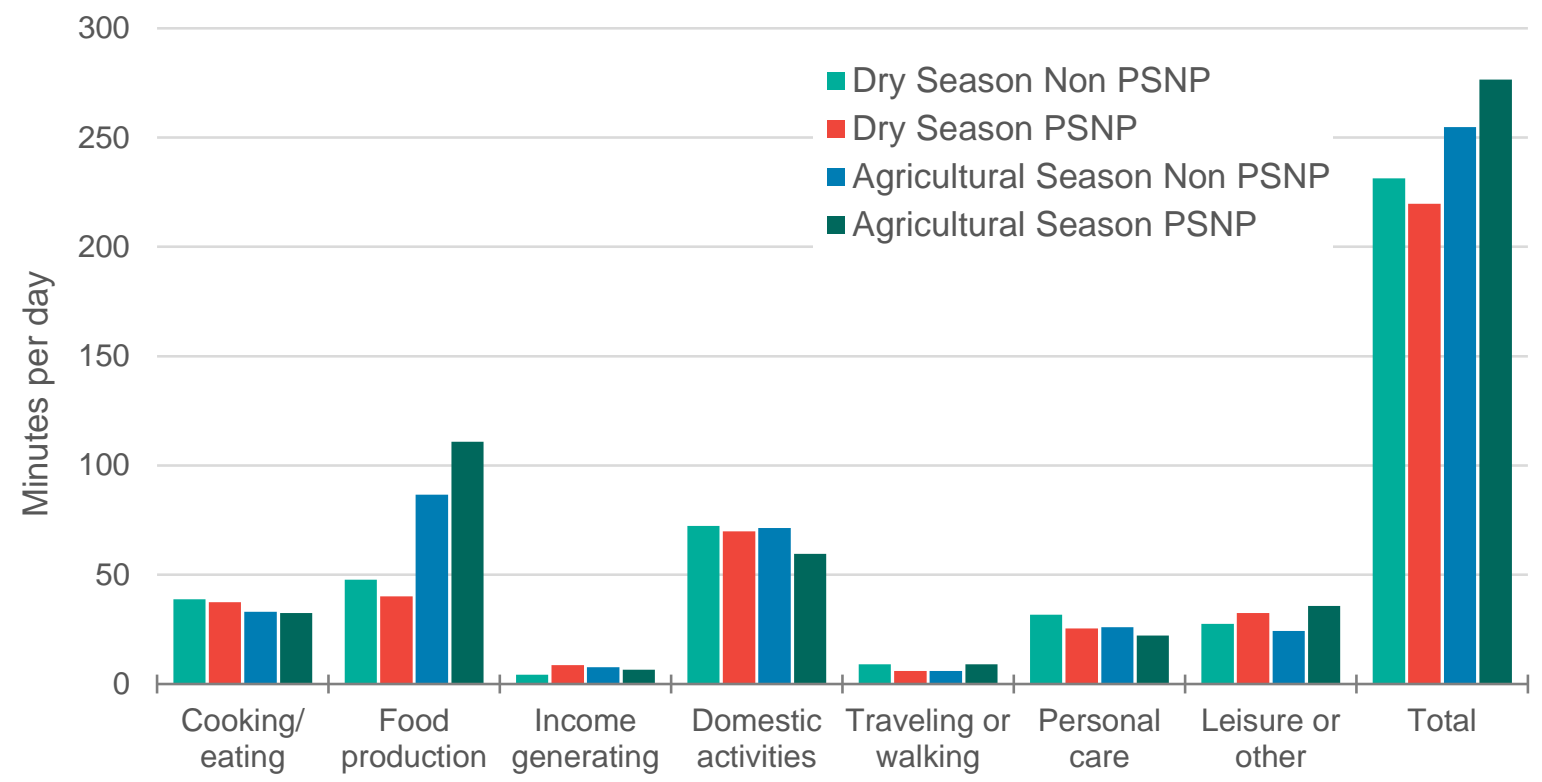

Source: Authors' compilation.

Index children were under the age of 23 months when their households were recruited into the study in March 2019. As they aged between the two rounds of data collection, it is possible that 
some of the decrease in time spent with a child is due to the increase in the age of the index child. A postpartum mother can be expected to spend more time with her newborn infant than would a mother with a four-month-old baby. To explore this relationship, Table 4.11 and Figures 4.7, 4.8, and 4.9 show the total amount of time spent without a child, disaggregated by the age of the index child. The index child's age was broken into five categories, children 0 to 2.9 months, 3 to 5.9 months, 6 to 8.9 months, 9 to 11.9 months, and 12 to 14.9 months. There were no index children in the 12 to 14.9 month age category during March 2019 data collection, and there were no index children in the 0 to 2.9 month age category during the August 2019 data collection.

Table 4.11 shows that the amount of time that mothers spent with children decreased as the index child aged. However, in each age category, mothers spent less time with a child in August compared to March. For mothers with a child aged 6 to 8.9 months, the amount of time spent with the child increased between March and August, and the amount of time providing active childcare stayed the same. For every other age, the amount of time spent with the child and the amount of time spent providing active childcare decreased from March to August.

Table 4.11. Amount of time (minutes) mothers spent with child, by age of index child

\begin{tabular}{|c|c|c|c|c|}
\hline & \multicolumn{2}{|c|}{ March 2019} & \multicolumn{2}{|c|}{ August 2019} \\
\hline & $\begin{array}{c}\text { Time } \\
\text { with child }\end{array}$ & $\begin{array}{l}\text { Time providing } \\
\text { active care }\end{array}$ & $\begin{array}{c}\text { Time } \\
\text { with child }\end{array}$ & $\begin{array}{l}\text { Time providing } \\
\text { active care }\end{array}$ \\
\hline $0-2.9$ months & 744 & 315 & & \\
\hline 3 - 5.9 months & 708 & 259 & & \\
\hline $6-8.9$ months & 647 & 211 & 665 & 211 \\
\hline 9 - 11.9 months & 665 & 214 & 625 & 190 \\
\hline 12 - 14.9 months & 658 & 202 & 622 & 163 \\
\hline $15-17.9$ months & 640 & 196 & 614 & 170 \\
\hline 18 - 20.9 months & 625 & 166 & 614 & 167 \\
\hline $21-23.9$ months & 653 & 175 & 603 & 143 \\
\hline $24-26.9$ months & & & 607 & 167 \\
\hline More than 27 months & & & 599 & 158 \\
\hline
\end{tabular}

Source: Authors' compilation.

Figure 4.8 shows the amount of time mothers spent providing active care to their children disaggregated by region in March 2019. In all regions, mothers spent the most time on childcare when they had an index child less than 3 months old. With each increase in age category except 9 to 11.9 months, there was a steady decline in the number of minutes mothers in Amhara spent providing childcare. In the other regions, there was a decrease in the amount of time after the first 2.9 months of age. However, there was more variability. The time mothers in Oromia spent providing active childcare increased after 12 months of age. In Tigray, the time increased between 12 and 17.9 months before decreasing again. Mothers in SNNP decreased steadily during the first 12 months, but then leveled off. 
Figure 4.8. Mothers' time spent on active childcare, by age of index child and region, March 2019

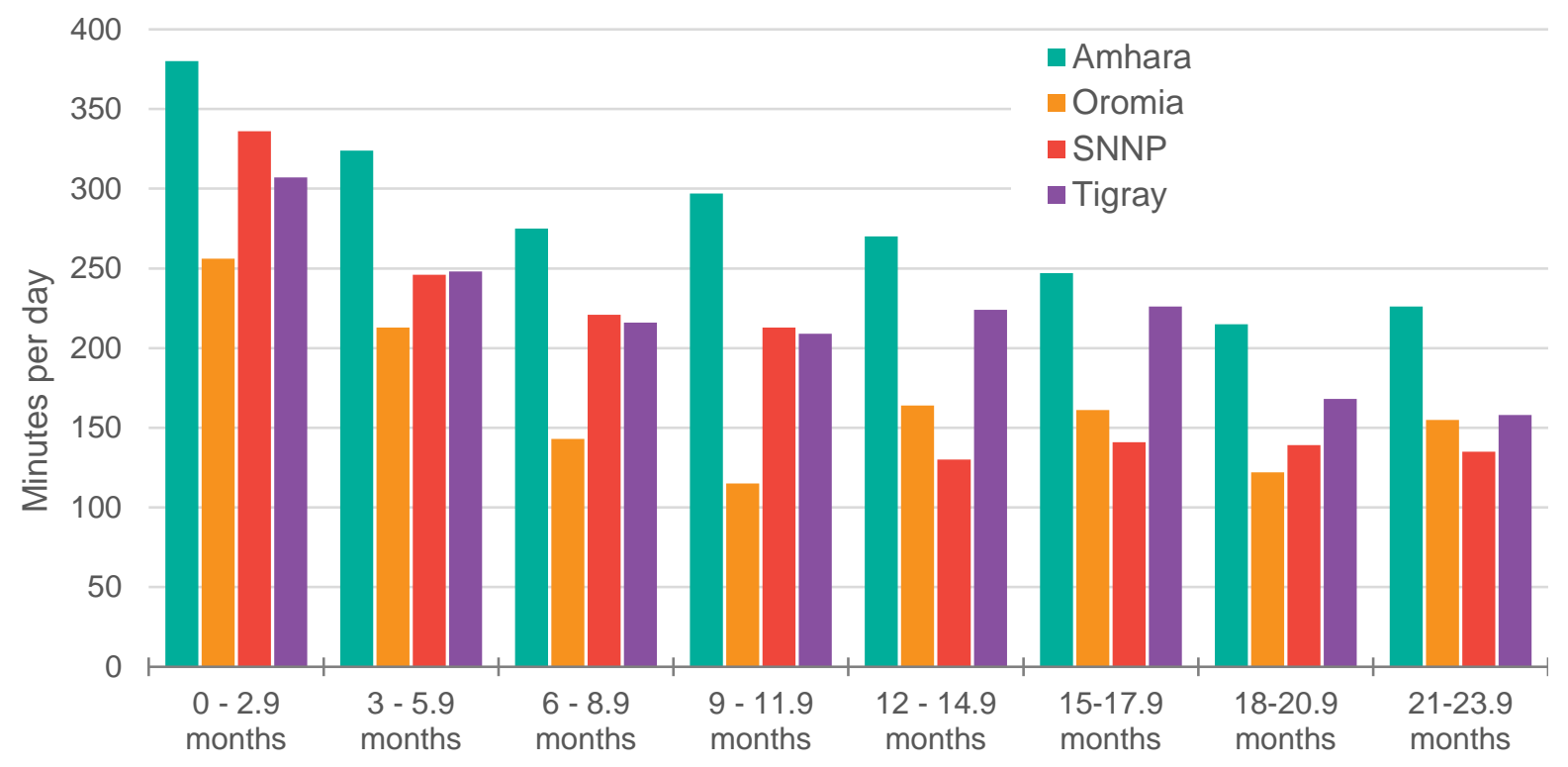

Source: Authors' compilation.

Figure 4.9 shows the amount of time mothers spent providing active care to their children disaggregated by region in August 2019. There is less of a distinct pattern in the amount of time spent on childcare after the index child is 6 months of age or older.

Figure 4.9. Mothers' time spent providing active childcare, by age of index child and region, August 2019

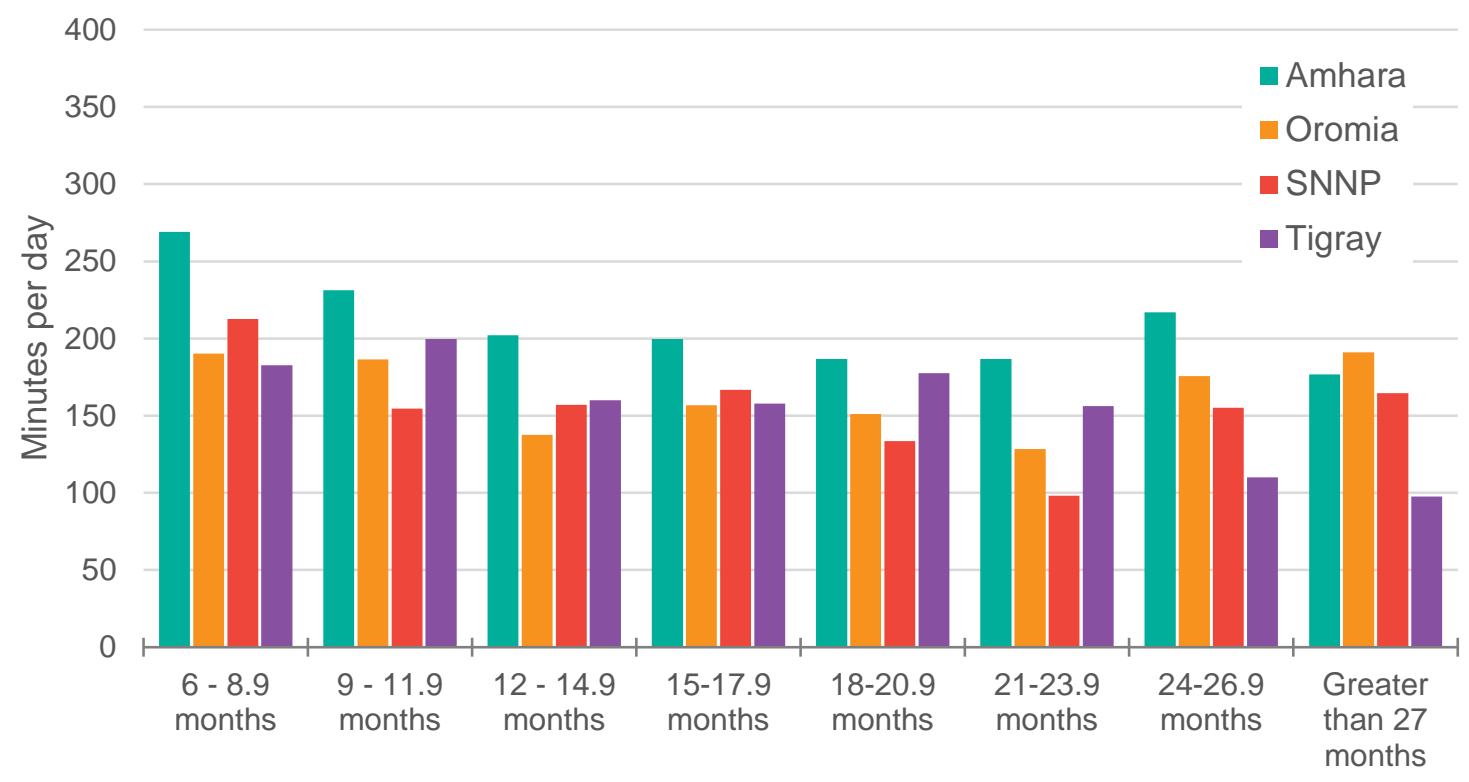

Source: Authors' compilation.

Figure 4.10 shows the amount of time spent on childcare disaggregated by PSNP beneficiary status, month of data collection, and age of the index child. For each age group, there were decreases in the amount of time that mothers spent in active childcare compared to younger age groups. Additionally, for PSNP mothers, for each age category there were decreases in the amount of time mothers spent on active childcare between March and August. However, some of these differences were very small. Mothers in PSNP beneficiary households spent more time in active childcare when their index children were less than 6 months old then did mothers in nonbeneficiary 
households. There were decreases in the amount of time spent with a child in all age categories compared to having an index child under the age of 3 months.

\section{Figure 4.10. Mothers' time spent on active childcare, by age of index child, PSNP status and survey round}

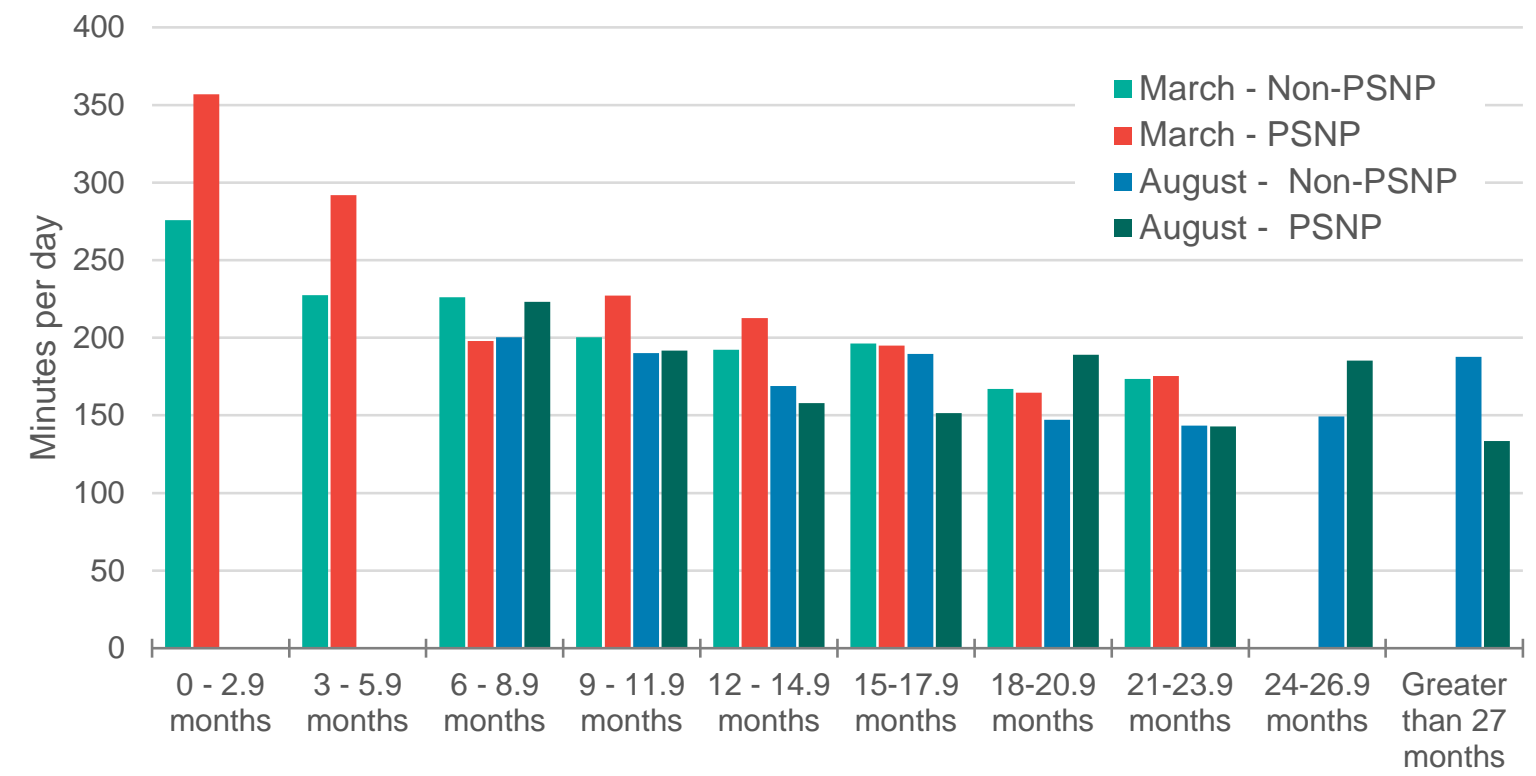

Source: Authors' compilation.

\subsection{Physical activity}

Physical activity was measured using the Global Physical Activity Questionnaire (GPAQ). GPAQ measures physical activity "in a typical week" as recalled by survey participants in a face-to-face interview. It collects information on the frequency (days per week) and duration (minutes per day) of physical activity across three domains: activity at work and home, travel to and from places, and recreational activities. For each activity, the questionnaire collects information on the intensity of activity - inactive, moderate, or vigorous (Cleland et al. 2014). WHO developed GPAQ as a global standard for monitoring physical activity (WHO 2005).

Data collected by the GPAQ is converted from the minutes in a week spent at different exertion levels to metabolic equivalents (MET). METs are a commonly used unit to express the intensity and duration of physical activity. A MET is the ratio of a person's working metabolic rate to their resting metabolic rate. One MET is defined as the energy cost of sitting quietly and is roughly equivalent to $1 \mathrm{kcal} / \mathrm{kg} / \mathrm{hr}$. As activities increase in intensity, METs increase. An activity of moderate intensity, such as a brisk walk or jog, is estimated to consume four times as many calories, or an increase in the workload four times that of sitting quietly, so is equivalent to 4 METs. Travel to and from places is considered to be moderate intensity. Vigorous activity is equivalent to 8 METs. To calculate the METs from an activity that required moderate exertion, the minutes spent at that activity would be divided by 60 to get the value in hours, multiplied by 4 . To calculate the METs for an activity that required vigorous exertion, the number of minutes spent on the vigorous activity would be divided by 60 then multiplied by 8 .

METs should not be directly translated into caloric expenditure. Caloric expenditure is affected by a variety of factors, including age, genetics, and physical fitness. However, METs can estimate a person's workload or overall activity level. METs can also be used to compare activities by the same person to determine which activity would consume the most calories. 
Table 4.12. Indicators of physical activity disaggregated by season and region

\begin{tabular}{|c|c|c|c|c|c|c|c|c|c|c|}
\hline & \multicolumn{5}{|c|}{ March 2019} & \multicolumn{5}{|c|}{ August 2019} \\
\hline & Amhara & Oromia & SNNP & Tigray & All & Amhara & Oromia & SNNP & Tigray & All \\
\hline Number of observations: & 332 & 319 & 317 & 326 & 1,294 & 328 & 307 & 303 & 317 & 1,255 \\
\hline \multicolumn{11}{|l|}{ Work domain } \\
\hline $\begin{array}{l}\text { Moderate intensity } \\
\text { work, minutes }\end{array}$ & 560 & 342 & 571 & 346 & 455 & 762 & 538 & 709 & 672 & 672 \\
\hline $\begin{array}{l}\text { Vigorous intensity } \\
\text { work, minutes }\end{array}$ & 151 & 119 & 165 & 97 & 133 & 378 & 200 & 274 & 118 & 243 \\
\hline Total minutes working & 711 & 461 & 737 & 443 & 588 & 1,139 & 737 & 982 & 791 & 915 \\
\hline $\begin{array}{l}\text { METs moderate } \\
\text { intensity work }\end{array}$ & 37 & 23 & 38 & 23 & 30 & 51 & 36 & 47 & 45 & 45 \\
\hline $\begin{array}{l}\text { METs vigorous } \\
\text { intensity work }\end{array}$ & 20 & 16 & 22 & 13 & 18 & 50 & 27 & 36 & 16 & 32 \\
\hline Total METs from work & 57 & 39 & 60 & 36 & 48 & 101 & 62 & 84 & 61 & 77 \\
\hline \multicolumn{11}{|l|}{ Travel domain } \\
\hline Traveling, minutes & 457 & 259 & 279 & 361 & 340 & 300 & 320 & 292 & 240 & 288 \\
\hline METs from traveling & 30 & 17 & 19 & 24 & 23 & 20 & 21 & 19 & 16 & 19 \\
\hline \multicolumn{11}{|l|}{ All activities } \\
\hline $\begin{array}{l}\text { Moderate intensity } \\
\text { activities, minutes }\end{array}$ & 1017 & 603 & 851 & 708 & 797 & 1,065 & 861 & 1,001 & 914 & 962 \\
\hline $\begin{array}{l}\text { Vigorous intensity } \\
\text { activities, minutes }\end{array}$ & 153 & 122 & 167 & 98 & 135 & 380 & 201 & 274 & 121 & 245 \\
\hline Total active minutes & 1,170 & 725 & 1,018 & 806 & 931 & 1,445 & 1,063 & 1,275 & 1,035 & 1207 \\
\hline $\begin{array}{l}\text { Total sedentary } \\
\text { minutes }\end{array}$ & 8,910 & 9,355 & 9,062 & 9,274 & 9,149 & 8,635 & 9,017 & 8,805 & 9,045 & 8873 \\
\hline $\begin{array}{l}\text { METs moderate } \\
\text { intensity activities }\end{array}$ & 68 & 40 & 57 & 47 & 53 & 71 & 57 & 67 & 61 & 64 \\
\hline $\begin{array}{l}\text { METs vigorous } \\
\text { intensity activities }\end{array}$ & 20 & 16 & 22 & 13 & 18 & 51 & 27 & 36 & 16 & 33 \\
\hline Total active METs & 88 & 56 & 79 & 60 & 71 & 122 & 84 & 103 & 77 & 97 \\
\hline $\begin{array}{l}\text { Total METs from } \\
\text { sedentary activities }\end{array}$ & 149 & 156 & 151 & 155 & 152 & 144 & 150 & 147 & 151 & 148 \\
\hline Total METs & 237 & 212 & 230 & 215 & 224 & 266 & 235 & 250 & 228 & 245 \\
\hline
\end{tabular}

Source: Authors' compilation.

Note: MET = Metabolic equivalent.

Table 4.12 disaggregates indicators of physical activity by season and region. These indicators include the minutes spent on an activity at a specific exertion level and the METs from that activity. The minutes spent in the work domain and the travel domain and the METs from time spent in those activity domains are reported. Minutes spent in and METs from recreational activities are not reported separately, but they are included in the total rows.

In all groups, the total number of minutes spent working at moderate or vigorous activity increased from March (588 min/week) to August 2019 (915 min/week). There were corresponding changes in the METs. Respondents living in Amhara and SNNP reported spending the most time at work during both seasons. The increase in total minutes was greatest in Amhara. There were increases between March and August 2019 in minutes spent in moderate work and in vigorous work in all regions. The increase in the total minutes, moderate minutes, and vigorous minutes spent working is to be expected since August 2019 is the rainy season when respondent households are engaged in agriculture.

Respondents in SNNP spent the most minutes per week working in March 2019 (737 minutes) and the most minutes working in moderate and in vigorous activity. This resulted in their having the highest METs from work at that time. Respondents in Amhara spent the most minutes per week working in August 2019 (1,139 minutes). They spent the most minutes working in both moderate and vigorous activity. They had the highest METs from work during August 2019. The same 
individual working in each region during March would have a greater workload and the highest caloric expenditure in SNNP compared to the other regions. This same individual would have a greater workload and the highest caloric expenditure working in Amhara in August 2019 compared to the other regions in both seasons.

There is very little change from minutes and METs from vigorous work and total minutes and METs at vigorous activity. This is because there were very few minutes and METs spent in vigorous recreational activity. Minutes and METs from moderate activity combine moderate work, transportation, and moderate recreational activity. There were very few respondents that participated in moderate recreational activity.

In March 2019, respondents in Amhara reported the greatest total METs compared to other regions, including SNNP, which had the greatest METs from work. This is due to the greater amount of time that respondents from Amhara spent in transport by walking or bicycling. In August 2019, respondents from Amhara again reported the greatest total METs. However, this is due to the increase in METs from work. The METs from traveling was similar to that in other regions. Overall the respondents in Amhara and SNNP reported the greatest total METs in both March and August 2019. This would indicate that in both seasons, respondents in those regions have a greater workload than respondents living in Oromia or Tigray.

Table 4.13 disaggregates indicators of physical activity by PSNP beneficiary status and season. Similar to the results disaggregated by region, there are increases in both the total minutes worked and the METs from work in both groups in August compared to March. In March 2019, respondents in the nonbeneficiary group reported greater minutes in work than beneficiaries. However, beneficiaries reported more time in vigorous work activities than nonbeneficiaries. This results in there being very little difference in their METs from work and their total METs. In March 2019, it appears that the workload in nonbeneficiaries and beneficiaries is the same.

Table 4.13. Indicators of physical activity disaggregated by season and PSNP status

\begin{tabular}{|c|c|c|c|c|}
\hline & \multicolumn{2}{|c|}{ March 2019} & \multicolumn{2}{|c|}{ August 2019} \\
\hline & non-PSNP & PSNP & non-PSNP & PSNP \\
\hline Number of observations: & 645 & 649 & 636 & 619 \\
\hline \multicolumn{5}{|l|}{ Work domain } \\
\hline Minutes spent at moderate intensity work & 484 & 426 & 629 & 715 \\
\hline Minutes spent at vigorous intensity work & 125 & 140 & 216 & 272 \\
\hline Total minutes working & 609 & 567 & 845 & 987 \\
\hline METs from moderate intensity work & 32 & 28 & 42 & 48 \\
\hline METs from vigorous intensity work & 17 & 19 & 29 & 36 \\
\hline Total METs from work & 49 & 47 & 71 & 84 \\
\hline \multicolumn{5}{|l|}{ Travel } \\
\hline Minutes spent traveling & 333 & 348 & 256 & 320 \\
\hline METs from traveling & 22 & 23 & 17 & 21 \\
\hline \multicolumn{5}{|l|}{ All activities } \\
\hline Total minutes spent on moderate intensity activities & 818 & 775 & 888 & 1037 \\
\hline Total minutes spent on vigorous intensity activities & 127 & 142 & 218 & 274 \\
\hline Total active minutes & 945 & 918 & 1106 & 1311 \\
\hline Total sedentary minutes & 9135 & 9162 & 8974 & 8769 \\
\hline Total METs from moderate intensity activities & 55 & 52 & 59 & 69 \\
\hline Total METs from vigorous activity & 17 & 19 & 29 & 36 \\
\hline Total active METs & 72 & 71 & 88 & 106 \\
\hline Total METs from sedentary activities & 152 & 153 & 150 & 146 \\
\hline Total METs (sedentary, moderate, and active) & 224 & 223 & 238 & 252 \\
\hline
\end{tabular}

Source: Authors' compilation.

Note: MET = Metabolic equivalent. 
In August 2019, PSNP beneficiaries reported more minutes in work, both moderate and vigorous, and more METs from work, both moderate and vigorous, than nonbeneficiaries. They also reported more minutes and METs from transportation. This resulted in greater total METs in August 2019 for PSNP beneficiaries compared to nonbeneficiaries. PSNP beneficiaries have a greater workload in August than nonbeneficiaries. The same individual would have a greater caloric expenditure as a PSNP beneficiary than as a nonbeneficiary.

Table 4.14 and 4.15 use the time use data to explore the activities that the respondents were involved in when they perceived they were engaged in vigorous energy exertion. The data is from the 24-hour recall of time use and perceived energy expenditure, which is not the same set of data as was used for the previous two tables. These values were calculated by taking the activities from the time use dataset in which participants said they had high or vigorous energy exertion. The total minutes spent in vigorous activity can be seen in the first line of the tables. The minutes spent in high or vigorous rates of activity differ between Table 4.12 and Table 4.14 and Table 4.13 and Table 4.15, respectively. This is likely a result of the different time scales. Tables 4.12 and 4.13 are weekly, whereas Tables 4.14 and 4.15 are based on recall over the past 24 hours. The following rows in the tables are the percent of time spent in high or vigorous levels of energy exertion in different activities. For the purposes of this table, childcare was limited to when it was listed as a primary or secondary activity. Additionally, the time use categories of food procurement, food production, or income generating activities are disaggregated into their different activities to better see which activities require a higher level of exertion.

Table 4.14. Activities during minutes spent at vigorous exertion level disaggregated by season and region

\begin{tabular}{|c|c|c|c|c|c|c|c|c|c|c|}
\hline & \multicolumn{5}{|c|}{ March 2019} & \multicolumn{5}{|c|}{ August 2019} \\
\hline & Amhara & Oromia & SNNP & Tigray & All & Amhara & Oromia & SNNP & Tigray & All \\
\hline $\begin{array}{l}\text { Minutes spent at } \\
\text { vigorous exertion }\end{array}$ & 31 & 34 & 47 & 32 & 36 & 65 & 21 & 63 & 36 & 46 \\
\hline \multicolumn{11}{|c|}{ Percent of minutes engaged in activity } \\
\hline Childcare & 0.6 & 0.0 & 0.0 & 0.8 & 0.3 & 0.0 & 0.0 & 0.3 & 0.0 & 0.1 \\
\hline Cooking/ eating & 31.2 & 25.1 & 24.5 & 36.5 & 29.0 & 22.1 & 32.7 & 23.5 & 37.8 & 27.1 \\
\hline Crop production & 0.9 & 0 & 3.6 & 0.1 & 1.3 & 14.7 & 1.0 & 11.1 & 6.6 & 9.7 \\
\hline Tending livestock & 1.0 & 0.4 & 1.1 & 1.3 & 0.9 & 1.7 & 1.2 & 4.6 & 0.7 & 2.4 \\
\hline Time at market & 1.1 & 0.6 & 1.3 & 0.1 & 0.8 & 0.8 & 0 & 2.2 & 0.0 & 1.0 \\
\hline Domestic work & 13.4 & 10.0 & 7.0 & 5.3 & 9.2 & 10.8 & 6.0 & 4.6 & 8.2 & 7.5 \\
\hline $\begin{array}{l}\text { Fetching water or } \\
\text { fuelwood }\end{array}$ & 14.2 & 9.6 & 13.7 & 3.9 & 10.8 & 6.0 & 7.8 & 12.0 & 1.7 & 7.5 \\
\hline Wage work & 0.0 & 0.0 & 0.0 & 0.0 & 0.0 & 0.0 & 0.0 & 0.0 & 3.2 & 0.5 \\
\hline $\begin{array}{l}\text { Own business } \\
\text { activities }\end{array}$ & 0.9 & 1.2 & 1.3 & 2.4 & 1.4 & 0.0 & 0.2 & 0 & 0.8 & 0.2 \\
\hline PSNP & 1.0 & 0.0 & 1.6 & 1.6 & 1.0 & 0.0 & 0.0 & 0.0 & 0.0 & 0.0 \\
\hline $\begin{array}{l}\text { Attending PSNP } \\
\text { nutrition session }\end{array}$ & 0.0 & 0.7 & 0 & 0.1 & 0.2 & 0.3 & 0.0 & 0.0 & 1.0 & 0.3 \\
\hline Walking or traveling & 3.0 & 4.6 & 2.3 & 2.6 & 3.1 & 0.9 & 4.3 & 3.7 & 0.1 & 2.3 \\
\hline Personal care & 19.7 & 25.0 & 15.4 & 31.5 & 22.2 & 31.0 & 29.1 & 15.1 & 33.0 & 25.9 \\
\hline Leisure or other & 12.8 & 22.8 & 28.4 & 13.8 & 19.6 & 11.6 & 17.6 & 22.9 & 6.9 & 15.6 \\
\hline
\end{tabular}

Source: Authors' compilation.

Table 4.14 disaggregates the time spent in vigorous energy exertion by region and season. All respondents in all regions spent more time in the previous day in vigorous activities in August 2019 than in March, except in Oromia. PSNP activities accounted for a very small percentage of the time spent in vigorous activities in March 2019. In both seasons, the greatest percentage of time spent in vigorous activities was spent preparing food and eating. This accounted for 27 percent (August) to 
29 percent (March) of the time spent in vigorous activity. There was also a large difference between regions. In March, the respondents in SNNP devoted the lowest percentage of time in vigorous activity to preparing food and eating, while respondents in Tigray devoted the most time in vigorous activity to that same activity. In August, Amhara devoted the least amount of time in vigorous activity to preparing food and eating. There is a corresponding increase in the percent of time spent in vigorous activity on crop production which increased from 1 percent in March to 15 percent in August.

Table 4.15 looks at the time spent in vigorous energy expenditure disaggregated by PSNP status and season. There is an increase in the minutes spent in vigorous activity between March and August with a larger increase in women who benefit from PSNP compared to nonbeneficiaries. In March 2019, PSNP related activities made up a small percentage of the time spent in vigorous activity (2 percent). Cooking and eating and personal care activities made up the largest percentage of time spent in vigorous activities. In August 2019, women who benefit from PSNP reported a greater percentage of their vigorous activity to be related to crop production than did nonbeneficiaries.

Table 4.15. Percent of vigorous time spent in different activities

\begin{tabular}{lcccc} 
& \multicolumn{2}{c}{ March 2019} & \multicolumn{2}{c}{ August 2019} \\
& Non-PSNP & PSP & Non-PSNP & PSNP \\
\hline Minutes spent at vigorous exertion & 332 & 319 & 317 & 326 \\
Percent of minutes engaged in activity & & & & \\
Childcare & 0.0 & 0.7 & 0.2 & 0.0 \\
Cooking/ eating & 27.0 & 31.0 & 25.4 & 28.8 \\
Crop production & 1.7 & 0.9 & 6.8 & 12.6 \\
Tending livestock & 1.0 & 0.9 & 1.6 & 3.1 \\
Time at market & 1.1 & 0.6 & 0.8 & 1.2 \\
Domestic work & 10.8 & 7.6 & 6.9 & 8.1 \\
Fetching water or fuelwood & 11.3 & 10.4 & 8.7 & 6.4 \\
Wage work & 0.0 & 0.0 & 0.1 & 1.0 \\
Own business activities & 1.0 & 1.8 & 0.1 & 0.2 \\
PSNP & 0.0 & 2.1 & 0.0 & 0.0 \\
Attending PSNP nutrition session & 0.4 & 0.0 & 0.2 & 0.4 \\
Walking or traveling & 3.3 & 2.9 & 2.4 & 2.2 \\
Personal care & 22.3 & 22.2 & 29.6 & 22.3 \\
Leisure or other & 20.2 & 19.0 & 17.3 & 13.9 \\
\hline
\end{tabular}

Source: Authors' compilation. 


\section{CHILDREN: ANTHROPOMETRY AND HEALTH}

Aligned with the National Nutrition Program of the Government of Ethiopia, one of the core objectives of PSNP-4 is to improve the nutritional status of children. To track progress, stunting prevalence among children under 5 years of age in localities in which PSNP operates is used as an indicator (GFDRE 2014).

This chapter reports on the information on child anthropometrics (weight and length) (Section 5.1) and child health (Section 5.2). As we do throughout this report, we restrict the sample to children 6 to 23 months of age. Consequently, our estimates of child anthropometry, e.g., stunting and wasting, are not directly comparable to those reported in the main PSNP evaluation or the statistics reported in DHS reports. Indeed, it is now well-known that the risk of acute and chronic undernutrition vary substantially across child age (Victora et al. 2010). This is also true for Ethiopia (Golan et al. 2019). Therefore, we advise against comparing stunting and wasting prevalence across samples based on different child age ranges.

Another important and innovative feature of these data is that children were measured during different seasons. Despite the strong emphasis on seasonality in PSNP and other social policy programming, there is surprisingly little prior information about how children's anthropometric outcomes vary between postharvest and lean seasons in rural Ethiopia. In Section 5.1.1, we review prior evidence on seasonality of child anthropometric outcomes in Ethiopia.

\subsection{Child anthropometric measures}

Anthropometric measure - length, weight, and mid-upper arm circumference (MUAC) - were obtained for all index children. Enumerators were carefully trained by a qualified nurse to take these measurements. The electronic questionnaire used during the fieldwork further alerted the enumerators for outlier values and required them to re-measure the child if the height or weight value was biologically implausible. Moreover, given the focus on children 6 to 23 months of age, all heights were measured lying down, i.e., lengths. Where possible, weights were obtained with children wearing light clothing.

Lengths, weights, and MUAC were measured twice. In the analysis stage, biologically implausible measurements were first removed from the data and the average of the remaining measurements were used. Average lengths and weights were then converted to z-scores using the WHO growth standards (WHO 2006; de Onis et al. 2007). These standards allow us to assess child length and weight relative to well-nourished children of the same age and sex. A z-score expresses these measures in terms of standard deviations. For example, the length-for-age z-score is calculated by taking the child's length and subtracting the median length of a reference population of children of the same sex and age and dividing this by the standard deviation for that reference population. Children with positive z-scores have lengths above this reference population. Children with negative $z$-scores have lengths below this reference population. ${ }^{8}$

- Children are acutely undernourished (wasted) if they have a weight-for-length z-score below -2.0, i.e., their weight, given their length, is two standard deviations below the median weight for a child of the same age and sex. Acute undernourishment is more sensitive to recent episodes of illness or inadequate food intake.

- Children are considered to be stunted and chronically undernourished if they have a lengthfor-age z-score below -2.0. Chronic undernutrition reflects the malign synergistic effects of continued inadequate food intake together with repeated infection. Over a protracted period of time, the child's body fails to receive sufficient nutrients - calories, protein, fat, and

${ }^{8}$ All anthropometric measures reported were calculated using the zanthro06 command (Leroy 2011) in Stata 15.0. 
micronutrients - to grow or the need to fight repeated infections diverts energy that otherwise would be used for child growth.

- Weight-for-age is an amalgam of these measures. A child is considered underweight if his or her weight-for-age z-score is below -2.0.

MUAC is used to identify acute undernutrition in children 6 to 59 months of age. We use cut-off values defined by WHO and UNICEF (2009), and that have also been recently validated for Ethiopia by UNICEF and the Federal Ministry of Health. ${ }^{9}$ A MUAC measure less than $11.5 \mathrm{~cm}$ is taken as an indicator of severe acute malnutrition, while MUAC measurements between $11.5 \mathrm{~cm}$ and $12.5 \mathrm{~cm}$ indicate moderate acute malnutrition. Measurements above $12.5 \mathrm{~cm}$ are considered normal.

There are several features of these measurement data that are worth bearing in mind. First, instructions on how to weigh children were widely followed with more than 90 percent of children weighed wearing light or no clothing. Length of all children were measured lying down. Second, only few births are registered-in each round less than 15 percent of the children had a birth certificate and less than 20 percent had the child's birth date recorded on a clinic card. ${ }^{10}$ Therefore, in most cases, caregivers were aided by the enumerator to give their best recollection of when the child was born. Third, to account for measurement error in anthropometric results we dropped children with biologically impossible z-scores - those below -6.0 and above 6.0 for length for age z-score and those below -5.0 and above 5.0 for weight-for-length and weight-for age z-scores. Table 5.1 shows the share of children 6 to 23 months of age with biologically implausible values in each round.

\section{Table 5.1. Child measurement records with biologically implausible values, by anthropometric indicator and survey round, percent}

\begin{tabular}{lccc} 
Survey round & LAZ & WLZ & WAZ \\
March 2017 & 1.4 & 3.0 & 1.0 \\
August 2017 & 0.9 & 1.2 & 1.2 \\
March 2019 & 0.7 & 1.2 & 0.9 \\
August 2019 & 1.0 & 1.2 & 0.9 \\
\hline All rounds & 1.0 & 1.7 & 1.0 \\
\hline
\end{tabular}

Source: Authors' compilation.

Note: $L A Z=L$ ength-for-age $Z$ score, WLZ=Weight-for-length $Z$ score, WAZ=Weight-for-age $Z$ score. Biologically implausible values were defined as LAZ: below -6.0 and above 6.0; WLZ: below -5.0 and above 5.0; and WAZ: below -5.0 and above 5.0.

Finally, in each March round, the sample was formed of children under 24 months of age. These same children were re-contacted in August when they were approximately 6 to 29 months of age. Figure 5.1 shows the age distribution in both March survey rounds. Compared to 2019, in the 2017 sample, there were fewer very young children (0 to 6 months) in the sample and more relatively older children (12 to 23 months).

\footnotetext{
${ }^{9}$ See https://www.unicef.org/ethiopia/media/631/file/Humanitarian\%20Situation\%20Report\%20.pdf (accessed 7 December 2019)

${ }^{10}$ In March 2017, $14 \%$ of the children had a birth certificate and $7.6 \%$ had their date of birth recorded on a clinic card. The corresponding percentages in 2019 were $6.4 \%$ with birth certificate and $18.8 \%$ with a date of birth on a clinic card.
} 
Figure 5.1. Child age distributions for the full sample, March 2017 and March 2019
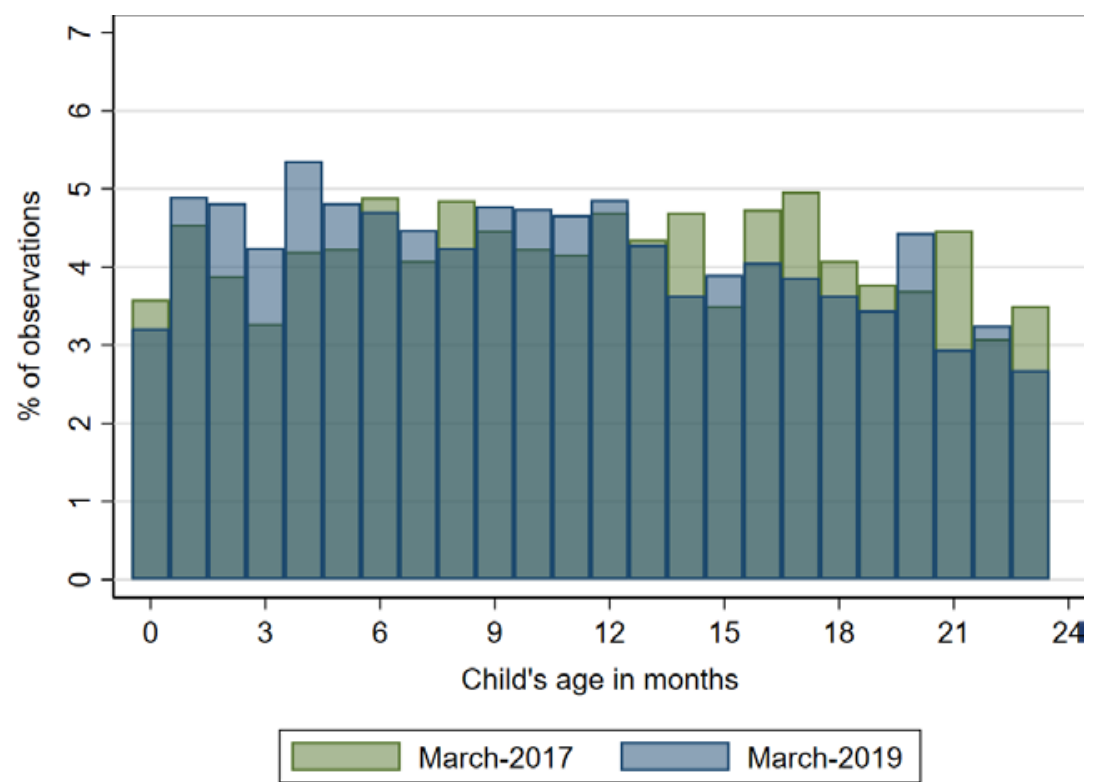

Source: Authors' compilation.

Here we report the anthropometric outcomes for children 6 to 23 months of age and, thus, ignore children who were less than 6 months of age in the March rounds and those who were older than 23 months of age in the August rounds. Figure 5.2 shows the children's age distribution in each survey round when the sample is restricted to children 6 to 23 months of age. The size of the box shows the difference between the 25th percentile, which is the bottom of the box, and the 75th percentile, which is the top of the box. The bottom and top rule show the $5^{\text {th }}$ and $95^{\text {th }}$ percentiles.

\section{Figure 5.2. Child age distributions by survey round}

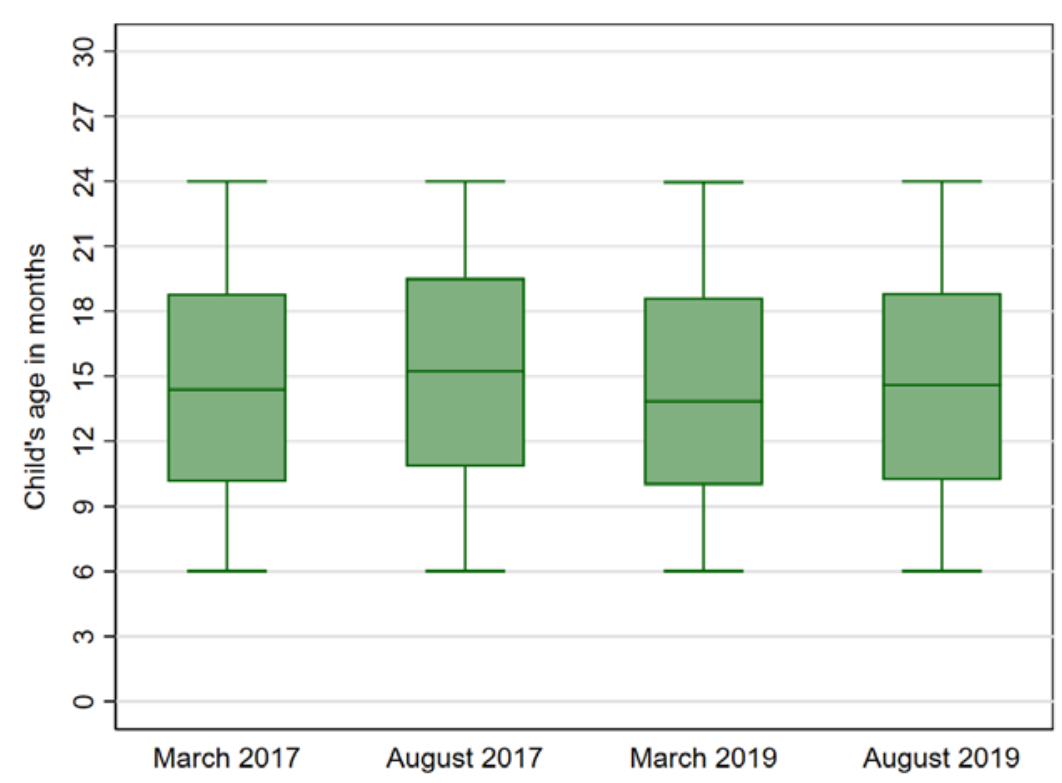

Source: Authors' compilation.

Note: In each round, the sample is restricted to children 6 to 23 months of age.

In line with Figure 5.1, the median age in the sample is systematically higher in the 2017 survey rounds compared to the corresponding 2019 rounds. Moreover, despite restricting the sample to the same age group in each round, the median age, which is denoted by the horizontal rules inside the boxes, is somewhat higher in the August rounds. This may have some implications on the comparability of the anthropometric outcomes between March and August rounds. In particular, length-for-age z-score have distinct age patterns with older children typically recording lower 
z-scores and are, thus, more likely to be stunted (Victora et al. 2010). Using nationally representative DHS data, Golan et al., (2019) document rapid growth faltering among Ethiopian children during the 6 to 23 month age range.

\subsubsection{Prior evidence on seasonality of child anthropometric outcomes in Ethiopia}

The evidence on seasonal changes in child chronic and acute undernutrition in Ethiopia is surprisingly scarce. In this section, we review the previous literature on this topic. We begin by noting that most of the studies summarized here are based on small samples or geographically narrow areas.

A recent longitudinal study in Oromia found that the prevalence of acute under five child wasting prevalence increased in the post-harvest season: wasting prevalence among children 6 to 36 months of age was 7.4 percent in July and August and 11.2 percent in January and February (Egata, Berhane, and Worku 2013). As a part of an impact evaluation of a UNICEF cash transfer pilot program in Tigray, Berhane et al. (2015) took anthropometric measurements seven times over a 24-month period in two woredas in Tigray. Some of the changes in stunting prevalence across the survey rounds are large, ranging from 0.4 percentage points to more than 8 percentage points. As expected, fluctuations in wasting prevalence was even larger across seasons. In the rural localities, wasting prevalence was generally higher at the beginning of the year between January and June, while the opposite was true in the urban localities. Another study from two woredas in Tigray and one from Oromia showed how child stunting prevalence increased from 40 percent to 46 percent between January and February to July and August (Roba et al. 2016). The authors also report that wasting prevalence decreased from 12 percent in January and February to 8.5 percent in July and August. In an earlier study by Lindtjørn and Alemu (2002) in Oromia region, more than 5,500 anthropometric measurements were taken from 678 children over a six year period. The authors document large and erratic seasonal variations in stunting, especially among children less than two years of age. Finally, Chotard et al. (2010) pooled a large number of UNICEF surveys from the Horn of Africa to study seasonal changes in wasting prevalence in the region. Similar to the evidence reviewed above, the authors conclude that wasting peaks in the first half of the calendar year during the dry season. In an average year, the seasonal increase in wasting is approximately five percentage points.

To summarize, the previous literature has documented large seasonal fluctuations in child stunting prevalence with no apparent clear seasonal pattern. ${ }^{11}$ Wasting prevalence, on the other hand, is generally found to be lower in the lean (wet) season as compared to post-harvest (dry) season.

\subsubsection{Chronic undernutrition}

We report first on chronic undernutrition. A child is considered stunted if his or her length-for-age Z-score (LAZ) is less than -2.0 standard deviations. Figure 5.3 shows the LAZ distribution in each survey round. The median LAZ varies marginally across rounds and is slightly lower in August than in March rounds, possibly because of the differences in the age distribution (see Figure 5.2). We see that the median LAZ is just above the threshold for stunting (-2.0 standard deviations).

\footnotetext{
${ }^{11}$ As we discuss below, we believe that this can be explained by the large share of children just below and above the stunting threshold in a given sample from Ethiopia.
} 
Figure 5.3. Length for age distributions by survey round

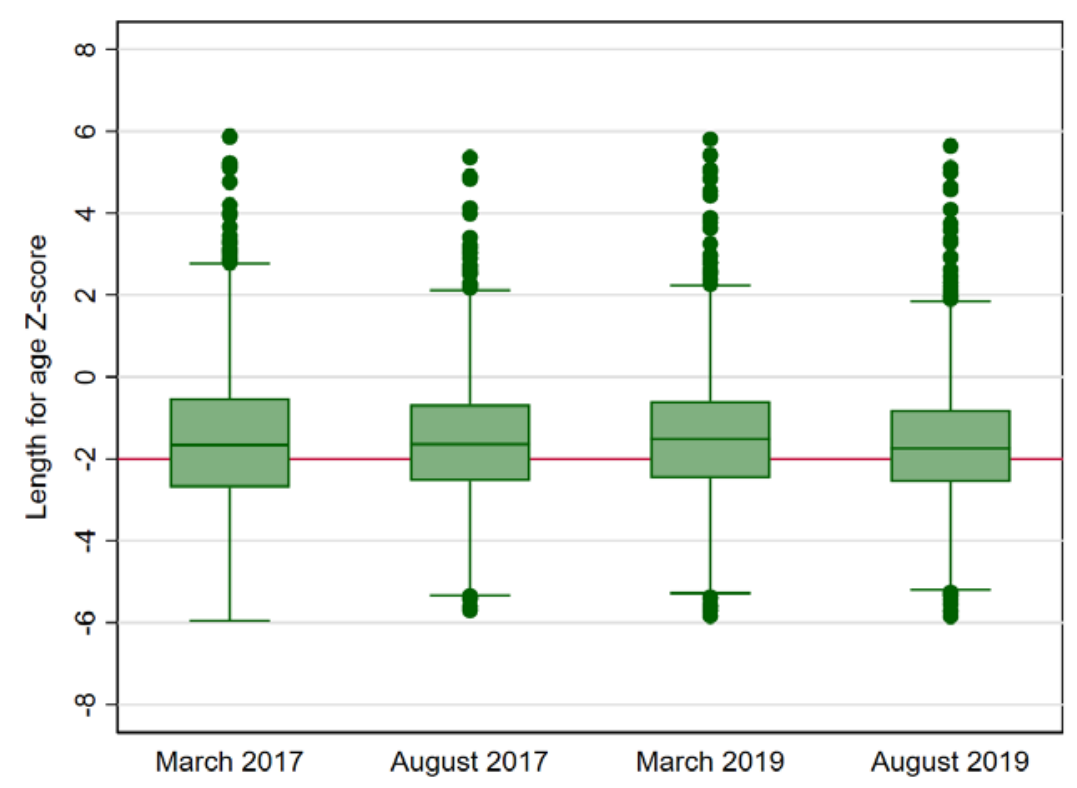

Source: Authors' compilation.

Note: In each round, the sample is restricted to children 6 to 23 months of age. Biologically implausible LAZ values are dropped. The horizontal solid line indicates the threshold for stunting ( $L A Z=-2)$. LAZ = length-for-age $z$-score.

Figure 5.4 shows the full LAZ distribution in each survey round. A striking feature of these distributions is the large number of observations just around the stunting threshold, which is the red solid vertical line in the graphs. The LAZ distributions are very similar in the 2017 rounds but in 2019, we see that the distribution shifts left in the August round.

With these distributional qualities of our data in mind, Figure 5.5 reports the stunting prevalence by survey round. While the graph presents the stunting rates in both PSNP and non-PSNP households, we focus our discussion on the stunting rates in PSNP households (blue bars). There are a number ways to look at these statistics.

First, we can compare the seasonal fluctuations within a single year. In March 2017, 45 percent of the children aged 6 to 23 months were stunted, while in August 2017 the stunting prevalence fell by 4 percentage points to 41 percent. However, this difference is not statistically different from zero $(p=0.125)$. The opposite trend emerges in 2019; stunting prevalence increases from 39 percent in March to 44.5 percent in August. This time, the difference between the two survey rounds is statistically different from zero $(p=0.014)$.

Second, we can look at differences across years in the same season. Starting with March, the stunting rate was nearly 6 percentage lower in 2019 compared to 2017 and this difference is statistically different from zero $(\mathrm{p}=0.037)$.

Some of these changes in stunting rates are large. As highlighted, in each round there are large numbers of children just below and above the stunting threshold (LAZ=-2.0 SD). Therefore, even small differences in heights can result in large fluctuations in stunting prevalence. We demonstrate this with a simulation where we alter the stunting threshold by a small amount. In the first simulation scenario, we move the stunting threshold up and down by 0.05 standard deviations to -1.95 or -2.05 . In the second scenario, we use -1.90 and -2.10 as stunting thresholds. In terms of height, these are small adjustments - for a 1-year child, one standard deviation (SD) in the WHO growth standard is approximately $2.5 \mathrm{~cm}$, so $0.1 \mathrm{SD}$ translates into $0.25 \mathrm{~cm}$ and $0.05 \mathrm{SD}$ to $0.125 \mathrm{~cm}$. 
Figure 5.4. Full length for age distributions by survey round in 2017 and 2019

March 2017

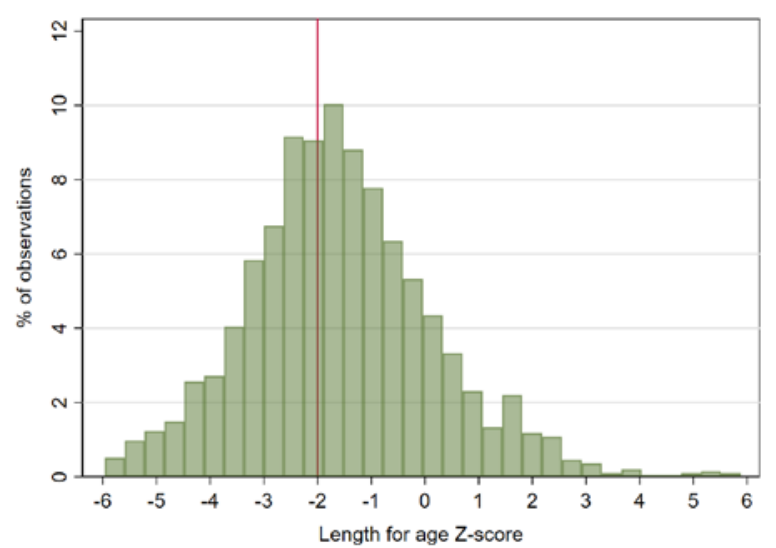

March 2019

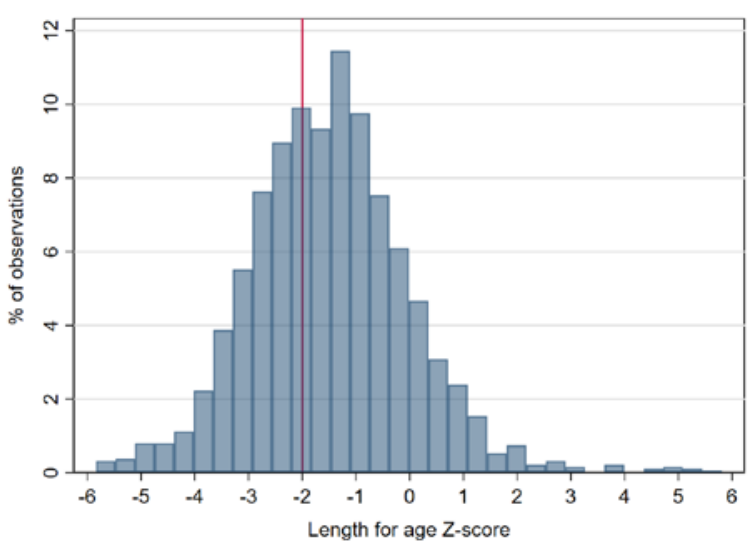

August 2017

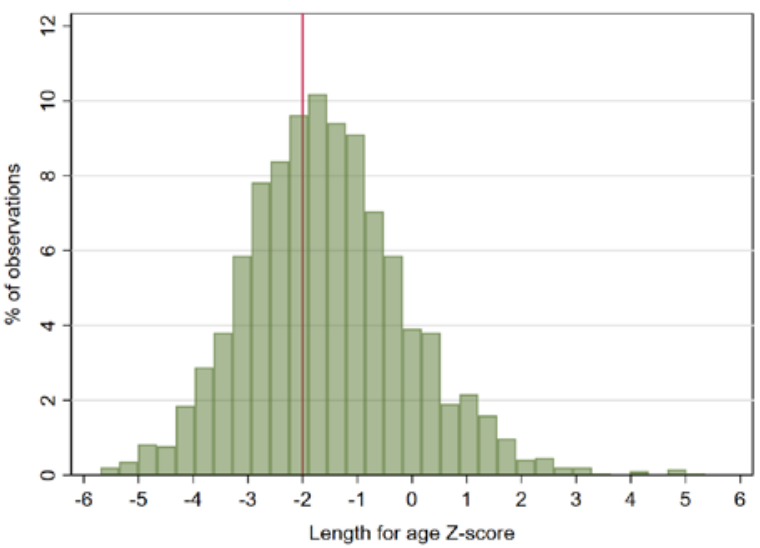

August 2019

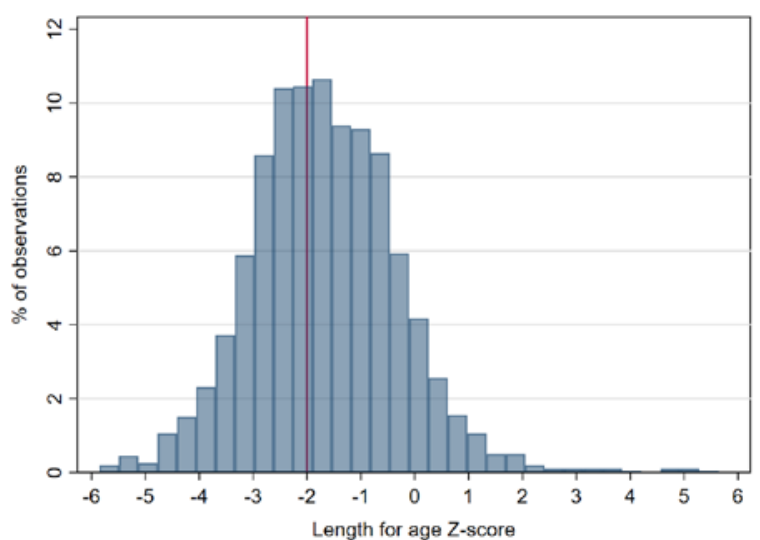

Source: Authors' compilation.

Note: In each round, the sample is restricted to children 6 to 23 months of age. Biologically implausible LAZ values are dropped. The vertical solid line indicates the threshold for stunting (LAZ=-2). LAZ = length-for-age $Z$-score.

Figure 5.5. Stunting prevalence in PSNP and non-PSNP households by survey round

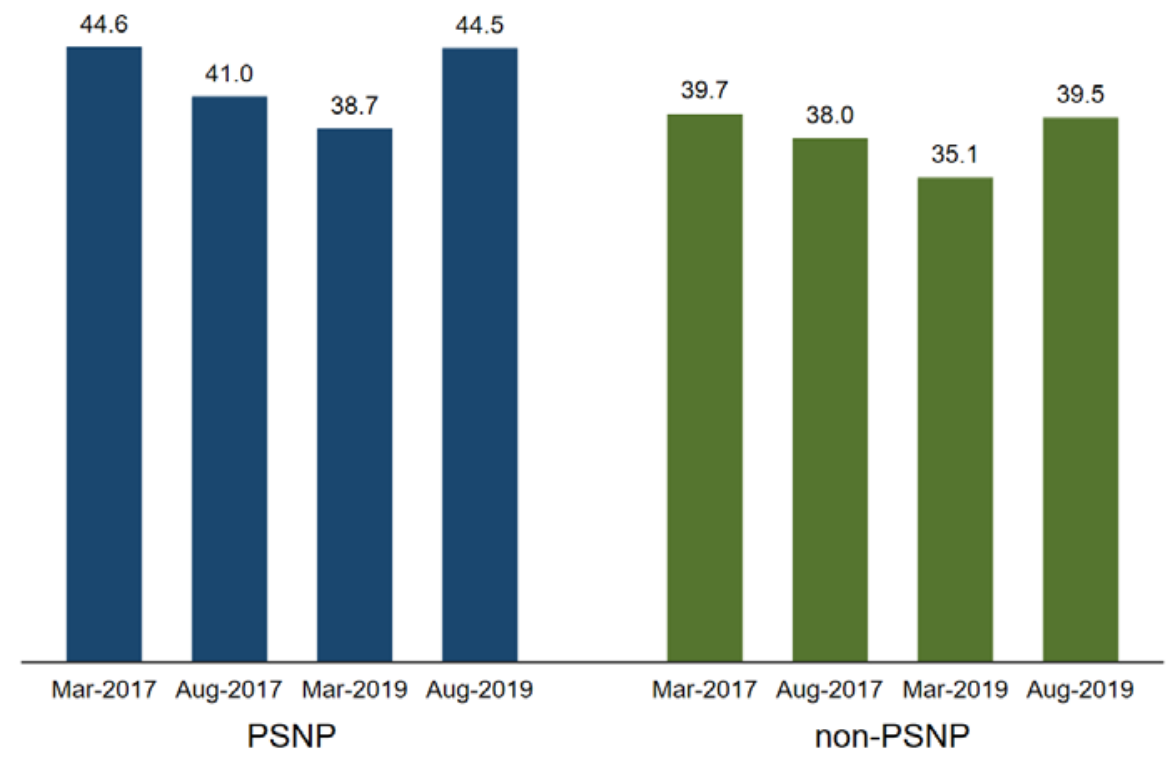

Source: Authors' compilation.

Note: Sample restricted to children 6 to 23 months of age.

Figure 5.6 shows the results of this simulation exercise. Moving the stunting threshold up by 0.05 SD $(-2.00$ to -1.95$)$ reduces stunting prevalence by 1.0 to 1.5 percentage points. Increasing it by 
0.10 SD (-2.00 to -1.90$)$, reduces stunting prevalence by about 3 percentage points. The changes in stunting prevalence are similar in absolute terms when we move the stunting threshold up by the same amounts.

Figure 5.6. Simulation exercise: alternative stunting thresholds

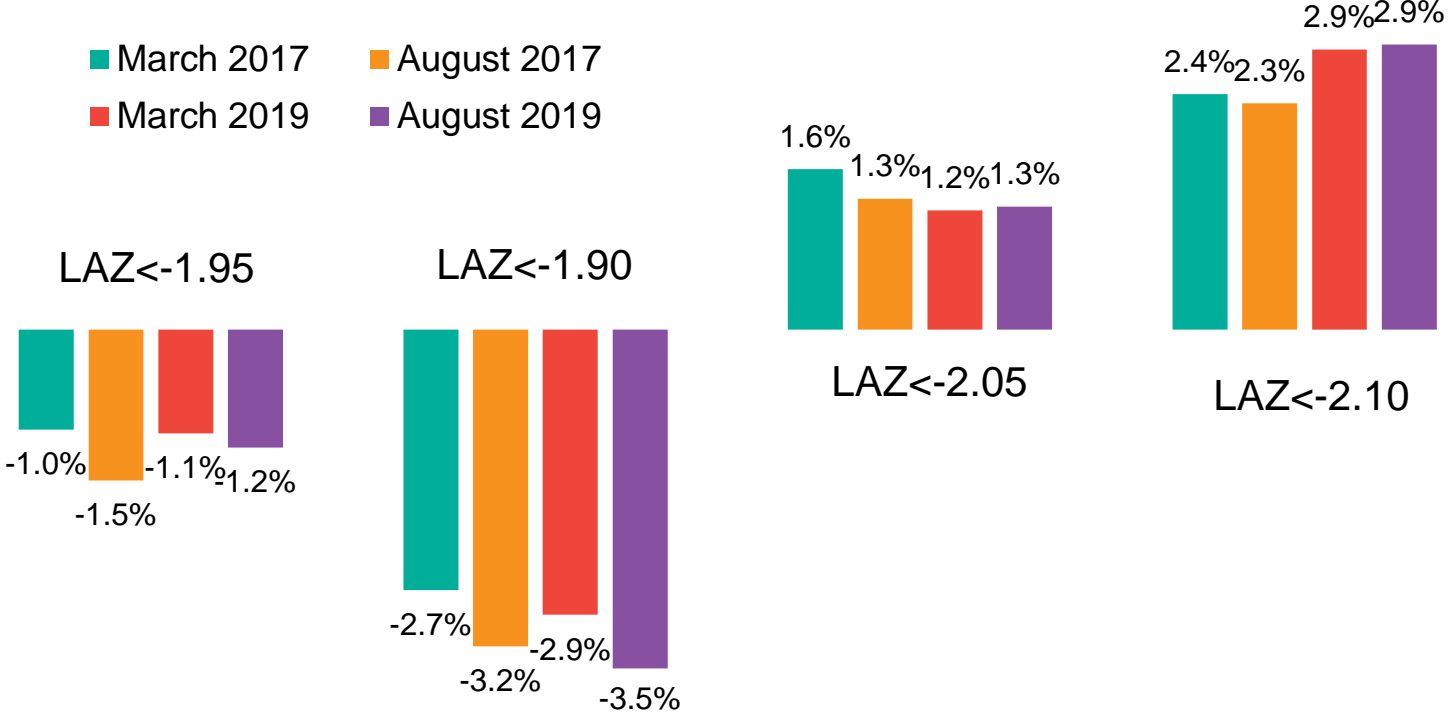

Source: Authors' compilation.

Note: numbers are percentage points indicating the change in stunting prevalence in each scenario. LAZ = length-for-age $Z$-score.

This exercise illustrates how sensitive our stunting estimates are to even small changes in the LAZ distribution. This may explain the large and often erratic intra-annual fluctuations in stunting rates documented in previous work (Section 5.1.1).

The increase in stunting prevalence in August 2019 is explained by very young children who were less than 6 months old in March 2019 and, thus, were not included in the stunting prevalence calculations in that round. This cohort of children, born between late 2018 and early 2019, were ages 6 to 11 months in August 2019. Our analysis reveals that they experienced unusually fast growth faltering. This is demonstrated in Figure 5.7, which shows the mean length-for-age z-score by child's age in each survey round, contrasting the LAZ-age curves across years and seasons. We see that when compared to the March 2019 round (Figure 5.7b) and August 2017 round (Figure 5.7d), the mean LAZ-age trajectory in August 2019 was significantly lower for children 6 to 11 months of age. After this, the trajectories run in parallel across all rounds. This faster growth faltering may be explained by the elevated infection risk for children 6 to 23 months of age in March 2019 (see Section 5.2). 
Figure 5.7. Relationship between length-for-age z-score and child's age in months

a) March vs August 2017

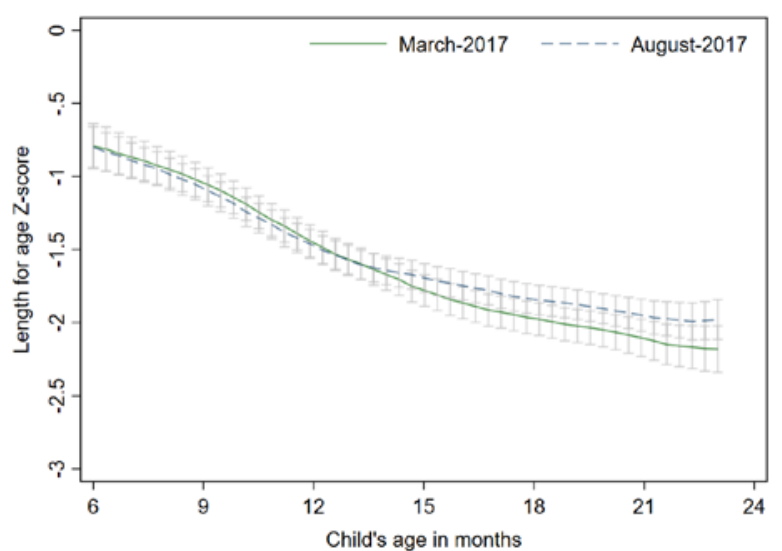

c) March 2017 vs March 2019

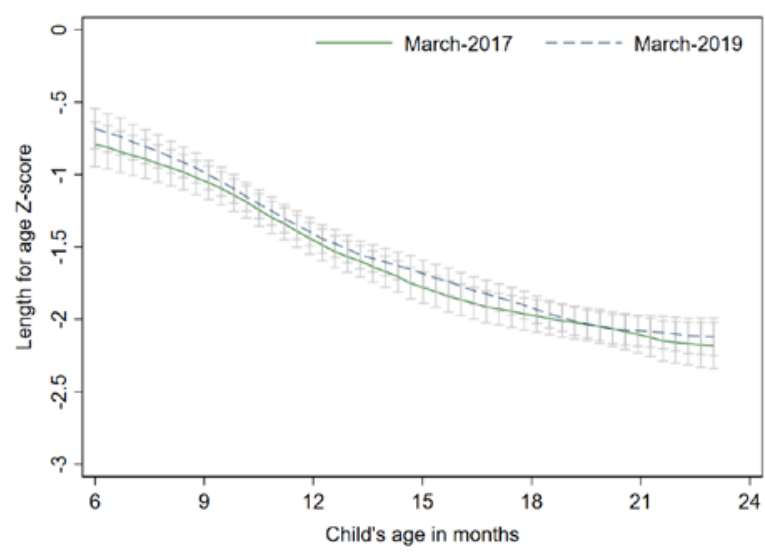

b) March vs August 2019

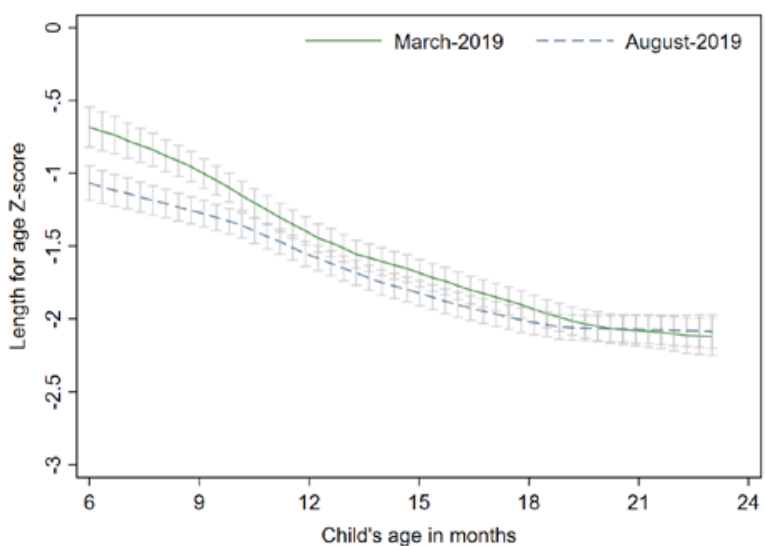

d) August 2017 vs August 2019

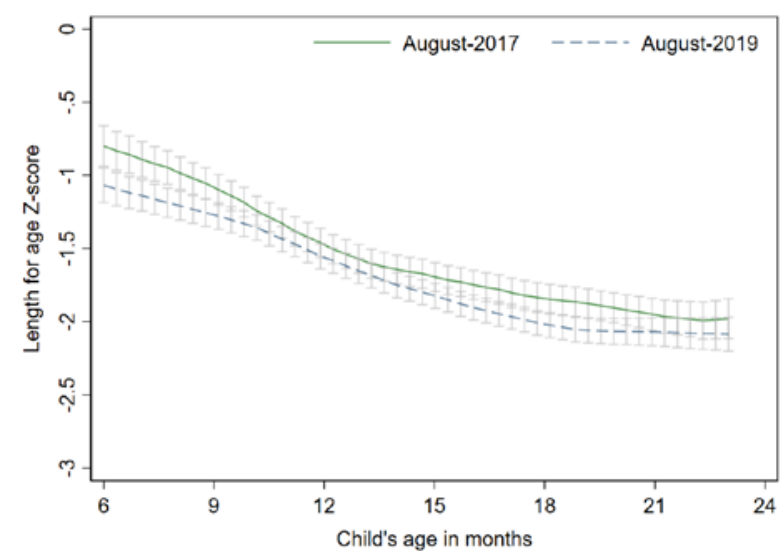

Source: Authors' compilation.

Note: Local polynomial regression. The vertical grey bars represent $95-\%$ confidence intervals.

Table 5.2 shows the mean $L A Z$ as well as the stunting ( $L A Z<-2)$ and severe stunting (LAZ $<-3)$ prevalence for all index children between 6 and 23 months of age by beneficiary status. In all survey rounds, we see that the children in PSNP households are relatively worse off across all chronic undernutrition outcomes. Except for the August 2017 round, the differences in stunting prevalence between PSNP and non-PSNP households are statistically different from zero at the $10 \%$ significance level. ${ }^{12}$

\footnotetext{
12 The p-values are as follows: March 2017: 0.040; August 2017: 0.186; March 2019: 0.087; August 2019: 0.020.
} 
Table 5.2. Mean length-for-age z-score and stunting prevalence of index children 6 to 23 months of age, by survey round and beneficiary status

\begin{tabular}{|c|c|c|c|c|}
\hline \multicolumn{5}{|c|}{ March 2017} \\
\hline Beneficiary status & $\mathbf{N}$ & LAZ & Stunted (\%) & Severely stunted (\%) \\
\hline Non-PSNP & 1,175 & -1.52 & 39.7 & 19.0 \\
\hline PSNP & 778 & -1.64 & 44.6 & 19.9 \\
\hline All & 1,953 & -1.57 & 41.7 & 19.4 \\
\hline \multicolumn{5}{|c|}{ August 2017} \\
\hline Beneficiary status & $\mathbf{N}$ & LAZ & Stunted (\%) & Severely stunted (\%) \\
\hline Non-PSNP & 1,188 & -1.48 & 38.0 & 13.8 \\
\hline PSNP & 756 & -1.66 & 41.0 & 17.5 \\
\hline All & 1,944 & -1.55 & 39.1 & 15.2 \\
\hline \multicolumn{5}{|c|}{ March 2019} \\
\hline Beneficiary status & $\mathbf{N}$ & LAZ & Stunted (\%) & Severely stunted (\%) \\
\hline Non-PSNP & 1,099 & -1.46 & 35.1 & 13.4 \\
\hline PSNP & 786 & -1.53 & 38.7 & 15.3 \\
\hline All & 1,885 & -1.49 & 36.6 & 14.2 \\
\hline \multicolumn{5}{|c|}{ August 2019} \\
\hline Beneficiary status & $\mathbf{N}$ & LAZ & Stunted (\%) & Severely stunted (\%) \\
\hline Non-PSNP & 1,186 & -1.60 & 39.5 & 14.0 \\
\hline PSNP & 804 & -1.77 & 44.5 & 16.0 \\
\hline All & 1,990 & -1.67 & 41.5 & 14.8 \\
\hline
\end{tabular}

Source: Authors' compilation.

Note: $L A Z$ = length-for-age $z$-score.

Table 5.3 reports the same outcomes by child sex. Compared to girls, boys have lower length for age z-score and are more likely to be stunted - a finding consistent with previous work in sub-Saharan Africa (Wamani et al. 2007).

Table 5.3. Mean length-for-age z-score and stunting prevalence of index children 6 to 23 months of age, by survey round and sex of the child

\begin{tabular}{|c|c|c|c|c|}
\hline \multicolumn{5}{|c|}{ March 2017} \\
\hline Sex & $\mathbf{N}$ & LAZ & Stunted (\%) & Severely stunted (\%) \\
\hline Girls & 980 & -1.36 & 37.1 & 15.0 \\
\hline Boys & 973 & -1.79 & 46.2 & 23.7 \\
\hline All & 1,953 & -1.57 & 41.7 & 19.4 \\
\hline \multicolumn{5}{|c|}{ August 2017} \\
\hline Sex & $\mathbf{N}$ & LAZ & Stunted (\%) & Severely stunted (\%) \\
\hline Girls & 970 & -1.39 & 33.9 & 11.0 \\
\hline Boys & 974 & -1.72 & 44.4 & 19.4 \\
\hline All & 1,944 & -1.55 & 39.1 & 15.2 \\
\hline \multicolumn{5}{|c|}{ March 2019} \\
\hline Sex & $\mathbf{N}$ & LAZ & Stunted (\%) & Severely stunted (\%) \\
\hline Girls & 910 & -1.39 & 33.6 & 11.4 \\
\hline Boys & 975 & -1.58 & 39.4 & 16.7 \\
\hline All & 1,885 & -1.49 & 36.6 & 14.2 \\
\hline \multicolumn{5}{|c|}{ August 2019} \\
\hline Sex & $\mathbf{N}$ & LAZ & Stunted (\%) & Severely stunted (\%) \\
\hline Girls & 960 & -1.54 & 37.4 & 11.7 \\
\hline Boys & 1,030 & -1.79 & 45.3 & 17.8 \\
\hline All & 1,990 & -1.67 & 41.5 & 14.8 \\
\hline
\end{tabular}

Source: Authors' compilation.

Note LAZ = length-for-age z-score. 
Table 5.4 breaks down these data by child's age. Consistent with previous research on child anthropometry in Ethiopia (Golan et al. 2019) and elsewhere (Victora et al. 2010), we see that stunting risk is considerably higher for older children. ${ }^{13}$ Appendix $C$ provides the regional breakdown of the chronic anthropometric measures. We caution against drawing strong conclusions about changes in stunting prevalence within regions due to the smaller number of observations in each and issues related to the high density of observations around the stunting threshold.

Table 5.4. Mean length-for-age z-score and stunting prevalence of index children 6 to 23 months of age, by survey round and child age

\begin{tabular}{|c|c|c|c|c|}
\hline \multicolumn{5}{|c|}{ March 2017} \\
\hline Age in months & $\mathbf{N}$ & LAZ & Stunted (\%) & Severely stunted (\%) \\
\hline $6-11$ & 682 & -0.94 & 25.4 & 10.3 \\
\hline $12-17$ & 693 & -1.72 & 44.7 & 20.6 \\
\hline $18-23$ & 578 & -2.14 & 57.3 & 28.5 \\
\hline All & 1,953 & -1.57 & 41.7 & 19.4 \\
\hline \multicolumn{5}{|c|}{ August 2017} \\
\hline Age in months & $\mathbf{N}$ & LAZ & Stunted (\%) & Severely stunted (\%) \\
\hline $6-11$ & 607 & -0.98 & 21.7 & 6.8 \\
\hline $12-17$ & 667 & -1.69 & 42.3 & 15.9 \\
\hline $18-23$ & 670 & -1.93 & 51.8 & 22.2 \\
\hline All & 1,944 & -1.55 & 39.1 & 15.2 \\
\hline \multicolumn{5}{|c|}{ March 2019} \\
\hline Age in months & $\mathbf{N}$ & LAZ & Stunted (\%) & Severely stunted (\%) \\
\hline $6-11$ & 718 & -0.91 & 22.0 & 8.2 \\
\hline $12-17$ & 638 & -1.66 & 40.3 & 15.0 \\
\hline $18-23$ & 529 & -2.06 & 52.0 & 21.2 \\
\hline All & 1,885 & -1.49 & 36.6 & 14.2 \\
\hline \multicolumn{5}{|c|}{ August 2019} \\
\hline Age in months & $\mathbf{N}$ & LAZ & Stunted (\%) & Severely stunted (\%) \\
\hline $6-11$ & 698 & -1.20 & 28.2 & 9.0 \\
\hline $12-17$ & 707 & -1.80 & 44.0 & 16.3 \\
\hline $18-23$ & 585 & -2.08 & 54.4 & 20.0 \\
\hline All & 1,990 & -1.67 & 41.5 & 14.8 \\
\hline
\end{tabular}

Source: Authors' compilation.

Note LAZ = length-for-age z-score.

\subsubsection{Acute undernutrition}

As noted in Section 5.1, acute undernutrition among children is usually measured using weight for length z-scores or MUAC. Children are defined as acutely undernourished (wasted) if they have a weight-for-length z-score below -2.0, i.e., their weight, given their length, is two standard deviations below the median length for a child of the same age and sex. Based on the MUAC cut-off values defined by WHO and UNICEF (2009), a MUAC measure less than $11.5 \mathrm{~cm}$ is taken as an indicator of severe acute malnutrition. MUAC between $11.5 \mathrm{~cm}$ and $12.5 \mathrm{~cm}$ indicates moderate acute malnutrition while measurements above this range are considered normal. Appendix $C$ provides the regional breakdown of the acute anthropometric measures.

Figure 5.8 shows the weight for length distributions for each survey round. The median weightfor-length z-score (WLZ) is well above the wasting threshold (-2.0 standard deviations) and remains relatively stable across the survey rounds.

\footnotetext{
${ }^{13}$ We also note that in August 2017, the number of observations in the '6-11 months' category is somewhat lower and the number of observations in the '18-23 month' category is somewhat higher than in other survey rounds. This is due the slight imbalance in the age distributions in the March 2017 and 2019 rounds. See Figure 5.1.
} 
Figure 5.8. Weight for length distributions by survey round

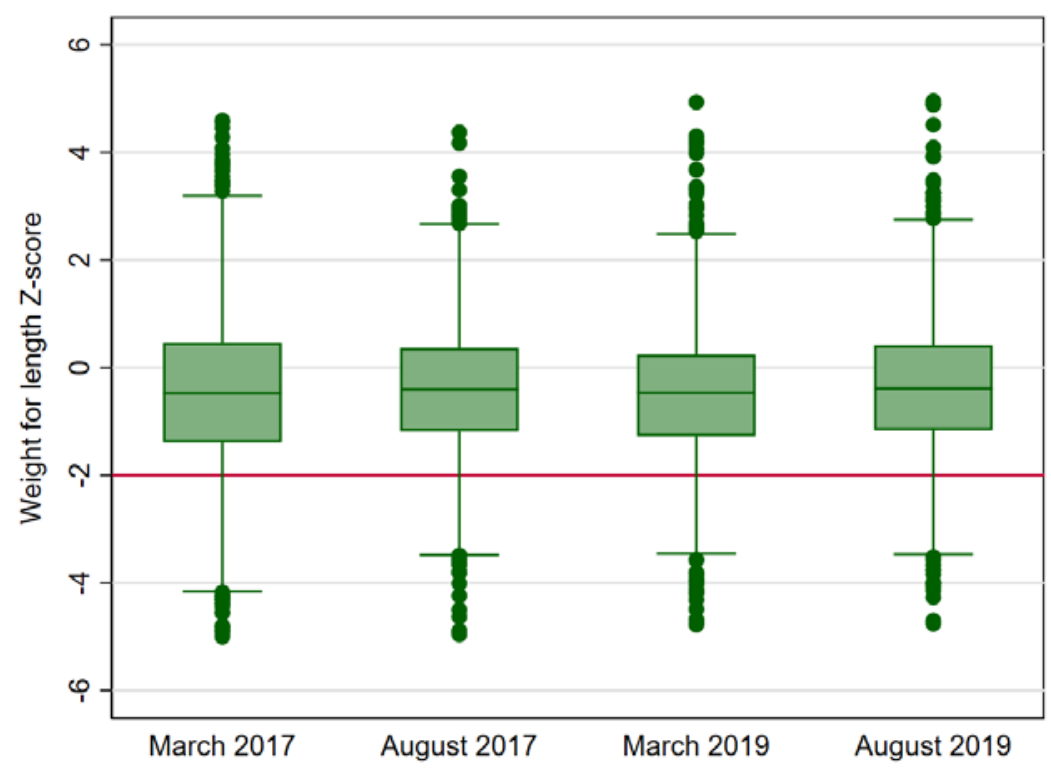

Source: Authors' compilation.

Figure 5.9 reports the wasting prevalence for PSNP and non-PSNP households. The seasonal fluctuations are large and to the same direction in both years with wasting prevalence higher in March and lower in August. For PSNP households, these seasonal differences in wasting prevalence are statistically significant in both years $(p<0.03)$.

In March 2017, wasting prevalence in PSNP households was 15 percent and was 12.3 percent two years later. However, this difference is not statistically different from zero $(p=0.113)$. Shifting to the August rounds, the difference in wasting rate between the two years is marginal ( 0.7 percentage points) and not statistically significant.

Figure 5.9. Wasting prevalence in PSNP and non-PSNP households by survey round

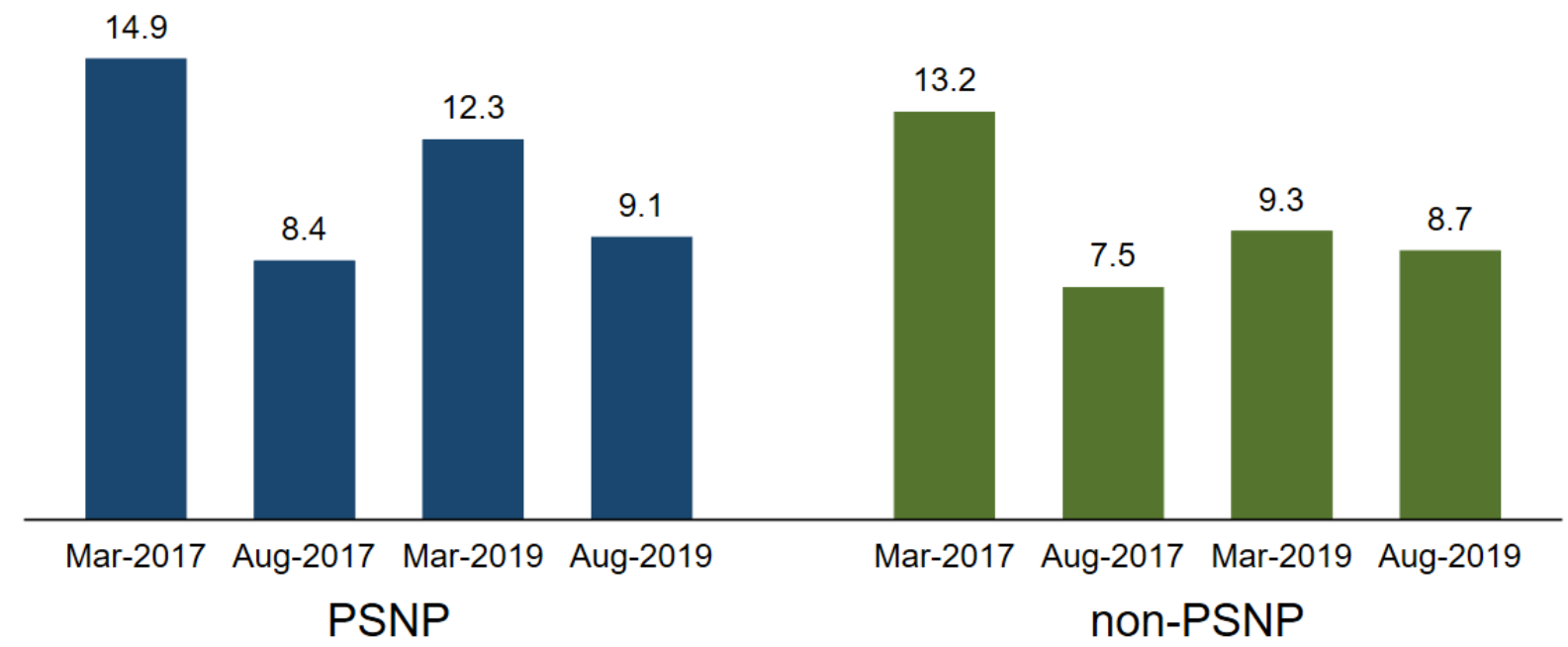

Source: Authors' compilation.

Table 5.5 summarizes the mean WLZ and wasting (WLZ<-2.0) and severe wasting (WLZ<-3.0) prevalence in each survey round. In most survey rounds, the differences in mean WLZ, wasting prevalence, and severe wasting prevalence are small. Only in March 2019 is the difference in wasting prevalence between PSNP and non-PSNP rounds statistically significant $(p=0.023)$. 
Table 5.5. Mean weight-for-length z-score and wasting prevalence of index children 6 to 23 months of age, by survey round and beneficiary status

\begin{tabular}{|c|c|c|c|c|}
\hline \multicolumn{5}{|c|}{ March 2017} \\
\hline Beneficiary status & $\mathbf{N}$ & WLZ & Wasted (\%) & Severely wasted (\%) \\
\hline Non-PSNP & 1,154 & -0.45 & 13.2 & 5.5 \\
\hline PSNP & 766 & -0.53 & 14.9 & 5.5 \\
\hline All & 1,920 & -0.48 & 13.9 & 5.5 \\
\hline \multicolumn{5}{|c|}{ August 2017} \\
\hline Beneficiary status & $\mathbf{N}$ & WLZ & Wasted (\%) & Severely wasted (\%) \\
\hline Non-PSNP & 1,185 & -0.41 & 7.5 & 1.9 \\
\hline PSNP & 753 & -0.41 & 8.4 & 1.5 \\
\hline All & 1,938 & -0.41 & 7.8 & 1.8 \\
\hline \multicolumn{5}{|c|}{ March 2019} \\
\hline Beneficiary status & $\mathbf{N}$ & WLZ & Wasted (\%) & Severely wasted (\%) \\
\hline Non-PSNP & 1,094 & -0.43 & 9.3 & 2.1 \\
\hline PSNP & 782 & -0.61 & 12.3 & 3.7 \\
\hline All & 1,876 & -0.50 & 10.6 & 2.8 \\
\hline \multicolumn{5}{|c|}{ August 2019} \\
\hline Beneficiary status & $\mathbf{N}$ & WLZ & Wasted (\%) & Severely wasted (\%) \\
\hline Non-PSNP & 1,186 & -0.33 & 8.7 & 1.4 \\
\hline PSNP & 800 & -0.45 & 9.1 & 1.6 \\
\hline All & 1,986 & -0.38 & 8.9 & 1.5 \\
\hline
\end{tabular}

Source: Authors' compilation.

Note WLZ = weight-for-length z-score.

Table 5.6 disaggregates these data by child sex. As with the chronic undernutrition measures, boys are more likely to be acute undernourished.

Table 5.6. Mean weight-for-length z-score and wasting prevalence of index children 6 to 23 months of age, by survey round and sex of the child

\begin{tabular}{|c|c|c|c|c|}
\hline \multicolumn{5}{|c|}{ March 2017} \\
\hline Sex & $\mathbf{N}$ & WLZ & Wasted (\%) & Severely wasted (\%) \\
\hline Girls & 967 & -0.41 & 12.2 & 5.3 \\
\hline Boys & 953 & -0.56 & 15.5 & 5.7 \\
\hline All & 1,920 & -0.48 & 13.9 & 5.5 \\
\hline \multicolumn{5}{|c|}{ August 2017} \\
\hline Sex & $\mathbf{N}$ & WLZ & Wasted (\%) & Severely wasted (\%) \\
\hline Girls & 968 & -0.39 & 7.3 & 1.8 \\
\hline Boys & 970 & -0.42 & 8.4 & 1.8 \\
\hline All & 1,938 & -0.41 & 7.8 & 1.8 \\
\hline \multicolumn{5}{|c|}{ March 2019} \\
\hline Sex & $\mathbf{N}$ & WLZ & Wasted (\%) & Severely wasted (\%) \\
\hline Girls & 904 & -0.44 & 8.2 & 2.0 \\
\hline Boys & 972 & -0.56 & 12.8 & 3.5 \\
\hline All & 1,876 & -0.50 & 10.6 & 2.8 \\
\hline \multicolumn{5}{|c|}{ August 2019} \\
\hline Sex & $\mathbf{N}$ & WLZ & Wasted (\%) & Severely wasted (\%) \\
\hline Girls & 957 & -0.37 & 7.4 & 1.4 \\
\hline Boys & 1,029 & -0.39 & 10.2 & 1.7 \\
\hline All & 1,986 & -0.38 & 8.9 & 1.5 \\
\hline
\end{tabular}

Source: Authors' compilation.

Note WLZ = weight-for-length z-score. 
Table 5.7 reports the mean WLZ and wasting prevalence by child's age. We see that younger children are more likely to be acutely malnourished compared to the older children.

Table 5.7. Mean weight-for-length z-score and wasting prevalence of index children 6 to 23 months of age, by survey round and child age

\begin{tabular}{|c|c|c|c|c|}
\hline \multicolumn{5}{|c|}{ March 2017} \\
\hline Age in months & $\mathbf{N}$ & WLZ & Wasted (\%) & Severely wasted (\%) \\
\hline $6-11$ & 669 & -0.49 & 17.5 & 7.9 \\
\hline $12-17$ & 679 & -0.51 & 12.7 & 4.4 \\
\hline $18-23$ & 572 & -0.45 & 11.0 & 3.8 \\
\hline All & 1,920 & -0.48 & 13.9 & 5.5 \\
\hline \multicolumn{5}{|c|}{ August 2017} \\
\hline Age in months & $\mathbf{N}$ & WLZ & Wasted (\%) & Severely wasted (\%) \\
\hline $6-11$ & 604 & -0.42 & 9.4 & 2.8 \\
\hline $12-17$ & 667 & -0.47 & 8.8 & 1.5 \\
\hline $18-23$ & 667 & -0.33 & 5.4 & 1.0 \\
\hline All & 1,938 & -0.41 & 7.8 & 1.8 \\
\hline \multicolumn{5}{|c|}{ March 2019} \\
\hline Age in months & $\mathbf{N}$ & WLZ & Wasted (\%) & Severely wasted (\%) \\
\hline $6-11$ & 714 & -0.52 & 11.6 & 3.4 \\
\hline $12-17$ & 635 & -0.54 & 11.8 & 2.2 \\
\hline $18-23$ & 527 & -0.44 & 7.6 & 2.7 \\
\hline All & 1,876 & -0.50 & 10.6 & 2.8 \\
\hline \multicolumn{5}{|c|}{ August 2019} \\
\hline Age in months & $\mathbf{N}$ & WLZ & Wasted (\%) & Severely wasted (\%) \\
\hline $6-11$ & 695 & -0.36 & 10.2 & 2.0 \\
\hline $12-17$ & 706 & -0.42 & 9.8 & 1.1 \\
\hline $18-23$ & 585 & -0.35 & 6.2 & 1.4 \\
\hline All & 1,986 & -0.38 & 8.9 & 1.5 \\
\hline
\end{tabular}

Source: Authors' compilation.

Note WLZ = weight-for-length z-score.

Figure 5.10. Mid-upper arm circumference distributions by survey round

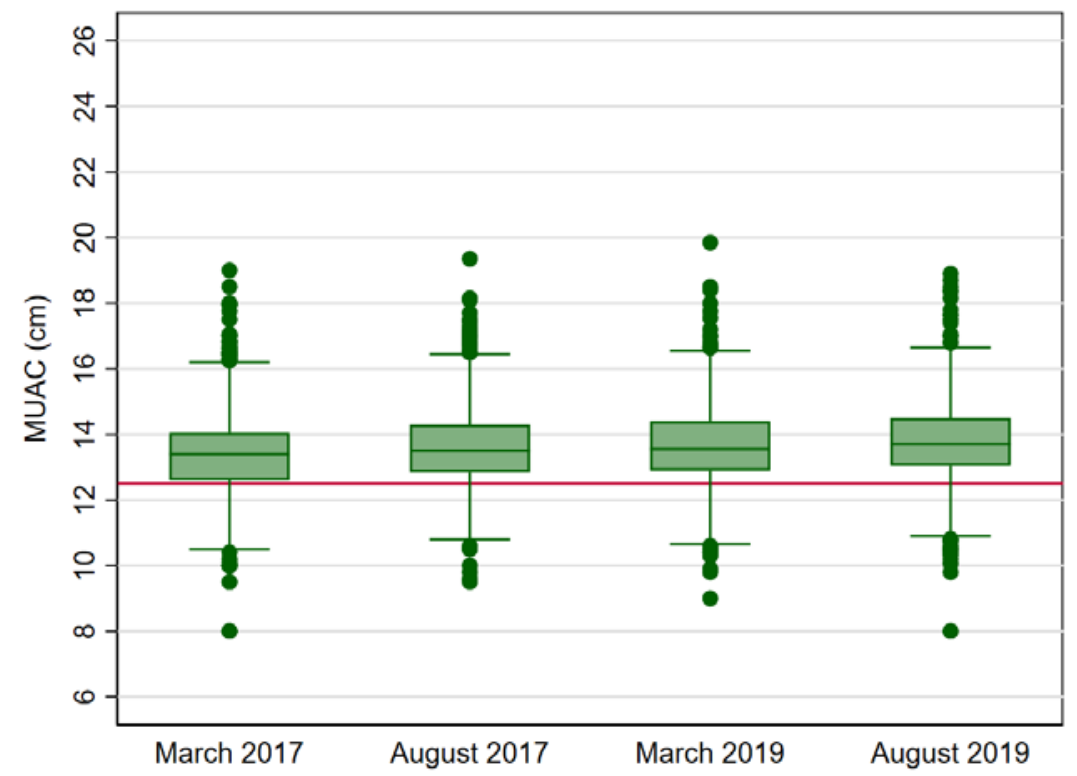

Source: Authors' compilation.

Figure 5.10 displays the MUAC distribution in each survey round. The median MUAC varies marginally across rounds and is slightly lower in March than in August round. In each survey round, 
the median MUAC is well above the threshold for moderate acute malnutrition (MUAC $=12.5 \mathrm{~cm}$ ). The 25th percentile of the distribution also lies above this threshold.

Figure 5.11 shows the prevalence of severe (MUAC $<11.5 \mathrm{~cm})$ and moderate $(11.5 \mathrm{~cm}<$ MUAC $<12.5 \mathrm{~cm}$ ) acute malnutrition based on the MUAC measure. As with wasting, we see that both severe and moderate acute malnutrition prevalence are higher in the lean season (August) compared to the postharvest season (March).

Figure 5.11. Severe and moderate acute malnutrition prevalence based on MUAC in PSNP and non-PSNP households by survey round

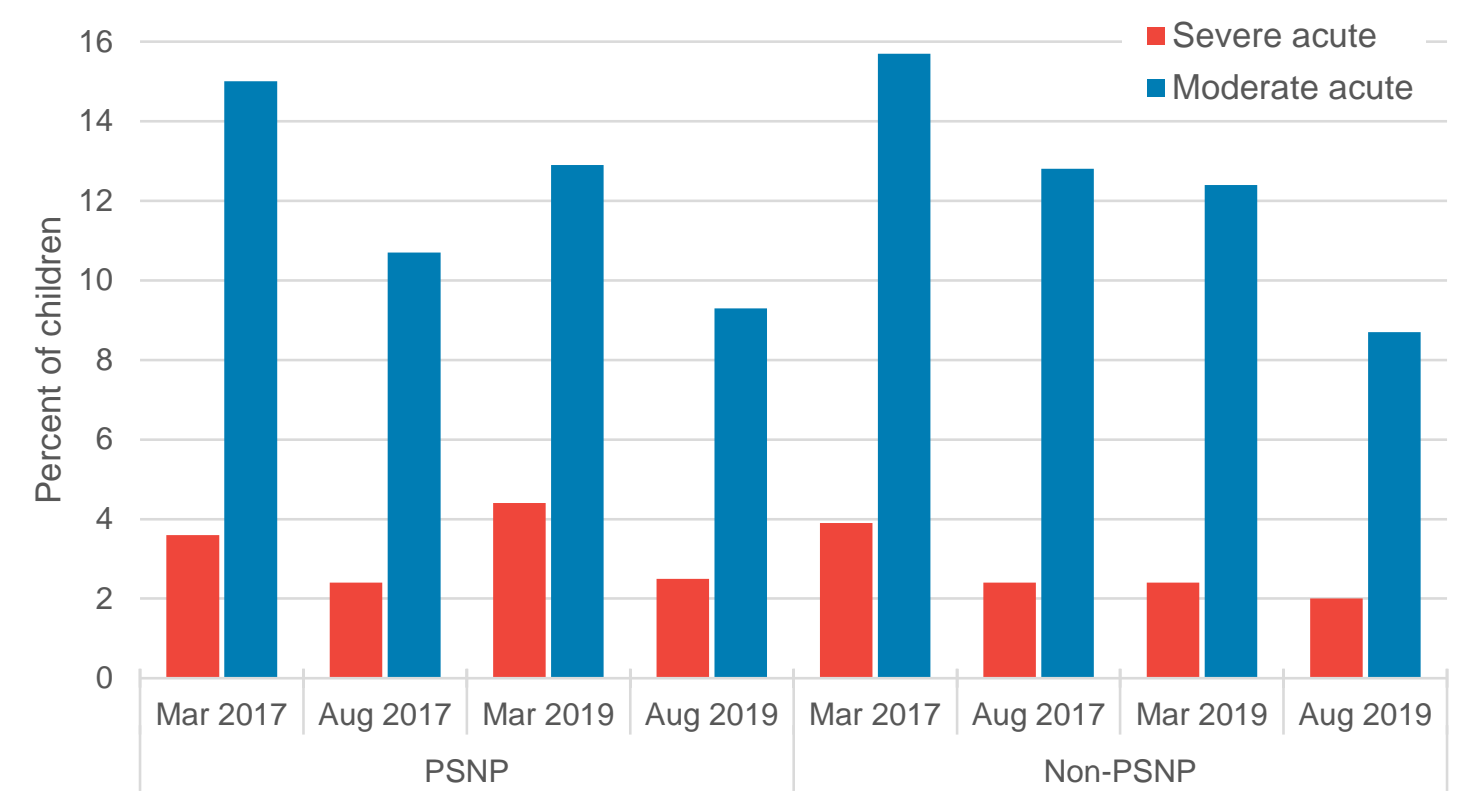

Source: Authors' compilation.

Note: MUAC = mid-upper arm circumference. $M U A C<11.5 \mathrm{~cm}$ indicates severe acute malnutrition, MUAC above $11.5 \mathrm{~cm}$ but below $12.5 \mathrm{~cm}$ indicates moderate acute malnutrition. MUAC above $12.5 \mathrm{~cm}$ is considered normal.

Table 5.8 reports MUAC results for all index children between 6 and 23 months of age. The mean MUAC measurement in our sample remain stable across the survey rounds, ranging in value between $13.4 \mathrm{~cm}$ in March 2017 and $13.8 \mathrm{~cm}$ in August 2019. The differences between PSNP and non-PSNP households are marginal across all these indicators. 
Table 5.8. Mean MUAC and acute malnutrition prevalence of index children 6 to 23 months of age, by survey round and beneficiary status

\begin{tabular}{|c|c|c|c|c|c|}
\hline \multicolumn{6}{|c|}{ March 2017} \\
\hline Beneficiary status & $\mathbf{N}$ & MUAC & $<11.5 \mathrm{~cm}(\%)$ & $11.5-12.5 \mathrm{~cm}(\%)$ & $>12.5 \mathrm{~cm}(\%)$ \\
\hline Non-PSNP & 1,186 & 13.4 & 3.9 & 15.7 & 80.5 \\
\hline PSNP & 783 & 13.4 & 3.6 & 15.0 & 81.5 \\
\hline All & 1,969 & 13.4 & 3.7 & 15.4 & 80.9 \\
\hline \multicolumn{6}{|c|}{ August 2017} \\
\hline Beneficiary status & $\mathbf{N}$ & MUAC & $<11.5 \mathrm{~cm}(\%)$ & $11.5-12.5 \mathrm{~cm}(\%)$ & $>12.5 \mathrm{~cm}(\%)$ \\
\hline Non-PSNP & 1,187 & 13.6 & 2.4 & 12.8 & 84.8 \\
\hline PSNP & 758 & 13.6 & 2.4 & 10.7 & 86.9 \\
\hline All & 1,945 & 13.6 & 2.4 & 12.0 & 85.6 \\
\hline \multicolumn{6}{|c|}{ March 2019} \\
\hline Beneficiary status & $\mathbf{N}$ & MUAC & $<11.5 \mathrm{~cm}(\%)$ & $11.5-12.5 \mathrm{~cm}(\%)$ & $>12.5 \mathrm{~cm}(\%)$ \\
\hline Non-PSNP & 1,101 & 13.7 & 2.4 & 12.4 & 85.2 \\
\hline PSNP & 789 & 13.5 & 4.4 & 12.9 & 82.6 \\
\hline All & 1,890 & 13.6 & 3.2 & 12.6 & 84.1 \\
\hline \multicolumn{6}{|c|}{ August 2019} \\
\hline Beneficiary status & $\mathbf{N}$ & MUAC & $<11.5 \mathrm{~cm}(\%)$ & $11.5-12.5 \mathrm{~cm}(\%)$ & $>12.5 \mathrm{~cm}(\%)$ \\
\hline Non-PSNP & 1,191 & 13.8 & 2.0 & 8.7 & 89.3 \\
\hline PSNP & 806 & 13.7 & 2.5 & 9.3 & 88.2 \\
\hline All & 1,997 & 13.8 & 2.2 & 9.0 & 88.8 \\
\hline
\end{tabular}

Source: Authors' compilation.

Note: MUAC = mid-upper arm circumference. $M U A C<11.5 \mathrm{~cm}$ indicates severe acute malnutrition, MUAC above $11.5 \mathrm{~cm}$ but below $12.5 \mathrm{~cm}$ indicates moderate acute malnutrition. MUAC above $12.5 \mathrm{~cm}$ is considered normal.

Table 5.9 shows that, compared to boys, MUAC is more likely to identify girls as acutely malnourished. This is in contrast to the chronic and acute malnutrition indicators reported above.

Table 5.9. Mean MUAC and acute malnutrition prevalence of index children 6 to 23 months of age, by survey round and sex of the child

\begin{tabular}{|c|c|c|c|c|c|}
\hline \multicolumn{6}{|c|}{ March 2017} \\
\hline Sex & $\mathbf{N}$ & MUAC & $<11.5 \mathrm{~cm}(\%)$ & $11.5-12.5 \mathrm{~cm}(\%)$ & $>12.5 \mathrm{~cm}(\%)$ \\
\hline Girls & 989 & 13.3 & 5.6 & 17.3 & 77.0 \\
\hline Boys & 980 & 13.6 & 1.8 & 13.5 & 84.7 \\
\hline All & 1,969 & 13.4 & 3.7 & 15.4 & 80.9 \\
\hline \multicolumn{6}{|c|}{ August 2017} \\
\hline Sex & $\mathbf{N}$ & MUAC & $<11.5 \mathrm{~cm}(\%)$ & $11.5-12.5 \mathrm{~cm}(\%)$ & $>12.5 \mathrm{~cm}(\%)$ \\
\hline Girls & 970 & 13.5 & 2.9 & 14.8 & 82.3 \\
\hline Boys & 975 & 13.8 & 1.9 & 9.2 & 88.9 \\
\hline All & 1,945 & 13.6 & 2.4 & 12 & 85.6 \\
\hline \multicolumn{6}{|c|}{ March 2019} \\
\hline Sex & $\mathbf{N}$ & MUAC & $<11.5 \mathrm{~cm}(\%)$ & $11.5-12.5 \mathrm{~cm}(\%)$ & $>12.5 \mathrm{~cm}(\%)$ \\
\hline Girls & 909 & 13.5 & 4.0 & 14.6 & 81.4 \\
\hline Boys & 981 & 13.8 & 2.5 & 10.8 & 86.6 \\
\hline All & 1,890 & 13.6 & 3.2 & 12.6 & 84.1 \\
\hline \multicolumn{6}{|c|}{ August 2019} \\
\hline Sex & $\mathbf{N}$ & MUAC & $<11.5 \mathrm{~cm}(\%)$ & $11.5-12.5 \mathrm{~cm}(\%)$ & $>12.5 \mathrm{~cm}(\%)$ \\
\hline Girls & 963 & 13.6 & 3.1 & 11.6 & 85.3 \\
\hline Boys & 1,034 & 13.9 & 1.4 & 6.5 & 92.2 \\
\hline All & 1,997 & 13.8 & 2.2 & 9.0 & 88.8 \\
\hline
\end{tabular}

Source: Authors' compilation.

Note: MUAC = mid-upper arm circumference. $M U A C<11.5 \mathrm{~cm}$ indicates severe acute malnutrition, MUAC above $11.5 \mathrm{~cm}$ but below $12.5 \mathrm{~cm}$ indicates moderate acute malnutrition. MUAC above $12.5 \mathrm{~cm}$ is considered normal. 
Table 5.10 reports the same statistics by child's age. As with the wasting indicator, we see that younger children are more likely to be identified as acutely malnourished compared to the older children.

Table 5.10. Mean MUAC and acute malnutrition prevalence of index children 6 to 23 months of age, by survey round and child age

\begin{tabular}{|c|c|c|c|c|c|}
\hline \multicolumn{6}{|c|}{ March 2017} \\
\hline Age in months & $\mathbf{N}$ & MUAC & $<11.5 \mathrm{~cm}(\%)$ & $11.5-12.5 \mathrm{~cm}(\%)$ & $>12.5 \mathrm{~cm}(\%)$ \\
\hline $6-11$ & 691 & 13.2 & 6.2 & 19.5 & 74.3 \\
\hline $12-17$ & 695 & 13.5 & 3.3 & 16.0 & 80.7 \\
\hline $18-23$ & 583 & 13.6 & 1.4 & 9.9 & 88.8 \\
\hline All & 1,969 & 13.4 & 3.7 & 15.4 & 80.9 \\
\hline \multicolumn{6}{|c|}{ August 2017} \\
\hline Age in months & $\mathbf{N}$ & MUAC & $<11.5 \mathrm{~cm}(\%)$ & $11.5-12.5 \mathrm{~cm}(\%)$ & $>12.5 \mathrm{~cm}(\%)$ \\
\hline $6-11$ & 607 & 13.4 & 3.4 & 17.4 & 79.2 \\
\hline $12-17$ & 669 & 13.6 & 2.4 & 11.6 & 86.0 \\
\hline $18-23$ & 669 & 13.8 & 1.5 & 7.4 & 91.1 \\
\hline All & 1,945 & 13.6 & 2.4 & 12 & 85.6 \\
\hline \multicolumn{6}{|c|}{ March 2019} \\
\hline Age in months & $\mathbf{N}$ & MUAC & $<11.5 \mathrm{~cm}(\%)$ & $11.5-12.5 \mathrm{~cm}(\%)$ & $>12.5 \mathrm{~cm}(\%)$ \\
\hline $6-11$ & 719 & 13.5 & 4.5 & 16.4 & 79.1 \\
\hline $12-17$ & 639 & 13.6 & 3.3 & 11.9 & 84.8 \\
\hline $18-23$ & 532 & 13.8 & 1.5 & 8.5 & 90.0 \\
\hline All & 1,890 & 13.6 & 3.2 & 12.6 & 84.1 \\
\hline \multicolumn{6}{|c|}{ August 2019} \\
\hline Age in months & $\mathbf{N}$ & MUAC & $<11.5 \mathrm{~cm}(\%)$ & $11.5-12.5 \mathrm{~cm}(\%)$ & $>12.5 \mathrm{~cm}(\%)$ \\
\hline $6-11$ & 701 & 13.6 & 3.3 & 11.8 & 84.9 \\
\hline $12-17$ & 709 & 13.8 & 2.1 & 7.9 & 90.0 \\
\hline $18-23$ & 587 & 14.0 & 1.0 & 6.8 & 92.2 \\
\hline All & 1,997 & 13.8 & 2.2 & 9.0 & 88.8 \\
\hline
\end{tabular}

Source: Authors' compilation.

Note: MUAC = mid-upper arm circumference. $M U A C<11.5 \mathrm{~cm}$ indicates severe acute malnutrition, MUAC above $11.5 \mathrm{~cm}$ but below $12.5 \mathrm{~cm}$ indicates moderate acute malnutrition. MUAC above $12.5 \mathrm{~cm}$ is considered normal.

WHO definition of acute malnutrition combines WLZ and MUAC: A child is defined as acutely malnourished if his or her WLZ<-2 or MUAC $<12.5 \mathrm{~cm}$. Figure 5.12 reports the acute malnutrition prevalence based on this definition among PSNP and non-PSNP children. The acute malnutrition rates are considerably higher if we consider the WHO definition, implying that low WLZ and low MUAC identify different children as acutely malnourished. 
Figure 5.12. Prevalence of acute malnutrition based on WHO definition, children 6 to 23 months of age, by survey round and PSNP status

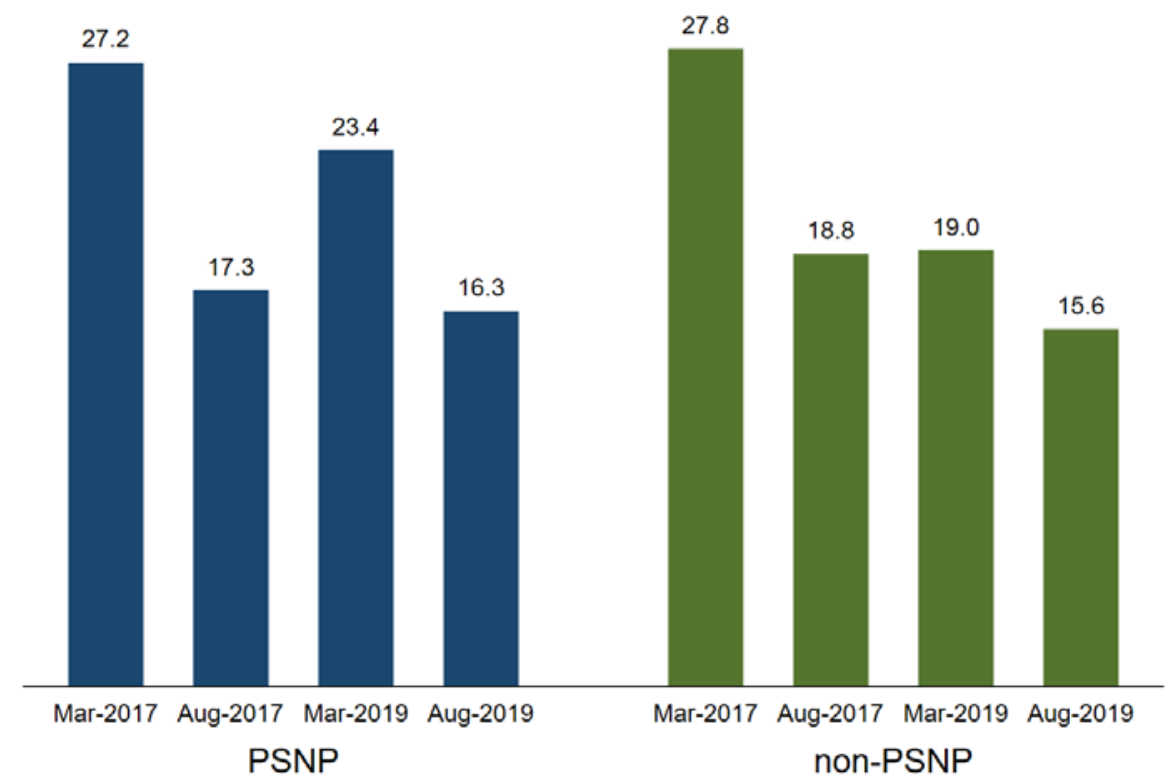

Source: Authors' compilation.

Note: WHO definition: a child is defined as acutely malnourished if his/her WLZ $<-2$ or MUAC $<12.5 \mathrm{~cm}$.

\subsubsection{Other measures of undernutrition}

Finally, we briefly report anthropometric outcomes based on weight-for-age, which is considered a combination of acute and chronic malnutrition. A child is considered underweight if his or her weight-for-age $Z$ score (WAZ) is below -2.0 and severely underweight is her WAZ is less than -3.0. Appendix $C$ provides the regional breakdown of these anthropometric measures.

Table 5.11. Mean weight-for-age z-score and underweight prevalence of index children 6 to 23 months of age, by survey round and beneficiary status

\begin{tabular}{|c|c|c|c|c|}
\hline \multicolumn{5}{|c|}{ March 2017} \\
\hline Beneficiary status & $\mathbf{N}$ & WAZ & Underweight (\%) & Severely underweight (\%) \\
\hline Non-PSNP & 1,180 & -1.14 & 24.8 & 7.8 \\
\hline PSNP & 781 & -1.25 & 28.3 & 8.8 \\
\hline All & 1,961 & -1.18 & 26.2 & 8.2 \\
\hline \multicolumn{5}{|c|}{ August 2017} \\
\hline Beneficiary status & $\mathbf{N}$ & WAZ & Underweight (\%) & Severely underweight (\%) \\
\hline Non-PSNP & 1,185 & -1.04 & 19.3 & 4.1 \\
\hline PSNP & 753 & -1.14 & 22.6 & 3.9 \\
\hline All & 1,938 & -1.08 & 20.6 & 4.0 \\
\hline \multicolumn{5}{|c|}{ March 2019} \\
\hline Beneficiary status & $\mathbf{N}$ & WAZ & Underweight (\%) & Severely underweight (\%) \\
\hline Non-PSNP & 1,097 & -1.05 & 21.8 & 5.4 \\
\hline PSNP & 784 & -1.24 & 26.5 & 6.6 \\
\hline All & 1,881 & -1.13 & 23.8 & 5.9 \\
\hline \multicolumn{5}{|c|}{ August 2019} \\
\hline Beneficiary status & $\mathbf{N}$ & WAZ & Underweight (\%) & Severely underweight (\%) \\
\hline Non-PSNP & 1,190 & -1.06 & 21.3 & 5.3 \\
\hline PSNP & 802 & -1.23 & 24.8 & 6.6 \\
\hline All & 1,992 & -1.13 & 22.7 & 5.8 \\
\hline
\end{tabular}

Source: Authors' compilation.

Note: WAZ = Weight-for-age z-score. 
Table 5.11 reports the mean WAZ and underweight prevalence in each round by beneficiary status. We see that underweight prevalence is generally higher in PSNP households compared to non-PSNP households. Moreover, the underweight prevalence is somewhat lower in the August rounds compared to the March rounds.

\subsection{Child health}

Indicators related to the health of the index child included three childhood illnesses: fever, diarrhea, and acute respiratory infection. The mother of the index child reported on any such symptoms experienced by the index child in the two weeks prior to the interview.

Fever is a common symptom of acute infections in children. Diarrhea, a major cause of death and morbidity among infants and children, was reported by mothers as loose stools at any time during the two-week period. Acute respiratory infection (ARI) was estimated by reporting a cough accompanied by shortness of breath. Previous work from Ethiopia suggests that prevalence of illness varies seasonally (Branca et al. 1993; Ferro-Luzzi et al. 2001).

Figures 5.13, 5.14, and 5.15 show the prevalence of illnesses across the four survey rounds. The percent of children in PSNP households who had fever in the 2 weeks prior to the interview is around 30 percent in all rounds (Figure 5.13), except in March 2019 when 35 percent of the children were reported to have had fever.

Figure 5.13. Prevalence of fever among children 6 to 23 months of age, by survey round and PSNP status

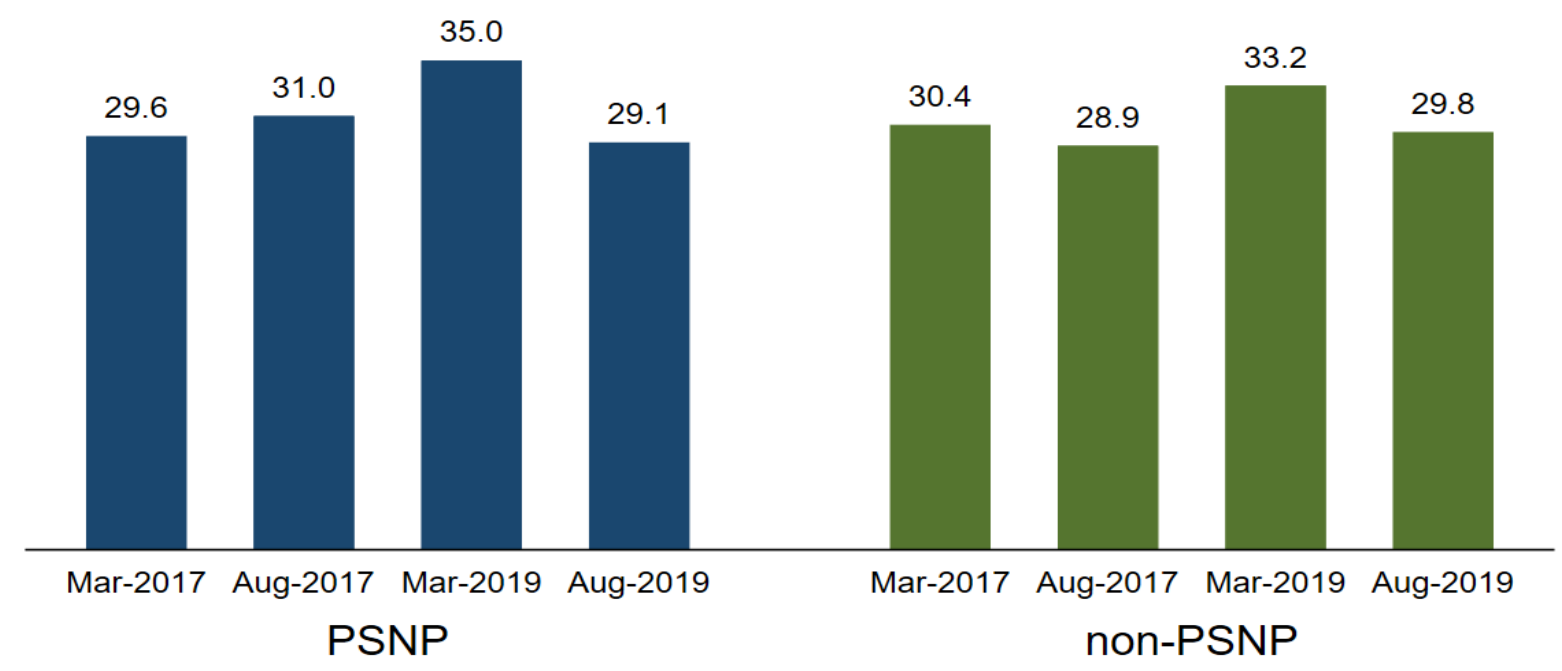

Source: Authors' compilation.

Diarrhea prevalence among children originating from PSNP households is around 23 percent in all survey rounds, except March 2019 (Figure 5.14). As with fever, this survey round shows elevated diarrhea risk - nearly 32 percent of children 6 to 23 months of age were reported to have suffered from diarrhea in the two-week period prior to the interview. 
Figure 5.14. Prevalence of diarrhea among children 6 to 23 months of age, by survey round and PSNP status

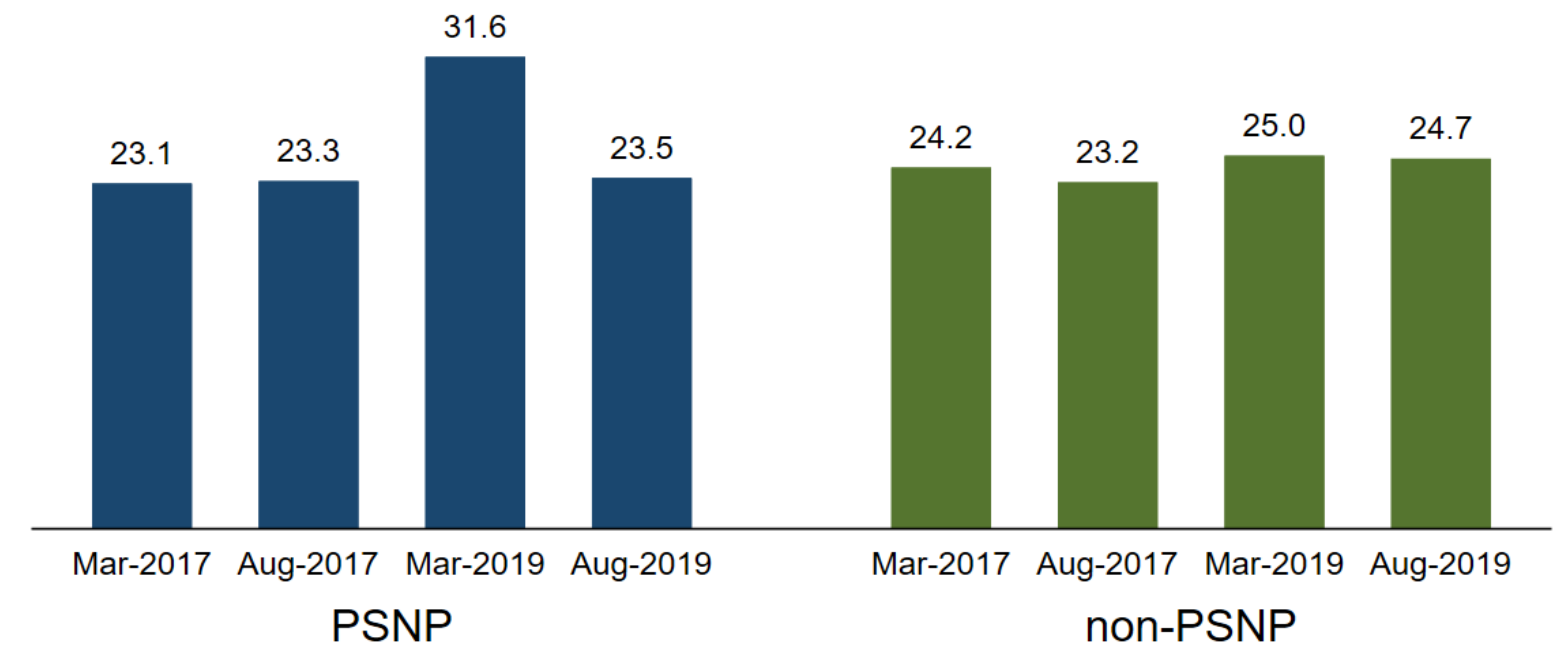

Source: Authors' compilation.

ARI shows a more distinct seasonal pattern (Figure 5.15): In both March rounds, the ARI prevalence was 15 to 16 percent in PSNP households. In August, the corresponding prevalence was between 10 and 12 percent.

Figure 5.15. Prevalence of acute respiratory infection (ARI) among children 6 to 23 months of age, by survey round and PSNP status

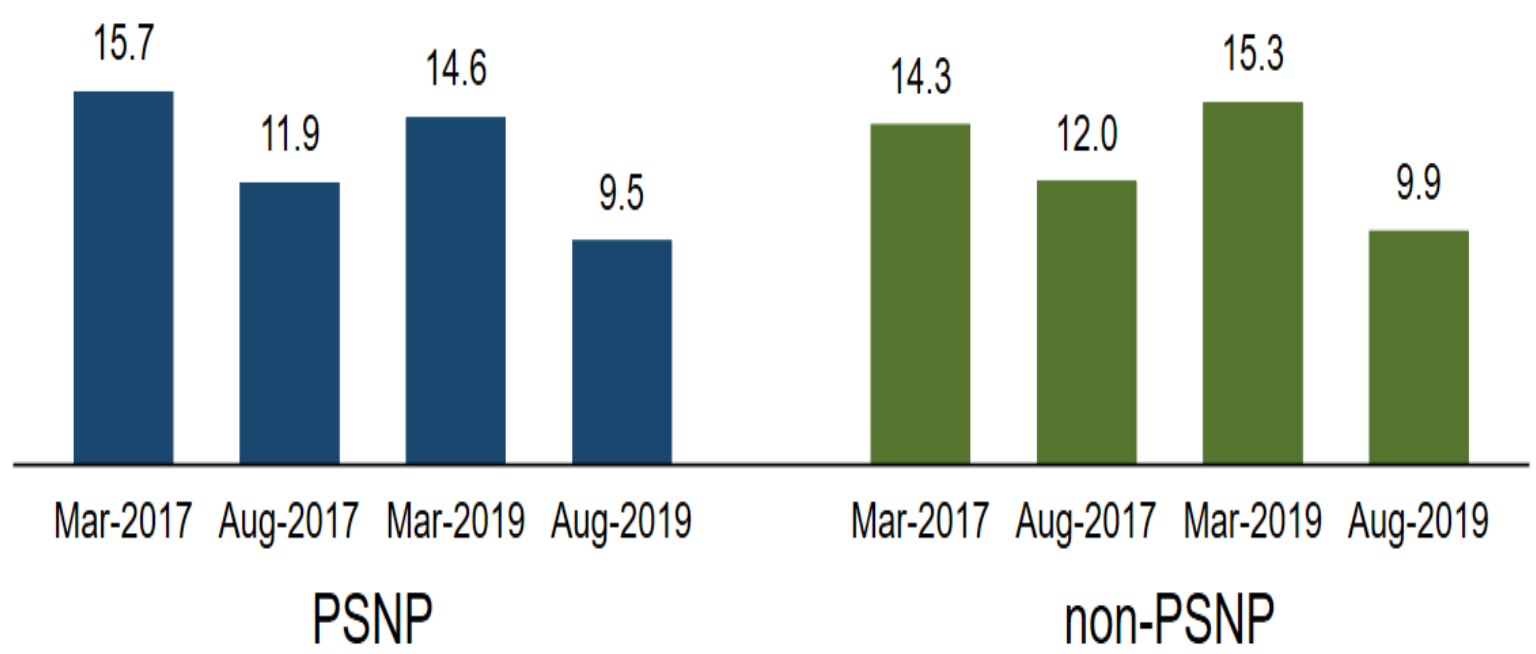

Source: Authors' compilation.

Across all illness indicators, the differences between PSNP and non-PSNP households are marginal. The only clear exception is diarrhea prevalence in March 2019 when the risk of diarrhea did not seem to increase among children from non-PSNP households. Appendix C provides the regional breakdown of the illness prevalence.

To examine how illness risk changes with child age, we used data for all children, i.e., including those less than 6 months of age in March and those older than 23 months in August rounds. We regressed fever, diarrhea and ARI indicators on child age. Figure 5.16 shows the results of the local polynomial regression. We see that the fever and diarrhea risk increases first and then decline as children get older and as their immune systems get stronger. In contrast, ARI risk remain relatively constant along the child-age gradient. 
Figure 5.16. Relationship between illness risk and child age

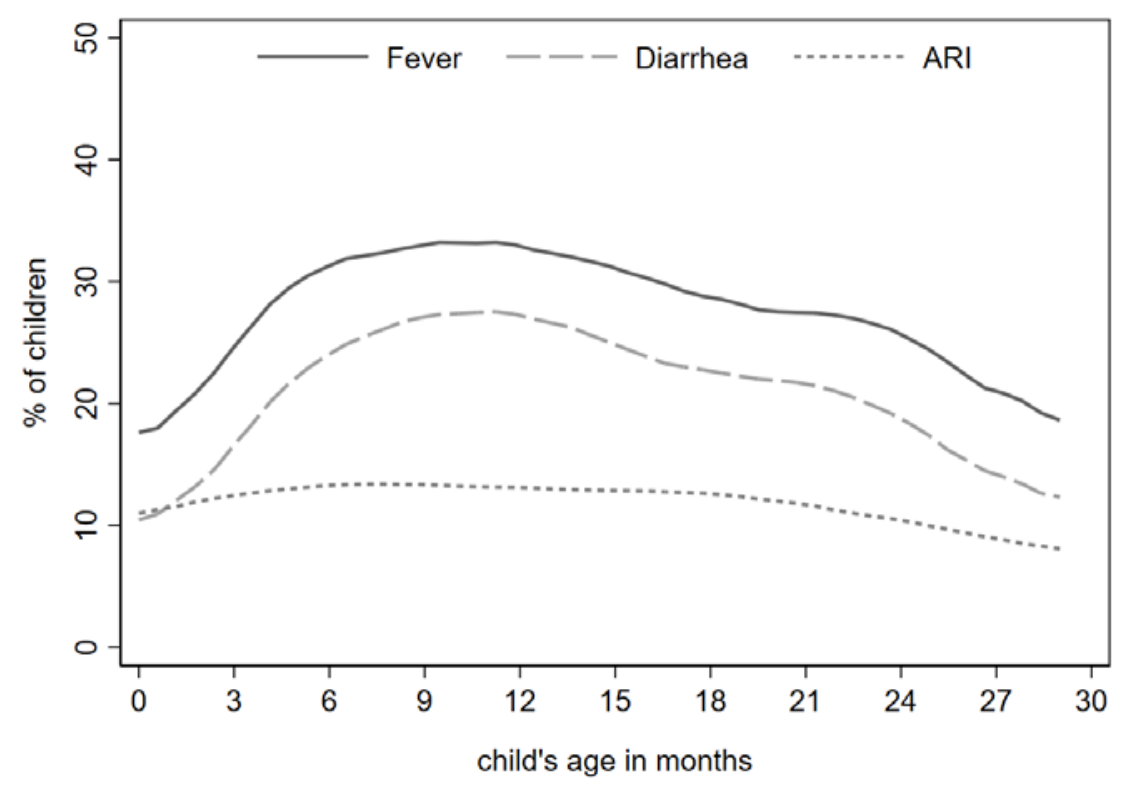

Source: Authors' compilation.

Note: Local polynomial regression. ARI = Acute respiratory infection. 


\section{INFANT AND YOUNG CHILD FEEDING (IYCF)}

The fourth phase of PSNP places a new emphasis on nutrition sensitivity, with a new high-level indicator of "\% of children age 6-23 months of age who receive minimum acceptable diet" (PNSP-4 PIM, p. 2-3). A minimum acceptable diet is a composite index of adequate dietary diversity and meal frequency. Therefore, improving this outcome requires that caregivers have a good understanding of recommended infant and young child feeding practices and that PSNP transfers are sufficiently large so that caregivers are able to afford nutritious foods to provide their children. This chapter focuses on the first requirement of understanding. We report on mothers' knowledge about IYCF practices (Section 6.1) and then assess actual IYCF practices by examining dietary diversity and meal frequency (Section 6.2).

\subsection{Knowledge and attitudes on infant and young child feeding}

The sample used in this sub-chapter is all mothers of index children. They were asked about their knowledge and attitudes regarding IYCF practices. We first report on their knowledge and attitudes regarding breastfeeding using data collected in the March survey rounds. WHO recommends that breastfeeding is initiated within the first hour after birth (WHO 2013). Table 6.1 shows about 80 percent of all respondents agree with this, stating that breastfeeding should begin immediately after the baby is born. Regional disaggregation in Table 6.2 shows that the agreement with this is highest in Oromia. Less than 1 percent of the mothers think that baby should not be breastfed at all. Differences between mothers based on whether they participated in PSNP are marginal (Table 6.1). Mothers from households not participating in PSNP are somewhat more likely to agree with the WHO recommendation that breastfeeding be initiated within the first hour after birth.

Table 6.1. Perceptions on when to start breastfeeding by PSNP status, percent of mothers

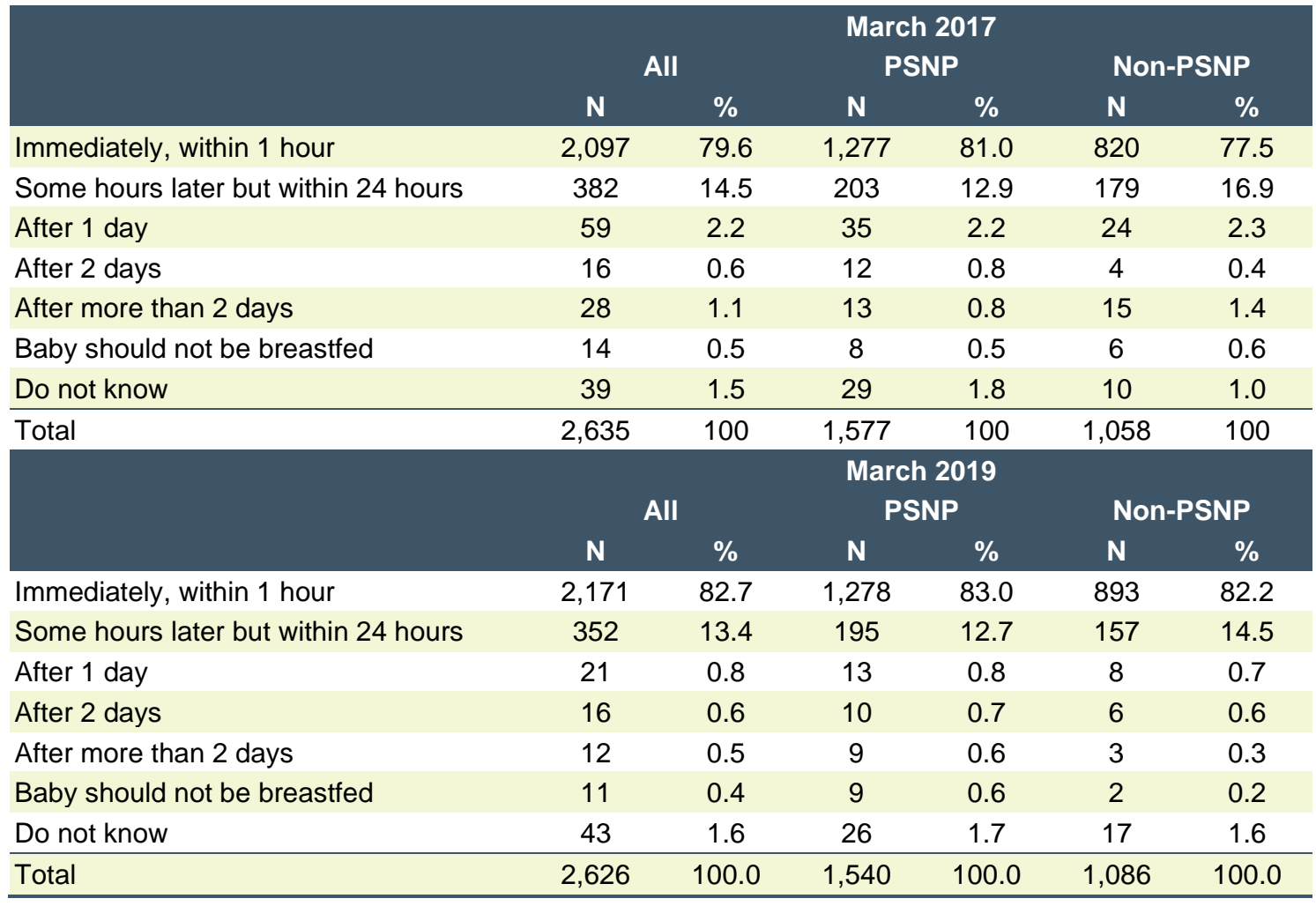

Source: Authors' compilation.

Note: March rounds only. Sample used is all mothers of index children 
Table 6.2. Perceptions on when to start breastfeeding by region, percent of mothers

\begin{tabular}{lcccccccc} 
& \multicolumn{4}{c}{ March 2017} & \multicolumn{4}{c}{ March 2019} \\
& Amhara & Oromia & SNNP & Tigray & Amhara & Oromia & SNNP & Tigray \\
Immediately, within 1 hour & 72.2 & 85.3 & 81.7 & 79.2 & 78.5 & 84.8 & 79.9 & 87.6 \\
Some hours later but within 24 hours & 16.2 & 8.9 & 15.9 & 17.0 & 15.5 & 10.0 & 17.2 & 10.9 \\
After 1 day & 6.1 & 1.4 & 0.9 & 0.6 & 1.2 & 0.8 & 0.9 & 0.3 \\
After 2 days & 0.5 & 1.2 & 0.5 & 0.3 & 1.5 & 0.9 & 0.0 & 0.0 \\
After more than 2 days & 2.7 & 1.1 & 0.0 & 0.5 & 1.8 & 0.0 & 0.0 & 0.0 \\
Baby should not be breastfed & 0.3 & 0.5 & 0.5 & 0.9 & 0.2 & 0.8 & 0.5 & 0.3 \\
Do not know & 2.1 & 1.7 & 0.6 & 1.5 & 1.4 & 2.8 & 1.5 & 0.9 \\
\hline Total & 100 & 100 & 100 & 100 & 100 & 100 & 100 & 100 \\
\hline
\end{tabular}

Source: Authors' compilation.

Note: March rounds only. Sample used is all mothers of index children

WHO further recommends that babies are exclusively breastfed for the first six months of their life (WHO 2013). Table 6.3 shows that in each round nearly 85 percent of mothers agree with this recommendation. Again, there are little differences between PNSP and non-PSNP mothers.

Regional disaggregation in Table 6.4 shows that more than 87 percent of the mothers in SNNP agree with the WHO recommendation in both survey rounds. In Oromia, this corresponding figure is 80 percent.

Table 6.3. Perceptions on when to stop exclusive breastfeeding by PSNP status, percent of mothers

\begin{tabular}{|c|c|c|c|c|c|c|}
\hline \multicolumn{7}{|c|}{ March 2017} \\
\hline & \multicolumn{2}{|c|}{ All } & \multicolumn{2}{|c|}{ PSNP } & \multicolumn{2}{|c|}{ Non-PSNP } \\
\hline & $\mathbf{N}$ & $\%$ & $\mathbf{N}$ & $\%$ & $\mathbf{N}$ & $\%$ \\
\hline Less than 1 month & 33 & 1.3 & 19 & 1.2 & 14 & 1.3 \\
\hline 1 to 4 months & 117 & 4.4 & 72 & 4.6 & 45 & 4.3 \\
\hline 5 months & 46 & 1.8 & 27 & 1.7 & 19 & 1.8 \\
\hline 6 months & 2,222 & 84.3 & 1,323 & 83.9 & 899 & 85.0 \\
\hline 7 months & 59 & 2.2 & 31 & 2.0 & 28 & 2.7 \\
\hline 8 to 11 months & 20 & 0.8 & 13 & 0.8 & 7 & 0.7 \\
\hline 12 months & 35 & 1.3 & 21 & 1.3 & 14 & 1.3 \\
\hline More than 12 months & 37 & 1.4 & 28 & 1.8 & 9 & 0.9 \\
\hline Don't know & 66 & 2.5 & 43 & 2.7 & 23 & 2.2 \\
\hline Total & 2,635 & 100 & 1,577 & 100 & 1,058 & 100 \\
\hline \multicolumn{7}{|c|}{ March 2019} \\
\hline & \multicolumn{2}{|c|}{ All } & \multicolumn{2}{|c|}{ PSNP } & \multicolumn{2}{|c|}{ Non-PSNP } \\
\hline & $\mathbf{N}$ & $\%$ & $\mathbf{N}$ & $\%$ & $\mathbf{N}$ & $\%$ \\
\hline Less than 1 month & 9 & 0.3 & 7 & 0.5 & 2 & 0.2 \\
\hline 1 to 4 months & 148 & 5.6 & 90 & 5.8 & 58 & 5.3 \\
\hline 5 months & 59 & 2.3 & 35 & 2.3 & 24 & 2.2 \\
\hline 6 months & 2,225 & 84.7 & 1,293 & 84.0 & 932 & 85.8 \\
\hline 7 months & 73 & 2.8 & 45 & 2.9 & 28 & 2.6 \\
\hline 8 to 11 months & 40 & 1.5 & 28 & 1.8 & 12 & 1.1 \\
\hline 12 months & 24 & 0.9 & 15 & 1.0 & 9 & 0.8 \\
\hline More than 12 months & 13 & 0.5 & 10 & 0.7 & 3 & 0.3 \\
\hline Don't know & 35 & 1.3 & 17 & 1.1 & 18 & 1.7 \\
\hline Total & 2,626 & 100 & 1,540 & 100 & 1,086 & 100 \\
\hline
\end{tabular}

Source: Authors' compilation.

Note: March rounds only. Sample used is all mothers of index children 
Table 6.4. Perceptions on when to stop exclusive breastfeeding by region, percent of mothers

\begin{tabular}{lcccccccc} 
& \multicolumn{4}{c}{ March $\mathbf{2 0 1 7}$} & \multicolumn{4}{c}{ March 2019} \\
& Amhara & Oromia & SNNP & Tigray & Amhara & Oromia & SNNP & Tigray \\
\hline Less than 1 month & 0.3 & 2.6 & 1.1 & 1.1 & 6.0 & 0.5 & 0.3 & 0.6 \\
1 to 4 months & 4.1 & 2.5 & 4.4 & 6.8 & 0.0 & 6.5 & 5.5 & 4.6 \\
5 months & 2.6 & 0.9 & 1.7 & 1.8 & 1.7 & 4.5 & 2.2 & 0.8 \\
6 months & 85.2 & 80.5 & 87.5 & 84.1 & 84.1 & 80.0 & 88.6 & 86.2 \\
7 months & 2.0 & 4.0 & 2.0 & 1.1 & 2.3 & 3.1 & 0.8 & 5.0 \\
8 to 11 months & 0.8 & 0.8 & 1.1 & 0.5 & 2.9 & 0.9 & 0.8 & 1.5 \\
12 months & 3.3 & 0.3 & 0.3 & 1.4 & 2.3 & 0.3 & 0.3 & 0.8 \\
More than 12 months & 0.3 & 3.4 & 0.6 & 1.4 & 0.2 & 1.2 & 0.5 & 0.2 \\
Don't know & 1.5 & 5.1 & 1.5 & 2.0 & 0.8 & 3.1 & 1.1 & 0.5 \\
\hline Total & 100 & 100 & 100 & 100 & 100 & 100 & 100 & 100 \\
\hline
\end{tabular}

Source: Authors' compilation.

Note: March rounds only. Sample used is all mothers of index children

Next, we report on mothers' knowledge and attitudes regarding complementary feeding. The sample in this analysis is based on mothers whose index child is 6 to 23 months of age, and we use data from all four survey rounds.

The questionnaire also tested mothers' knowledge about complementary feeding through a battery of questions. The responses to the 12 questions were marked and the correct response to each question received one point. Table 6.5 displays the questions and the percent of mothers who answered them correctly in the two March survey rounds. In contrast to knowledge about breastfeeding related issues, we observe poor knowledge regarding complementary feeding related issues, e.g., sources of important nutrients, consequences of nutrient deficiencies, etc. Overall, these findings resonate with earlier research on maternal nutrition knowledge in Ethiopia (Kim et al. 2015; Abebe, Haki, and Baye 2016). The table further shows marginal differences between PSNP and non-PSNP households. There is also little changes in caregiver knowledge over time. Knowledge regarding minimum meal frequency improved, while the opposite was true for knowledge regarding food types to complement breastfeeding.

Table 6.5. Correct responses to questions about complementary feeding practices, by round and PSNP status, percent of mothers responding correctly

\begin{tabular}{|c|c|c|c|c|c|c|c|}
\hline & \multicolumn{3}{|c|}{ March 2017} & \multicolumn{3}{|c|}{ March 2019} \\
\hline & & All & $\begin{array}{l}\text { non- } \\
\text { PSNP }\end{array}$ & PSNP & All & $\begin{array}{l}\text { non- } \\
\text { PSNP }\end{array}$ & PSNP \\
\hline 1. & Consequences of iron deficiency * & 52 & 56 & 47 & 46 & 47 & 45 \\
\hline & Sources of iron * & 35 & 37 & 32 & 36 & 36 & 35 \\
\hline 3. & Consequences of vitamin A deficiency * & 38 & 41 & 33 & 39 & 40 & 38 \\
\hline & Sources of vitamin A * & 25 & 27 & 22 & 26 & 26 & 25 \\
\hline 5. & What seasoning is often fortified with iodine & 57 & 58 & 55 & 52 & 51 & 53 \\
\hline 6. & Are gruels traditionally prepared too thin & 14 & 13 & 16 & 18 & 18 & 18 \\
\hline 7. & Food types to complement breastfeeding * & 70 & 73 & 67 & 58 & 59 & 58 \\
\hline & $\begin{array}{l}\text { Can a 1-year old child eat alone without any } \\
\text { supervision of an adult }\end{array}$ & 86 & 86 & 85 & 85 & 85 & 86 \\
\hline & Minimum meal frequency & 68 & 67 & 68 & 80 & 81 & 80 \\
\hline & $\begin{array}{l}\text { What should a mother do when her child older } \\
\text { than } 6 \text { months has diarrhea * }\end{array}$ & 77 & 78 & 75 & 74 & 76 & 72 \\
\hline & How much should a child be fed when s/he is sick & 28 & 26 & 30 & 31 & 31 & 30 \\
\hline & How often should a child be fed when s/he is sick & 31 & 30 & 32 & 34 & 35 & 33 \\
\hline
\end{tabular}

Source: Authors' compilation.

Note: March rounds only. Sample used is mothers whose index child is 6 to 23 months of age

* More than one correct response; a point given if the respondent identified at least one of them. 
We then aggregated these responses into a score. Each correct response is given one point, yielding an IYCF score ranging between 0 and 12. We then converted these scores into percentage terms; 0 percent indicating that the caregiver did not know the correct response to any of the 12 questions and 100 percent is given to caregivers who knew the correct response to all 12 . Focusing on PSNP households, Figure 6.1 displays the mean score in each survey round. Over the study period, the mean knowledge score improved by four percentage points. ${ }^{14}$ However, even in August 2019 , the average caregiver provided correct responses to only about half of the questions about age-appropriate complementary feeding practices.

Table 6.6 shows the average scores by PSNP status and region. The differences between caregivers residing in PSNP and non-PSNP households are mostly negligible. Regional disaggregation reveals that in August 2019 the differences in caregiver knowledge are marginal between Oromia, SNNP, and Tigray, while caregivers in Amhara region display somewhat poorer knowledge.

Figure 6.1. Mean complementary feeding knowledge score among caregivers in PSNP households, by survey round, percentage score

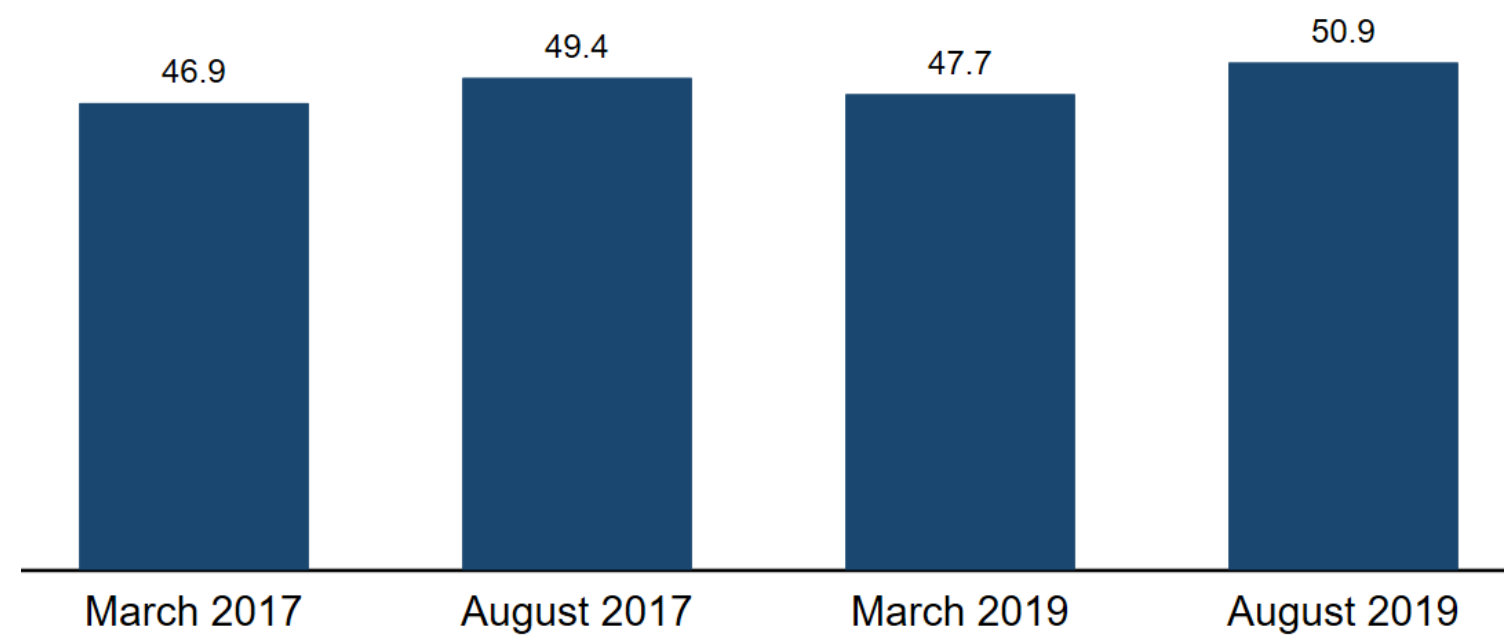

Source: Authors' compilation.

Note: Sample used is mothers whose index child is 6 to 23 months of age. Score is calculated as the percentage of correct responses to the questions about complementary feeding practices listed in Table 6.5.

Table 6.6. Average complementary feeding knowledge percentage score, by PSNP status and region

\begin{tabular}{lcccccccc} 
& \multicolumn{2}{c}{ March $\mathbf{2 0 1 7}$} & \multicolumn{2}{c}{ August 2017} & \multicolumn{2}{c}{ March 2019 } & \multicolumn{2}{c}{ August 2019 } \\
& mean & median & mean & median & mean & median & mean & median \\
Full sample & 48.3 & 50.0 & 50.4 & 50.0 & 48.3 & 50.0 & 51.5 & 50.0 \\
\hline Non-PSNP & 49.2 & 50.0 & 51.1 & 50.0 & 48.8 & 50.0 & 51.9 & 50.0 \\
PSNP & 46.9 & 41.7 & 49.4 & 50.0 & 47.7 & 50.0 & 50.9 & 50.0 \\
\hline Amhara & 40.3 & 33.3 & 46.2 & 41.7 & 43.4 & 41.7 & 45.1 & 41.7 \\
Oromia & 46.7 & 41.7 & 49.6 & 50.0 & 46.8 & 41.7 & 56.0 & 58.3 \\
SNNP & 53.2 & 50.0 & 55.2 & 58.3 & 55.9 & 58.3 & 52.2 & 50.0 \\
Tigray & 52.9 & 50.0 & 50.6 & 50.0 & 47.4 & 50.0 & 53.0 & 50.0 \\
\hline
\end{tabular}

Source: Authors' compilation.

Note: March rounds only. Sample used is mothers whose index child is 6 to 23 months of age

Score is calculated as the percentage of correct responses to the questions about complementary feeding practices listed in Table 6.5 .

We also studied how the score varies by mother's age and level of education. First, as noted, maternal education levels are extremely low in this context - more than $\mathbf{8 0}$ percent of mothers have

${ }^{14}$ This four percentage point difference is statistically different from zero $(p=0.011)$. 
no schooling and only about 5 percent of the mothers have completed primary school (see Chapter 3). Figure 6.2 reveals that there are little differences in knowledge score across mother's age. Figure 6.3 displays the relationship with mother's level of education. We see that the knowledge score increases with the level of education, but very slowly. The low levels of formal education mean that gaining nutrition knowledge outside the classroom - for example from Health Extension Workers or media - becomes important (Thomas, Strauss, and Henriques 1991; Glewwe 1999; Block 2004, 2007; Hirvonen et al. 2017).

Figure 6.2. Relationship between complementary feeding knowledge score and mother's age

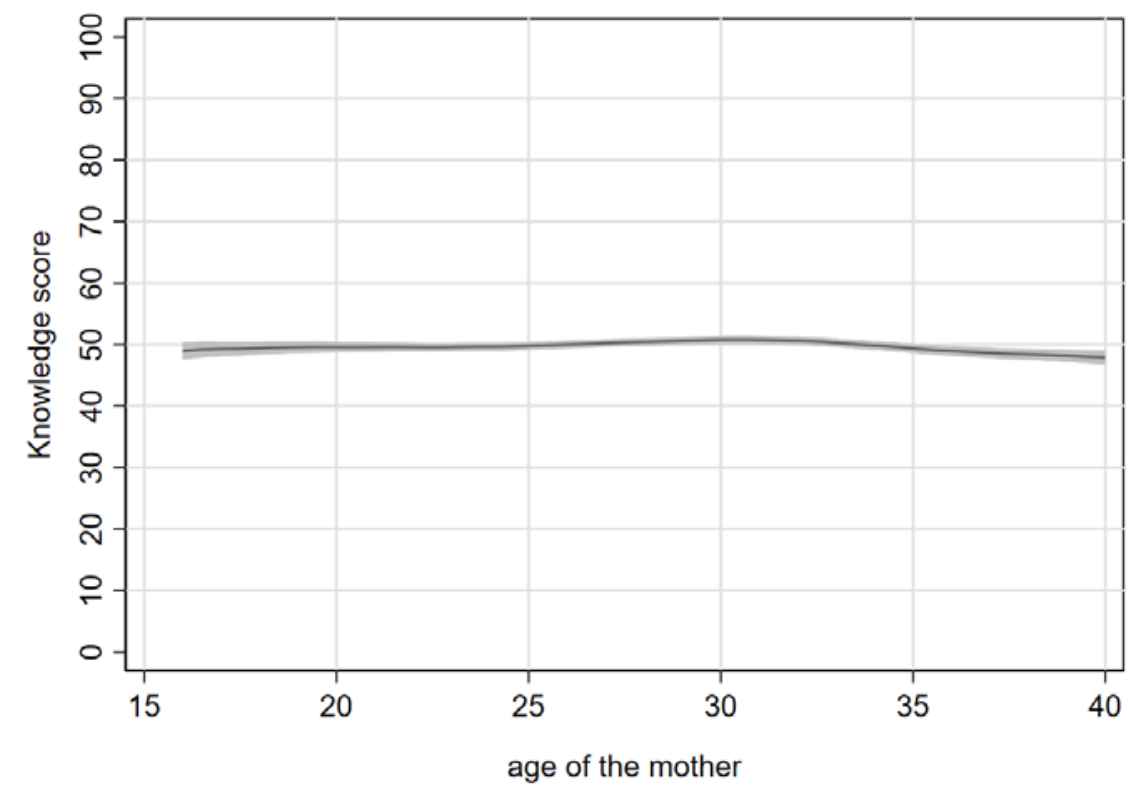

Source: Authors' compilation.

Note: March rounds only. Sample used is mothers whose index child is 6 to 23 months of age

Local polynomial regression. The shaded area represent 95-\% confidence interval. Source: all survey rounds.

Figure 6.3. Relationship between complementary feeding knowledge score mother's level of education

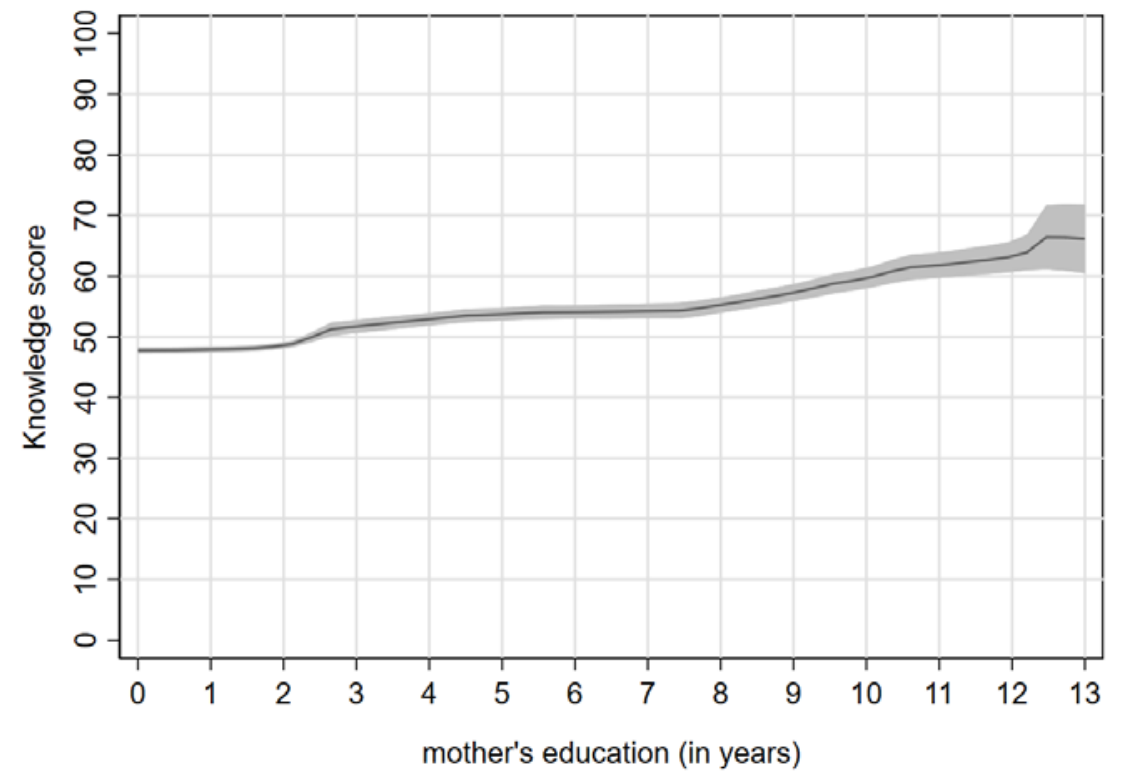

Source: Authors' compilation.

Note: March rounds only. Sample used is mothers whose index child is 6 to 23 months of age

Local polynomial regression. The shaded area represent 95-\% confidence interval. Source: all survey rounds. 


\subsection{Infant and young child feeding practices}

The sample used in this sub-chapter is made up of index children age 6 to 23 months unless otherwise stated. The child feeding practices examined are those described under the $\mathrm{WHO}-$ recommended IYCF indicators, which are widely accepted and used to capture optimal feeding practices in populations (WHO 2010). Optimal IYCF practices captured by these indicators cover a range of practices along with criteria to assess the adequacy of those practices. This includes ageappropriate breastfeeding practices around timing, duration, and exclusivity and timely and adequate consumption of high quality complementary foods. The eight core IYCF indicators are calculated using WHO guidelines (Appendix D). Depending on the indicator, we also consider index children less than 6 months of age in this analysis.

Figure 6.4 presents the first four WHO indicators related to appropriate breastfeeding practices and timely introduction of complementary foods for children residing in PSNP households in March 2017 and March 2019. Prevalence of recommended breastfeeding practices were generally high in both rounds. More than 70 percent of the children were put to the breast within one hour of birth and were exclusive breastfed at 6 months of age. ${ }^{15}$ Nearly all children 12 to 15 months of age received breast milk during the previous day. ${ }^{16}$ However, initiation of complementary feeding practices were often delayed. About 54 percent of children 6 to 8 months of age were given complementary foods (solid, semi-solid, or soft food) in 2017 and 64 percent in 2019. ${ }^{17}$ As seen in Table 6.7, the differences in these indicators among PSNP and non-PSNP households are marginal. Table 6.8 breaks these data further by region.

Figure 6.4. Prevalence of age-appropriate breastfeeding practices and introduction of complementary feeding, PSNP households

\section{Early initiation of breastfeeding}

Exclusive breastfeeding at 6 months

Continued breastfeeding at 1 year

Introduction of (semi) solid or soft foods

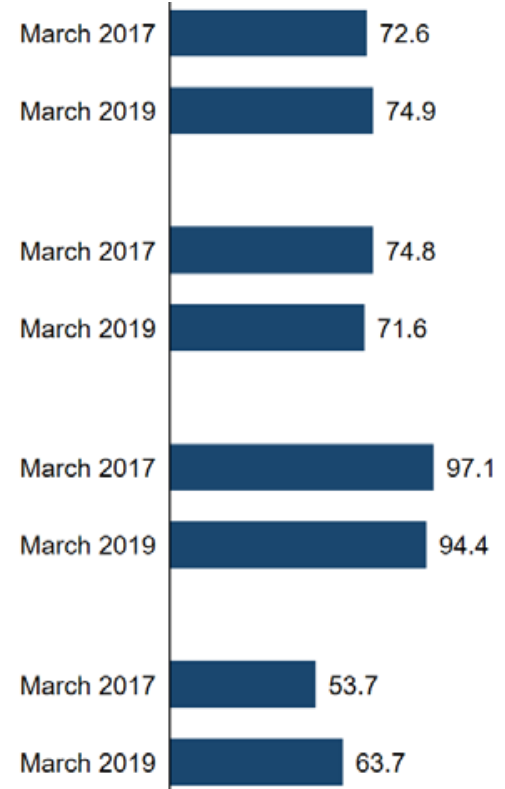

Source: Authors' compilation.

Note: March rounds only. Sample used is mothers whose index child is 6 to 23 months of age

Age group for 'early initiation of breastfeeding' is 0 to 23.9 months, for 'exclusive breastfeeding at 6 months 0 to 5.9 months, for 'continued breastfeeding at 1 year' 12 to 15.9 months; and 'introduction of (semi) solid or soft foods' 6 to 8.9 months.

\footnotetext{
${ }^{15}$ The reported differences between March 2017 and 2019 rounds in 'early initiation of breastfeeding' and 'exclusive breastfeeding at 6 months' are not statistically different from zero $(p=0.232 \& p=0.363)$.

${ }^{16}$ The difference between March 2017 and 2019 rounds is not statistically different from zero $(p=0.161)$.

${ }^{17}$ This difference between March 2017 and 2019 rounds is statistically different from zero $(p=0.045)$.
} 
Table 6.7. WHO recommended IYCF indicators related to breastfeeding and introduction of complementary feeding, by year and by PSNP status

\begin{tabular}{|c|c|c|c|c|c|c|c|c|}
\hline \multirow{4}{*}{ Age group, months } & \multirow{2}{*}{\multicolumn{2}{|c|}{$\begin{array}{c}\text { Early initiation } \\
\text { of } \\
\text { breastfeeding } \\
0-23.9\end{array}$}} & \multirow{2}{*}{\multicolumn{2}{|c|}{$\begin{array}{c}\text { Exclusive } \\
\text { breastfeeding } \\
\text { at } 6 \text { months } \\
0-5.9\end{array}$}} & \multirow{2}{*}{\multicolumn{2}{|c|}{$\begin{array}{c}\text { Continued } \\
\text { breastfeeding } \\
\text { at } 1 \text { year } \\
12-15.9\end{array}$}} & \multirow{2}{*}{\multicolumn{2}{|c|}{$\begin{array}{c}\text { Introduction } \\
\text { of (semi) solid } \\
\text { or soft foods } \\
6-8.9\end{array}$}} \\
\hline & & & & & & & & \\
\hline & \multicolumn{6}{|c|}{ March 2017} & \multirow[b]{2}{*}{$\mathbf{N}$} & \multirow[b]{2}{*}{$\%$} \\
\hline & $\mathbf{N}$ & $\%$ & $\mathbf{N}$ & $\%$ & $\mathbf{N}$ & $\%$ & & \\
\hline Non-PSNP & 1,577 & 72.7 & 437 & 76.2 & 329 & 95.4 & 285 & 54.4 \\
\hline PSNP & 1,058 & 72.6 & 306 & 74.8 & 242 & 97.1 & 190 & 53.7 \\
\hline All & 2,635 & 72.7 & 743 & 75.6 & 571 & 96.1 & 475 & 54.1 \\
\hline \multicolumn{9}{|c|}{ March 2019} \\
\hline & $\mathbf{N}$ & $\%$ & $\mathbf{N}$ & $\%$ & $\mathbf{N}$ & $\%$ & $\mathbf{N}$ & $\%$ \\
\hline Non-PSNP & 1,540 & 73.7 & 503 & 72.0 & 344 & 98.3 & 275 & 60.0 \\
\hline PSNP & 1,086 & 74.9 & 335 & 71.6 & 198 & 94.4 & 201 & 63.7 \\
\hline All & 2,626 & 74.2 & 838 & 71.8 & 542 & 96.9 & 476 & 61.6 \\
\hline
\end{tabular}

Source: Authors' compilation.

Note: March rounds only. Sample used is mothers whose index child is 6 to 23 months of age

See Appendix D for detailed description of the IYCF indicators. IYCF = Infant and young child feeding.

Table 6.8. WHO recommended IYCF indicators related to breastfeeding and introduction of complementary feeding, by year and by region

\begin{tabular}{|c|c|c|c|c|c|c|c|c|}
\hline \multirow{4}{*}{ Age group, months } & \multicolumn{2}{|c|}{$\begin{array}{l}\text { Early initiation } \\
\text { of } \\
\text { breastfeeding }\end{array}$} & \multirow{2}{*}{\multicolumn{2}{|c|}{$\begin{array}{c}\text { Exclusive } \\
\text { breastfeeding } \\
\text { at } 6 \text { months } \\
0-5.9\end{array}$}} & \multirow{2}{*}{\multicolumn{2}{|c|}{$\begin{array}{c}\text { Continued } \\
\text { breastfeeding } \\
\text { at } 1 \text { year } \\
12-15.9\end{array}$}} & \multirow{2}{*}{\multicolumn{2}{|c|}{$\begin{array}{c}\text { Introduction } \\
\text { of (semi) solid } \\
\text { or soft foods } \\
6-8.9\end{array}$}} \\
\hline & \multicolumn{2}{|c|}{ 0-23.9 } & & & & & & \\
\hline & \multicolumn{4}{|c|}{ March 2017} & \multirow[b]{2}{*}{$\mathbf{N}$} & \multirow[b]{2}{*}{$\%$} & \multirow[b]{2}{*}{$\mathbf{N}$} & \multirow[b]{2}{*}{$\%$} \\
\hline & $\mathbf{N}$ & $\%$ & $\mathbf{N}$ & $\%$ & & & & \\
\hline Amhara & 661 & 74.4 & 201 & 81.1 & 137 & 98.5 & 95 & 54.7 \\
\hline Oromia & 652 & 73.8 & 182 & 72.0 & 127 & 90.6 & 144 & 62.5 \\
\hline SNNP & 662 & 73.1 & 186 & 71.0 & 142 & 97.9 & 114 & 47.4 \\
\hline Tigray & 660 & 69.4 & 174 & 78.2 & 165 & 97.0 & 122 & 50.0 \\
\hline \multirow[t]{3}{*}{ All } & 2,635 & 72.7 & 743 & 75.6 & 571 & 96.1 & 475 & 54.1 \\
\hline & \multicolumn{5}{|c|}{ March 2019} & \multirow[b]{2}{*}{$\%$} & \multirow[b]{2}{*}{$\mathbf{N}$} & \multirow[b]{2}{*}{$\%$} \\
\hline & $\mathbf{N}$ & $\%$ & $\mathbf{N}$ & $\%$ & $\mathbf{N}$ & & & \\
\hline Amhara & 666 & 74.8 & 195 & 80.0 & 128 & 98.4 & 101 & 58.4 \\
\hline Oromia & 650 & 72.6 & 237 & 67.1 & 143 & 93.0 & 124 & 63.7 \\
\hline SNNP & 650 & 72.9 & 219 & 68.5 & 120 & 97.5 & 144 & 65.3 \\
\hline Tigray & 660 & 76.4 & 187 & 73.3 & 151 & 98.7 & 107 & 57.0 \\
\hline All & 2,626 & 74.2 & 838 & 71.8 & 542 & 96.9 & 476 & 61.6 \\
\hline
\end{tabular}

Source: Authors' compilation.

Note: March rounds only. Sample used is mothers whose index child is 6 to 23 months of age

See Appendix D for detailed description of the IYCF indicators. IYCF = Infant and young child feeding.

Next, we look at IYCF indicators related to adequate consumption of high quality complementary foods. Figure 6.5 shows the prevalence of age-appropriate complementary feeding practices among children residing in PSNP households. As documented in earlier work in Ethiopia (Golan et al. 2019), only a few children received the minimum dietary diversity of four 4 food groups out of seven. In March 2017, only 2.7 percent of PSNP children aged 6 to 23 months met the criteria for minimum dietary diversity, while in August 2017, this rose to 5.0 percent. ${ }^{18}$ In March 2019, 4.7 percent of PSNP children met the minimum dietary diversity criteria and this increased to 5.8 percent in August 2019. ${ }^{19}$ Similarly, the prevalence of children meeting the minimum meal frequency increased from

\footnotetext{
${ }^{18}$ This difference is statistically different from zero $(p=0.027)$.

19 This difference is not statistically different from zero $(p=0.313)$.
} 
37 percent in March 2017 to 47 percent in August 2017. ${ }^{20}$ In March 2019, 50.5 percent of PSNP children met the minimum meal frequency and this rose to 53.7 percent in August $2019 .{ }^{21}$ The share of children meeting their minimum acceptable diet increased only marginally from 1.9 percent in March 2017 to 3.1 percent in August 2017. ${ }^{22}$ The corresponding percentages were somewhat higher in 2019, and again we see positive trends between March and August rounds. ${ }^{23}$

Figure 6.5. Prevalence of age-appropriate complementary feeding practices, PSNP households

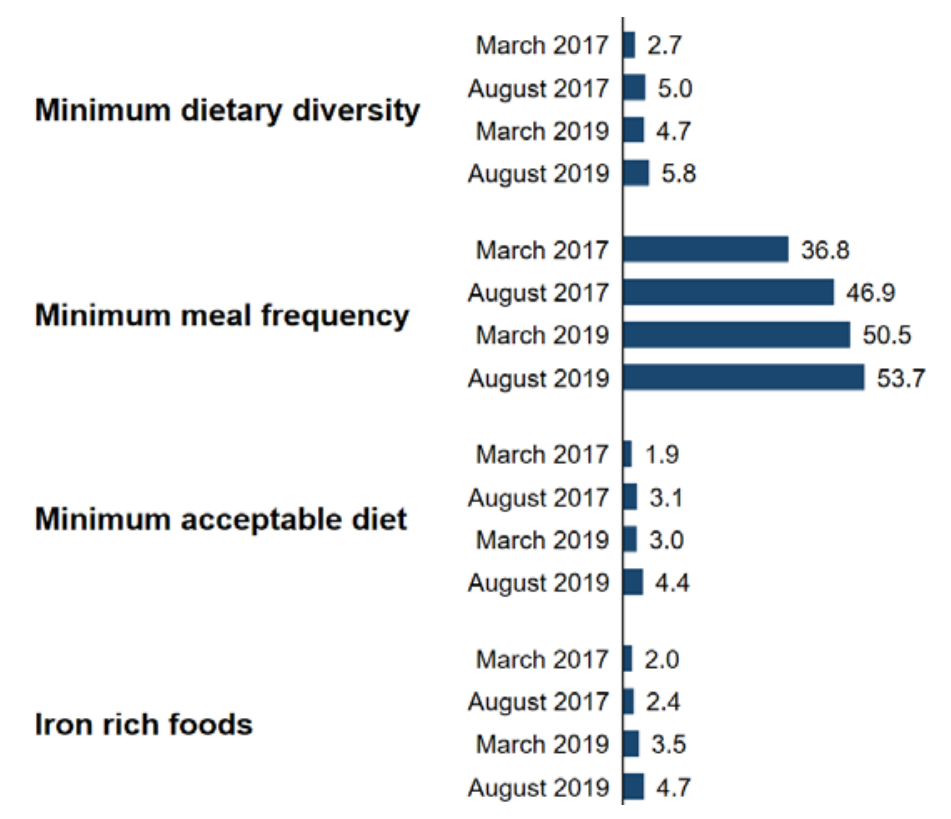

Source: Authors' compilation.

Note: For all indicators, the sample is restricted to children age 6 to 23.9 months residing in PSNP households.

The consumption of iron-rich food in children was less than 5 percent in all survey rounds with marginal improvement over time. ${ }^{24}$ The differences in these IYCF indicators among PSNP and nonPSNP households (Table 6.9) are marginal, except for the minimum dietary diversity and minimum meal frequency for which the prevalence were somewhat higher in non-PSNP households when compared to PSNP households. Table 6.10 breaks these statistics further by region.

\footnotetext{
${ }^{20}$ This difference is statistically different from zero $(p=0.000)$.

${ }^{21}$ This difference is not statistically different from zero $(p=0.288)$.

${ }^{22}$ This difference is not statistically different from zero $(p=0.175)$.

${ }^{23}$ This difference in 2019 rounds is not statistically different from zero $(p=0.152)$.

${ }^{24}$ The difference between the March and August rounds in 2017 is not statistically significant $(p=0.679)$ and the same applies to the two rounds in $2019(p=0.311)$.
} 
Table 6.9. WHO recommended IYCF indicators related to quality and quantity of complementary feeding, by PSNP status

\begin{tabular}{|c|c|c|c|c|c|c|c|c|}
\hline & \multicolumn{2}{|c|}{$\begin{array}{l}\text { Minimum dietary } \\
\text { diversity }\end{array}$} & \multicolumn{2}{|c|}{$\begin{array}{c}\text { Minimum meal } \\
\text { frequency } \\
\text { March } 2017\end{array}$} & \multicolumn{2}{|c|}{$\begin{array}{c}\text { Minimum } \\
\text { acceptable diet }\end{array}$} & \multicolumn{2}{|c|}{$\begin{array}{l}\text { Consumption of } \\
\text { iron-rich foods }\end{array}$} \\
\hline & $\mathbf{N}$ & $\%$ & $\mathbf{N}$ & $\%$ & $\mathbf{N}$ & $\%$ & $\mathbf{N}$ & $\%$ \\
\hline Non-PSNP & 1,192 & 2.8 & 1,192 & 38.4 & 1,192 & 1.1 & 1,192 & 2.3 \\
\hline PSNP & 788 & 2.7 & 788 & 36.8 & 788 & 1.9 & 788 & 2.0 \\
\hline All & 1,980 & 2.7 & 1,980 & 37.8 & 1,980 & 1.4 & 1,980 & 2.2 \\
\hline \multicolumn{9}{|c|}{ August 2017} \\
\hline & $\mathbf{N}$ & $\%$ & $\mathbf{N}$ & $\%$ & $\mathbf{N}$ & $\%$ & $\mathbf{N}$ & $\%$ \\
\hline Non-PSNP & 1,195 & 6.4 & 1,191 & 51.0 & 1,195 & 4.3 & 1,192 & 2.2 \\
\hline PSNP & 765 & 5.0 & 761 & 46.9 & 765 & 3.1 & 761 & 2.4 \\
\hline All & 1,960 & 5.9 & 1,952 & 49.4 & 1,960 & 3.8 & 1,953 & 2.3 \\
\hline \multicolumn{9}{|c|}{ March 2019} \\
\hline & $\mathbf{N}$ & $\%$ & $\mathbf{N}$ & $\%$ & $\mathbf{N}$ & $\%$ & $\mathbf{N}$ & $\%$ \\
\hline Non-PSNP & 1,106 & 6.1 & 1,106 & 49.6 & 1,106 & 4.6 & 1,106 & 4.4 \\
\hline PSNP & 792 & 4.7 & 792 & 50.5 & 792 & 3.0 & 792 & 3.5 \\
\hline All & 1,898 & 5.5 & 1,898 & 50.0 & 1,898 & 4.0 & 1,898 & 4.1 \\
\hline \multicolumn{9}{|c|}{ August 2019} \\
\hline & $\mathbf{N}$ & $\%$ & $\mathbf{N}$ & $\%$ & $\mathbf{N}$ & $\%$ & $\mathbf{N}$ & $\%$ \\
\hline Non-PSNP & 1,196 & 7.9 & 1,196 & 56.5 & 1,196 & 6.1 & 1,196 & 4.0 \\
\hline PSNP & 814 & 5.8 & 814 & 53.7 & 814 & 4.4 & 814 & 4.7 \\
\hline All & 2,010 & 7.1 & 2,010 & 55.4 & 2,010 & 5.4 & 2,010 & 4.3 \\
\hline
\end{tabular}

Source: Authors' compilation.

Note: For all indicators, the sample is restricted to children age 6 to 23.9 months.

See Appendix D for detailed description of the IYCF indicators. IYCF = Infant and young child feeding.

This analysis shows that dietary diversity is particularly poor among young children and is the main reason the prevalence of children achieving their minimum acceptable diet is low. This finding prompts us to conduct further analysis on children's diets. 
Table 6.10. WHO recommended IYCF indicators related to quality and quantity of complementary feeding, by region

\begin{tabular}{|c|c|c|c|c|c|c|c|c|}
\hline & \multicolumn{2}{|c|}{$\begin{array}{l}\text { Minimum dietary } \\
\text { diversity }\end{array}$} & \multicolumn{2}{|c|}{$\begin{array}{c}\text { Minimum meal } \\
\text { frequency } \\
\text { March } 2017\end{array}$} & \multicolumn{2}{|c|}{$\begin{array}{c}\text { Minimum } \\
\text { acceptable diet }\end{array}$} & \multicolumn{2}{|c|}{$\begin{array}{l}\text { Consumption of } \\
\text { iron-rich foods }\end{array}$} \\
\hline & $\mathbf{N}$ & $\%$ & $\mathbf{N}$ & $\%$ & $\mathbf{N}$ & $\%$ & $\mathbf{N}$ & $\%$ \\
\hline Amhara & 478 & 2.1 & 478 & 42.7 & 478 & 1.3 & 478 & 1.9 \\
\hline Oromia & 488 & 1.2 & 488 & 38.5 & 488 & 0.4 & 488 & 1.8 \\
\hline SNNP & 494 & 3.6 & 494 & 47.6 & 494 & 2.8 & 494 & 2.0 \\
\hline Tigray & 520 & 3.8 & 520 & 23.3 & 520 & 1.2 & 520 & 3.1 \\
\hline All & 1,980 & 2.7 & 1,980 & 37.8 & 1,980 & 1.4 & 1,980 & 2.2 \\
\hline \multicolumn{9}{|c|}{ August 2017} \\
\hline & $\mathbf{N}$ & $\%$ & $\mathbf{N}$ & $\%$ & $\mathbf{N}$ & $\%$ & $\mathbf{N}$ & $\%$ \\
\hline Amhara & 467 & 4.9 & 463 & 55.7 & 467 & 3.9 & 463 & 1.5 \\
\hline Oromia & 510 & 7.1 & 507 & 59.6 & 510 & 5.5 & 507 & 0.6 \\
\hline SNNP & 486 & 3.9 & 483 & 50.7 & 486 & 3.1 & 484 & 1.4 \\
\hline Tigray & 499 & 7.4 & 499 & 32.1 & 499 & 2.8 & 499 & 5.4 \\
\hline All & 1,962 & 5.9 & 1,952 & 49.4 & 1,962 & 3.8 & 1,953 & 2.3 \\
\hline \multicolumn{9}{|c|}{ March 2019} \\
\hline & $\mathbf{N}$ & $\%$ & $\mathbf{N}$ & $\%$ & $\mathbf{N}$ & $\%$ & $\mathbf{N}$ & $\%$ \\
\hline Amhara & 494 & 8.1 & 494 & 51.4 & 494 & 6.7 & 494 & 3.6 \\
\hline Oromia & 453 & 4.0 & 453 & 53.0 & 453 & 2.6 & 453 & 2.0 \\
\hline SNNP & 457 & 5.0 & 457 & 55.6 & 457 & 3.9 & 457 & 4.2 \\
\hline Tigray & 494 & 4.7 & 494 & 40.7 & 494 & 2.4 & 494 & 6.3 \\
\hline All & 1,898 & 5.5 & 1,898 & 50.0 & 1,898 & 4.0 & 1,898 & 4.1 \\
\hline \multicolumn{9}{|c|}{ August 2019} \\
\hline & $\mathbf{N}$ & $\%$ & $\mathbf{N}$ & $\%$ & $\mathbf{N}$ & $\%$ & $\mathbf{N}$ & $\%$ \\
\hline Amhara & 480 & 7.5 & 480 & 55.8 & 480 & 6.5 & 480 & 3.8 \\
\hline Oromia & 520 & 5.2 & 520 & 62.3 & 520 & 4.6 & 520 & 1.5 \\
\hline SNNP & 504 & 7.7 & 504 & 58.3 & 504 & 6.0 & 504 & 5.6 \\
\hline Tigray & 506 & 7.9 & 506 & 44.9 & 506 & 4.7 & 506 & 6.3 \\
\hline All & 2,010 & 7.1 & 2,010 & 55.4 & 2,010 & 5.4 & 2,010 & 4.3 \\
\hline
\end{tabular}

Source: Authors' compilation.

Note: For all indicators, the sample is restricted to children age 6 to 23.9 months.

See Appendix D for detailed description of the IYCF indicators. IYCF = Infant and young child feeding.

Figure 6.6 shows how dietary diversity varied by age in 2017. We see that dietary diversity increases slowly but steadily as the children age. Compared to the March survey round, the dietary diversity score was higher in all age groups in August. Figure 6.7 displays the corresponding relationship in 2019. As before, dietary diversity is higher among older children, but only marginally. In 2019, the difference in the dietary diversity score between the March and August surveys is negligible. 
Figure 6.6. Dietary diversity and child age in 2017 , by survey round

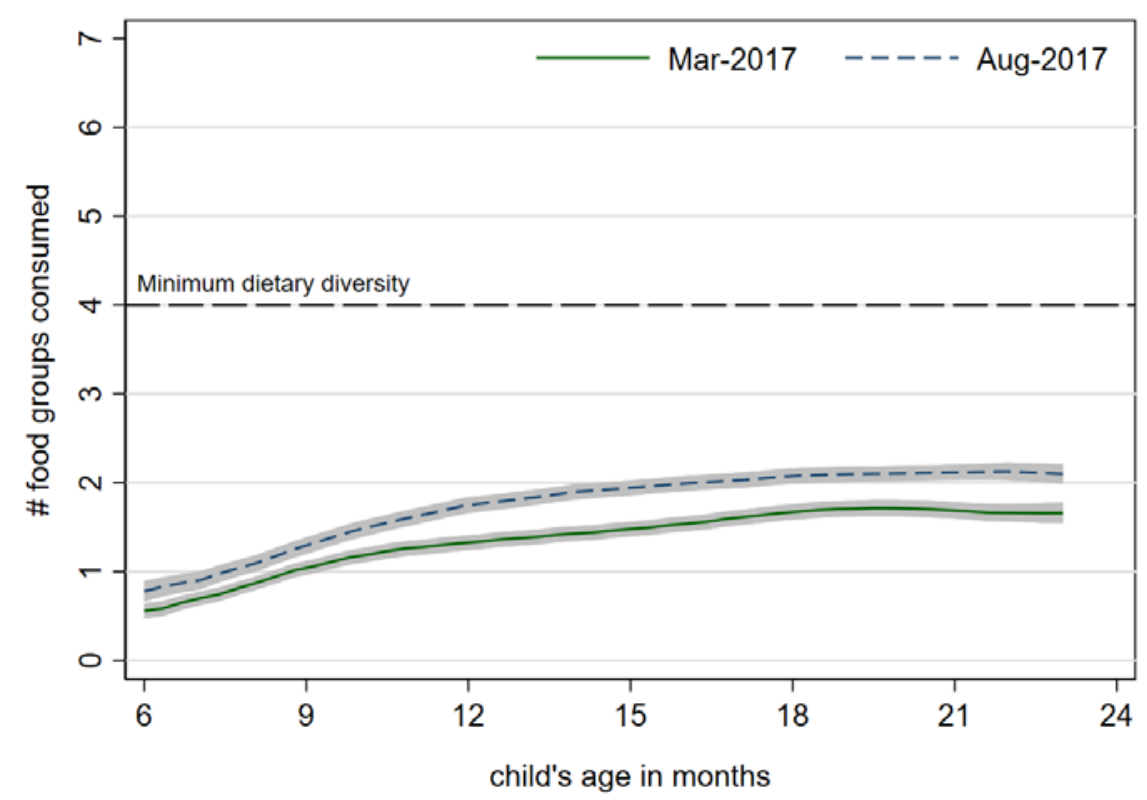

Source: Authors' compilation.

Note: For all indicators, the sample is restricted to children age 6 to 23.9 months.

Local polynomial regression. The shaded area represent $95-\%$ confidence interval. The dashed horizontal line marks the threshold for minimum dietary diversity (4 food groups out of 7 ).

\section{Figure 6.7. Dietary diversity and child age in 2019 , by survey round}

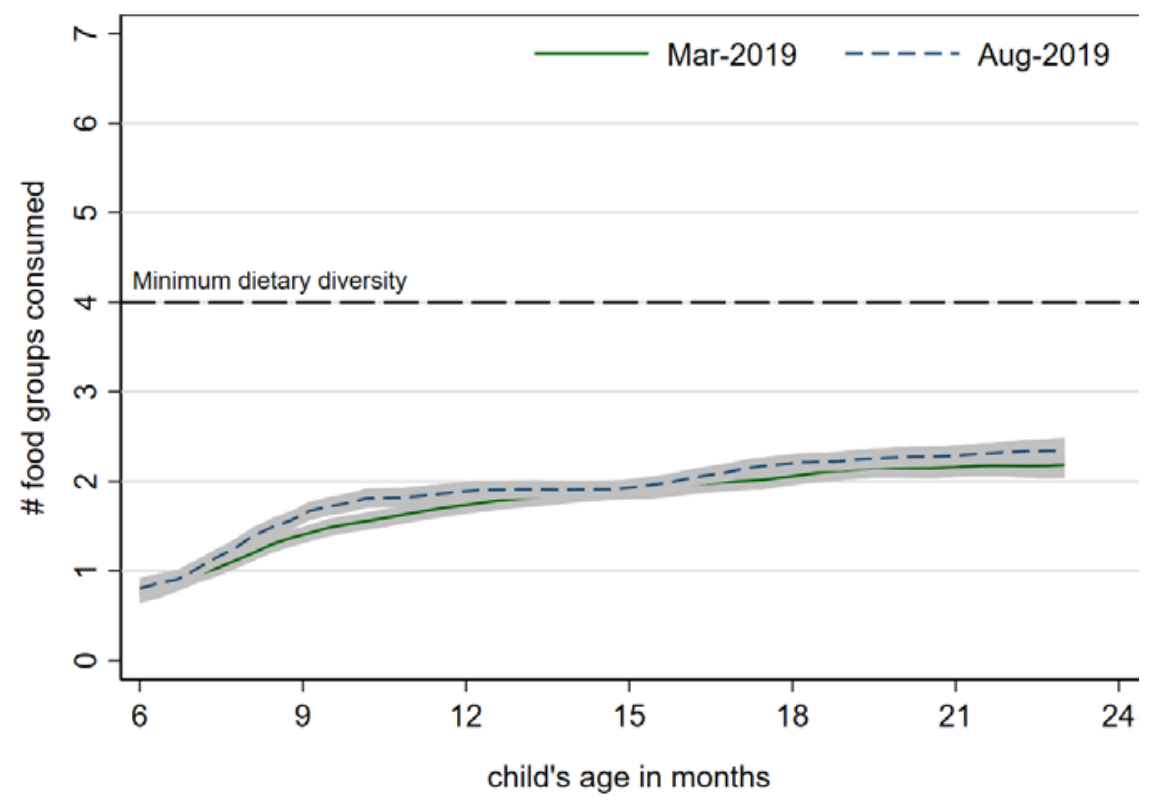

Source: Authors' compilation.

Note: For all indicators, the sample is restricted to children age 6 to 23.9 months.

Local polynomial regression. The shaded area represent 95-\% confidence interval. The dashed horizontal line marks the threshold for minimum dietary diversity (4 food groups out of 7 ).

Table 6.11 shows the number of food groups consumed by children aged 6 to 23.9 months of age by different age groups in PSNP and non-PSNP households. Because of the delay in the introduction of complementary foods (see Table 6.7), the mean number of food groups consumed by children age 6 to11 months is close to 1.0, indicating that many children in this age group were still exclusively breastfed and, thus, did not yet consume from any of the seven food groups. 
Table 6.11. Number of food groups consumed in the past 24 hours among index children, by age group and PSNP status

\begin{tabular}{|c|c|c|c|}
\hline & 6-23 months & 6-11 months & $12-23$ months \\
\hline \multicolumn{4}{|c|}{ March 2017} \\
\hline Non-PSNP & 1.1 & 0.9 & 1.6 \\
\hline PSNP & 1.0 & 0.9 & 1.5 \\
\hline All & 1.0 & 0.9 & 1.6 \\
\hline \multicolumn{4}{|c|}{ August 2017} \\
\hline Non-PSNP & 1.8 & 1.2 & 2.1 \\
\hline PSNP & 1.7 & 1.1 & 2.0 \\
\hline All & 1.8 & 1.2 & 2.0 \\
\hline \multicolumn{4}{|c|}{ March 2019} \\
\hline Non-PSNP & 1.3 & 1.3 & 2.0 \\
\hline PSNP & 1.2 & 1.2 & 1.9 \\
\hline All & 1.3 & 1.2 & 2.0 \\
\hline \multicolumn{4}{|c|}{ August 2019} \\
\hline Non-PSNP & 2.0 & 1.5 & 2.2 \\
\hline PSNP & 1.8 & 1.3 & 2.0 \\
\hline All & 1.9 & 1.4 & 2.1 \\
\hline
\end{tabular}

Source: Authors' compilation.

Note: The sample is restricted to children age 6 to 23.9 months.

Figure 6.8. shows the full distribution of the dietary diversity score in August 2019 among children aged 6 to 23 months of age who originate from PSNP households. Most children in PSNP households are far from meeting the recommended dietary diversity of four food groups.

Figure 6.8. Distribution of children's dietary diversity scores in August 2019, PSNP households

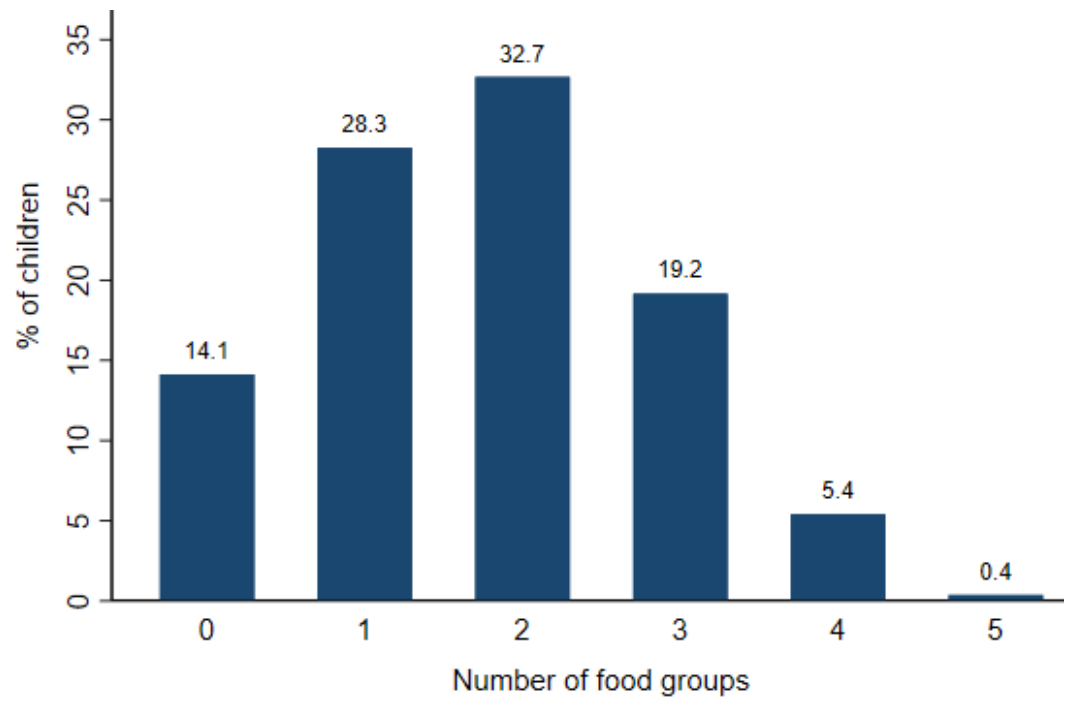

Source: Authors' compilation.

Note: The sample is restricted to children age 6 to 23.9 months.

Starting from the bottom part of the distribution, we see that 14 percent of the children did not consume from any food group in the previous 24 hours. About 28 percent of the children in August 2019 consumed only from one food group. For these children, their dietary diversity would have to increase by three food groups in order to meet the minimum recommended dietary diversity. About one-third were two food groups shy from meeting the recommendation, while 19 percent of the children were missing just one food group. The remaining 5.8 percent consumed from four or five food groups, but none consumed from six or seven food groups. 
As the share of children with a dietary diversity score of zero is high, we highlight two things.

- The nationally and regionally representative DHS survey shows similarly high percentages in this regard. According to the DHS, about 24 percent of children aged 6 to 23 months in Amhara region did not consume from any of the seven food groups in the past 24 hours, 17 percent in Oromia, 28 percent in SNNP and 15 percent in Tigray.

- In Figure 6.9 we regress the percent of children not consuming from any food groups against their age. We see that the percentage is very high, at between 40 and 50 percent, among children 6 to 8 months of age. The share of children not consuming from any food groups gradually declines as the children age. This strongly suggest that the initiation of complementary foods is delayed for many children in this context. This finding is in line with the analysis carried out in Section 6.2 where we found widespread misconceptions about the optimal age at which to begin complementary feeding.

Figure 6.9. Percent of children consuming zero food groups and child's age, PSNP households in August 2019

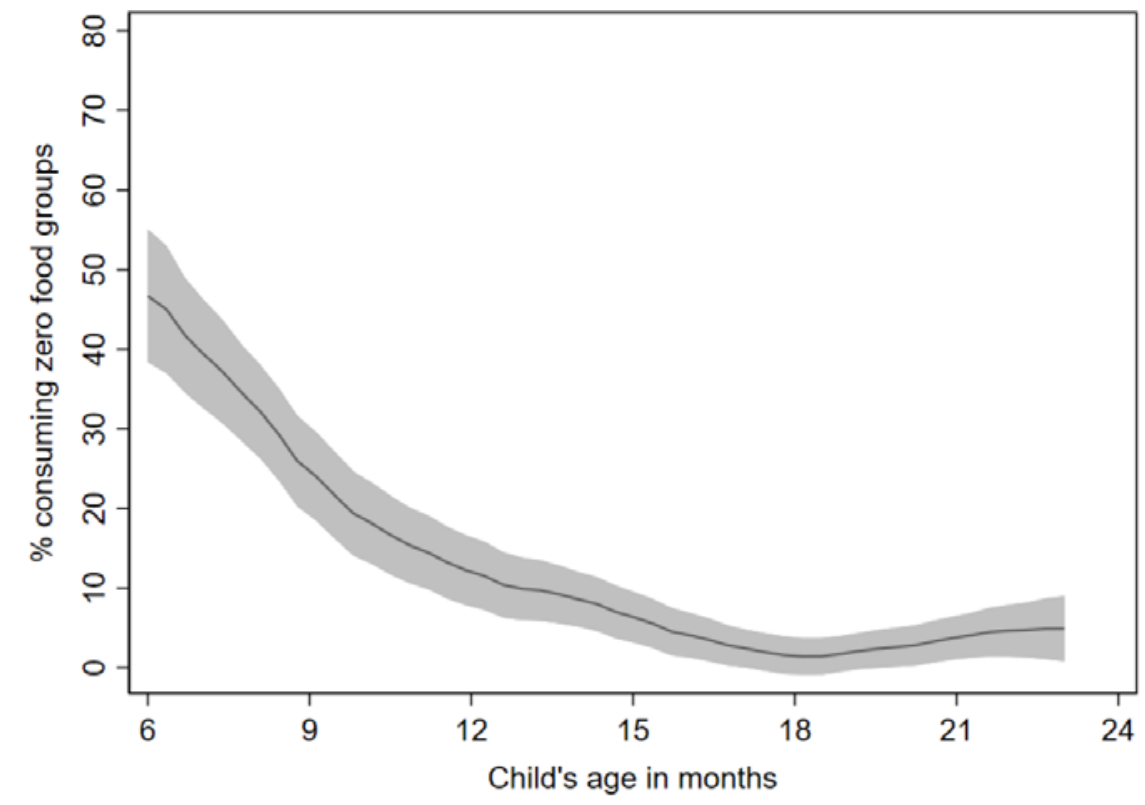

Source: Authors' compilation.

Note: The sample is restricted to children age 6 to 23.9 months.

Local polynomial regression. The shaded area represent 95-\% confidence interval.

Among the seven food groups, the grains, roots, and tubers food group were the single most consumed food group among index children originating from PSNP households in all survey rounds (Figure 6.10). About 76 percent of children ages 6 to 23 months consumed grains, roots, and tubers in March and nearly 80 percent in August. However, the remaining six food groups were consumed at much lower levels, particularly flesh foods (organ meats, meat, poultry, and fish) and eggs, at 6 percent or less. As for seasonal patterns, we see that dairy consumption increased in both years from March to August, possibly because the March round coincided with the Orthodox fasting season (Lent), during which Orthodox Christians abstain from consuming animal source foods. ${ }^{25}$ The August survey round also partly coincided with a two-week fasting period. We also see some increase in the prevalence of children consuming fruits and vegetables in the August rounds.

${ }^{25}$ While young children are typically exempted from fasting, the fasting period is likely to affect the availability of animal source foods in the households and food markets (Kim et al. 2018). 
Figure 6.10. Intake of seven food groups in the past 24 hours among index children age 6 to 23 months in PSNP households, by survey round

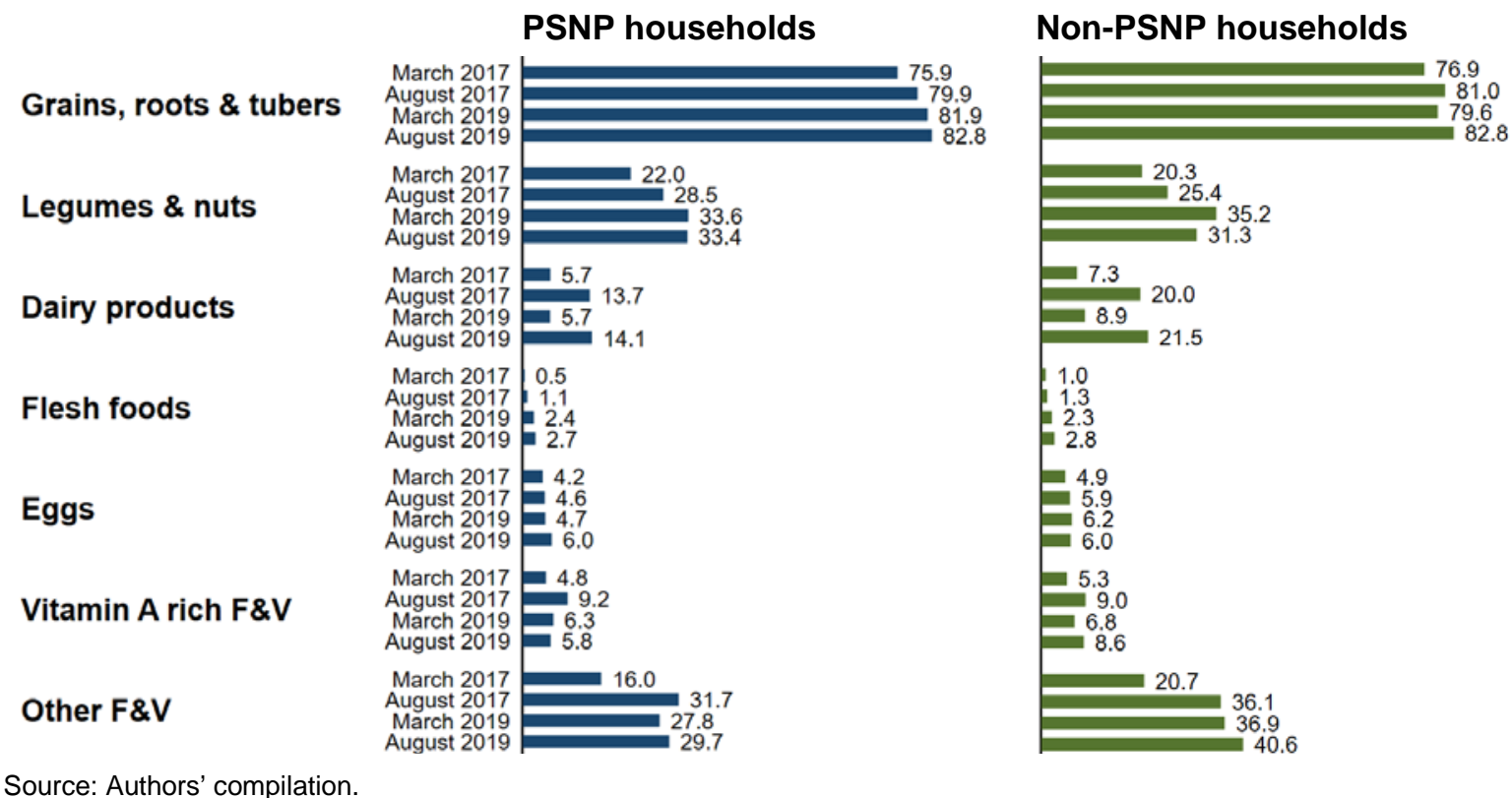

Note: The sample is restricted to children age 6 to 23.9 months.

The consumption patterns among children residing in non-PSNP households are nearly identical to those residing in PSNP households, except children in non-PSNP households were more likely to have consumed from the dairy and the fruit \& vegetables food groups in all survey rounds.

In Table 6.12, we specifically look at the consumption animal source foods - dairy products, flesh foods, and eggs. We see considerable seasonality in consumption patterns. Between 12 and 14 percent of all index children 6 to 23 months of age consumed animal source foods in the previous day in the March rounds. This increased to between 23 and 24 percent in the August rounds. In all survey rounds, the share is somewhat higher among non-PSNP households compared to PSNP households. We also see that children in Amhara are least likely to consume animal source foods compared to children in other regions. In the last two rows, we compare these shares among children originating from Orthodox households to other households (mostly Muslim and Protestant). In both survey rounds, children in non-Orthodox households were more likely to have consumed animal source foods in the previous day than children in Orthodox households. However, even among non-Orthodox children, the prevalence increases from March to August.

Table 6.12. Percent of children consuming animal source foods by round, PSNP status, region, and household religion

\begin{tabular}{lcccc} 
& March 2017 & August 2017 & March 2019 & August 2019 \\
& $\%$ & $\%$ & $\%$ & $\%$ \\
\hline Full sample & 11.6 & 22.7 & 14.3 & 24.2 \\
\hline Non-PSNP & 12.7 & 25.3 & 15.9 & 27.0 \\
PSNP & 10.0 & 18.5 & 12.1 & 20.1 \\
\hline Amhara & 6.5 & 9.5 & 10.5 & 12.1 \\
Oromia & 12.7 & 33.3 & 12.8 & 28.1 \\
SNNP & 15.6 & 28.1 & 18.8 & 37.3 \\
Tigray & 11.5 & 18.8 & 15.4 & 18.8 \\
\hline Orthodox & 9.4 & 15.2 & 12.2 & 17.6 \\
Non-Orthodox & 13.7 & 29.6 & 16.4 & 30.2 \\
\hline
\end{tabular}

Source: Authors' compilation.

Note: The sample is restricted to children age 6 to 23.9 months. 
Finally, UNICEF (2019) now recommends that breastmilk is included as an additional food group when the dietary diversity score is calculated. Table 6.13 reports the dietary diversity score based on eight food groups instead of seven. We also re-calculated the prevalence of children meeting the minimum dietary diversity and minimum acceptable diet based on this indicator. As more than 90 percent of the children ages 6 to 23 months in our sample are breastfed, the dietary diversity score increases by approximately one food group. However, because of the adjustment of the number of recommended food groups from four to five to indicate a minimum acceptable diet, we do not see meaningful changes in the minimum dietary diversity and minimum acceptable diet prevalence.

Table 6.13. Dietary diversity score, minimum dietary diversity prevalence, and minimum acceptable diet prevalence based on eight food groups

\begin{tabular}{lcccccc} 
& \multicolumn{3}{c}{ March 2017} & & August 2017 \\
min-DDS & MAD & DDS & min-DD & MAD \\
All & 2.3 & $2.6 \%$ & $1.4 \%$ & 2.7 & $4.8 \%$ & $3.6 \%$ \\
Non-PSNP & 2.3 & $2.6 \%$ & $1.0 \%$ & 2.7 & $5.3 \%$ & $4.0 \%$ \\
PSNP & 2.2 & $2.5 \%$ & $1.9 \%$ & 2.6 & $4.2 \%$ & $3.0 \%$ \\
Amhara & 2.4 & $2.1 \%$ & $1.3 \%$ & 2.7 & $4.3 \%$ & $3.7 \%$ \\
Oromia & 2.0 & $1.2 \%$ & $0.4 \%$ & 2.7 & $6.3 \%$ & $5.3 \%$ \\
SNNP & 2.3 & $3.2 \%$ & $2.8 \%$ & 2.5 & $3.1 \%$ & $2.7 \%$ \\
Tigray & 2.4 & $3.7 \%$ & $1.0 \%$ & 2.7 & $5.6 \%$ & $2.8 \%$ \\
& & March 2019 & & & August 2019 & \\
All & DDS & min-DDS & MAD & DDS & min-DDS & MAD \\
Non-PSNP & 2.6 & $5.0 \%$ & $3.8 \%$ & 2.8 & $6.2 \%$ & $5.1 \%$ \\
PSNP & 2.7 & $5.7 \%$ & $4.3 \%$ & 2.9 & $7.1 \%$ & $5.9 \%$ \\
Amhara & 2.6 & $3.9 \%$ & $3.0 \%$ & 2.7 & $4.8 \%$ & $4.1 \%$ \\
Oromia & 2.9 & $7.3 \%$ & $6.5 \%$ & 2.8 & $7.3 \%$ & $6.5 \%$ \\
SNNP & 2.4 & $3.5 \%$ & $2.4 \%$ & 2.7 & $4.2 \%$ & $3.8 \%$ \\
Tigray & 2.6 & $5.0 \%$ & $3.9 \%$ & 2.8 & $6.5 \%$ & $5.6 \%$ \\
\hline
\end{tabular}

Source: Authors' compilation.

Note: The sample is restricted to children age 6 to 23.9 months.

$\mathrm{DDS}=$ Dietary diversity score $(\min =0, \max =8), \min -\mathrm{DDS}=$ minimum dietary diversity $(5$ food groups out of 8 ), and MAD = Minimum Acceptable Diet based on the revised min-DDS. 


\section{ACCESS TO THE PRODUCTIVE SAFETY NET PROGRAM}

In this chapter, we briefly describe access to PSNP by our study participants. We address three questions:

- How much work is undertaken under the program and by whom;

- How much payment do PSNP participants receive; and

- Are protocols regarding moving pregnant and lactating women from the Public Works component to the Direct Support component being followed?

\subsection{Work}

The survey instrument asks respondents to recall the number of days worked on PSNP each month between Tir (starts mid-January) and Nehasse (starts mid-August) in 2011 of the Ethiopian Calendar (EC) (2018/19 Gregorian calendar). These data are recorded at the individual level and, as much as possible, are taken from respondents' client cards.

We have data on days worked for 896 households. As Table 7.1 shows, across our full sample, the average PSNP household worked 76.7 days on PSNP over this eight month period. Mean days worked was highest in SNNP and lowest in Oromia. Days worked were roughly equal in Tigray and Amhara.

Table 7.1. Mean days worked on PSNP Public Works between Tir and Nehasse EC2011, by month and region

\begin{tabular}{lcccccccc|c|c} 
Region & January & February & March & April & May & June & July & August & \multicolumn{3}{c}{ Total } & $\begin{array}{c}\text { Sample } \\
\text { size }\end{array}$ \\
\hline Tigray & 11.2 & 10.7 & 12.6 & 12.7 & 12.4 & 11.1 & 7.3 & 2.2 & 80.3 & 228 \\
Amhara & 13.6 & 13.3 & 13.3 & 12.7 & 12.0 & 11.3 & 2.9 & 0.7 & 79.9 & 254 \\
Oromia & 8.7 & 8.4 & 8.4 & 8.1 & 7.8 & 6.8 & 1.9 & 0.8 & 50.8 & 196 \\
SNNP & 14.1 & 14.1 & 14.2 & 14.4 & 14.3 & 14.4 & 4.8 & 2.4 & 92.6 & 218 \\
\hline All & 12.0 & 11.8 & 12.3 & 12.1 & 11.7 & 11.0 & 4.3 & 1.5 & 76.7 & 896 \\
\hline
\end{tabular}

Source: Authors' compilation from household questionnaire, August 2019.

Note: In the Gregorian calendar, Tir starts mid-January and Nehasse starts mid-August.

Table 7.1 disaggregates mean days worked on PSNP Public Works by month and region. In SNNP, mean days worked on PSNP are virtually identical between Tir and Sene (starts mid-June) between 14.1 and 14.4 days each month. Work in that period accounts for 92 percent of all Public Works days completed in SNNP. In Tigray and Amhara, again there is relatively little variation in mean days worked by month between Tir and Sene. In Tigray, the means are slightly lower than Amhara, but there are more days worked in Hamle (starts mid-July). Across all months, days worked are consistently lower in Oromia than elsewhere.

Table 7.2 reports the percent of individuals by type who worked on PSNP in EC2011. Across all households reporting that they undertook work on PSNP, 87.3 percent reported that the household head did some of this work and 20.2 percent reported that spouses of the head worked on PSNP. These results are consistent with the fact that 42 percent of mothers in our sample report that they have never undertaken work on PSNP. Participation by other household members, such as children of the head or other relatives, was low. In our sample, 80.7 percent of households reported that males worked on PSNP, while 29.5 percent reported that females did so. 
Table 7.2. Individuals by type who worked on PSNP, Tir to Nehasse EC2011

\begin{tabular}{lccccccc} 
& Head & Spouse & $\begin{array}{c}\text { Child of } \\
\text { head }\end{array}$ & $\begin{array}{c}\text { Other } \\
\text { relative }\end{array}$ & Males & Females \\
Households reporting this person worked, \% & 87.3 & 20.2 & 2.0 & 1.6 & 80.7 & 29.5 \\
\hline
\end{tabular}

Source: Authors' compilation from household questionnaire, August 2019.

Note: In the Gregorian calendar, Tir starts mid-January and Nehasse starts mid-August.

Figure 7.1 disaggregates the results reported in Table 7.2 by region. The most striking regional differences relate to participation by sex. In Tigray and SNNP, females are much more likely to undertake work under the PSNP Public Works component compared to Amhara and Oromia. This partly reflects that female-headed households are more common in Tigray and, to a lesser extent, Oromia than elsewhere. In female-headed households in Amhara, other household members, such as adult children of the female head, are more likely to work on PSNP than in other regions.

\section{Figure 7.1. Percent of individuals by type who worked on PSNP between Tir and} Nehasse EC2011, by region

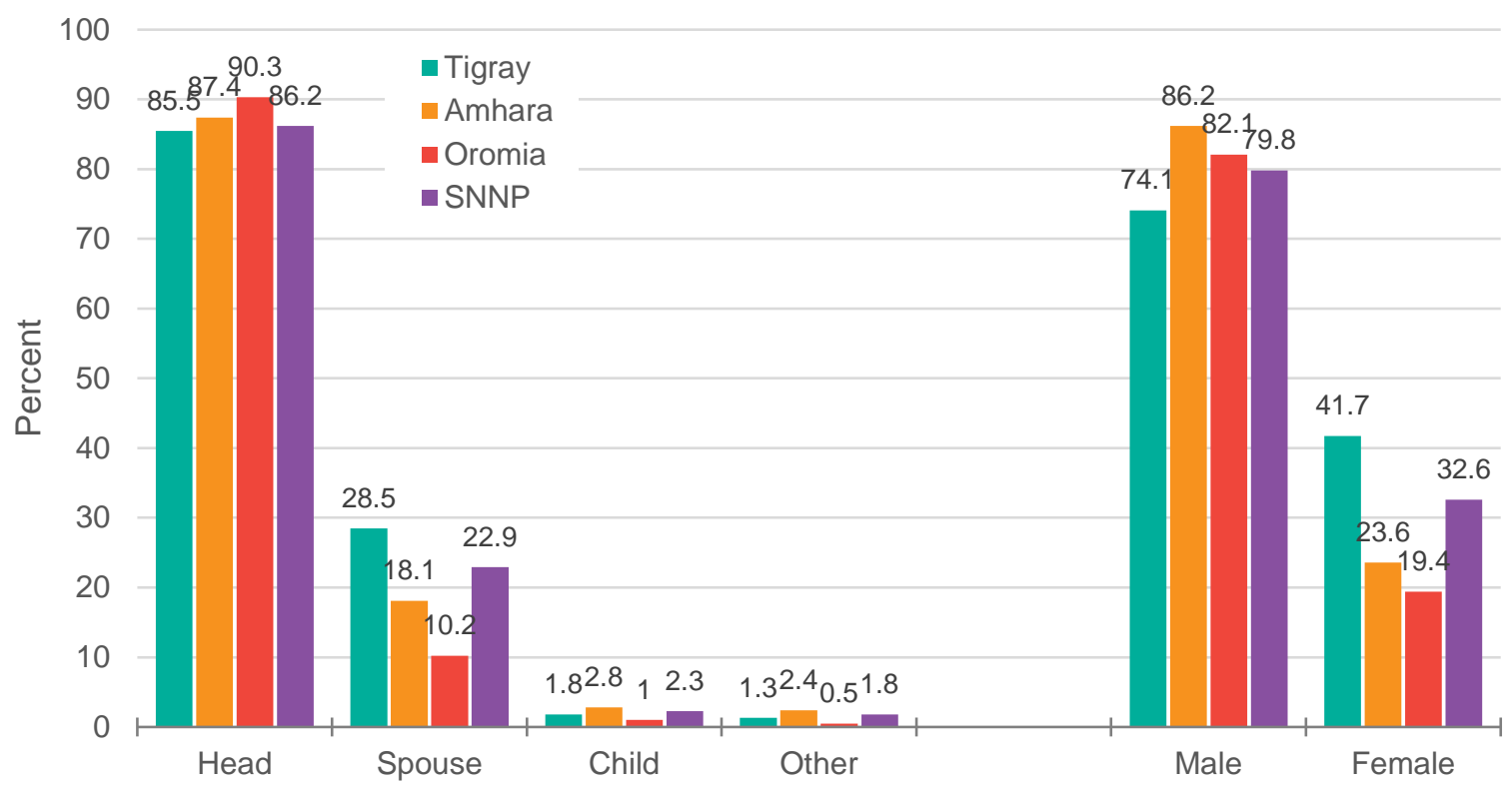

Source: Authors' compilation from household questionnaire, August 2019.

Note: In the Gregorian calendar, Tir starts mid-January and Nehasse starts mid-August.

Table 7.4 disaggregates the number of days worked on PSNP by sex. Across all regions, males averaged 60.1 days worked and females 16.6 days. Women worked more days in Tigray (20.8) and SNNP (23.5) compared to Amhara and Oromia.

Table 7.3. Total days worked on PSNP between Tir and Nehasse EC2011, by sex

\begin{tabular}{lcccc}
\multicolumn{1}{r}{ Region } & \multicolumn{3}{c}{ Total days worked } & Percent work \\
Tigray & All & Males & Females & by females \\
Amhara & 70.3 & 59.4 & 20.8 & 25.9 \\
Oromia & 79.9 & 68.2 & 11.6 & 14.5 \\
SNNP & 50.8 & 40.1 & 10.7 & 21.1 \\
\hline All & 92.6 & 69.1 & 23.5 & 25.4 \\
\hline
\end{tabular}

Source: Authors' compilation from household questionnaire, August 2019.

Note: In the Gregorian calendar, Tir starts mid-January and Nehasse starts mid-August. 


\subsection{PSNP payment levels}

Table 7.4 shows the mean level of payments received by PSNP participants by region and type between Tir and Nehasse EC2011 (January to August 2019). Across all regions, mean payments were 3,648 Birr per household. Mean payments were slightly higher in Oromia, 4,144 Birr per household, than in other regions. Cash accounts for 73 percent of the value of all payments. In SNNP, virtually all payments were in cash and cash accounted for 79 percent of payments received in Amhara. By contrast, 46 percent of the value of all payments was made through in-kind payments in Tigray.

Table 7.4. Mean value of payments (birr) received between Tir and Nehasse EC2011, by region and type

\begin{tabular}{lccc} 
Region & $\begin{array}{c}\text { Value of in-kind } \\
\text { payments }\end{array}$ & $\begin{array}{c}\text { Cash } \\
\text { payments }\end{array}$ & $\begin{array}{c}\text { Total } \\
\text { payments }\end{array}$ \\
\hline Tigray & 1,633 & 1,871 & 3,504 \\
Amhara & 734 & 2,873 & 3,608 \\
Oromia & 1,372 & 2,773 & 4,144 \\
SNNP & 36 & 3,433 & 3,469 \\
\hline All & 954 & 2,694 & 3,648 \\
\hline
\end{tabular}

Source: Authors' compilation from household questionnaire, August 2019.

Note: In the Gregorian calendar, Tir starts mid-January and Nehasse starts mid-August.

Table 7.5 outlines the number of payments received between Tir and Nehasse EC2011 by region. The average PSNP household received 4.5 payments over this period. The average number of payments received was highest in SNNP at 5.1 payments - 57.9 percent of PSNP participants in SNNP received six payments between Tir and Nehasse. The mean number of payments received was lower in Tigray (3.9) and Amhara (4.3) and in these regions, beneficiaries were less likely to receive more than four payments.

Table 7.5. Distribution of number of payments received between Tir and Nehasse EC2011, by region

\begin{tabular}{cccccc}
$\begin{array}{c}\text { Number of } \\
\text { payments }\end{array}$ & Tigray & Amhara & $\begin{array}{c}\text { Oromia } \\
\text { Percent }\end{array}$ & SNNP & All \\
\hline 1 & 5.6 & 4.7 & 3.5 & 0.0 & 3.6 \\
2 & 14.4 & 6.4 & 4.5 & 2.4 & 7.4 \\
3 & 22.9 & 30.0 & 16.3 & 15.0 & 21.8 \\
4 & 19.0 & 10.8 & 11.9 & 10.1 & 13.2 \\
5 & 18.0 & 12.8 & 16.3 & 14.6 & 15.4 \\
6 & 20.3 & 35.4 & 47.5 & 57.9 & 38.6 \\
\hline Mean & 3.9 & 4.3 & 4.8 & 5.1 & 4.5 \\
\hline
\end{tabular}

Source: Authors' compilation from household questionnaire, August 2019.

Note: In the Gregorian calendar, Tir starts mid-January and Nehasse starts mid-August.

Figure 7.2 shows the mean level of payments received by PSNP participants by region and month between Tir and Nehasse EC2011. There are three patterns. In Oromia, payments are relatively uniform between Tir and Sene with little in the way of payments made in Hamle or Nehasse. In SNNP, payments follow a pattern in which they were slightly lower in one month (Tir, Megabit, Ginbot) followed by a slightly higher payment in the following (Yekatit, Miazia, Sene) with virtually no payments made in Hamle or Nehasse. In Tigray and Amhara, mean payments are lower in Tir compared to the other regions, but are higher in Sene, Hamle, and Nehasse. 
Figure 7.2. Mean value of payments (birr) received between Tir and Nehasse EC2011, by month and region

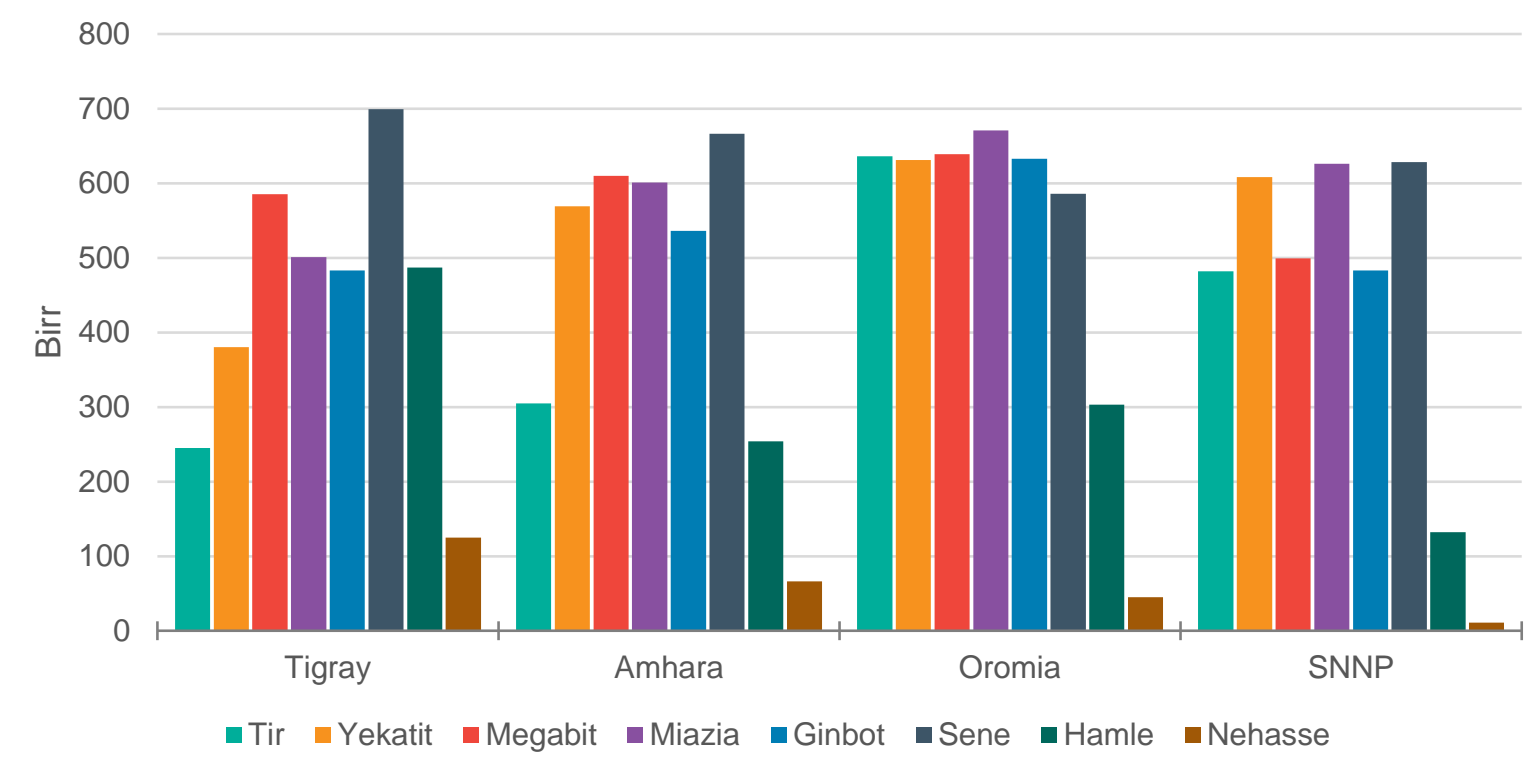

Source: Authors' compilation from household questionnaire, August 2019.

Note: In the Gregorian calendar, Tir starts mid-January and Nehasse starts mid-August.

\subsection{Protections for pregnant and lactating mothers benefitting from PSNP}

The first "1000 days" from the onset of pregnancy to a child's second birthday are critical for child development. Health and nutritional shocks during this period can cause irreversible damage to a child's physical and cognitive development. Recognizing this, the fourth phase of PSNP aimed to protect pregnant women and lactating mothers from any extra work burden during this critical period. The PSNP-4 PIM (pp. 3-8) states:

Pregnant women and lactating mothers must not participate in Public Works but are still eligible for the Public Works and links to social services component. Within this component they are designated a temporary Direct Support client (from the moment the pregnancy is identified by a health agent and until the child is one year old) [...].

The survey instrument also included a module on mothers' understanding of PSNP benefits and conditions of working in Public Works during pregnancy and lactation. This module was administered for all mothers of index children in PSNP households who reported being pregnant since January 2018. As a result, the sample used here is considerably smaller than in the analysis presented above and becomes especially small if we disaggregate by region. For this reason, we only present results for the full sample.

Table 7.6 reports that of the 812 women who reported a pregnancy after Tir EC2010, 28.3 percent were working on PSNP Public Works. Among those who were working on Public Works, 59.1 percent stopped working when they learned they were pregnant, up from only 31 percent of women who reported stopping when this question was asked as part of our baseline survey. 35.5 percent stopped working when they were four months pregnant and 81.3 had stopped by the sixth month of pregnancy. 11.7 percent continued to work until giving birth. 57.6 percent of respondents said that they wished they could have stopped working earlier. This represents an improvement over the baseline survey where 20 percent of pregnant women had continued to work until giving birth and nearly 68 percent said that they wished to have stopped working earlier. More than half were advised by a health worker to stop working during pregnancy, a significant improvement over the 2017 baseline survey when this advice was received by only one-third of pregnant women. 29.1 
percent of pregnant women received advice from a social worker to stop working; 43.4 percent received this advice from a Development Agent. However, 28.6 percent of women reported that they were discouraged from stopping work by the Community Food Security Task Force; a percentage essentially unchanged from the 2017 survey. About 57 percent of the mothers started receiving (temporary) Direct Support payments after they stopped working. In 26 percent of households, other household members put in more Public Work days after the mother stopped working. These percentages are essentially unchanged from 2017.

\section{Table 7.6. PSNP protections during pregnancy for women in PSNP households}

\begin{tabular}{lcc} 
& Sample size & Percent \\
\hline Ever pregnant since Tir EC 2010 (Jan 2018) & 812 & \\
Currently pregnant & 42 & 28.3 \\
Respondent worked on public works & 63.3 \\
Other household members on public works & 230 & \\
Working on public works when pregnant & 203 \\
Stopped working before giving birth & 59.1 \\
Stopped working after first learning pregnant & 35.5 \\
Stopped working when four months pregnant & 81.3 \\
Stopped working when six months pregnant & 57.6 \\
Wished to have stopped earlier & 56.6 \\
Advised by health worker to stop work & 29.1 \\
Advised by social worker to stop work & \\
Advised by Development Agent to stop work & 43.4 \\
Discouraged from stopping work by Community Food Security Task Force & \\
Discouraged from stopping work by husband & \\
Household received Direct Support payments after stopped working & 13.3 \\
Other household members worked more days after stopped working & 57.6 \\
\hline
\end{tabular}

Source: Authors' compilation from household questionnaire, March 2019.

After giving birth, 36 percent of women resumed working on public works on average at about 5.1 months after delivery (Table 7.7). The commonly cited reasons for not resuming Public Works was that a health worker advised against resuming or because the household was receiving (temporary) Direct Support. With the caveat that the sample sizes are small, 49 out of 73 women reported that working affected breastfeeding. The main reason for this was that the child had to be left at home when the mother was working. Nearly 83 percent of the mothers said that there is no a child care center in their community or kebele; the same percentage who had reported this problem in the 2017 baseline survey. 42 percent of mothers noted that they could take their child to the worksite, but that there was no place to breastfeed the child. 
Table 7.7. PSNP protections post-pregnancy for women in PSNP households

\begin{tabular}{lcc} 
& Sample size & Percent \\
\hline Stopped working before giving birth & 203 & \\
Did not resume work after giving birth & 130 & \\
Reasons for not resuming work: & & 9.2 \\
Public works not operating & 28.5 \\
Household received temporary Direct Support & 14.6 \\
Advised by health worker not to return to work & 13.9 \\
Did not want to return to work & 9.2 \\
Was not healthy enough to work & 73 & 24.6 \\
Other & \\
Resumed work after giving birth & 27.4 \\
Resumed work 1-5 months after giving birth & 64.4 \\
Resumed work 6-11 months after giving birth & 8.2 \\
Resumed work 12 months or more after giving birth & 49 \\
Work adversely affected breastfeeding & \\
Had to leave child at home & \\
Could take child but no place to breastfeed at worksite & 53.1 \\
\hline Supervisors did not permit breastfeeding during work hours & & 42.8 \\
Too tired from working to breastfeed & 4.1 \\
Not produced enough breastmilk & & 20.4 \\
\hline
\end{tabular}

Source: Authors' compilation from household questionnaire, March 2019. 


\section{HEALTH POSTS AND HEALTH EXTENSION WORKERS}

PNSP-4 has as its goal: "Resilience to shocks and livelihoods enhanced, and food security and nutrition improved, for rural households vulnerable to food insecurity" (PNSP-4 PIM, 2014, p. 2-3). It is seen as contributing to the policy objective of the National Nutrition Programme, "to improve nutritional status of women and children in Ethiopia". One of the indicators by which PNSP-4 will be assessed is the percent of "children 6-23 months of age who receive minimum acceptable diet". Achieving these nutrition-related goals and indicators requires greater involvement by the Government of Ethiopia, with its cadre of frontline workers - Health Extension Workers (HEW) expected to play a leading role. Evidence of this is found in the PSNP-4 Program Implementation Manual (PIM), which contains 25 references to activities that HEWs are expected to achieve. These include:

- Membership in Kebele Food Security Task Force or the Community Food Security Task Force (pp. 18-8 and 18-6), the Kebele Appeals Committee (p. 18-9), and the Kebele Development Committee (p. 18-9)

- Provide links to community health and nutrition services, through:

- Identifying which households with malnourished children should be referred to PSNP for temporary Direct Support;

- Mapping out community behavioral change communications interventions available at community level;

- Planning implementation of community behavioral change communications in collaboration with DAs and volunteer groups;

- Providing training, awareness raising, and behavior change communication on nutrition, hygiene, and sanitation, as well as other modules of the Health Extension Programme, to PSNP clients, as well as to non-clients;

- Conducting awareness raising with Public Works clients on the improved Gender and Social Development provisions of PSNP-4 in coordination with DAs;

- Where the Community-based Nutrition program is operational, organizing Community Conversations on Nutrition prior to the start of the PNSP planning process at community level;

- Tracking attendance of PSNP temporary Direct Support clients at health centers and participation in nutrition behavioral change communication activities. This relates to their work in monitoring soft conditionalities under temporary Direct Support; and

- Supporting the DA in tracking participation in nutrition related community behavioral change communications. (p. 18-10)

Have HEWs been integrated into PSNP? What does their workload look like? How has their workload been affected by PSNP? And how have PSNP demands affected their job motivation and satisfaction? The objective of this chapter is to provide information on these topics. As part of the August 2017 and August 2019 surveys, we interviewed 249 and 250 HEWs, respectively, one in each kebele surveyed. ${ }^{26}$ Responses from those interviews are summarized in this chapter.

${ }^{26}$ Enumerators were instructed to interview one HEW per kebele. Of those interviewed in 2019, 44.6 percent were also interviewed in 2017. Of the remainder, 32 percent had moved to a different health post but continued to work as a HEW, 29 percent still worked at the same health post but were not available for interview because was away for personal reasons, and 18 percent still worked at the health post but were not available for interview because the individual was away for work-related reasons. 


\subsection{Health Extension Workers and health post characteristics}

We begin by describing some basic characteristics of HEWs and the health posts where they work. Characteristics of HEWs as of August 2019 are reported in Table 8.1. (Appendix E, Table E1 provides these descriptive statistics for 2017.) The average HEW is in her mid-late 20s. She has either a post-secondary qualification, usually a technical or vocational certificate (30.8 percent) or a college or university degree (42.4 percent). Nearly all are from the woreda in which they work -33.6 percent are from the same kebele and woreda where they are now stationed; 52 percent are from the same woreda but a different kebele. There is relatively little variation in these characteristics across regions, although a slightly higher percentage of HEWs in SNNP have only primary or secondary schooling relative to other regions.

Table 8.1. Health Extension Worker characteristics, by region, 2019

\begin{tabular}{lccccc} 
& Tigray & Amhara & Oromia & SNNP & All \\
& 30.0 & 26.0 & 25.9 & 28.0 & 27.5 \\
$\begin{array}{l}\text { Age (years, mean) } \\
\text { Place of origin (percent): }\end{array}$ & & & & & \\
$\quad$ This woreda and kebele & 37.9 & 11.3 & 19.0 & 64.1 & 33.6 \\
$\quad$ This woreda, different kebele & 51.5 & 74.2 & 63.8 & 20.3 & 52.0 \\
$\quad$ Another woreda & 10.6 & 14.5 & 17.2 & 15.6 & 14.4 \\
Highest level of schooling completed (percent): & & & & & \\
$\quad$ Primary & 3.0 & 1.6 & 8.6 & 25.0 & 9.6 \\
$\quad$ Secondary & 15.2 & 6.5 & 13.8 & 14.6 & 12.4 \\
Post-secondary: Technical or vocational & 13.6 & 40.3 & 37.9 & 32.8 & 30.8 \\
$\quad$ Post-secondary: College or university & 59.1 & 45.2 & 39.7 & 25.0 & 42.4 \\
$\quad$ Other & 9.1 & 6.4 & 0.0 & 2.6 & 4.8 \\
Married (percent) & 74.2 & 61.3 & 77.6 & 68.7 & 70.0 \\
Number of children under 5 (mean) & 0.71 & 0.5 & 0.72 & 0.62 & 0.64 \\
\hline
\end{tabular}

Source: Authors' compilation from HEW quantitative survey, August 2019.

Table 8.2 describes the health post characteristics in both 2017 and 2019. In 2019, the average health post had 2.2 HEWs who work between 21 and 26 days per month and between 8.0 and 9.2 hours per day. While physical infrastructure is improving, it remains strikingly rudimentary. Just over 20 percent of health posts have electricity, 40 percent have piped water, and 41 percent have a VIP latrine. Fewer than half have the height boards needed to measure children's heights. Health posts in Tigray tend to be somewhat better equipped than health posts found elsewhere. At the time of the survey, the average HEW's client caseload included 27 pregnant women and 104 children under 24 months of age. Caseloads are considerably higher in Oromia relative to other regions. 
Table 8.2. Health post characteristics, by region, 2017 and 2019

\begin{tabular}{|c|c|c|c|c|c|c|c|c|c|c|}
\hline & \multicolumn{5}{|c|}{2017} & \multicolumn{5}{|c|}{2019} \\
\hline & Tigray & Amhara & Oromia & SNNP & All & Tigray & Amhara & Oromia & SNNP & All \\
\hline $\begin{array}{l}\text { Number of HEWs at } \\
\text { health post, mean }\end{array}$ & 2.2 & 2.1 & 2.2 & 2.1 & 2.1 & 2.2 & 2.0 & 2.3 & 2.1 & 2.2 \\
\hline $\begin{array}{l}\text { Days worked per } \\
\text { month, mean }\end{array}$ & 25.3 & 26.8 & 22.5 & 23.8 & 24.6 & 26.3 & 26.6 & 21.1 & 22.5 & 24.2 \\
\hline $\begin{array}{l}\text { Hours worked per day, } \\
\text { mean }\end{array}$ & 9.1 & 8.2 & 8.4 & 8.6 & 8.6 & 9.2 & 8.0 & 8.5 & 8.1 & 8.5 \\
\hline \multicolumn{11}{|l|}{$\begin{array}{l}\text { Health Equipment: } \\
\text { Health Post has ... }\end{array}$} \\
\hline $\begin{array}{l}\text { Board to measure } \\
\text { children's height, \% }\end{array}$ & & & & & & 57.6 & 33.9 & 46.6 & 29.7 & 42.0 \\
\hline $\begin{array}{l}\text { Scale to measure } \\
\text { children's weight, \% }\end{array}$ & & & & & & 95.5 & 83.9 & 86.2 & 84.4 & 87.6 \\
\hline $\begin{array}{l}\text { Scale to measure } \\
\text { adult's weight, } \%\end{array}$ & & & & & & 74.2 & 50.0 & 50.0 & 64.1 & 60.0 \\
\hline $\begin{array}{l}\text { Equipment to } \\
\text { measure blood } \\
\text { pressure, } \%\end{array}$ & & & & & & 60.6 & 50.0 & 53.5 & 43.8 & 52.0 \\
\hline Examination table, \% & & & & & & 83.3 & 59.7 & 68.9 & 67.2 & 70.0 \\
\hline \multicolumn{11}{|l|}{$\begin{array}{l}\text { Infrastructure, } \% \text { of } \\
\text { Health Posts: }\end{array}$} \\
\hline Has electricity & 35.4 & 11.7 & 13.3 & 14 & 18.9 & 39.4 & 11.3 & 13.8 & 20.3 & 21.6 \\
\hline Has refrigerator & 47.7 & 20.0 & 26.7 & 21.9 & 29.3 & 65.2 & 46.8 & 53.5 & 45.3 & 52.8 \\
\hline \multicolumn{11}{|l|}{ Type of toilet: } \\
\hline Flush toilet & 0.0 & 0.0 & 0.0 & 1.6 & 0.4 & 1.5 & 0.0 & 0.0 & 1.6 & 0.8 \\
\hline $\begin{array}{l}\text { Ventilated improved } \\
\text { pit (VIP) latrine }\end{array}$ & 72.3 & 16.7 & 10.0 & 37.5 & 34.9 & 74.2 & 16.1 & 24.1 & 46.9 & 41.2 \\
\hline $\begin{array}{l}\text { Pit latrine/traditional } \\
\text { pit toilet }\end{array}$ & 24.6 & 63.3 & 76.7 & 53.1 & 53.8 & 18.2 & 67.8 & 55.2 & 45.3 & 46.0 \\
\hline $\begin{array}{l}\text { All other types of } \\
\text { toilets }\end{array}$ & 3.1 & 20 & 13.3 & 7.8 & 10.8 & 6.1 & 16.1 & 20.7 & 6.2 & 12.0 \\
\hline \multicolumn{11}{|l|}{ Water supply: } \\
\hline Piped water & 36.9 & 40.0 & 31.7 & 42.2 & 37.8 & 40.9 & 37.1 & 29.3 & 54.7 & 40.8 \\
\hline Wells/boreholes & 49.2 & 33.3 & 16.7 & 17.2 & 29.3 & 45.5 & 30.6 & 20.7 & 4.7 & 25.6 \\
\hline $\begin{array}{l}\text { All other water } \\
\text { sources }\end{array}$ & 13.8 & 25.0 & 46.7 & 35.9 & 30.1 & 13.6 & 24.2 & 37.9 & 39.6 & 28.8 \\
\hline No water access & 0.0 & 1.7 & 5.0 & 4.7 & 2.8 & 0.0 & 8.1 & 12.1 & 0.0 & 4.8 \\
\hline \multicolumn{11}{|l|}{ Internet access: } \\
\hline Fixed line internet & & & & & & 6.1 & 8.1 & 6.9 & 6.2 & 6.8 \\
\hline 3G network internet & & & & & & 31.8 & 35.5 & 34.5 & 42.2 & 36.0 \\
\hline \multicolumn{11}{|l|}{ Client level, mean: } \\
\hline Pregnant women, no. & 46 & 48 & 121 & 47 & 65 & 20.4 & 45.0 & 93.4 & 52.8 & 51.7 \\
\hline Children 0-24mo., no. & 269 & 213 & 302 & 216 & 250 & 133.9 & 196.4 & 277.4 & 176.9 & 193.7 \\
\hline \multicolumn{11}{|l|}{ Client load, mean: } \\
\hline $\begin{array}{l}\text { Pregnant women per } \\
\text { HEW }\end{array}$ & 23.7 & 26.7 & 70.3 & 24.6 & 35.9 & 11.1 & 24.6 & 48.7 & 26.6 & 27.1 \\
\hline $\begin{array}{l}\text { Children 0-24m per } \\
\text { HEW }\end{array}$ & 131.6 & 112.9 & 166.8 & 117.2 & 131.9 & 74.4 & 110.7 & 140.6 & 96.2 & 104.4 \\
\hline
\end{tabular}

Source: Authors' compilation from HEW quantitative survey, August 2017 and August 2019.

The activities envisaged that HEWs will undertake as part of PNSP-4 are in addition to their other responsibilities. What exactly do HEWs do? As part of the survey, we asked about 25 different activities and whether these had been done in the last one month. Table 8.3 gives the percent of HEWs reporting that did that activity in the month prior to the August 2019 survey and their 
subjective assessment of how much time they spent on each. ${ }^{27}$ There is little regional variation in these activity patterns.

\section{Table 8.3. Undertaking specific activity and assessment of time spent on it, by} activity group, 2019, percent of Health Extension Workers reporting

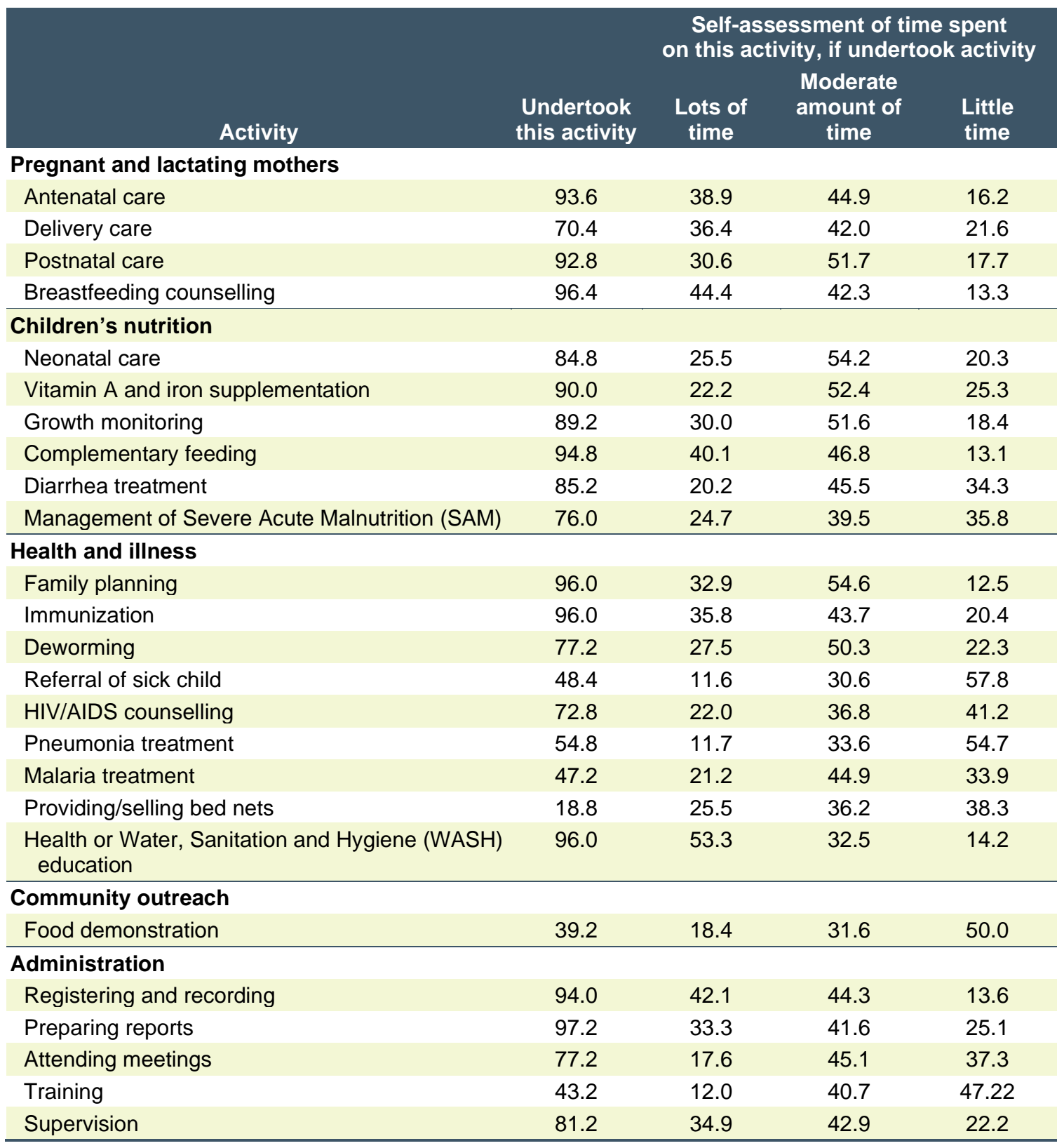

Source: Authors' compilation from HEW quantitative survey, August 2019.

\subsection{Health Extension Workers and PSNP}

The activities that HEWs are supposed to undertake with respect to PSNP can be loosely divided into three categories: Membership in bodies charged with oversight of implementation, such as local Food Security Task Forces; liaison with other individuals responsible for aspects of PSNP, such as Development Agents; and implementation of activities directly related to the nutrition objectives of PSNP-4.

Tables 8.4 and 8.5 report HEW membership in two bodies that oversee the implementation of aspects of PSNP, the Kebele Food Security Task Force and the Kebele Appeals Committee, respectively. In most kebeles, a HEW is a member of the Kebele Food Security Task Force, either

\footnotetext{
${ }^{27}$ Data for 2017 are found in the Appendix.
} 
the HEW we interviewed or another HEW working at the same health post (Table 8.4). The majority of Kebele Appeals Committees have a HEW as a member (Table 8.5) and participation by HEWs in this committee has increased over time. There are some regional variations in membership, with HEWs more likely to be members of these committees in Tigray and Amhara and somewhat less likely to be members in Oromia and SNNP.

\section{Table 8.4. Health Extension Workers reporting membership in Kebele Food Security} Task Force, 2017 and 2019, percent

\begin{tabular}{lccccc} 
& Tigray & Amhara & $\begin{array}{c}\text { Oromia } \\
2017\end{array}$ & SNNP & All \\
HEW is member of this committee & & & 41.7 & 51.6 & 55.4 \\
Another HEW is a member of this committee & 24.6 & 28.3 & 5.0 & 14.1 & 18.1 \\
Any HEW a member of this committee & 92.3 & 88.3 & 46.7 & 65.7 & 73.5 \\
HEW is member of this committee & & & 2019 & & 63.6 \\
Another HEW is a member of this committee & 27.3 & 24.1 & 3.0 & 71.9 & 15.2 \\
Any HEW a member of this committee & 90.9 & 91.9 & 53.5 & 76.6 & 78.8 \\
\hline
\end{tabular}

Source: Authors' compilation from HEW quantitative survey, August 2017 and August 2019.

Table 8.5. Health Extension Workers reporting membership in Kebele Appeals Committee, 2017 and 2019, percent

\begin{tabular}{|c|c|c|c|c|c|}
\hline & Tigray & Amhara & $\begin{array}{c}\text { Oromia } \\
2017\end{array}$ & SNNP & All \\
\hline $\mathrm{HEW}$ is member of this committee & 36.9 & 41.7 & 33.3 & 40.6 & 38.2 \\
\hline Another HEW is a member of this committee & 33.9 & 20.0 & 13.3 & 7.8 & 18.9 \\
\hline \multirow[t]{2}{*}{ Any HEW a member of this committee } & 70.8 & 61.7 & 46.6 & 48.4 & 57.1 \\
\hline & & & 2019 & & \\
\hline $\mathrm{HEW}$ is member of this committee & 47.0 & 54.8 & 44.8 & 54.7 & 50.4 \\
\hline Another HEW is a member of this committee & 28.8 & 16.1 & 13.8 & 17.2 & 19.2 \\
\hline Any HEW a member of this committee & 75.8 & 70.9 & 58.6 & 71.9 & 69.6 \\
\hline
\end{tabular}

Source: Authors' compilation from HEW quantitative survey, August 2017 and August 2019.

Another HEW responsibility is to liaise with other individuals responsible for health, nutrition or other aspects of PSNP implementation. Table 8.6 describes interactions as of August 2019 with the Health Development Army (HDA), agriculture DAs, and social workers. ${ }^{28}$ The active presence of HDAs is reported in most kebeles, and most HEWs are responsible for supervising the HDAs and meet with them on a weekly (35.7 percent) or monthly (50.9 percent) basis. Most HEWs report meeting with the DAs in their kebele, at least on a weekly basis (65 percent). Many HEWs (64 percent) also reported meeting with the DAs to talk about PSNP in the past month. Social workers are deployed in 40 percent of the kebeles on average (more in Tigray), and 87 percent of HEWs report meeting with social workers on a monthly or less frequent basis. About 19 percent of HEWs have never discussed PSNP with social workers.

${ }^{28}$ Data for 2017 is found in the Appendix. 
Table 8.6. Interactions of Health Extension Workers with HDAs, DAs, and Social Workers, 2019

\begin{tabular}{|c|c|c|c|c|c|}
\hline Health Develo & $\begin{array}{l}\text { Tigray } \\
\text { nent Ar }\end{array}$ & Amhara & Oromia & SNNP & All \\
\hline $\begin{array}{l}\text { Are there any Health Development Armies (HDAs) } \\
\text { active in this kebele? }\end{array}$ & 98.5 & 96.8 & 74.1 & 100.0 & 92.8 \\
\hline Are you responsible for supervising the HDA leaders? & 98.5 & 98.3 & 83.7 & 96.9 & 95.3 \\
\hline $\begin{array}{l}\text { How many HDA leaders do you supervise? (number of } \\
\text { HDAs/kebele) }\end{array}$ & 20 & 28 & 15 & 27 & 23 \\
\hline \multicolumn{6}{|l|}{ How often do you usually meet with HDA leaders? } \\
\hline Every day or several times a week & 9.2 & 11.1 & 4.7 & 6.5 & 8.0 \\
\hline Weekly & 26.2 & 16.7 & 41.9 & 58.1 & 35.7 \\
\hline Monthly & 63.1 & 63.0 & 41.9 & 33.9 & 50.9 \\
\hline Less than once a month & 1.5 & 9.3 & 11.6 & 1.6 & 5.4 \\
\hline \multicolumn{6}{|c|}{ Development Agents } \\
\hline $\begin{array}{l}\text { Do you ever meet with the agriculture Development } \\
\text { Agents (DA) in your kebele? }\end{array}$ & 86.2 & 98.3 & 88.3 & 92.2 & 91.2 \\
\hline \multicolumn{6}{|l|}{ How often do you usually meet with DAs? } \\
\hline Every day or several times a week & 9.2 & 6.7 & 7.0 & 10.9 & 8.6 \\
\hline Weekly & 41.5 & 31.7 & 41.9 & 31.2 & 36.2 \\
\hline Monthly & 46.2 & 58.3 & 39.5 & 50.0 & 49.1 \\
\hline Less than once a month & 3.1 & 3.3 & 11.6 & 7.9 & 6.1 \\
\hline \multicolumn{6}{|l|}{$\begin{array}{l}\text { When was the last time you met with DAs to talk about } \\
\text { PSNP? }\end{array}$} \\
\hline During last month & 73.4 & 55.0 & 74.0 & 54.8 & 64.0 \\
\hline 1-3 months ago & 23.4 & 30.0 & 12.0 & 21.0 & 22.0 \\
\hline 4-6 months ago or longer & 0.0 & 5.0 & 10.0 & 9.7 & 6.0 \\
\hline Never & 3.2 & 10.0 & 4.0 & 14.5 & 8.0 \\
\hline \multicolumn{6}{|c|}{ Social Workers } \\
\hline Is there a Social Worker deployed in this kebele? & 87.8 & 25.8 & 25.9 & 17.2 & 40 \\
\hline \multicolumn{6}{|l|}{ How often do you usually meet with the Social Worker? } \\
\hline Every day or several times a week & 22.4 & 25.0 & 6.6 & 18.2 & 20.0 \\
\hline Weekly & 39.7 & 25.0 & 26.7 & 9.1 & 32.0 \\
\hline Monthly & 27.6 & 25.0 & 60.0 & 54.5 & 35.0 \\
\hline Less than once a month & 10.3 & 25.0 & 6.7 & 18.2 & 13.0 \\
\hline \multicolumn{6}{|l|}{$\begin{array}{l}\text { When was the last time you met with s Social Worker to } \\
\text { talk about PSNP? }\end{array}$} \\
\hline During last month & 70.7 & 50.0 & 66.7 & 63.6 & 66.0 \\
\hline 1-3 months ago & 13.8 & 18.8 & 6.7 & 9.1 & 13.0 \\
\hline 4-6 months ago or longer & 0.0 & 6.2 & 0.0 & 9.1 & 2.0 \\
\hline Never & 15.5 & 25.0 & 26.6 & 18.2 & 19.0 \\
\hline
\end{tabular}

Source: Authors' compilation from HEW quantitative survey, August 2019.

We now turn to the Health Extension Workers role in implementing PNSP-4. Since the program introduces several new aspects to PSNP implementation, it is useful to examine the training received by HEWs. Figure 8.1, Table 8.7, and Figure 8.2 describe these. 
Figure 8.1. Percent of HEWs who received training on PSNP implementation in the last 12 months, by region, 2017 and 2019

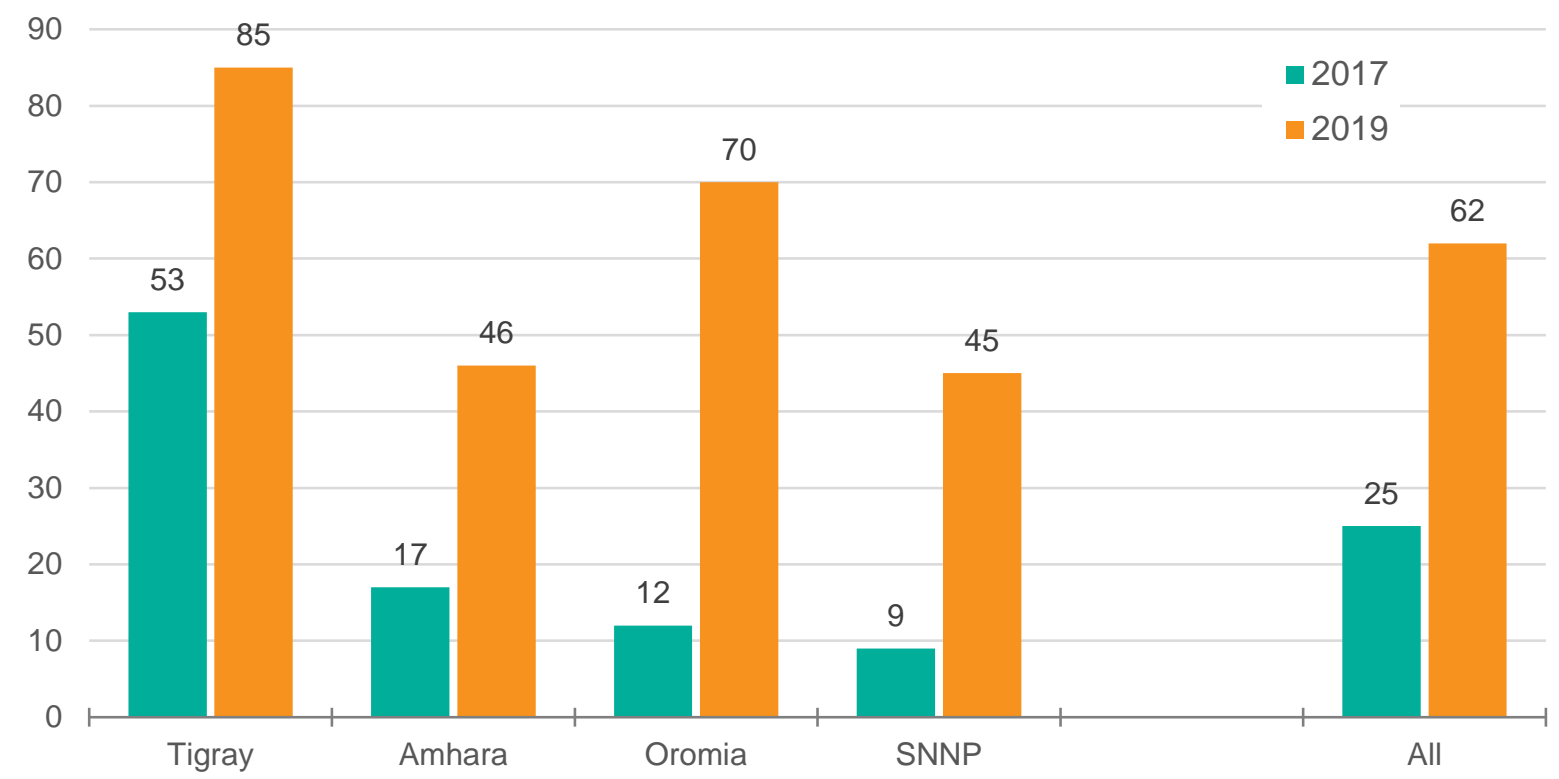

Source: Authors' compilation from HEW quantitative survey, August 2017 and August 2019.

Figure 8.1 shows that the percentage of HEWs who have received training on PSNP has increased markedly since 2017 . While this increase has occurred in all regions, differences across regions remain with a greater share of HEWs in Tigray and Oromia reporting having received training in the August 2019 survey than in Amhara and SNNP. There is some regional variation in the intensity of training, with it typically taking 1 or 2 days in SNNP and Tigray and 2 or 3 days in Amhara and Oromia.

Table 8.7. Days of PSNP training received, by region, 2019, percent of HEWs

\begin{tabular}{lccccc}
\multicolumn{1}{c}{ Days: } & $\mathbf{1}$ & $\mathbf{2}$ & $\mathbf{3}$ & $\mathbf{4 +}$ & Total \\
Amhara & 21 & 29 & 32 & 18 & 100 \\
Oromia & 10 & 39 & 35 & 16 & 100 \\
SNNP & 32 & 48 & 8 & 8 & 100 \\
Tigray & 42 & 47 & 11 & 0 & 100 \\
All regions & 29 & 42 & 20 & 9 & 100 \\
\hline
\end{tabular}

Source: Authors' compilation from HEW quantitative survey, August 2019.

Sample consists of HEWs who reported receiving training on PSNP in the last 12 months.

By contrast, the percentage of HEWs who have ever received training on Timed and AgeAppropriate Messaging for infant and young child feeding fell between 2017 and 2019 (Figure 8.2). Most HEWs who received this training (71 percent), received it a year ago or longer. 
Figure 8.2. Percent of HEWs who ever received training on Timed and AgeAppropriate Messaging for infant and young child feeding, by region, 2017 and 2019

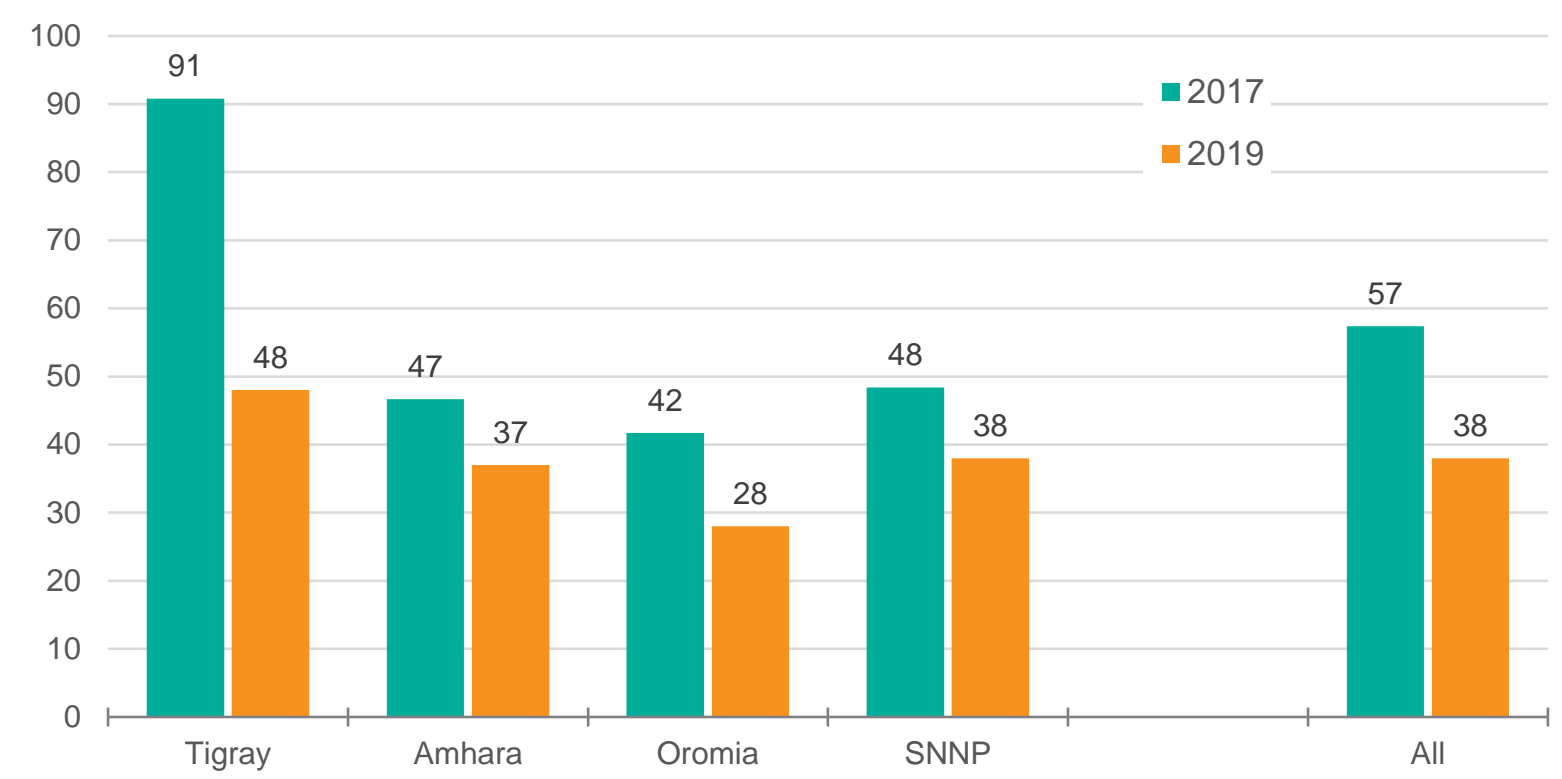

Source: Authors' compilation from HEW quantitative survey, August 2017 and August 2019.

Was the PSNP training effective? One way of answering this question is to assess HEWs knowledge of two major changes introduced into PNSP-4: the transition of pregnant and lactating women to Temporary Direct Support; and the transition of mothers of severely malnourished children to Temporary Direct Support. On these, the PNSP-4 PIM states:

Transition of pregnant and lactating women to Direct Support until one year postpartum: Women will be transitioned to Direct Support on confirmation by a health worker that she has undergone a first antenatal check-up. In the absence of this referral, the pregnant woman will be automatically transitioned at four months of pregnancy. (PIM, section 8.4.3)

The primary caregiver of a malnourished child under five years old is to transition to temporary Direct Support and receive a transfer without participating in Public Works. (PIM, section 8.4.2). In addition:

- Monthly check up of the child at the closest health facility;

- Attendance at behavioral change communications sessions provided by HEWs or the Health Development Army as informed by the HEW; and

- Participation in treatment, e.g., community management of acute malnutrition or targeted supplementary feeding, as advised

Figures 8.3, 8.4, and 8.5 show HEW responses to questions on these aspects of PSNP-4 implementation. In all cases, untrained HEWs - those who did not receive PSNP training in the last 12 months - are much more likely to give incorrect responses. In 2019, a greater percentage of HEWs provided corrected answers to questions about the transition of pregnant and lactating women to temporary Direct Support until one year postpartum. However, there was a decline in the percentage of HEWs who could correctly describe how mothers of malnourished children were supposed to be transitioned to temporary Direct Support. In 2019, only 47 percent of HEWs who had received PSNP training knew that mothers of malnourished children should be moved to Temporary Direct Support, and an alarming 24 percent believed that no special arrangements are needed (Figure 8.5). 
Figure 8.3. When should a pregnant woman stop working in public works? - HEW responses (\%) by training status

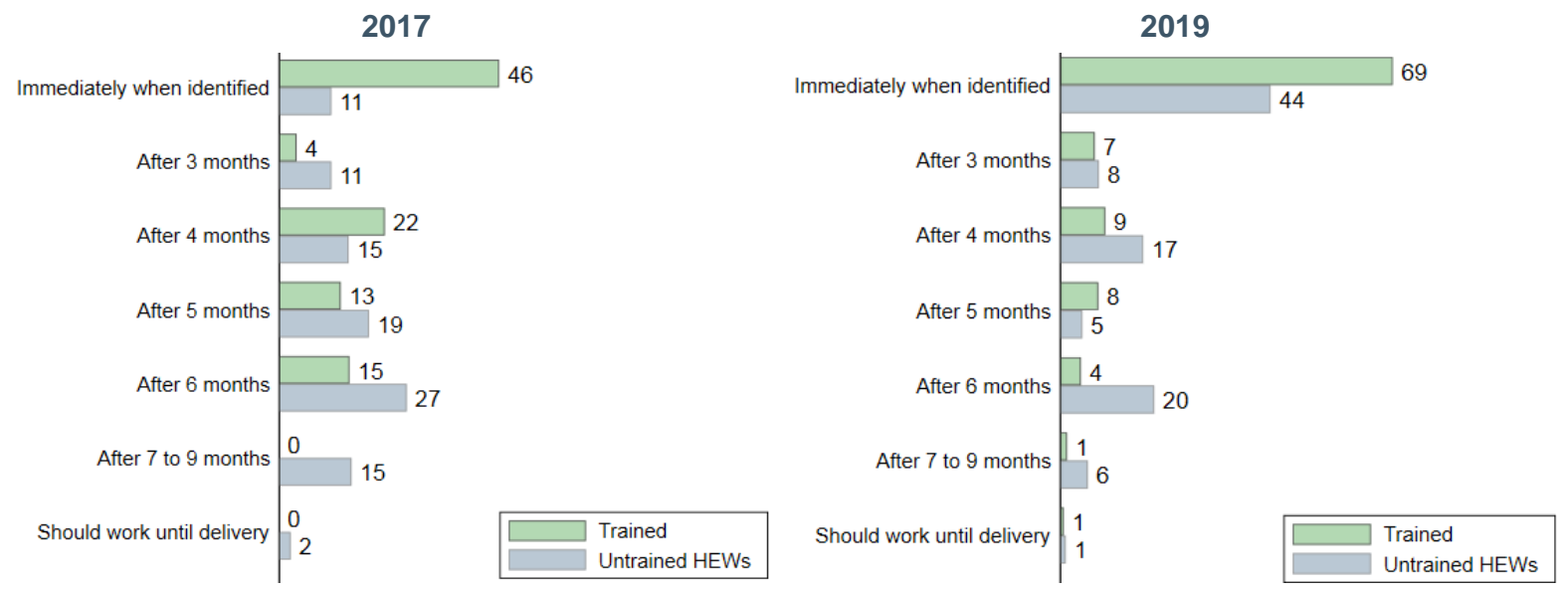

Source: Authors' compilation from HEW quantitative survey, August 2017 and August 2019.

Figure 8.4. When should a new mother return to Public Works? - HEW responses (\%) by training status

2017

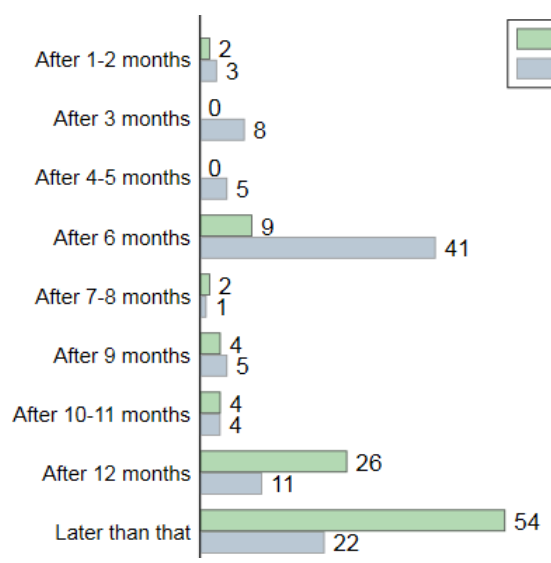

2019

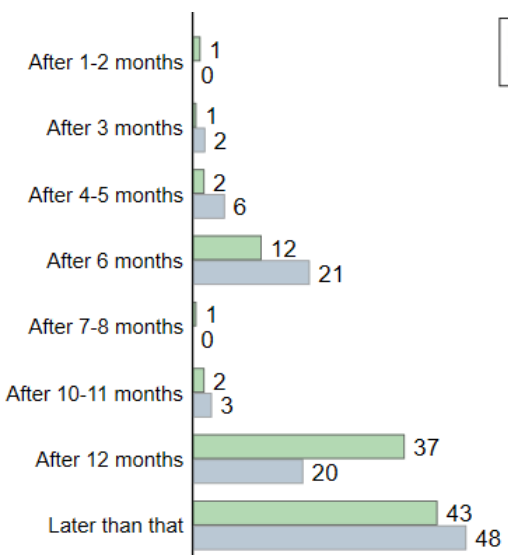

Source: Authors' compilation from HEW quantitative survey, August 2017 and August 2019.

Figure 8.5. What is the arrangement for PSNP households with a malnourished child under five years old? - HEW responses (\%) by training status
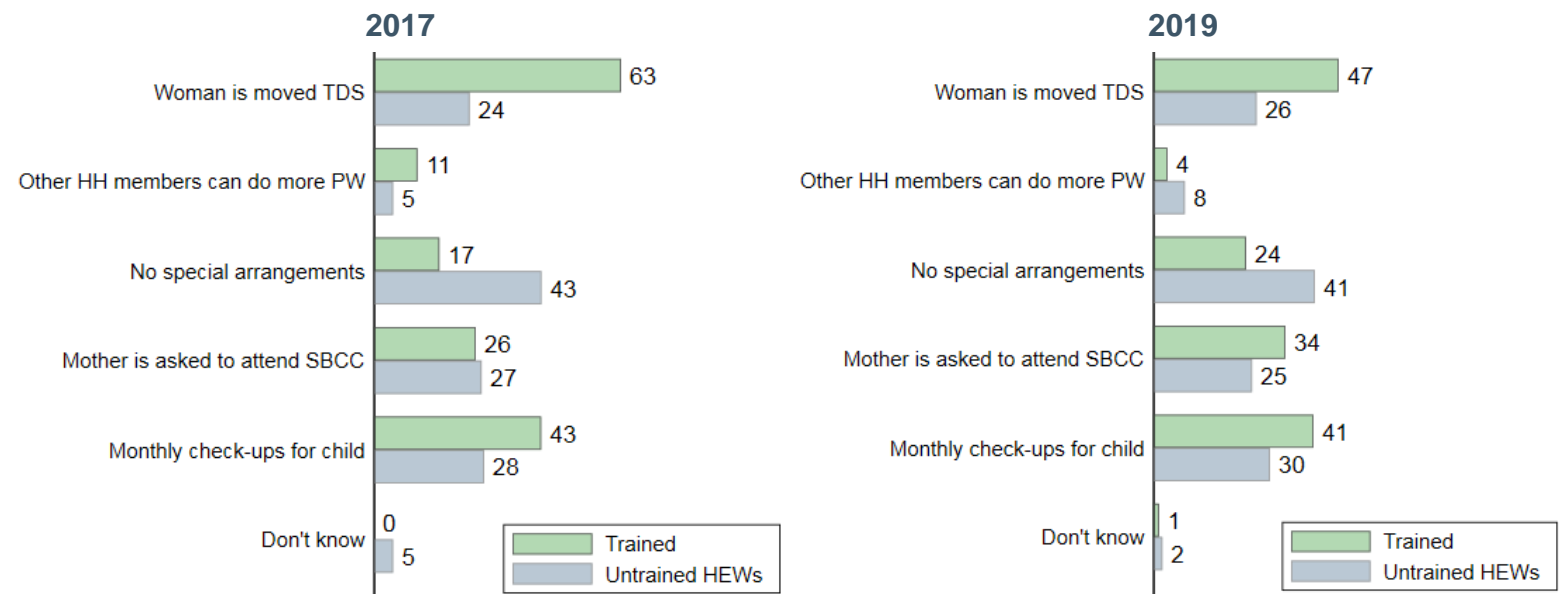

Source: Authors' compilation from HEW quantitative survey, August 2017 and August 2019. 


\subsection{Workload, job satisfaction, and stress of Health Extension Workers}

Table 8.3 showed that HEWs are already responsible for a wide range of activities. To determine whether it was possible for them to accommodate the additional activities required under PNSP-4, we first wanted to understand in more detail how they spend their time. HEWs were asked to recall how much time they had spent on the following activities: home visits (the number of visits, the time spent per visit, and the total amount of travel time for these home visits); group meetings (the number of group meetings and the time spent in each group meeting); administrative meetings, such as those associated with PSNP; and operations of the health post or clinic. These questions were asked for the three day period immediately preceding the interview. Table 8.8 summarizes these data.

Table 8.8. Hours worked by Health Extension Workers per day by activity and region, 2017 and 2019

\begin{tabular}{lcccccccccc} 
& \multicolumn{1}{c}{} & \multicolumn{1}{c}{2017} & & \multicolumn{9}{c}{2019} \\
& Tigray & Amhara & Oromia & SNNP & All & Tigray & Amhara Oromia & SNNP & All \\
Home visits & 1.9 & 2.4 & 1.3 & 2.6 & 2.0 & 0.5 & 0.5 & 0.6 & 0.8 & 0.6 \\
& $(23 \%)$ & $(30 \%)$ & $(17 \%)$ & $(31 \%)$ & $(25 \%)$ & $(10 \%)$ & $(14 \%)$ & $(18 \%)$ & $(18 \%)$ & $(15 \%)$ \\
Travel for home visits & 0.6 & 0.7 & 0.5 & 0.9 & 0.7 & 0.8 & 0.4 & 0.5 & 0.8 & 0.6 \\
& $(7 \%)$ & $(9 \%)$ & $(6 \%)$ & $(11 \%)$ & $(9 \%)$ & $(17 \%)$ & $(12 \%)$ & $(15 \%)$ & $(17 \%)$ & $(15 \%)$ \\
Group meetings & 0.2 & 0.3 & 0.6 & 0.6 & 0.4 & 0.6 & 0.2 & 0.1 & 0.4 & 0.3 \\
& $(2 \%)$ & $(4 \%)$ & $(8 \%)$ & $(7 \%)$ & $(5 \%)$ & $(11 \%)$ & $(6 \%)$ & $(5 \%)$ & $(9 \%)$ & $(8 \%)$ \\
Health post & 3.5 & 3.0 & 4.1 & 3.9 & 3.6 & 2.6 & 2.2 & 1.6 & 2.2 & 2.2 \\
& $(43 \%)$ & $(38 \%)$ & $(53 \%)$ & $(47 \%)$ & $(44 \%)$ & $(51 \%)$ & $(59 \%)$ & $(51 \%)$ & $(49 \%)$ & $(52 \%)$ \\
Meetings & 2.0 & 1.4 & 1.3 & 0.3 & 1.3 & 0.6 & 0.3 & 0.3 & 0.3 & 0.4 \\
& $(24 \%)$ & $(18 \%)$ & $(17 \%)$ & $(4 \%)$ & $(16 \%)$ & $(11 \%)$ & $(8 \%)$ & $(9 \%)$ & $(6 \%)$ & $(9 \%)$ \\
\hline TOTAL & 8.2 & 7.9 & 7.8 & 8.3 & 8.1 & 5.0 & 3.8 & 3.0 & 4.5 & 4.1 \\
\hline
\end{tabular}

Source: Authors' compilation from HEW quantitative survey, August 2017 and August 2019.

Note: Percent of all hours worked are noted in parentheses in each cell (column totals).

Across all regions, the amount of time HEWs report spending on these activities declined from around 8 hours per day in 2017 to 4.1 hours per day in 2019. Most time was spent at the health post. In 2019 , only 13 percent of HEWs reported doing a home visit. The mean time spent on home visits declined markedly from 2.0 hours per day in 2017 to 0.6 hours per day in 2019, a 70 percent decline.

We also asked HEWs whether they perceived that their workload had changed and, if yes, the reasons for this. Responses are summarized in Table 8.9. ${ }^{29}$

${ }^{29}$ Responses to these questions in the August 2017 survey are found in the Appendix. 
Table 8.9. Perceptions of change in workload, by region, 2019

\begin{tabular}{|c|c|c|c|c|c|}
\hline & Tigray & Amhara & Oromia & SNNP & All \\
\hline \multicolumn{6}{|l|}{ Overall, how would you describe your workload } \\
\hline Too little & 1.5 & 1.6 & 10.5 & 3.4 & 4.1 \\
\hline Just right & 24.6 & 24.2 & 49.1 & 32.2 & 32.1 \\
\hline Too much & 73.9 & 74.2 & 40.4 & 64.4 & 63.8 \\
\hline \multicolumn{6}{|c|}{$\begin{array}{l}\text { In the past } 12 \text { months, would you say that your workload is } \\
\text { less, more, or the same as before? }\end{array}$} \\
\hline Less & 1.5 & 20.9 & 17.5 & 16.9 & 14.0 \\
\hline Same & 13.9 & 8.1 & 40.3 & 15.2 & 18.9 \\
\hline More & 84.6 & 71.0 & 42.1 & 67.8 & 67.1 \\
\hline \multicolumn{6}{|c|}{$\begin{array}{l}\text { If workload has increased, what are the reasons for this } \\
\text { (\% of HEWs who report this reason as either the first, } \\
\text { second, or third reason for higher workload) }\end{array}$} \\
\hline Increased number of people/patients & 12.9 & 15.9 & 54.2 & 35.0 & 25.3 \\
\hline Increased coverage areas & 12.9 & 0.0 & 12.5 & 15.0 & 9.9 \\
\hline More government programs and services & 44.4 & 34.1 & 8.3 & 7.5 & 27.2 \\
\hline More activities from projects & 1.8 & 11.4 & 8.3 & 7.5 & 6.8 \\
\hline More supervision/inspection & 5.6 & 0.0 & 4.2 & 2.5 & 3.1 \\
\hline Multiple sites of work (more villages a & 1.8 & 4.6 & 0.0 & 2.5 & 2.5 \\
\hline Staff shortage/covering other's work & 18.5 & 27.3 & 12.5 & 30.0 & 22.8 \\
\hline More paperwork & 0.0 & 2.3 & 0.0 & 0.0 & 0.6 \\
\hline More meetings & 1.8 & 0.0 & 0.0 & 0.0 & 0.6 \\
\hline \multicolumn{6}{|c|}{$\begin{array}{l}\text { In the past } 12 \text { months, has your workload become less, } \\
\text { more, or the same as before because of activities related } \\
\text { to infant and young child feeding (such as giving } \\
\text { messages and food demonstrations)? }\end{array}$} \\
\hline Less & 15.6 & 25.8 & 21.1 & 15.2 & 19.4 \\
\hline Same & 43.8 & 32.3 & 56.1 & 47.5 & 44.6 \\
\hline More & 40.6 & 41.9 & 22.8 & 37.3 & 35.9 \\
\hline \multicolumn{6}{|c|}{$\begin{array}{l}\text { In the last } 12 \text { months have you spent time beyond your } \\
\text { usual work hours to keep up with your workload? }\end{array}$} \\
\hline Yes & 90.6 & 87.1 & 50.9 & 69.5 & 75.2 \\
\hline No & 9.4 & 12.9 & 49.1 & 30.5 & 24.8 \\
\hline \multicolumn{6}{|l|}{ If Yes, how much additional time } \\
\hline Less than 30 minutes & 1.7 & 3.7 & 6.9 & 2.4 & 3.3 \\
\hline 30-60 minutes & 20.7 & 11.1 & 20.7 & 34.2 & 20.9 \\
\hline 1-2 hours & 53.5 & 66.7 & 44.8 & 39.0 & 52.8 \\
\hline 3-4 hours & 20.7 & 14.8 & 17.2 & 14.6 & 17.0 \\
\hline More than 4 hours & 3.4 & 3.7 & 10.3 & 9.8 & 6.0 \\
\hline
\end{tabular}

Source: Authors' compilation from HEW quantitative survey, August 2019.

In 2019, most HEWs perceived that their workload was "too much". Most HEWs also perceived that their workload had increased in the last 12 months, and the vast majority stated that they have spent more time than their usual hours to keep up with this increased workload, adding 1 or 2 hours per day. While these responses are found in all regions, they are especially pronounced in Tigray. In all regions, about 25 percent of HEWs ascribe this change to an increased number of people or patients, and about 22 percent feel that it has resulted from staff shortages. Increased training sessions, paperwork, and meetings are not seen as a cause of higher workload. Instead, it is seen as being driven by the need to support more government programs and services and from increased activities from projects. Again, this is most pronounced in Tigray.

How does this high and increasing workload affect self-confidence, job motivation, and job satisfaction? HEW' responses on these issues are presented in Tables 8.10 and 8.11. HEWs generally feel confident in their performance, that they are contributing to improve the conditions of the communities they working in, and are confident about advising families about the best ways to 
feed their children. However, only 30 percent think that they have received enough training and support to meet their current responsibilities, and 75 percent would like more training on how to counsel mothers on child feeding. Confidence in the amount of training HEWs have received declined between 2017 and 2019.

Table 8.10. Self-confidence, job motivation, and job satisfaction of Health Extension Workers, all regions, 2017 and 2019, percent

\begin{tabular}{|c|c|c|c|c|c|c|}
\hline & \multicolumn{3}{|c|}{2017} & \multicolumn{3}{|c|}{2019} \\
\hline & & $\begin{array}{l}\text { Neither } \\
\text { agree } \\
\text { nor }\end{array}$ & & & $\begin{array}{l}\text { Neither } \\
\text { agree } \\
\text { nor }\end{array}$ & \\
\hline & Agree & disagree & Disagree & Agree & disagree & Disagree \\
\hline \multicolumn{7}{|l|}{ Self confidence } \\
\hline $\begin{array}{l}\text { I feel confident that I am performing very well } \\
\text { as a HEW. }\end{array}$ & 91.6 & 6.0 & 2.4 & 93.6 & 2.8 & 3.6 \\
\hline $\begin{array}{l}\text { I receive adequate training and support to meet } \\
\text { my current responsibilities }\end{array}$ & 47.4 & 16.5 & 36.1 & 30.8 & 13.6 & 55.6 \\
\hline $\begin{array}{l}\text { I feel I need more training to counsel mothers } \\
\text { well about child feeding. }\end{array}$ & 69.5 & 5.6 & 24.9 & 75.2 & 4.8 & 20 \\
\hline $\begin{array}{l}\text { I feel confident about advising families about } \\
\text { the best ways to feed their children. }\end{array}$ & 87.1 & 7.2 & 5.6 & 89.2 & 6.8 & 4.0 \\
\hline $\begin{array}{l}\text { I am contributing to improve the conditions of } \\
\text { the communities I am working in }\end{array}$ & 95.2 & 2.8 & 2.0 & 96.8 & 2 & 1.2 \\
\hline \multicolumn{7}{|l|}{ Job motivation and job satisfaction } \\
\hline I find my job to be motivating, and I like to do it & 82.3 & 6.8 & 10.8 & 78.0 & 10.8 & 11.2 \\
\hline $\begin{array}{l}\text { I feel that people in the community value the } \\
\text { work that we do in the communities }\end{array}$ & 92.4 & 5.2 & 2.4 & 86.8 & 9.2 & 4.0 \\
\hline $\begin{array}{l}\text { I find it difficult to cope with the demands of } \\
\text { being a HEW. }\end{array}$ & 41.4 & 9.6 & 49.0 & 39.2 & 12.4 & 48.4 \\
\hline $\begin{array}{l}\text { I have a lot of pressure in this job. It really } \\
\text { seems like the workload keeps increasing }\end{array}$ & 79.9 & 8.4 & 11.6 & 73.2 & 10.4 & 16.4 \\
\hline $\begin{array}{l}\text { If I suggest to a mother a good feeding } \\
\text { practice, she is likely to try it out. }\end{array}$ & 79.1 & 13.3 & 7.6 & 77.6 & 16.4 & 6.0 \\
\hline $\begin{array}{l}\text { It is possible for all the families in our } \\
\text { communities to prevent child malnutrition by } \\
\text { improving how they feed their children. }\end{array}$ & 78.7 & 6.8 & 14.5 & 65.2 & 19.6 & 15.2 \\
\hline $\begin{array}{l}\text { Mothers in our communities are capable of } \\
\text { feeding their young children adequately with a } \\
\text { variety of foods }\end{array}$ & 37.8 & 16.9 & 45.4 & 27.2 & 20.4 & 52.4 \\
\hline $\begin{array}{l}\text { I am satisfied with my salary and benefits when } \\
\text { I compare this job to other similar jobs }\end{array}$ & 32.9 & 8.4 & 58.6 & 14.4 & 5.2 & 80.4 \\
\hline $\begin{array}{l}\text { I feel secure that I will not lose my job in the } \\
\text { near future }\end{array}$ & 78.7 & 5.6 & 15.7 & 66.0 & 8.8 & 25.2 \\
\hline
\end{tabular}

Source: Authors' compilation from HEW quantitative survey, August 2017 and August 2019.

Note that a small number of "not applicable" responses, all from SNNP, are included in "neither agree nor disagree".

Generally, work motivation is high, with 78 percent stating that they find their job to be motivating, and that they like to do it and 86 percent feel that people in the community value the work they do. However, most feel that their workload is increasing as their workload increases, and 39 percent state that they are finding it difficult to cope with the demands of being a HEW. There is a suggestion in these data that HEWs are becoming more skeptical about the prospects for improving nutrition in their communities. The percentage of HEWs who agree with the statement that "It is possible for all the families in our communities to prevent child malnutrition by improving how they feed their children" fell from 78 to 65 percent between 2017 and 2019 and the share of HEWS that agree with the statement that "Mothers in our communities are capable of feeding their young children adequately with a variety of foods" fell from 37 to 27 percent. 
Table 8.11. Overall job satisfaction of Health Extension Workers, all regions, 2017 and 2019, percent

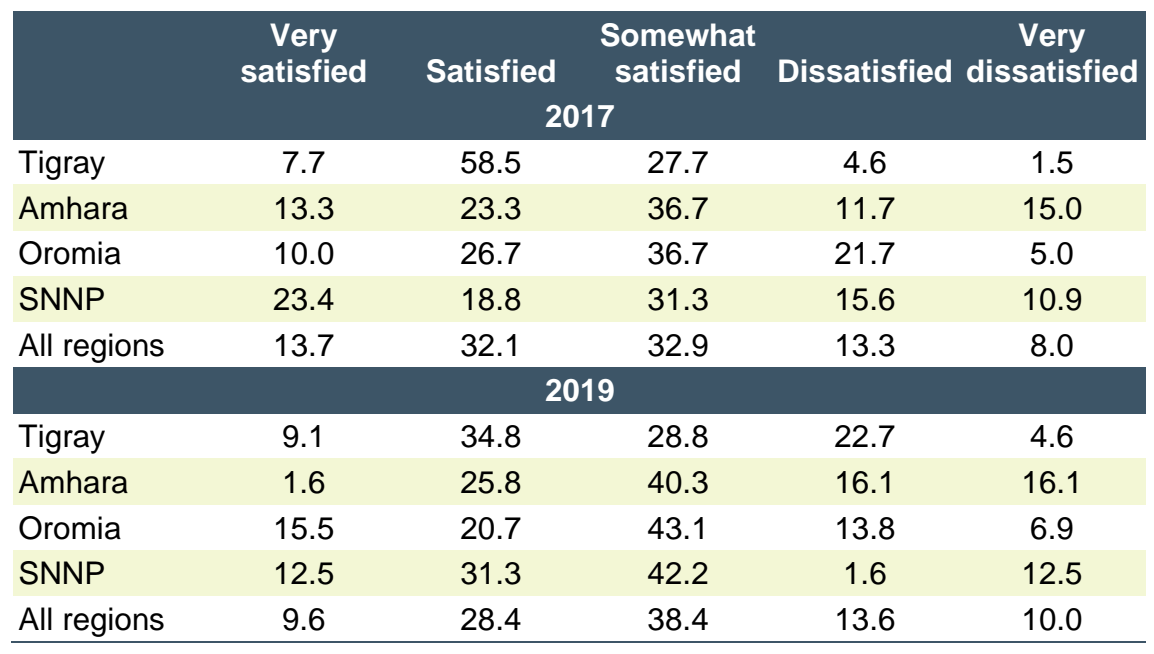

Source: Authors' compilation from HEW quantitative survey, August 2017 and August 2019.

The percentage of HEWs who agree with the statement that, "I am satisfied with my salary and benefits when I compare this job to other similar jobs" fell from 32 to 14 percent between 2017 and 2019. Consistent with this and with other trends regarding job motivation, the percentage of HEWs who report that, overall, they are "very satisfied" or "satisfied" with jobs fell by 7.8 percentage points (Table 8.11). In Tigray and Amhara, where HEWs have consistently raised concerns about workload (see Table 8.9 and Appendix E, Table E6), there are large increases in the percentage of HEWs who are "dissatisfied" or "very dissatisfied" with their jobs.

We wondered if the time pressures faced by HEWs was leading to adverse effects on their mental health. For this reason, in both 2017 and 2019, we administered the 22-item Maslach Burnout Inventory (MBI). This questionnaire is used to assess burnout in health professionals by asking them to identify the frequency with which the various feelings (22 items) occur over a 12month period. These are grouped into three dimensions or subscales: emotional exhaustion ("emotional over-extension, exhaustion and depletion" in one's work, 9 items), depersonalization ("impersonal, callous, negative and detached" feelings to the recipients of one's services, 5 items), and reduced personal accomplishment (feelings of competence and successful achievement in one's work with people, 8 items). Individual item scores are found in Appendix E, Tables E7 and E8. Mean scores are shown in Table 8.12. These mean values are relatively constant across region and time.

Table 8.12. Mean stress score by dimension/subscale among Health Extension Workers, by region and year

\begin{tabular}{lcccccc} 
& \multicolumn{2}{c}{$\begin{array}{c}\text { Emotional } \\
\text { Exhaustion }\end{array}$} & \multicolumn{2}{c}{$\begin{array}{c}\text { Personal } \\
\text { Accomplishment }\end{array}$} & \multicolumn{2}{c}{ Depersonalization } \\
Max score: & \multicolumn{2}{c}{54} & \multicolumn{2}{c}{48} & \multicolumn{2}{c}{30} \\
& 2017 & 2019 & 2017 & $\mathbf{2 0 1 9}$ & $\mathbf{2 0 1 7}$ & $\mathbf{2 0 1 9}$ \\
Amhara & 18.9 & 18.4 & 37.4 & 36.4 & 7.0 & 7.3 \\
Oromia & 15.1 & 15.6 & 35.4 & 33.6 & 6.1 & 7.4 \\
SNNP & 16.5 & 15.4 & 37.1 & 37.2 & 8.2 & 6.8 \\
Tigray & 13.1 & 12.9 & 41.2 & 37.6 & 5.3 & 4.8 \\
\hline All regions & 15.9 & 15.5 & 37.8 & 36.3 & 6.6 & 6.5 \\
\hline
\end{tabular}

Source: Authors' compilation from HEW quantitative survey, August 2017 and August 2019.

More informative, however, are patterns and prevalence of medium and high levels of stress. These are shown in Table 8.13. In 2019, 34 percent of HEWs showed signs of medium or high 
levels of emotional exhaustion; 50 percent of HEWs provided responses consistent with medium or high levels of reduced levels of personal accomplishment; and 54 percent showed signs of medium or high levels of depersonalization. Reduced sense of personal accomplishment increased between 2017 and 2019. This is consistent with results in Table 8.10 that showed reductions in the share of HEWs who agreed with the statements that "It is possible for all the families in our communities to prevent child malnutrition by improving how they feed their children" and the share who agreed with the statement that "Mothers in our communities are capable of feeding their young children adequately with a variety of foods".

Table 8.13. Health Extension Workers emotional exhaustion, personal accomplishment, and depersonalization, by region and year, percent

\begin{tabular}{lcccccc} 
Stress level: & \multicolumn{2}{c}{ Low } & \multicolumn{2}{c}{ Medium } & \multicolumn{2}{c}{ High } \\
& 2017 & 2019 & 2017 & 2019 & 2017 & 2019 \\
Emotional exhaustion & & & & & \\
\hline Amhara & 52 & 57 & 33 & 24 & 15 & 19 \\
Oromia & 68 & 64 & 23 & 20 & 8 & 16 \\
SNNP & 53 & 65 & 30 & 32 & 17 & 3 \\
Tigray & 77 & 77 & 18 & 15 & 5 & 8 \\
\hline All regions & 63 & 66 & 26 & 23 & 11 & 11 \\
Personal accomplishment & & & & & \\
\hline Amhara & 55 & 43 & 12 & 28 & 33 & 29 \\
Oromia & 52 & 38 & 12 & 24 & 37 & 38 \\
SNNP & 55 & 56 & 14 & 16 & 31 & 27 \\
Tigray & 72 & 57 & 12 & 15 & 15 & 28 \\
\hline All regions & 59 & 49 & 12 & 20 & 29 & 30 \\
Depersonalization & 43 & 43 & 33 & 36 & 23 & 21 \\
\hline Amhara & 43 & 42 & 38 & 35 & 15 & 24 \\
Oromia & 47 & 49 & 28 & 48 & 27 & 13 \\
SNNP & 45 & 39 & 31 & 28 & 15 & 11 \\
\hline Tigray & 54 & 62 & 33 & 37 & 20 & 17 \\
\hline All regions & 47 & 47 & & & & \\
\hline
\end{tabular}

Source: Authors' compilation from HEW quantitative survey, August 2017 and August 2019.

Note: Emotional Exhaustion: Low stress level= "17 or less"; Moderate stress level = "18-29"; High stress level = "30 or more". Personal Accomplishment: High stress level = "33 or less"; Moderate stress level = "34 to 39"; Low stress level = "40 or More". Depersonalization: Low stress level = "5 or Less"; Moderate stress level = "6-11"; High stress level = "12 or More". 


\section{EXPOSURE TO HEALTH AND NUTRITION SERVICES}

This chapter reports on the exposure to health and nutrition services for mothers of index children in two different child age-groups - exposure to antenatal care services among mothers with children less than 6 months of age (March round only); and contact with HEWs and exposure to nutrition services among mothers with children 6 to 23 months of age (both March and August rounds).

\subsection{Exposure to antenatal care services among mothers with children less than 6 months of age}

Between 2017 and 2019, indicators of antenatal care (facility-based) and delivery at a healthcare facility improved among both PSNP and non-PSNP mothers. However, aside from the consumption of iron supplements, exposure to nutrition-specific interventions during these women's last pregnancy decreased over time.

While exposure to home visits during pregnancy by health or community workers decreased by about 7 percentage points in both PSNP and non-PSNP between the two survey rounds, the percentage of women who received any antenatal care visits (facility-based) or four or more visits increased over time in both groups (Table 9.1). Timing of first antenatal care visit also improved in both groups by on month, from, on average, the fifth month of pregnancy to the fourth month. In 2019, more women reported visiting the health center or hospital for antenatal care, rather than local health posts, compared to those in 2017. These patterns were observed across all regions (Table 9.2).

Among nutrition interventions received during pregnancy, more women, regardless of PSNP status, reported consuming iron supplements in 2019 than in 2017 (Table 9.1). However, exposure to any nutrition counseling decreased in both groups over time - exposure to breastfeeding counseling decreased by at least 20 percentage points for all regions and all women.

Delivery at healthcare facilities increased by about 6 percentage points among both PSNP and non-PSNP mothers between 2017 and 2019, with more women reporting giving birth at a health center or hospital (Table 9.1). Thus, a trend of increased facility-based care, particularly at health centers or hospitals, was observed between the two survey rounds, alongside decreased exposure to community-based care at heath posts or at home.

Table 9.1. Use of antenatal care services by PSNP status, 2017 and 2019

\begin{tabular}{|c|c|c|c|c|}
\hline & \multicolumn{2}{|c|}{ March 2017} & \multicolumn{2}{|c|}{ March 2019} \\
\hline & $\begin{array}{l}\text { Non- } \\
\text { PSNP }\end{array}$ & PSNP & $\begin{array}{l}\text { Non- } \\
\text { PSNP }\end{array}$ & PSNP \\
\hline Total observations & 1,577 & 1,058 & 1,106 & 792 \\
\hline Received home visit by health/community worker while pregnant & 29.3 & 32.5 & 22.6 & 26.0 \\
\hline Those who received home visit, observations & 347 & 258 & 250 & 206 \\
\hline Timing of first home visit (months pregnant) & 5.02 & 5.21 & 4.0 & 4.1 \\
\hline \multicolumn{5}{|l|}{ Provider who conducted home visit, \%: } \\
\hline Health Extension Worker & 96.9 & 96.2 & 97.6 & 96.6 \\
\hline Volunteer (Health or Women's Development Armies) & 0.8 & 0.4 & 0.8 & 0.5 \\
\hline Social worker & 2.0 & 2.3 & 0.8 & 1.5 \\
\hline Traditional Birth Attendant (trained or untrained) & 0.3 & 1.1 & 0.0 & 0.5 \\
\hline Other & 0.0 & 0.0 & 0.8 & 1.0 \\
\hline Received antenatal care, \% & 73.5 & 76.4 & 79.5 & 82.4 \\
\hline Received 4+ antenatal care sessions, $\%$ & 32.2 & 35.2 & 41.6 & 41.8 \\
\hline Those who received antenatal care, observations & 885 & 609 & 879 & 652 \\
\hline Number of times received antenatal care & 3.5 & 3.5 & 3.8 & 3.7 \\
\hline Timing of first antenatal care visit (months pregnant) & 5.0 & 5.2 & 4.0 & 4.1 \\
\hline
\end{tabular}




\begin{tabular}{|c|c|c|c|c|}
\hline & \multicolumn{2}{|c|}{ March 2017} & \multicolumn{2}{|c|}{ March 2019} \\
\hline & $\begin{array}{l}\text { Non- } \\
\text { PSNP }\end{array}$ & PSNP & $\begin{array}{l}\text { Non- } \\
\text { PSNP }\end{array}$ & PSNP \\
\hline \multicolumn{5}{|l|}{ Location of antenatal care, \%: } \\
\hline Health post & 61.4 & 60.4 & 42.3 & 46.8 \\
\hline Health center & 54.9 & 56.5 & 71.3 & 69.8 \\
\hline Hospital & 3.7 & 3.3 & 7.5 & 6.1 \\
\hline Other & 2.1 & 1.6 & 1.1 & 1.1 \\
\hline Both at health post and health center & 18.6 & 18.4 & 17.5 & 19.5 \\
\hline Consumed any iron supplements during pregnancy, \% & 49.4 & 53.5 & 57.0 & 63.2 \\
\hline Suffered from night blindness during pregnancy, $\%$ & 16.6 & 17.8 & 16.7 & 22.6 \\
\hline $\begin{array}{l}\text { Received counseling or information about nutrition for pregnant women } \\
\text { during pregnancy, } \%\end{array}$ & 53.5 & 59.8 & 51.5 & 58.7 \\
\hline Those who received counseling or information, observations & 637 & 473 & 567 & 461 \\
\hline \multicolumn{5}{|l|}{ Provider of counseling or information: } \\
\hline Health Extension Worker & 80.4 & 81.4 & 60.5 & 61.2 \\
\hline Doctor & 1.4 & 1.9 & 2.3 & 2.2 \\
\hline Nurse/midwife & 17.7 & 15.6 & 33.9 & 32.7 \\
\hline Other & 0.5 & 1.1 & 3.35 & 3.9 \\
\hline Received counseling about breastfeeding during pregnancy & 54.7 & 59.5 & 47.0 & 53.6 \\
\hline Those who received breastfeeding counseling, observations: & 619 & 467 & 517 & 420 \\
\hline \multicolumn{5}{|l|}{ Provider of breastfeeding counseling: } \\
\hline Health Extension Worker & 82.0 & 83.3 & 58.2 & 62.6 \\
\hline Doctor & 1.4 & 1.5 & 1.5 & 1.9 \\
\hline Nurse/midwife & 16.0 & 14.1 & 36.4 & 31.2 \\
\hline Other & 0.6 & 1.1 & 3.9 & 4.2 \\
\hline \multicolumn{5}{|l|}{ Where gave birth: } \\
\hline Home & 52.1 & 53.1 & 46.3 & 45.3 \\
\hline Health post & 7.5 & 6.0 & 3.2 & 2.9 \\
\hline Health center & 32.9 & 35.3 & 40.6 & 40.9 \\
\hline Hospital & 6.0 & 4.0 & 9.3 & 9.8 \\
\hline Other & 1.5 & 1.6 & 0.5 & 0.8 \\
\hline \multicolumn{5}{|l|}{ Who assisted during delivery: } \\
\hline Health Extension Worker & 9.8 & 8.0 & 4.5 & 3.2 \\
\hline Doctor & 4.0 & 3.8 & 5.5 & 5.7 \\
\hline Nurse/midwife & 33.1 & 34.3 & 42.7 & 44.6 \\
\hline Traditional Birth Attendant (trained or untrained) & 4.9 & 4.9 & 6.1 & 6.0 \\
\hline Volunteer (Health or Women's Development Armies) & 0.2 & 0.9 & 0.5 & 0.5 \\
\hline Social worker & 0.1 & 0.3 & 0.1 & 0.0 \\
\hline Husband & 4.8 & 5.6 & 3.0 & 1.9 \\
\hline Mother/mother-in-law & 17.2 & 16.3 & 11.8 & 9.7 \\
\hline Other family members & 2.1 & 2.3 & 1.0 & 1.8 \\
\hline Friends/neighbors & 21.9 & 21.2 & 22.9 & 25.1 \\
\hline Other & 1.9 & 2.4 & 1.9 & 1.5 \\
\hline
\end{tabular}

Source: Authors' compilation from surveys, March 2017 and March 2019.

Table 9.2. Use of antenatal care services by region, 2017 and 2019

\begin{tabular}{lcccccccc} 
& \multicolumn{4}{c}{ March 2017} & & \multicolumn{3}{c}{ March 2019} \\
& Amhara & Oromia & SNNP & Tigray & Amhara & Oromia & SNNP & Tigray \\
\hline Total observations & 478 & 502 & 505 & 522 & 494 & 453 & 457 & 493 \\
\hline $\begin{array}{l}\text { Received home visit by health or } \\
\text { community worker while pregnant }\end{array}$ & 30.4 & 10.6 & 39.9 & 41.0 & 21.7 & 6.6 & 30.9 & 36.1 \\
\hline $\begin{array}{l}\text { Those who received home visit, } \\
\text { observations }\end{array}$ & 141 & 52 & 201 & 211 & 107 & 30 & 141 & 178 \\
$\begin{array}{l}\text { Timing of first home visit (months } \\
\text { pregnant) }\end{array}$ & 5.1 & 5.0 & 5.0 & 5.2 & 3.9 & 3.8 & 4.5 & 4.1 \\
\hline
\end{tabular}




\begin{tabular}{|c|c|c|c|c|c|c|c|c|}
\hline & \multicolumn{4}{|c|}{ March 2017} & \multicolumn{4}{|c|}{ March 2019} \\
\hline & Amhara & Oromia & SNNP & Tigray & Amhara & Oromia & SNNP & Tigray \\
\hline \multicolumn{9}{|l|}{ Provider who conducted home visit, \%: } \\
\hline Health Extension Worker & 96.6 & 100.0 & 97.0 & 95.3 & 99.1 & 100 & 99.3 & 93.9 \\
\hline $\begin{array}{l}\text { Volunteer (Health or Women's } \\
\text { Development Armies) }\end{array}$ & 1.4 & 0.0 & 0.5 & 0.5 & 0.0 & 0.0 & 0.7 & 1.1 \\
\hline Social worker & 0.7 & 0.0 & 2.0 & 3.7 & 0.0 & 0.0 & 0.0 & 2.8 \\
\hline Traditional Birth Attendant & 1.4 & 0.0 & 0.5 & 0.5 & 0.0 & 0.0 & 0.0 & 0.6 \\
\hline Other & 0.0 & 0.0 & 0.0 & 0.0 & 0.9 & 0.0 & 0.0 & 1.7 \\
\hline Received antenatal care, \% & 77.4 & 55.9 & 82.9 & 82.1 & 82.2 & 57.7 & 91.2 & 90.5 \\
\hline Received 4+ antenatal care sessions, $\%$ & 27.0 & 21.3 & 43.2 & 41.4 & 36.6 & 22.7 & 52.7 & 53.8 \\
\hline $\begin{array}{l}\text { Those who received antenatal care, } \\
\text { observations }\end{array}$ & 369 & 279 & 418 & 428 & 406 & 261 & 417 & 447 \\
\hline Number of times received antenatal care & 3.4 & 3.3 & 3.7 & 3.5 & 3.7 & 3.4 & 3.9 & 3.8 \\
\hline $\begin{array}{l}\text { Timing of first antenatal care visit (months } \\
\text { pregnant) }\end{array}$ & 5.1 & 5.0 & 5.0 & 5.2 & 3.9 & 3.8 & 4.5 & 4.1 \\
\hline \multicolumn{9}{|l|}{ Location of antenatal care, \%: } \\
\hline Health post & 59.6 & 78.1 & 73.2 & 39.0 & 36.9 & 47.5 & 66.4 & 28.2 \\
\hline Health center & 58.8 & 26.5 & 46.7 & 80.4 & 78.6 & 56.7 & 58.5 & 83.0 \\
\hline Hospital & 1.9 & 3.9 & 1.2 & 7.0 & 3.4 & 6.9 & 6.2 & 10.7 \\
\hline Other & 3.3 & 3.2 & 1.0 & 0.9 & 1.5 & 1.1 & 1.0 & 0.9 \\
\hline Both at health post and health center & 21.1 & 8.6 & 20.8 & 20.6 & 16.7 & 9.2 & 28.5 & 15.7 \\
\hline $\begin{array}{l}\text { Consumed any iron supplements during } \\
\text { pregnancy, \% }\end{array}$ & 58.7 & 35.9 & 32.5 & 75.5 & 65.2 & 27.7 & 61.2 & 80.2 \\
\hline $\begin{array}{l}\text { Suffered from night blindness during } \\
\text { pregnancy, } \%\end{array}$ & 15.9 & 16.9 & 18.8 & 16.7 & 18.8 & 23.1 & 22.2 & 13.2 \\
\hline $\begin{array}{l}\text { Received counseling or information about } \\
\text { nutrition for pregnant women during } \\
\text { pregnancy, } \%\end{array}$ & 53.7 & 32.4 & 59.9 & 76.6 & 56.2 & 28.6 & 59.9 & 71.6 \\
\hline $\begin{array}{l}\text { Those who received counseling or } \\
\text { information, observations }\end{array}$ & 255 & 158 & 300 & 397 & 277 & 128 & 273 & 350 \\
\hline \multicolumn{9}{|l|}{ Provider of counseling or information: } \\
\hline Health Extension Worker & 79.2 & 91.8 & 83.0 & 75.8 & 51.6 & 57.0 & 77.7 & 56.3 \\
\hline Doctor & 2.0 & 1.9 & 1.3 & 1.5 & 2.9 & 3.1 & 1.5 & 2.0 \\
\hline Nurse/midwife & 16.9 & 6.3 & 15.3 & 22.2 & 44.0 & 23.4 & 19.8 & 39.1 \\
\hline Other & 1.9 & 0.0 & 0.4 & 0.5 & 1.4 & 16.4 & 1.1 & 2.5 \\
\hline $\begin{array}{l}\text { Received counseling about breastfeeding } \\
\text { during pregnancy }\end{array}$ & 52.1 & 33.5 & 62.4 & 76.7 & 48.8 & 25.2 & 60.2 & 63.4 \\
\hline $\begin{array}{l}\text { Those who received breastfeeding } \\
\text { counseling, observations: }\end{array}$ & 247 & 163 & 312 & 394 & 240 & 113 & 274 & 310 \\
\hline \multicolumn{9}{|l|}{ Provider of breastfeeding counseling: } \\
\hline Health Extension Worker & 85.0 & 92.6 & 84.0 & 75.6 & 54.6 & 57.5 & 72.3 & 54.8 \\
\hline Doctor & 1.6 & 1.8 & 1.6 & 1.0 & 1.3 & 0.9 & 1.5 & 2.6 \\
\hline Nurse/midwife & 12.1 & 4.9 & 13.8 & 22.6 & 42.1 & 24.8 & 24.8 & 39.4 \\
\hline Other & 1.3 & 0.7 & 0.6 & 0.8 & 0.0 & 0.9 & 0.4 & 3.2 \\
\hline \multicolumn{9}{|l|}{ Where gave birth: } \\
\hline Home & 65.7 & 73.9 & 43.2 & 28.7 & 56.3 & 76.4 & 32.6 & 19.8 \\
\hline Health post & 4.6 & 9.2 & 6.5 & 7.3 & 1.0 & 2.0 & 3.9 & 5.3 \\
\hline Health center & 25.7 & 12.4 & 42.4 & 53.8 & 37.2 & 17.2 & 51.9 & 55.5 \\
\hline Hospital & 2.1 & 4.2 & 6.1 & 8.0 & 5.1 & 4.0 & 10.7 & 18.0 \\
\hline Other & 4.6 & 9.2 & 6.5 & 7.3 & 0.4 & 0.4 & 0.9 & 1.4 \\
\hline \multicolumn{9}{|l|}{ Who assisted during delivery: } \\
\hline Health Extension Worker & 4.6 & 8.2 & 8.9 & 14.2 & 1.8 & 1.8 & 7.0 & 5.3 \\
\hline Doctor & 3.1 & 2.4 & 4.4 & 5.6 & 4.3 & 2.9 & 5.9 & 9.1 \\
\hline Nurse/midwife & 25.7 & 16.7 & 41.8 & 49.0 & 36.8 & 18.3 & 53.4 & 64.0 \\
\hline $\begin{array}{l}\text { Traditional Birth Attendant (trained or } \\
\text { untrained) }\end{array}$ & 3.1 & 5.8 & 0.0 & 0.0 & 1.8 & 22.3 & 1.1 & 0.2 \\
\hline
\end{tabular}




\begin{tabular}{lcccccccc} 
& \multicolumn{4}{c}{ March 2017} & \multicolumn{3}{c}{ March 2019} \\
& Amhara & Oromia & SNNP & Tigray & Amhara & Oromia & SNNP & Tigray \\
\hline $\begin{array}{l}\text { Volunteer (Health or Women's } \\
\text { Development Armies) }\end{array}$ & 0.6 & 0.6 & 0.6 & 0.6 & 0.6 & 1.1 & 0.0 & 0.2 \\
Social worker & & & & & & & & \\
Husband & 2.9 & 6.2 & 8.5 & 2.9 & 0.4 & 3.3 & 4.8 & 1.8 \\
Mother/mother-in-law & 20.9 & 17.9 & 13.5 & 15.3 & 15.0 & 9.9 & 9.4 & 9.3 \\
Other family members & 3.1 & 2.4 & 1.8 & 1.3 & 1.2 & 1.1 & 2.6 & 0.4 \\
Friends/neighbors & 32.4 & 29.9 & 16.0 & 9.0 & 35.2 & 38.6 & 14.4 & 7.5 \\
\hline
\end{tabular}

Source: Authors' compilation from surveys, March 2017 and March 2019.

\subsection{Contact with Health Extension Workers and exposure to nutrition services among mothers with children 6 to 23 months of age}

Overall, there were marginal differences in contacts with a HEW or visits to a health post or health center by PSNP status or over survey rounds (Figure 9.1). A slightly smaller share of mothers reported having any contact with a HEW or receiving home visit by a HEW in the three months prior to survey interviews between the 2017 and 2019 rounds, particularly among non-PSNP mothers. In the March 2019 round, for instance, 29 percent of non-PSNP mothers reported having any contact with HEW and 8 percent reported receiving a home visit by a HEW, compared with 36 percent and 10 percent, respectively, in March 2017. Meanwhile, contacts with HEWs remained relatively the same among PSNP mothers.

There was a slight increase in health post visits in the previous three months among PSNP mothers over time (Figure 9.1). In contrast, a decrease in health post visits over time was observed among non-PSNP mothers.

Health center visits in the previous three months increased between the 2017 and 2019 rounds among both PSNP and non-PSNP mothers (Figure 9.1). (This information was not collected in the August 2017 round.) Between the March 2017 and March 2019 rounds, there was a 6 to 8 percentage point increase in health center visits in the three months prior to interview among PSNP and non-PSNP mothers. This finding corroborates the increasing trend in exposure to facility-based care among mothers with children less than 6 months of age, presented in Section 9.1.

Figure 9.1. Contact with Health Extension Workers and health post or health center visits in the past three months, by PSNP status, 2017 and 2019
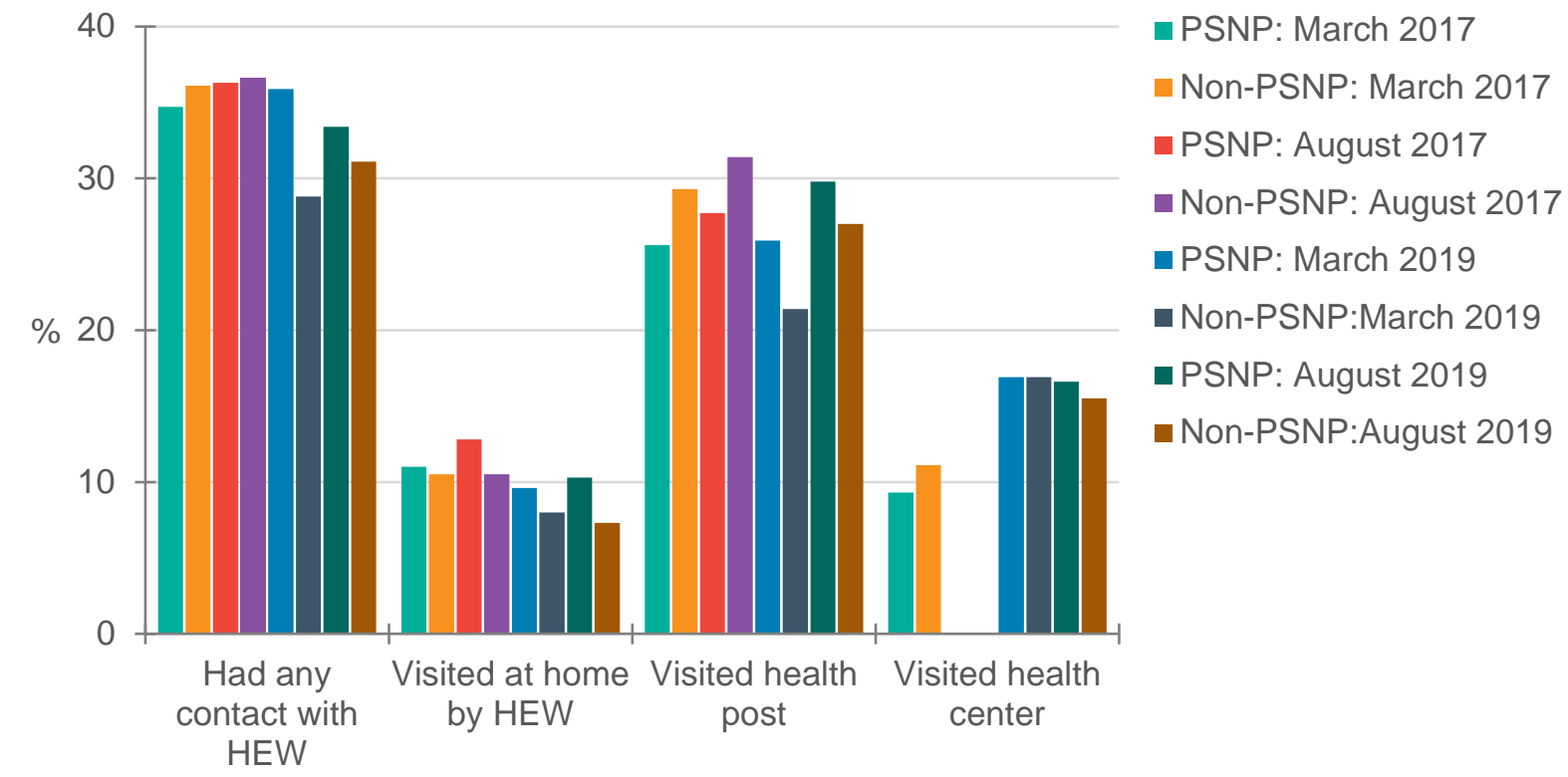

Source: Authors' compilation from surveys, March 2017 and March 2019. 
While mothers' report of exposure to nutrition information or counseling from HEWs or HDAs appeared to decrease over time, exposure to nutrition information from other sources, such as food demonstrations or community conversations or gatherings, increased significantly among both PSNP and non-PSNP mothers.

A substantially smaller share of mothers, regardless of PSNP status, reported receiving nutrition information from HEWs or HDAs in the three months prior to interviews between the 2017 and 2019 rounds (Table 9.3). Between August 2017 and August 2019, there was a 10 percentage point decrease in exposure to nutrition information from HEWs or HDAs among non-PSNP mothers and a 7 percentage point decrease among PSNP mothers. The decrease was observed across both frontline worker types and locations of contact - during home visits, at health posts, or elsewhere.

On the other hand, exposure to nutrition information from food demonstrations and community conversations or gatherings in the previous three months increased significantly over time in both groups. Between the March 2017 and March 2019 rounds, there was a 19 percentage point increase in exposure to food demonstrations among non-PSNP mothers and a 17 percentage point increase among PSNP mothers (Table 9.4). Regional disaggregation in Table 9.5 shows an increase across all regions between 2017 and 2019. A similar pattern was observed for exposure to community conversations or gatherings. Between the March 2017 and March 2019 rounds, there was a 14 percentage point increase in exposure to community conversations among non-PSNP mothers and a 17 percentage point increase among PSNP mothers. Again, regional disaggregation reveals an increase across all the regions between 2017 and 2019. Exposure to nutrition information on the radio remained relatively stable over time, except for a slight decrease in the PSNP group in 2019, corresponding with decreases observed in Amhara and Tigray.

An observation to note is that food demonstrations and community conversations or gatherings are typically led by HEWs and HDAs, but, mothers' report of exposure to these community-based activities was not reflected in their report of exposure to frontline workers, such as any contact with a HEW or exposure to nutrition information from HEWs or HDAs elsewhere. An implication of this inconsistency may be that mothers have a better recall of events or activities they participated in rather than of the type of frontline worker involved.

Table 9.3. Exposure to nutrition information from HEWs or HDAs in the past three months by PSNP status, 2017 and 2019

\begin{tabular}{|c|c|c|c|c|c|c|c|c|}
\hline & \multicolumn{2}{|c|}{ March 2017} & \multicolumn{2}{|c|}{ August 2017} & \multicolumn{2}{|c|}{ March 2019} & \multicolumn{2}{|c|}{ August 2019} \\
\hline & $\begin{array}{l}\text { Non- } \\
\text { PSNP }\end{array}$ & PSNP & $\begin{array}{l}\text { Non- } \\
\text { PSNP }\end{array}$ & PSNP & $\begin{array}{l}\text { Non- } \\
\text { PSNP }\end{array}$ & PSNP & $\begin{array}{l}\text { Non- } \\
\text { PSNP }\end{array}$ & PSNP \\
\hline From HEWs or HDA & 23.1 & 21.2 & 23.9 & 24.3 & 11.7 & 14.8 & 13.7 & 17.8 \\
\hline From HEW during home visit & 5.7 & 6.8 & 5.9 & 8.0 & 4.2 & 5.3 & 3.2 & 6.1 \\
\hline From HEW at health post & 15.5 & 13.2 & 16.6 & 15.6 & 7.6 & 10.0 & 9.2 & 12.1 \\
\hline From HEW elsewhere & 8.1 & 7.9 & 9.2 & 8.8 & 4.2 & 5.3 & 4.7 & 4.6 \\
\hline From HDA during home visit & 2.0 & 2.9 & 2.1 & 3.1 & 0.4 & 0.6 & 1.5 & 1.6 \\
\hline From HDA elsewhere & 2.8 & 2.1 & 2.6 & 2.3 & 0.5 & 0.9 & 0.7 & 1.5 \\
\hline
\end{tabular}

Source: Authors' compilation from surveys. 
Table 9.4. Exposure to nutrition information from other sources in the past three months by PSNP status, 2017 and 2019

\begin{tabular}{|c|c|c|c|c|c|c|c|c|}
\hline & \multicolumn{2}{|c|}{ March 2017} & \multicolumn{2}{|c|}{ August 2017} & \multicolumn{2}{|c|}{ March 2019} & \multicolumn{2}{|c|}{ August 2019} \\
\hline & $\begin{array}{l}\text { Non- } \\
\text { PSNP }\end{array}$ & PSNP & $\begin{array}{l}\text { Non- } \\
\text { PSNP }\end{array}$ & PSNP & $\begin{array}{l}\text { Non- } \\
\text { PSNP }\end{array}$ & PSNP & $\begin{array}{l}\text { Non- } \\
\text { PSNP }\end{array}$ & PSNP \\
\hline Attended food demonstration in community & 2.6 & 3.7 & 2.0 & 4.3 & 21.7 & 20.2 & 14.2 & 19.0 \\
\hline $\begin{array}{l}\text { Attended community conversation or } \\
\text { gathering that discussed child feeding or } \\
\text { nutrition }\end{array}$ & 6.6 & 6.7 & 5.4 & 6.9 & 20.7 & 23.5 & 17.9 & 18.9 \\
\hline Heard nutrition information on the radio & 7.4 & 7.2 & 7.3 & 7.0 & 7.9 & 5.9 & 7.3 & 5.0 \\
\hline
\end{tabular}

Table 9.5. Exposure to nutrition information from other sources in the past three months by region, 2017 and 2019

\begin{tabular}{rlccc} 
March 2017 Amhara & $\begin{array}{c}\text { Attended a food } \\
\text { demonstration in } \\
\text { community }\end{array}$ & $\begin{array}{c}\text { Attended a community } \\
\text { conversation or } \\
\text { gathering that discussed } \\
\text { child feeding or nutrition }\end{array}$ & $\begin{array}{c}\text { Heard nutrition } \\
\text { information on the } \\
\text { radio }\end{array}$ \\
Oromia & 4.2 & 3.8 & 4.8 \\
SNNP & 0 & 2.6 & 3.8 \\
Tigray & 2.4 & 9.4 & 8.4 \\
\hline August 2017 & Amhara & 5.4 & 10.2 & 11.9 \\
Oromia & 3.2 & 3.4 & 5.5 \\
SNNP & 0 & 2.3 & 3.8 \\
Tigray & 3 & 8.4 & 9 \\
\hline Amhara & 5.6 & 9.8 & 10.4 \\
\hline Oromia & 9.3 & 18.8 & 3.1 \\
SNNP & 15 & 14.3 & 3.3 \\
Tigray & 26.9 & 26.2 & 11.3 \\
\hline August 2019 2019 & Amhara & 22.6 & 22.4 & 3.7 \\
Oromia & 20.8 & 16.3 & 3.1 \\
SNNP & 36.4 & 22.2 & 11.3 \\
Tigray & 21.1 & 32.1 & 7.7 \\
\hline
\end{tabular}

Source: Authors' compilation from surveys.

Finally, one of the nutrition-specific interventions in the National Nutrition Programme (GFDRE 2013; 2016) is the monitoring of physical growth of children less than 2 years of age and the promotion of age-appropriate feeding practices. Growth monitoring and promotion is typically carried out by the HEWs and involves measuring the height, weight, and MUAC of children less than 2 years of age as well as providing nutrition counselling to mothers.

Table 9.6. Children 6 to 23 months of age exposure to growth monitoring and promotion in the past three months by PSNP status, percent

\begin{tabular}{|c|c|c|c|c|c|c|c|c|}
\hline & \multicolumn{2}{|c|}{ March 2017} & \multicolumn{2}{|c|}{ August 2017} & \multicolumn{2}{|c|}{ March 2019} & \multicolumn{2}{|c|}{ August 2019} \\
\hline & $\begin{array}{l}\text { Non- } \\
\text { PSNP }\end{array}$ & PSNP & $\begin{array}{l}\text { Non- } \\
\text { PSNP }\end{array}$ & PSNP & $\begin{array}{l}\text { Non- } \\
\text { PSNP }\end{array}$ & PSNP & $\begin{array}{l}\text { Non- } \\
\text { PSNP }\end{array}$ & PSNP \\
\hline Weight was measured & 25.5 & 24.5 & 17.0 & 21.6 & 15.2 & 15.0 & 13.9 & 16.8 \\
\hline Length or height was measured & 15.2 & 14.2 & 12.0 & 15.2 & 9.0 & 10.3 & 9.0 & 10.6 \\
\hline MUAC was measured & 25.8 & 27.2 & 20.3 & 27.3 & 17.9 & 20.1 & 16.5 & 23.1 \\
\hline Any growth monitoring & 32.8 & 32.0 & 23.1 & 29.0 & 21.9 & 22.3 & 19.2 & 26.0 \\
\hline $\begin{array}{l}\text { Among those receiving growth monitoring, } \\
\text { received advice on feeding }\end{array}$ & 61.0 & 57.7 & 53.4 & 50.9 & 50.4 & 50.6 & 45.2 & 47.9 \\
\hline
\end{tabular}

Source: Authors' compilation from surveys.

Note: MUAC = Mid-Upper Arm Circumference. 
Exposure to any growth monitoring in the three months prior to the survey interviews decreased over time among index children 6 to 23 months of age in both PSNP and non-PNSP households (Table 9.6). Between March 2017 and March 2019 rounds, any growth monitoring fell by 11 percentage points among children in non-PSNP households and fell by 10 percentage point among children in PSNP households. Decreases over time were observed for weight, height and MUAC measurement as well as in the provision of child feeding advice to mothers. Regional disaggregation (Table 9.7) also showed that exposure to growth monitoring and promotion fell across all the regions.

Table 9.7. Children 6 to 23 months of age exposure to growth monitoring and promotion in the past three months by region, percent

\begin{tabular}{|c|c|c|c|c|c|c|}
\hline & & $\begin{array}{l}\text { Weight was } \\
\text { measured }\end{array}$ & $\begin{array}{c}\text { Length or } \\
\text { height was } \\
\text { measured }\end{array}$ & $\begin{array}{l}\text { MUAC was } \\
\text { measured }\end{array}$ & $\begin{array}{l}\text { Any growth } \\
\text { monitoring }\end{array}$ & $\begin{array}{l}\text { Among those } \\
\text { receiving growth } \\
\text { monitoring, received } \\
\text { advice on feeding }\end{array}$ \\
\hline \multirow{4}{*}{$\begin{array}{r}\text { March } \\
2017\end{array}$} & Amhara & 28.7 & 13.0 & 37.0 & 43.5 & 54.9 \\
\hline & Oromia & 9.9 & 5.5 & 12.2 & 16.2 & 32.5 \\
\hline & SNNP & 27.3 & 20.1 & 22.9 & 29.3 & 69.4 \\
\hline & Tigray & 34.3 & 20.7 & 33.3 & 40.5 & 66.5 \\
\hline \multirow{4}{*}{$\begin{array}{c}\text { August } \\
2017\end{array}$} & Amhara & 18.2 & 10.9 & 22.9 & 25.2 & 53.0 \\
\hline & Oromia & 10.0 & 6.7 & 16.2 & 17.3 & 44.0 \\
\hline & SNNP & 23.4 & 18.2 & 24.7 & 27.3 & 56.3 \\
\hline & Tigray & 23.8 & 17.3 & 28.8 & 32.1 & 53.1 \\
\hline \multirow{4}{*}{$\begin{array}{r}\text { March } \\
2019\end{array}$} & Amhara & 14.6 & 10.1 & 22.4 & 23.7 & 44.4 \\
\hline & Oromia & 6.9 & 4.7 & 7.8 & 10.5 & 38.5 \\
\hline & SNNP & 12.3 & 8.3 & 15.8 & 19.0 & 55.2 \\
\hline & Tigray & 25.8 & 14.7 & 28.3 & 33.9 & 56.1 \\
\hline \multirow{4}{*}{$\begin{array}{c}\text { August } \\
2019\end{array}$} & Amhara & 14.4 & 8.1 & 20.0 & 23.5 & 48.2 \\
\hline & Oromia & 10.8 & 6.2 & 14.5 & 16.4 & 30.6 \\
\hline & SNNP & 12.5 & 7.7 & 13.3 & 14.7 & 54.1 \\
\hline & Tigray & 22.7 & 16.6 & 29.1 & 33.6 & 50.0 \\
\hline
\end{tabular}

Source: Authors' compilation from surveys. Note: MUAC = Mid-Upper Arm Circumference. 


\section{IMPACT EVALUATION METHOD}

The fundamental challenge of any impact evaluation is to estimate impact by comparing outcomes for beneficiaries to the counterfactual - what those outcomes would have been had the beneficiaries not received the program. In a randomized controlled trial design, the counterfactual is constructed by randomly assigning treatment and control group status between similarly eligible communities or households. When treatment assignment is random, households assigned to the control group are identical (in expectation) to households in the treatment group at baseline, so these control households provide a strong counterfactual. Impacts of the program can be measured as differences in outcomes or differences in changes in outcomes over time between the randomly assigned treatment and control households. When it is not possible to implement a randomized controlled trial or other experimental design, an identification strategy must be developed in which the counterfactual is constructed using statistical techniques to create a comparison group of households who are observationally similar to the beneficiary group.

The primary impact evaluation approach for this evaluation of nutrition-sensitive interventions in PSNP-4 combines difference-in-difference and matching methods. Matching approaches can be used for programs like PSNP in which targeting of beneficiaries at the community and household level is conducted by the program and cannot be subjected to randomization. With such a targeting design, regression discontinuity, an alternative impact evaluation approach, is infeasible, as the use of community targeting by the program means that there is no unique cut-off in a specific targeting characteristic that will separate beneficiaries from non-beneficiaries. Members of this research team have used matching methods successfully to evaluate the impact of PSNP in previous rounds (Gilligan et al. 2009; Berhane et al. 2014).

A common approach to estimate program impacts in non-experimental studies is to construct the counterfactual by matching program beneficiaries to non-beneficiaries using observed characteristics measured in the household survey using matching techniques, such as propensity score matching (Rosenbaum and Rubin 1983; Smith and Todd 2005) or covariate matching (Abadie and Imbens 2006). Such approaches estimate program impacts as a weighted average of differences in outcomes between beneficiaries and non-beneficiaries in which the weights are constructed using a measure of the degree of similarity of characteristics of households in these two groups. These approaches differ in part by the way that they construct the weights. Heckman, Ichimura, and Todd $(1997,1998)$ show that such matching approaches work well under certain conditions, including that households live in the same areas and use the same markets and that observable characteristics of households are measured in the same way. These conditions are likely to be met in the PSNP-4 evaluation samples because non-beneficiary households are sampled from PNSP kebeles and woredas.

As described in Chapter 2, the sampling strategy is based on a repeated cross-sectional design - while the survey localities remain the same, different households are interviewed at the baseline (2017) and endline (2019). Given this, our matching strategy combines difference-in-difference with matching in a context of repeated cross-section data. More specifically, following Blundell and Dias (2009) and Blundell et al. (2004), we match the treated households at the endline survey separately to three comparison groups: the treated group at the baseline survey, i.e., before treatment, in 2017; the control group at the baseline in 2017; and the control group at the endline in 2019. This approach creates the propensity score weights needed to construct the difference in outcomes across these groups. A single propensity score model is estimated on a sample including all four of these groups in which the participation variable is defined as 1 for all treated endline observations and 0 for all treated baseline, comparison endline, and comparison baseline observations. 
Calculating the treatment effect using the repeated cross section PSM approach requires that for each treated endline outcome observation, we subtract the weighted average treated baseline outcome for the matched comparison observations and the difference in the weighted average outcome between the endline and the baseline in the comparison group. The average of these differences in weighted averages across treatment observations is the estimated impact of the program. As with other PSM models, standard errors for measuring significance levels must be constructed using bootstrapping.

In our application, this strategy translates into conducting the matching three times:

1. PSNP households in 2019 (treated) to non-PSNP households in 2019 (control)

2. PSNP households in 2019 (treated) to PSNP households in 2017 (control)

3. PSNP households in 2019 (treated) to non-PSNP households in 2017 (control)

\subsection{Definition of treatment status}

The household questionnaire had a series of questions that asked households whether they had been selected into PSNP during the survey year or in previous years. In addition, households were asked a series of follow-up questions that help us to correctly determine households' beneficiary status, including questions on whether they had been selected into Public Works or Direct Support; the payments they received, and the amount of public works they have been carrying out.

We define treatment as households that were benefitting from PSNP in the year that the interview took place -2017 or 2019. We do not differentiate households by the level of payments that they received. Unlike earlier evaluations of PSNP, there is less variability in payment levels and, more specifically, far fewer PSNP households receiving near-zero payments. In 2019, PSNP payments between Tir and Nehasse EC2011 (January to August 2019) per household for selected percentiles were: 2,340 Birr at the $25^{\text {th }}$ percentile; 3,600 Birr at the median; and 4,800 Birr at the $75^{\text {th }}$ percentile. Nor do we account for whether households received access to nutrition BCC activities or not. As discussed in chapter 9, coverage of these activities is very low. Control households are formed of households in the surveyed communities that were not benefitting from PSNP that year.

\subsection{Covariate selection}

For our covariates for matching treatment with control households, we select variables that are likely to affect both the selection into PSNP and child or maternal nutrition outcomes. This selection is guided by theory, knowledge of how the program functions, and our previous impact evaluations of PSNP. Broadly, the household level variables can be categorized into household head characteristics (age, education level, + squared and cubed of both variables), ${ }^{30}$ household demographics (size and dependency ratio), and household assets (housing, land, livestock, etc.) The kebele questionnaire administered in 2016 asked detailed questions about the targeting views and practices in each kebele. ${ }^{31}$ We use these data to create a host of binary variables capturing different dimensions of whether the household is considered eligible by the kebele to be included in PSNP. We also include interaction terms of the kebele's views on household's PSNP eligibility status and region dummies. ${ }^{32}$ This approach permits interpretation of the eligibility criteria to vary across regions. Finally, kebele-level characteristics include the 'targeting knowledge score' of kebele leaders based on their understanding of the targeting guidelines laid out in the PIM, ${ }^{33}$ number of

\footnotetext{
${ }^{30}$ We also considered head's sex (male/female) and age but the balancing property was never satisfied when this variable was included into the model.

${ }^{31}$ As part of the baseline survey for the main evaluation of PSNP, we visited the same kebele in 2016 . One component of this baseline survey were focus group discussions with kebele informants.

${ }^{32}$ In few instances, these interactions violated the common support assumption. It is for this reason that not all eligibility score variables have been interacted.

${ }^{33}$ This is based on the data collected in 2016.
} 
development agents in the kebele, road quality in the kebele, whether the kebele publicly posts the list of PSNP beneficiaries, whether the kebele had sufficient funds to include all eligible households into the PSNP, and whether the kebele leaders received training on targeting.

Table 10.1 provides summary statistics of the variables used to estimate the propensity score from the March 2017 and March 2019 rounds. Note that the sample used here is slightly smaller than for other analyses using these datasets because a few kebeles were not benefitting from PSNP or because they were not visited in all four rounds. ${ }^{34}$

\section{Table 10.1. Covariates used to estimate the propensity score}

\begin{tabular}{|c|c|c|c|c|}
\hline & \multicolumn{2}{|c|}{ March 2017} & \multicolumn{2}{|c|}{ March 2019} \\
\hline & $\begin{array}{l}\text { Non- } \\
\text { PSNP }\end{array}$ & PSNP & $\begin{array}{l}\text { Non- } \\
\text { PSNP }\end{array}$ & PSNP \\
\hline Observations & 1,301 & 1,037 & 1,301 & 1,037 \\
\hline \multicolumn{5}{|l|}{ Household characteristics } \\
\hline Head age in years & 37.7 & 39.2 & 36.9 & 40.5 \\
\hline Head's age squared & 1537.2 & 1660.8 & 1491.2 & 1782.2 \\
\hline Mother has not gone to school & 0.811 & 0.862 & 0.524 & 0.598 \\
\hline Mother's age (in years) & 28.60 & 29.47 & 28.24 & 30.05 \\
\hline Child's age in full months & 11.78 & 11.49 & 10.84 & 11.04 \\
\hline Size is 3 or less & 0.150 & 0.097 & 0.199 & 0.078 \\
\hline Size is 4 to 5 & 0.347 & 0.368 & 0.343 & 0.348 \\
\hline Size is 6 to 7 & 0.326 & 0.335 & 0.278 & 0.361 \\
\hline Size is more than 7 & 0.177 & 0.200 & 0.18 & 0.214 \\
\hline Number of old members (60+ years) / household size & 0.014 & 0.019 & 0.014 & 0.023 \\
\hline Has $<0.5$ ha of land & 0.324 & 0.369 & 0.313 & 0.342 \\
\hline Has more than 1 ha of land & 0.327 & 0.287 & 0.375 & 0.338 \\
\hline Has 3 or more heads of cattle & 0.439 & 0.282 & 0.433 & 0.295 \\
\hline Has 1 or 2 head of cattle & 0.361 & 0.421 & 0.333 & 0.396 \\
\hline Has 5 or more sheep/goats & 0.168 & 0.168 & 0.19 & 0.157 \\
\hline Has 5 or less chicken \& no other livestock & 0.121 & 0.179 & 0.145 & 0.157 \\
\hline Owns no animals & 0.085 & 0.108 & 0.111 & 0.111 \\
\hline Tropical livestock units (TLU) owned by household & 3.490 & 2.633 & 3.608 & 2.769 \\
\hline Has corrugated iron roof & 0.460 & 0.372 & 0.526 & 0.437 \\
\hline Dwelling is in bad shape & 0.189 & 0.247 & 0.171 & 0.261 \\
\hline Owns a mobile phone & 0.428 & 0.322 & 0.539 & 0.414 \\
\hline Received 100 birr or more in remittances per month & 0.015 & 0.009 & 0.049 & 0.053 \\
\hline $\begin{array}{l}\text { An adult member in the household cannot work because of injury or } \\
\text { poor hearing/sight }\end{array}$ & 0.012 & 0.023 & 0.035 & 0.073 \\
\hline Has less than 0.5 ha of land and is considered eligible for PSNP & 0.145 & 0.178 & 0.132 & 0.166 \\
\hline Tigray & 0.035 & 0.055 & 0.037 & 0.054 \\
\hline Amhara & 0.038 & 0.038 & 0.029 & 0.029 \\
\hline Oromia & 0.035 & 0.033 & 0.029 & 0.036 \\
\hline SNNP & 0.036 & 0.053 & 0.036 & 0.047 \\
\hline Has between 0.5 and 1 ha of land and considered eligible for PSNP & 0.062 & 0.081 & 0.065 & 0.067 \\
\hline Tigray & 0.013 & 0.016 & 0.016 & 0.014 \\
\hline Amhara & 0.021 & 0.024 & 0.024 & 0.020 \\
\hline Oromia & 0.021 & 0.029 & 0.019 & 0.027 \\
\hline SNNP & 0.007 & 0.012 & 0.006 & 0.006 \\
\hline Has more than 1 ha of land and is considered eligible for PSNP & 0.005 & 0.013 & 0.011 & 0.015 \\
\hline Has one or more oxen and is considered eligible for PSNP & 0.182 & 0.146 & 0.191 & 0.136 \\
\hline Tigray & 0.074 & 0.049 & 0.078 & 0.045 \\
\hline Amhara & 0.067 & 0.049 & 0.058 & 0.047 \\
\hline
\end{tabular}

${ }^{34}$ Moreover, we do not have kebele-level information for new kebeles that were chosen to replace kebeles that we were not able to visit in 2019 due to security concerns. 


\begin{tabular}{|c|c|c|c|c|}
\hline & \multicolumn{2}{|c|}{ March 2017} & \multicolumn{2}{|c|}{ March 2019} \\
\hline & $\begin{array}{l}\text { Non- } \\
\text { PSNP }\end{array}$ & PSNP & $\begin{array}{l}\text { Non- } \\
\text { PSNP }\end{array}$ & PSNP \\
\hline Oromia & 0.027 & 0.031 & 0.039 & 0.029 \\
\hline SNNP & 0.015 & 0.016 & 0.016 & 0.015 \\
\hline $\begin{array}{l}\text { Has three or more heads of cattle and is considered eligible for } \\
\text { PSNP }\end{array}$ & 0.035 & 0.026 & 0.032 & 0.018 \\
\hline Tigray & 0.013 & 0.006 & 0.013 & 0.007 \\
\hline Amhara & 0.010 & 0.003 & 0.006 & 0.002 \\
\hline Oromia & 0.008 & 0.011 & 0.009 & 0.005 \\
\hline SNNP & 0.003 & 0.007 & 0.005 & 0.005 \\
\hline Has one or two heads of cattle and is considered eligible for PSNP & 0.126 & 0.151 & 0.134 & 0.135 \\
\hline Tigray & 0.027 & 0.046 & 0.039 & 0.038 \\
\hline Amhara & 0.055 & 0.048 & 0.054 & 0.054 \\
\hline Oromia & 0.027 & 0.037 & 0.025 & 0.020 \\
\hline SNNP & 0.018 & 0.020 & 0.015 & 0.023 \\
\hline Has five or more sheep/goats and is considered eligible for PSNP & 0.118 & 0.111 & 0.132 & 0.100 \\
\hline Tigray & 0.053 & 0.040 & 0.054 & 0.033 \\
\hline Amhara & 0.048 & 0.031 & 0.046 & 0.037 \\
\hline Oromia & 0.012 & 0.026 & 0.021 & 0.021 \\
\hline SNNP & 0.005 & 0.015 & 0.011 & 0.010 \\
\hline $\begin{array}{l}\text { Has a few chickens but no other animals and is considered eligible } \\
\text { for PSNP }\end{array}$ & 0.104 & 0.174 & 0.125 & 0.149 \\
\hline Tigray & 0.028 & 0.074 & 0.030 & 0.068 \\
\hline Amhara & 0.022 & 0.035 & 0.023 & 0.023 \\
\hline Oromia & 0.019 & 0.022 & 0.023 & 0.014 \\
\hline SNNP & 0.035 & 0.042 & 0.050 & 0.044 \\
\hline Has no animals and is considered eligible for PSNP & 0.076 & 0.108 & 0.102 & 0.107 \\
\hline Tigray & 0.021 & 0.041 & 0.026 & 0.051 \\
\hline Amhara & 0.011 & 0.016 & 0.017 & 0.016 \\
\hline Oromia & 0.018 & 0.018 & 0.016 & 0.011 \\
\hline SNNP & 0.026 & 0.033 & 0.043 & 0.029 \\
\hline Dwelling has metal roofing and is considered eligible for PSNP & 0.225 & 0.189 & 0.258 & 0.217 \\
\hline Tigray & 0.064 & 0.069 & 0.075 & 0.079 \\
\hline Amhara & 0.102 & 0.068 & 0.108 & 0.072 \\
\hline Oromia & 0.054 & 0.038 & 0.063 & 0.053 \\
\hline SNNP & 0.005 & 0.015 & 0.012 & 0.013 \\
\hline Dwelling is in a state of disrepair \& is considered eligible for PSNP & 0.177 & 0.231 & 0.153 & 0.236 \\
\hline Tigray & 0.018 & 0.034 & 0.020 & 0.032 \\
\hline Amhara & 0.061 & 0.067 & 0.047 & 0.071 \\
\hline Oromia & 0.050 & 0.050 & 0.052 & 0.063 \\
\hline SNNP & 0.048 & 0.081 & 0.035 & 0.070 \\
\hline Owns a mobile phone and is considered eligible for PSNP & 0.299 & 0.228 & 0.387 & 0.299 \\
\hline Tigray & 0.119 & 0.117 & 0.139 & 0.123 \\
\hline Amhara & 0.092 & 0.066 & 0.117 & 0.072 \\
\hline Oromia & 0.054 & 0.033 & 0.079 & 0.075 \\
\hline SNNP & 0.034 & 0.013 & 0.053 & 0.029 \\
\hline \multicolumn{5}{|l|}{ Kebele characteristics } \\
\hline Info on PSNP eligibility perception missing & 0.027 & 0.025 & 0.030 & 0.020 \\
\hline Households experienced a non-drought shock in the last 3 years & 0.386 & 0.379 & 0.351 & 0.360 \\
\hline Kebele did not have sufficient funds for all eligible households & 0.665 & 0.694 & 0.665 & 0.694 \\
\hline Kebele is connected to a road made of stones & 0.394 & 0.351 & 0.394 & 0.355 \\
\hline Kebele is connected to a dirt road & 0.324 & 0.373 & 0.332 & 0.363 \\
\hline Kebele officials received training on targeting in the last $12 \mathrm{~m}$ & 0.958 & 0.959 & 0.951 & 0.964 \\
\hline Score from a test of targeting knowledge (max 5 points) & 3.730 & 3.677 & 3.705 & 3.712 \\
\hline Only poorest households in woreda have access to PSNP benefits & 0.957 & 0.957 & 0.964 & 0.948 \\
\hline
\end{tabular}




\begin{tabular}{lccccc} 
& \multicolumn{2}{c}{ March 2017} & \multicolumn{2}{c}{ March 2019} \\
& $\begin{array}{c}\text { Non- } \\
\text { Non- }\end{array}$ & \multicolumn{2}{c}{ Nons } \\
Tigray & PSNP & PSNP & PSNP & PSNP \\
Amhara & 0.248 & 0.316 & 0.269 & 0.290 \\
Oromia & 0.297 & 0.264 & 0.286 & 0.275 \\
SNNP & 0.198 & 0.191 & 0.196 & 0.198 \\
\hline
\end{tabular}

Source: Authors' compilation from surveys, March 2017 and March 2019.

\subsection{Estimating the propensity score}

Table 10.2 provides the propensity score estimation results based on a logit model for each of the three scenario. As noted by Imbens $(2015,389)$, "the propensity score plays a mechanical role in balancing the covariates". In other words, the purpose of this exercise is to find a specification that leads to an accurate prediction of program participation. Therefore, we do not interpret the regression coefficients in Table 10.2.

\section{Table 10.2. Propensity score regressions}

\begin{tabular}{|c|c|c|c|}
\hline \multirow{3}{*}{ T } & (1) & (2) & (3) \\
\hline & $\begin{array}{c}\text { PSNP } \\
\text { beneficiary } \\
\text { in } 2019\end{array}$ & $\begin{array}{c}\text { PSNP } \\
\text { beneficiary } \\
\text { in } 2019\end{array}$ & $\begin{array}{c}\text { PSNP } \\
\text { beneficiary } \\
\text { in } 2019\end{array}$ \\
\hline & $\begin{array}{l}\text { Non-PSNP } \\
\text { beneficiary } \\
\text { in } 2019\end{array}$ & $\begin{array}{c}\text { PSNP } \\
\text { beneficiary } \\
\text { in } 2017\end{array}$ & $\begin{array}{c}\text { Non-PSNP } \\
\text { beneficiary } \\
\text { in } 2017\end{array}$ \\
\hline \multirow[t]{2}{*}{ Head age, years } & $0.0837^{* \star *}$ & -0.0206 & 0.0343 \\
\hline & $(0.0276)$ & $(0.0308)$ & $(0.0301)$ \\
\hline \multirow[t]{2}{*}{ Head's age squared } & $-0.00070^{* *}$ & 0.0002 & -0.0003 \\
\hline & $(0.00028)$ & $(0.00032)$ & $(0.00031)$ \\
\hline \multirow[t]{2}{*}{ Mother has not gone to school } & -0.0766 & $-1.748^{\star \star \star}$ & $-1.621^{\star \star \star}$ \\
\hline & $(0.108)$ & $(0.130)$ & $(0.120)$ \\
\hline \multirow[t]{2}{*}{ Mother's age (in years) } & 0.00912 & $0.0521^{\star \star \star}$ & $0.0523^{\star \star *}$ \\
\hline & $(0.0104)$ & $(0.0101)$ & $(0.0102)$ \\
\hline \multirow[t]{2}{*}{ Child's age, full months } & 0.0025 & -0.0118 & $-0.0183^{\star \star \star}$ \\
\hline & $(0.0069)$ & $(0.0072)$ & $(0.0070)$ \\
\hline \multirow[t]{2}{*}{ Household size is 3 or less } & 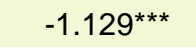 & -0.256 & $-1.045^{\star \star \star}$ \\
\hline & $(0.221)$ & $(0.250)$ & $(0.234)$ \\
\hline \multirow[t]{2}{*}{ Household size is 4 to 5} & -0.170 & 0.0352 & -0.234 \\
\hline & $(0.153)$ & $(0.163)$ & $(0.160)$ \\
\hline \multirow[t]{2}{*}{ Household size is 6 to 7} & 0.124 & 0.0957 & -0.0210 \\
\hline & $(0.133)$ & $(0.141)$ & $(0.138)$ \\
\hline \multirow[t]{2}{*}{ Number of old members (60+ years) / household size } & 1.592 & -0.636 & 1.444 \\
\hline & $(1.057)$ & $(1.032)$ & $(1.070)$ \\
\hline \multirow[t]{2}{*}{ Household has $<0.5$ ha of land } & 0.0538 & -0.0571 & 0.0526 \\
\hline & $(0.150)$ & $(0.156)$ & $(0.153)$ \\
\hline \multirow[t]{2}{*}{ Household has more than 1 ha of land } & -0.0234 & $0.275^{\star \star}$ & $0.326 * \star \star$ \\
\hline & $(0.122)$ & $(0.132)$ & $(0.127)$ \\
\hline \multirow[t]{2}{*}{ Household has 3 or more heads of cattle } & $-0.861^{\star \star \star}$ & $-0.388^{\star \star}$ & $-1.281^{\star \star \star}$ \\
\hline & $(0.192)$ & $(0.194)$ & $(0.197)$ \\
\hline \multirow[t]{2}{*}{ Household has 1 or 2 head of cattle } & -0.240 & $-0.358^{\star \star}$ & $-0.685^{\star \star \star}$ \\
\hline & $(0.170)$ & $(0.168)$ & $(0.177)$ \\
\hline \multirow[t]{2}{*}{ Household has 5 or more sheep/goats } & -0.0274 & -0.130 & 0.180 \\
\hline & $(0.220)$ & $(0.227)$ & $(0.224)$ \\
\hline \multirow[t]{2}{*}{ Household has 5 or less chicken \& no other livestock } & -0.451 & -0.437 & -0.730 \\
\hline & $(0.550)$ & $(0.654)$ & $(0.591)$ \\
\hline
\end{tabular}




\begin{tabular}{|c|c|c|c|}
\hline \multirow{2}{*}{ Treatment group: } & (1) & (2) & (3) \\
\hline & $\begin{array}{c}\text { PSNP } \\
\text { beneficiary } \\
\text { in } 2019\end{array}$ & $\begin{array}{c}\text { PSNP } \\
\text { beneficiary } \\
\text { in } 2019\end{array}$ & $\begin{array}{c}\text { PSNP } \\
\text { beneficiary } \\
\text { in } 2019\end{array}$ \\
\hline Control group: & $\begin{array}{l}\text { Non-PSNP } \\
\text { beneficiary } \\
\text { in } 2019\end{array}$ & $\begin{array}{c}\text { PSNP } \\
\text { beneficiary } \\
\text { in } 2017\end{array}$ & $\begin{array}{c}\text { Non-PSNP } \\
\text { beneficiary } \\
\text { in } 2017\end{array}$ \\
\hline \multirow[t]{2}{*}{ Household owns no animals } & -0.114 & 14.39 & -1.173 \\
\hline & $(0.872)$ & $(726.5)$ & $(0.745)$ \\
\hline \multirow[t]{2}{*}{ Corrugated iron roof } & $-0.0441^{\star \star}$ & 0.0159 & -0.0282 \\
\hline & $(0.0213)$ & $(0.0199)$ & $(0.0203)$ \\
\hline \multirow[t]{2}{*}{ Dwelling is in bad shape } & $-0.371^{\star \star \star}$ & 0.212 & $-0.267^{\star \star}$ \\
\hline & $(0.122)$ & $(0.137)$ & $(0.130)$ \\
\hline \multirow[t]{2}{*}{ Household owns a mobile phone } & 0.311 & $0.729 * \star$ & $1.061^{\star \star \star}$ \\
\hline & $(0.336)$ & $(0.363)$ & $(0.389)$ \\
\hline \multirow[t]{2}{*}{ Household received 100 birr or more in remittances per month } & $-0.447^{\star \star \star}$ & 0.160 & $-0.366^{\star \star}$ \\
\hline & $(0.154)$ & $(0.177)$ & $(0.164)$ \\
\hline \multirow[t]{2}{*}{ Tropical livestock units (TLU) owned by household } & $0.367^{*}$ & $2.009 * \star \star$ & $1.322^{\star \star \star}$ \\
\hline & $(0.217)$ & $(0.385)$ & $(0.303)$ \\
\hline \multirow{2}{*}{$\begin{array}{l}\text { An adult member in household cannot work because of injury or poor } \\
\text { hearing/sight }\end{array}$} & $0.558^{\star \star \star}$ & $1.010^{\star \star \star}$ & $1.719^{\star \star \star}$ \\
\hline & $(0.211)$ & $(0.255)$ & $(0.298)$ \\
\hline \multirow{2}{*}{$\begin{array}{l}\text { Household has less than } 0.5 \text { ha of land and is considered eligible for } \\
\text { PSNP }\end{array}$} & 0.224 & 0.405 & 0.298 \\
\hline & $(0.273)$ & $(0.262)$ & $(0.291)$ \\
\hline \multirow[t]{2}{*}{ Amhara } & -0.132 & -0.596 & $-0.687^{*}$ \\
\hline & $(0.388)$ & $(0.385)$ & $(0.397)$ \\
\hline \multirow[t]{2}{*}{ Oromia } & 0.151 & -0.483 & -0.249 \\
\hline & $(0.390)$ & $(0.396)$ & $(0.396)$ \\
\hline \multirow[t]{2}{*}{ SNNP } & 0.154 & -0.540 & 0.185 \\
\hline & $(0.363)$ & $(0.350)$ & $(0.377)$ \\
\hline \multirow{2}{*}{$\begin{array}{l}\text { Household has between } 0.5 \text { and } 1 \text { ha of land and is considered } \\
\text { eligible for PSNP }\end{array}$} & 0.185 & 0.502 & 0.523 \\
\hline & $(0.414)$ & $(0.401)$ & $(0.424)$ \\
\hline \multirow[t]{2}{*}{ Amhara } & -0.802 & -0.524 & -0.544 \\
\hline & $(0.525)$ & $(0.521)$ & $(0.542)$ \\
\hline \multirow[t]{2}{*}{ Oromia } & 0.396 & -0.395 & -0.112 \\
\hline & $(0.526)$ & $(0.523)$ & $(0.538)$ \\
\hline \multirow[t]{2}{*}{ SNNP } & -0.303 & $-1.300^{*}$ & -0.585 \\
\hline & $(0.713)$ & $(0.710)$ & $(0.769)$ \\
\hline \multirow[t]{2}{*}{ Household has one or more oxen and is considered eligible for PSNP } & -0.332 & 0.260 & -0.247 \\
\hline & $(0.230)$ & $(0.266)$ & $(0.243)$ \\
\hline \multirow[t]{2}{*}{ Amhara } & 0.227 & -0.301 & 0.172 \\
\hline & $(0.320)$ & $(0.358)$ & $(0.333)$ \\
\hline \multirow[t]{2}{*}{ Oromia } & 0.448 & -0.456 & 0.546 \\
\hline & $(0.377)$ & $(0.449)$ & $(0.420)$ \\
\hline \multirow[t]{2}{*}{ SNNP } & 0.742 & 0.292 & 0.406 \\
\hline & $(0.546)$ & $(0.642)$ & $(0.560)$ \\
\hline Household has three or more heads of cattle and is considered & -0.179 & -0.103 & -0.116 \\
\hline & $(0.493)$ & $(0.633)$ & $(0.519)$ \\
\hline Amhara & -0.447 & -0.534 & -0.863 \\
\hline & $(0.991)$ & $(1.180)$ & $(0.971)$ \\
\hline Oromia & -0.422 & -0.828 & -0.652 \\
\hline & $(0.773)$ & $(0.913)$ & $(0.838)$ \\
\hline SNNP & 0.306 & -0.0541 & 0.180 \\
\hline & $(0.899)$ & $(1.001)$ & $(0.967)$ \\
\hline
\end{tabular}




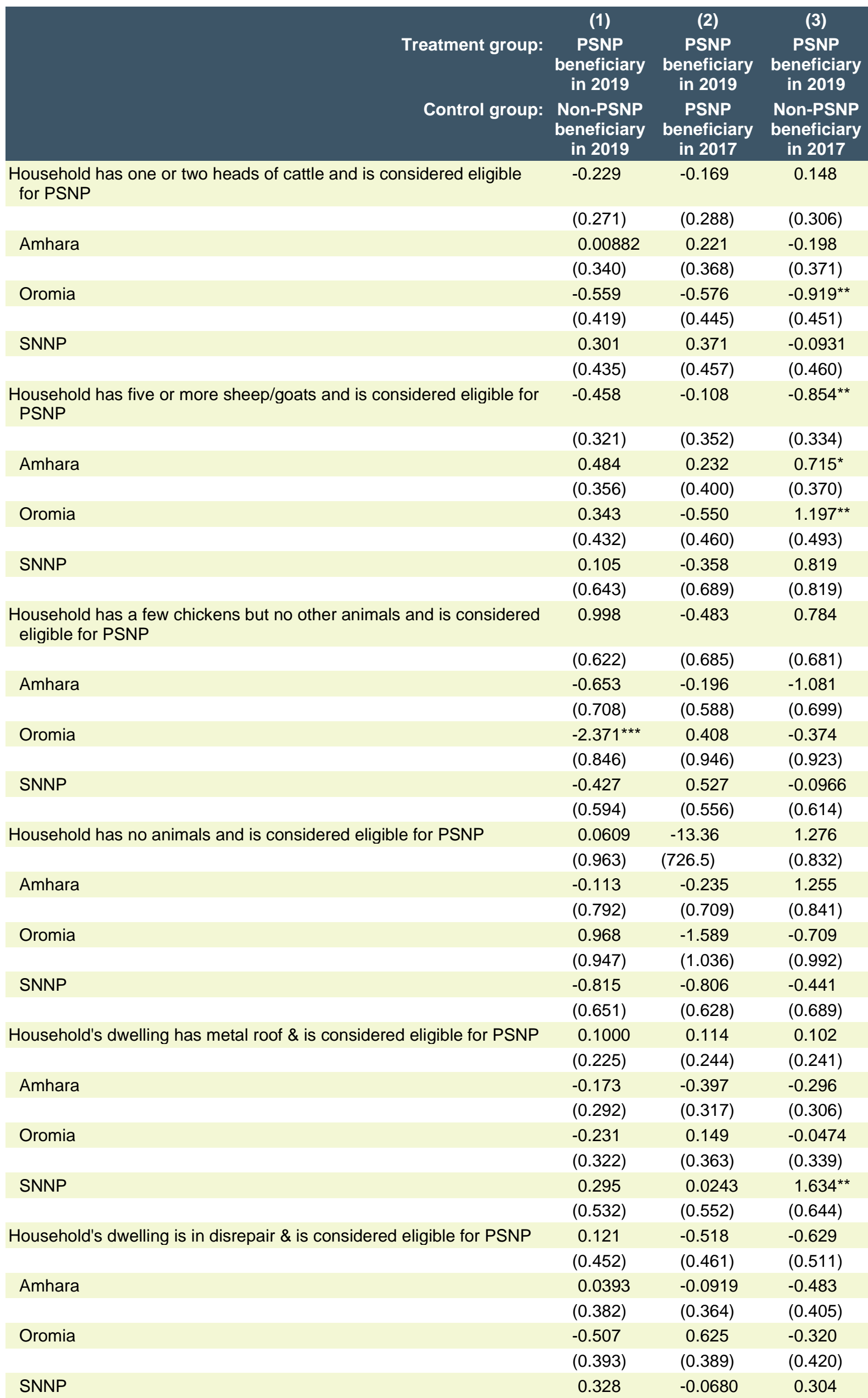




\begin{tabular}{|c|c|c|c|}
\hline \multirow{4}{*}{ Treatment group: } & (1) & (2) & (3) \\
\hline & $\begin{array}{c}\text { PSNP } \\
\text { beneficiary } \\
\text { in } 2019\end{array}$ & $\begin{array}{c}\text { PSNP } \\
\text { beneficiary } \\
\text { in } 2019\end{array}$ & $\begin{array}{c}\text { PSNP } \\
\text { beneficiary } \\
\text { in } 2019\end{array}$ \\
\hline & $\begin{array}{l}\text { Non-PSNP } \\
\text { beneficiary } \\
\text { in } 2019\end{array}$ & $\begin{array}{c}\text { PSNP } \\
\text { beneficiary } \\
\text { in } 2017\end{array}$ & $\begin{array}{l}\text { Non-PSNP } \\
\text { beneficiary } \\
\text { in } 2017\end{array}$ \\
\hline & $(0.392)$ & $(0.363)$ & $(0.411)$ \\
\hline \multirow[t]{2}{*}{ Household owns a mobile phone and is considered eligible for PSNP } & -0.0382 & -0.178 & -0.252 \\
\hline & $(0.222)$ & $(0.248)$ & $(0.240)$ \\
\hline \multirow[t]{2}{*}{ Amhara } & -0.149 & -0.0160 & 0.248 \\
\hline & $(0.261)$ & $(0.289)$ & $(0.280)$ \\
\hline \multirow[t]{2}{*}{ Oromia } & $0.623^{\star *}$ & $0.957 * \star *$ & $0.945^{\star \star *}$ \\
\hline & $(0.282)$ & $(0.329)$ & $(0.304)$ \\
\hline \multirow[t]{2}{*}{ SNNP } & 0.00137 & 0.565 & 0.591 \\
\hline & $(0.319)$ & $(0.434)$ & $(0.360)$ \\
\hline \multirow[t]{2}{*}{ Info on PSNP eligibility perception missing } & -0.0740 & -0.296 & 0.135 \\
\hline & $(0.344)$ & $(0.348)$ & $(0.356)$ \\
\hline \multirow[t]{2}{*}{ Household experienced a non-drought shock in the last 3 years } & -0.111 & -0.0826 & -0.122 \\
\hline & $(0.102)$ & $(0.106)$ & $(0.101)$ \\
\hline \multirow[t]{2}{*}{ Kebele did not have sufficient funds for all eligible households } & 0.132 & 0.0689 & $0.212^{*}$ \\
\hline & $(0.105)$ & $(0.116)$ & $(0.110)$ \\
\hline \multirow[t]{2}{*}{ Kebele is connected to a road made of stones } & -0.146 & 0.165 & 0.0742 \\
\hline & $(0.125)$ & $(0.134)$ & $(0.129)$ \\
\hline \multirow[t]{2}{*}{ Kebele is connected to a dirt road } & 0.0780 & 0.108 & $0.276^{\star \star}$ \\
\hline & $(0.126)$ & $(0.135)$ & $(0.132)$ \\
\hline \multirow[t]{2}{*}{ Kebele officials received training on targeting in the last $12 \mathrm{~m}$} & 0.196 & -0.00382 & -0.275 \\
\hline & $(0.250)$ & $(0.267)$ & $(0.263)$ \\
\hline \multirow[t]{2}{*}{ Score from a test of targeting knowledge (max 5 points) } & 0.0221 & 0.0821 & -0.0133 \\
\hline & $(0.0582)$ & $(0.0614)$ & $(0.0598)$ \\
\hline \multirow[t]{2}{*}{ Only poorest households in woreda have access to PSNP benefits } & -0.374 & -0.157 & -0.111 \\
\hline & $(0.238)$ & $(0.242)$ & $(0.234)$ \\
\hline \multirow[t]{2}{*}{ Amhara } & 0.0926 & $0.626^{\star \star *}$ & 0.0635 \\
\hline & $(0.231)$ & $(0.234)$ & $(0.238)$ \\
\hline \multirow[t]{2}{*}{ Oromia } & -0.0357 & 0.367 & -0.243 \\
\hline & $(0.264)$ & $(0.266)$ & $(0.266)$ \\
\hline \multirow[t]{2}{*}{ SNNP } & -0.368 & 0.299 & $-0.800^{\star * \star *}$ \\
\hline & $(0.224)$ & $(0.235)$ & $(0.230)$ \\
\hline Observations & 2,310 & 2,086 & 2,341 \\
\hline
\end{tabular}

Source: Authors' analysis of data from surveys, March 2017 and March 2019.

Note: Logit model; coefficients are log-odds units. Standard errors are reported in parentheses. Statistical significance denoted at $* * \star$ $p<0.01,{ }^{* *} p<0.05,{ }^{*} p<0.10$. Tigray region has been selected as the reference group.

Figure 10.1 shows the standard common support graphs for the three cases. We see that the region of common support is wide and dense in all graphs. Moreover, the number of households falling outside of the common support region ranges between 0.5 and 1.5 percent. Overall, this suggests that the sampling strategy in which we selected the control households from a pool of households that identified themselves as poor performed particularly well. 
Figure 10.1. Common support graphs

A) PSNP beneficiary in 2019 vs Non-PSNP beneficiary in 2019

Untreated

Treated: On support

Treated: Off support

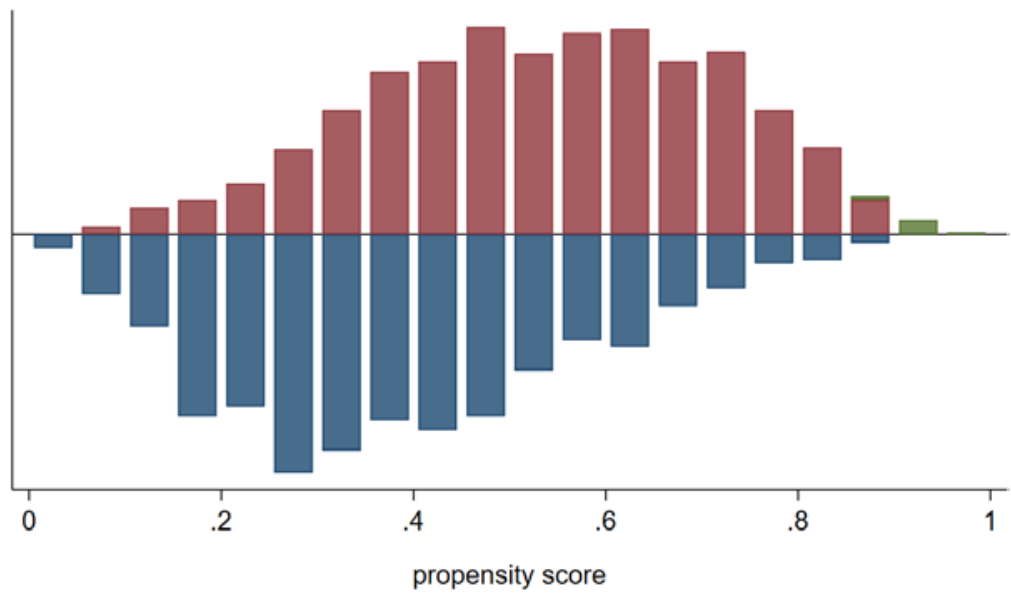

Source: Authors' analysis of data from March 2019 survey.

Note: $0.5 \%$ of households fall outside of common support.

B) PSNP beneficiary in 2019 vs PSNP beneficiary in 2017
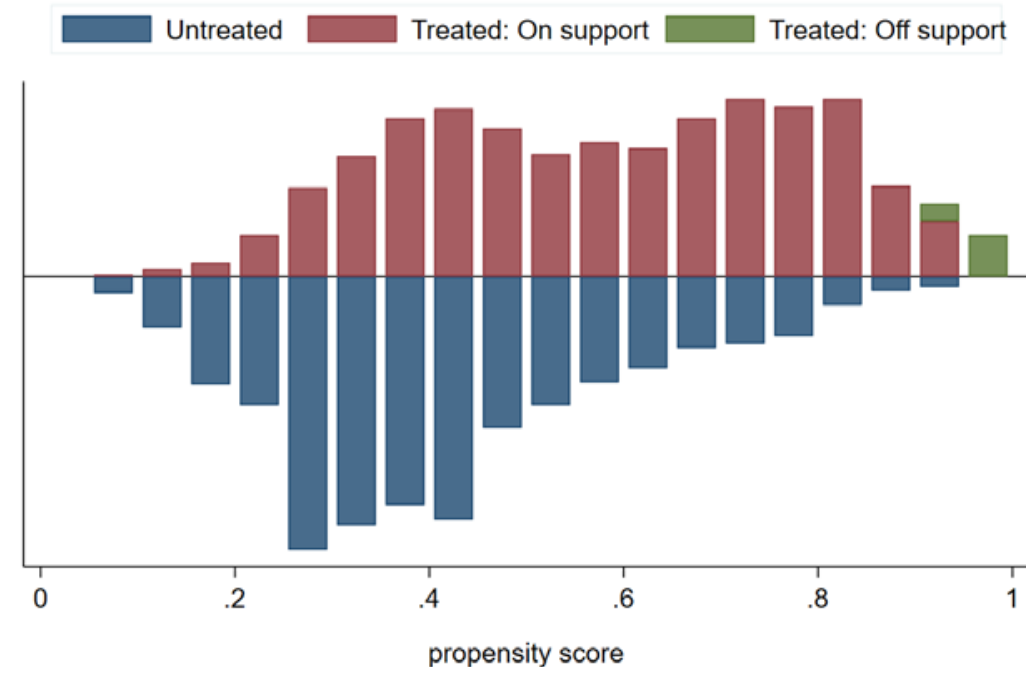

Source: Authors' analysis of data from March 2017 and March 2019 surveys. Note: $1.5 \%$ of households fall outside of common support

C) PSNP beneficiary in 2019 vs Non-PSNP beneficiary in 2017
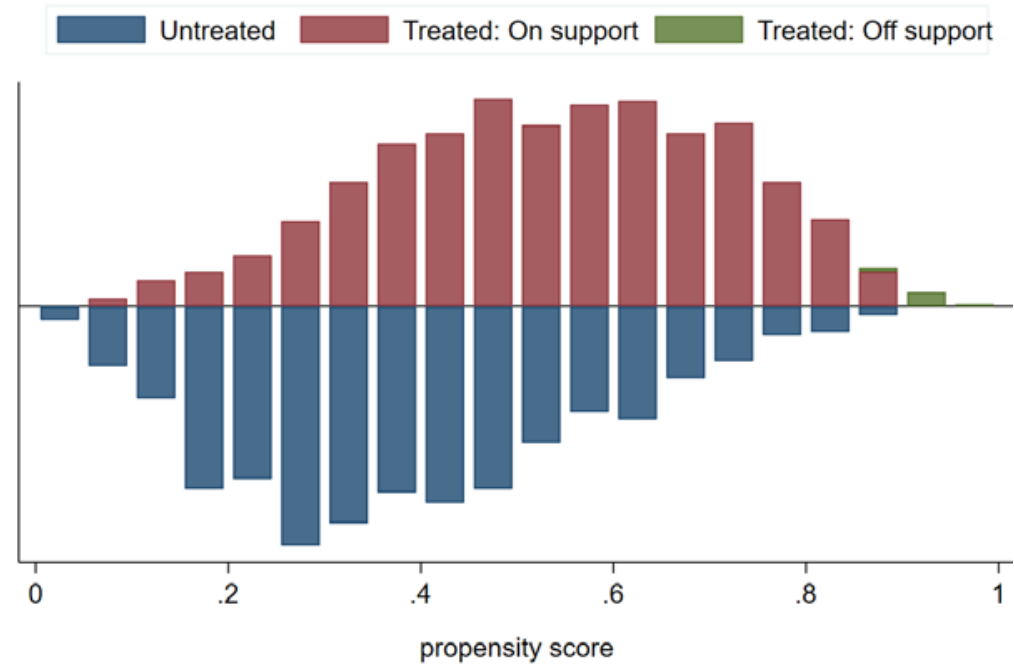

Source: Authors' analysis of data from March 2019 survey. Note: $1.4 \%$ of households fall outside of common support. 


\subsection{Choice of matching algorithm}

Blundell and Dias (2009) propose using kernel matching algorithms in the context of repeated cross-section and difference-in-difference matching. In our case, the kernel matching estimator uses weighted averages of all households within a neighborhood in the three control groups to construct the counterfactual outcome. Using all observations, instead of only the nearest ones, this kernel matching approach has the advantage of reducing variability in the estimator. The drawback is that the analytical standard errors will be not be valid. Instead, standard errors in this case need to be computed using bootstrap methods. 


\section{IMPACTS OF NUTRITION-SENSITIVE INTERVENTIONS OF PSNP}

In this chapter, we report the impact estimates on the study outcomes:

- Mothers' diet, anthropometry, workload, and time use for their own activities and child care (Section 11.2);

- Maternal IYCF knowledge, attitudes, and practices (Section 11.3); and

- Child anthropometry (Section 11.4).

The impact evaluation strategy is described in Chapter 10 and only briefly summarized here.

The primary approach in this impact evaluation is a combination of difference-in-difference and matching methods. Matching approaches can be used for programs like PSNP in which targeting of beneficiaries at the community and household level is conducted by the program and cannot be subjected to randomization and where a regression discontinuity design is infeasible, since the use of community targeting means that there is no unique cut-off in the targeting measure separating beneficiaries from non-beneficiaries. We construct the counterfactual by matching PSNP beneficiaries to non-beneficiaries using observed characteristics measured in the household and community surveys. We match households using covariates that are likely to affect both the selection of a household into PSNP and the study outcomes. These covariates are listed in Chapter 10. Their selection was guided by theory, knowledge of how the program functions, and our previous impact evaluations of PSNP.

The difference-in-difference with matching approach is conducted in a context of repeated crosssection data. Therefore, we follow Blundell and Dias (2009) and Blundell et al. (2004), and match the 2019 PSNP households separately to three control groups:

- PSNP households at the baseline (2017);

- non-PSNP households at the baseline (2017); and

- non-PSNP households in the endline (2019).

This approach then produces a three sets of weights that can be used to estimate the impact of PSNP-4. We match households using a kernel matching estimator and estimate the standard errors using bootstrap methods with 500 repetitions.

\subsection{Impacts on mothers}

\subsubsection{Maternal anthropometry}

In Chapter 4 we reported on trends in maternal anthropometric outcomes. The differences in mothers' body mass and MUAC measures between PSNP and non-PSNP households were marginal across all rounds.

Table 11.1 reports the impact estimates on maternal anthropometric outcomes. According to the matching estimator, we cannot reject the (null) hypothesis that PSNP had no impact on these outcomes. For all outcomes - underweight prevalence, BMI, and MUAC, the estimated impacts are small and not statistically different from zero. We therefore conclude that PSNP-4 had no impact on maternal anthropometric outcomes. 
Table 11.1. Impact of PSNP-4 on maternal anthropometry

\begin{tabular}{|c|c|c|c|c|}
\hline Season & $\mathbf{N}$ & $\begin{array}{l}\text { Size of } \\
\text { impact }\end{array}$ & $\begin{array}{l}95 \% \text { confidence } \\
\text { interval }\end{array}$ & Interpretation \\
\hline \multicolumn{5}{|c|}{ Outcome: Underweight (binary) } \\
\hline March & 4,409 & 0.0330 & $-0.028 ; 0.094$ & \multirow{3}{*}{$\begin{array}{l}\text { We cannot reject the hypothesis that PSNP-4 } \\
\text { had no impact on this outcome. The } \\
\text { estimated impact is not statistically different } \\
\text { from zero. }\end{array}$} \\
\hline August & 4,217 & 0.0045 & $-0.062 ; 0.071$ & \\
\hline March-August & 4,217 & -0.0136 & $-0.055 ; 0.028$ & \\
\hline \multicolumn{5}{|c|}{ Outcome: Body mass index (continuous) } \\
\hline March & 4,409 & -0.0360 & $-0.352 ; 0.280$ & Same as above. \\
\hline August & 4,217 & 0.0404 & $-0.272 ; 0.353$ & Same as above. \\
\hline March-August & 4,217 & 0.0225 & $-0.091 ; 0.136$ & Same as above. \\
\hline \multicolumn{5}{|c|}{ Outcome: MUAC (continuous) } \\
\hline March & 4,574 & 0.0597 & $-0.249 ; 0.368$ & Same as above. \\
\hline August & 4,467 & 0.1180 & $-0.210 ; 0.445$ & Same as above. \\
\hline March-August & 4,467 & -0.0482 & $-0.194 ; 0.097$ & Same as above. \\
\hline
\end{tabular}

Source: Authors' analysis of data from surveys.

Note: The impact is estimated using a difference-in-difference approach combined with a kernel matching method. Confidence intervals and $p$-values are estimated using bootstrap methods with 500 repetitions. See Chapter 10 for more details on the impact evaluation methodology. Asterisks indicate statistical significance: ${ }^{* *}=p<0.001,{ }^{* *}=p<0.01$, and ${ }^{*}=p<0.05$.

\subsubsection{Maternal diets}

As discussed in Chapter 4, mothers in PSNP localities consume extremely monotonous diets. The average mother in PSNP household consumes from less than 3 food groups and only 4 percent meet the minimum dietary diversity for women (MDD-W).

The impact estimates reported in Table 11.2 indicate that PSNP-4 had no impact on women's dietary diversity. The estimated impacts are close to and not statistically different from zero.

Table 11.2. Impact of PSNP-4 on maternal dietary diversity

\begin{tabular}{|c|c|c|c|c|}
\hline Season & $\mathbf{N}$ & $\begin{array}{l}\text { Size of } \\
\text { impact }\end{array}$ & $\begin{array}{l}\text { 95\% confidence } \\
\text { interval }\end{array}$ & Interpretation \\
\hline \multicolumn{5}{|c|}{ Outcome: Minimum diet diversity, MDD-W (binary) } \\
\hline March & 4,504 & -0.0132 & $-0.0358 ; 0.0094$ & \multirow{3}{*}{$\begin{array}{l}\text { We cannot reject the hypothesis that PSNP-4 } \\
\text { had no impact on this outcome. The } \\
\text { estimated impact is not statistically different } \\
\text { from zero. }\end{array}$} \\
\hline August & 4,390 & -0.0124 & $-0.0358 ; 0.0110$ & \\
\hline March-August & 4,390 & -0.0077 & $-0.0315 ; 0.0162$ & \\
\hline \multicolumn{5}{|c|}{ Outcome: Dietary diversity score (count) } \\
\hline March & 4,504 & 0.117 & $-0.027 ; 0.261$ & Same as above. \\
\hline August & 4,390 & -0.021 & $-0.173 ; 0.130$ & Same as above. \\
\hline March-August & 4,390 & -0.067 & $-0.202 ; 0.067$ & Same as above. \\
\hline
\end{tabular}

Source: Authors' analysis of data from surveys.

Note: The impact is estimated using a difference-in-difference approach combined with a kernel matching method. Confidence intervals and $p$-values are estimated using bootstrap methods with 500 repetitions. See Chapter 10 for more details on the impact evaluation methodology. Asterisks indicate statistical significance: ${ }^{* * *}=p<0.001,{ }^{* *}=p<0.01$, and $*=p<0.05$.

MDD-W = Minimum Dietary Diversity-Women.

\subsubsection{Physical activity and workload}

In Chapter 4, we also looked at mothers' physical activity and workload. In Table 11.3, we report the impact estimates on mother's perceived exertion measured as metabolic equivalents (METs) per week in work. These data were only collected in 2019. Therefore, the impact estimates are based on the same matching estimator, but without difference-in-difference. Instead, we are using crosssectional data from a sub-sample of mothers to which this module was administered.

As before, the impact estimates are small in magnitude and not statistically different from zero. Thus, we conclude that PSNP-4 had no impact on mothers' perceived physical workloads. 
Table 11.3. Impact of PSNP-4 on women's workload (year 2019 only)

\begin{tabular}{|c|c|c|c|c|}
\hline Season & $\mathbf{N}$ & $\begin{array}{l}\text { Size of } \\
\text { impact }\end{array}$ & $\begin{array}{l}95 \% \text { confidence } \\
\text { interval }\end{array}$ & Interpretation \\
\hline \multicolumn{5}{|c|}{ Outcome: Metabolic equivalents (METs) per week in work (continuous) } \\
\hline March 2019 & 4,504 & -0.189 & $-0.535 ; 0.157$ & \multirow{2}{*}{$\begin{array}{l}\text { We cannot reject the hypothesis that PSNP-4 } \\
\text { had no impact on this outcome. The } \\
\text { estimated impact is not statistically different } \\
\text { from zero. }\end{array}$} \\
\hline August 2019 & 4,390 & 0.222 & $-0.115 ; 0.558$ & \\
\hline
\end{tabular}

Source: Authors' analysis of data from 2019 surveys.

Note: The impact is estimated using a difference-in-difference approach combined with a kernel matching method. Confidence intervals and $p$-values are estimated using bootstrap methods with 500 repetitions. See Chapter 10 for more details on the impact evaluation methodology. Asterisks indicate statistical significance: ${ }^{* \star *}=p<0.001,{ }^{* \star}=p<0.01$, and ${ }^{*}=p<0.05$.

Next we test whether PSNP-4 had an impact on women's time use for their own activities and child care. These data were extensively discussed in Chapter 4. As above, we resort to a crosssectional matching approach. Table 11.4 shows that the estimated impacts are small and not statistically significant. Thus, we do not find evidence that PSNP-4 had an impact on these outcomes.

Table 11.4. Impact of PSNP-4 on women's time use for their own activities and childcare

\begin{tabular}{|c|c|c|c|c|}
\hline Season & $\mathbf{N}$ & $\begin{array}{l}\text { Size of } \\
\text { impact }\end{array}$ & $\begin{array}{l}\text { 95\% confidence } \\
\text { interval }\end{array}$ & Interpretation \\
\hline \multicolumn{5}{|c|}{ Outcome: Minutes spent in personal care (continuous) } \\
\hline March 2019 & 1,149 & -2.233 & $-6.799 ; 2.332$ & \multirow{2}{*}{$\begin{array}{l}\text { We cannot reject the hypothesis that PSNP-4 } \\
\text { had no impact on this outcome. The } \\
\text { estimated impact is not statistically different } \\
\text { from zero. }\end{array}$} \\
\hline August 2019 & 1,118 & -2.525 & $-6.566 ; 1.517$ & \\
\hline \multicolumn{5}{|c|}{ Outcome: Minutes spent caring for children, adults or elderly } \\
\hline March 2019 & 1,149 & 0.407 & $-0.264 ; 1.079$ & Same as above. \\
\hline August 2019 & 1,118 & -0.525 & $-1.107 ; 0.057$ & Same as above. \\
\hline
\end{tabular}

Source: Authors' analysis of data from 2019 surveys.

Note: The impact is estimated using a difference-in-difference approach combined with a kernel matching method. Confidence intervals and p-values are estimated using bootstrap methods with 500 repetitions. See Chapter 10 for more details on the impact evaluation methodology. Asterisks indicate statistical significance: ${ }^{* *}=p<0.001,{ }^{* *}=p<0.01$, and ${ }^{*}=p<0.05$.

\subsection{Impacts on maternal infant and young child feeding (IYCF) knowledge, attitudes, and practices}

Chapter 6 reported statistics on maternal knowledge and attitudes regarding care practices based on a complementary feeding knowledge score. The chapter then discussed various IYCF dietary outcomes: minimum dietary diversity, minimum meal frequency, minimum acceptable diet, and consumption of animal source foods. These outcomes were defined for children 6 to 23 months of age. In this section, we measure the impact on these outcomes in three ways: 1) only using data from March rounds; 2) only using data from August rounds; and 3) taking the difference in the outcomes between March and August rounds. We conclude this section by reporting PSNP-4's impact on hygiene conditions around the home.

\subsubsection{Maternal knowledge and attitudes}

We begin by assessing PSNP-4's impact on maternal knowledge and attitudes. In Section 6.2, we developed a 12-point knowledge score based on a quiz that tested caregivers' knowledge and attitudes regarding complementary feeding practices. We saw that the average score remained remarkably stable across survey rounds with negligible differences between PSNP and non-PSNP households. 
Against this background, Table 11.5 reports the impact estimates. According to the matching estimator, we cannot reject the (null) hypothesis that PSNP had no impact on maternal knowledge and attitudes on complementary feeding. The 95\%-confidence intervals are relatively wide but do not include values that could be interpreted as meaningful improvements in maternal knowledge. We therefore conclude that PSNP-4 had no impact on maternal knowledge regarding complementary feeding.

Table 11.5. Impact of PSNP-4 on maternal complementary feeding knowledge score

\begin{tabular}{|c|c|c|c|c|}
\hline Season & $\mathbf{N}$ & $\begin{array}{l}\text { Size of } \\
\text { impact }\end{array}$ & $\begin{array}{l}\text { 95\% confidence } \\
\text { interval }\end{array}$ & Interpretation \\
\hline \multicolumn{5}{|c|}{ Outcome: Maternal complementary feeding score (count) } \\
\hline March & 4,592 & 0.030 & $-0.364 ; 0.424$ & \multirow{2}{*}{$\begin{array}{l}\text { We cannot reject the hypothesis that PSNP-4 } \\
\text { had no impact on this outcome. The } \\
\text { estimated impact is not statistically different } \\
\text { from zero. }\end{array}$} \\
\hline August & 4,492 & 0.049 & $-0.339 ; 0.437$ & \\
\hline
\end{tabular}

Source: Authors' analysis of data from surveys.

Note: The impact is estimated using a difference-in-difference approach combined with a kernel matching method. Confidence intervals and $p$-values are estimated using bootstrap methods with 500 repetitions. See Chapter 10 for more details on the impact evaluation methodology. Asterisks indicate statistical significance: ${ }^{* \star *}=p<0.001,{ }^{* *}=p<0.01$, and ${ }^{*}=p<0.05$.

\subsubsection{Complementary feeding outcomes}

Next, we report on PSNP-4's impact on children's dietary outcomes. In Chapter 6, we reported that children's diet are poor. In each survey round, less than 6 percent of children aged 6 to 23 months met the criteria for a minimum acceptable diet. Diets are extremely monotonous with the average child in PSNP households consuming from two or fewer food groups.

Table 11.6 reports the impact estimates on children's dietary diversity: minimum dietary diversity, which equals 1 if the child consumed from 4 or more food groups and 0 otherwise; and dietary diversity score, which ranges in value from 0 to 7 . All impact estimates are small in magnitude and statistically not different from zero, indicating that PSNP-4 had no impact on children's dietary diversity.

Table 11.6. Impact of PSNP-4 on dietary diversity, children aged 6 to 23 months

\begin{tabular}{|c|c|c|c|c|}
\hline Season & $\mathbf{N}$ & $\begin{array}{l}\text { Size of } \\
\text { impact }\end{array}$ & $\begin{array}{l}95 \% \text { confidence } \\
\text { interval }\end{array}$ & Interpretation \\
\hline \multicolumn{5}{|c|}{ Outcome: Minimum diet diversity (binary) } \\
\hline March & 3,380 & -0.006 & $-0.037 ; 0.024$ & \multirow{3}{*}{$\begin{array}{l}\text { We cannot reject the hypothesis that PSNP-4 } \\
\text { had no impact on this outcome. The } \\
\text { estimated impact is not statistically different } \\
\text { from zero. }\end{array}$} \\
\hline August & 3,395 & 0.016 & $-0.024 ; 0.056$ & \\
\hline March-August & 3,395 & 0.010 & $-0.026 ; 0.045$ & \\
\hline \multicolumn{5}{|c|}{ Outcome: Dietary diversity score (count) } \\
\hline March & 3,380 & -0.019 & $-0.183 ; 0.144$ & Same as above. \\
\hline August & 3,395 & -0.010 & $-0.191 ; 0.170$ & Same as above. \\
\hline March-August & 3,395 & 0.024 & $-0.124 ; 0.172$ & Same as above. \\
\hline
\end{tabular}

Source: Authors' analysis of data from surveys.

Note: The impact is estimated using a difference-in-difference approach combined with a kernel matching method. Confidence intervals and $p$-values are estimated using bootstrap methods with 500 repetitions. See Chapter 10 for more details on the impact evaluation methodology. Asterisks indicate statistical significance: ${ }^{* * *}=p<0.001,{ }^{* *}=p<0.01$, and ${ }^{*}=p<0.05$.

In chapter 6 we documented a steady increase in the prevalence of children meeting the minimum meal frequency, increasing from 37 percent in March 2017 to 54 percent in August 2019. Table 11.7 reports the impact estimates on children's meal frequency: minimum meal frequency and actual meal frequency. As before, all impact estimates are statistically insignificant; we have no evidence that PSNP-4 had an impact on children's meal frequency. 
Table 11.7. Impact of PSNP-4 on meal frequency, children aged 6 to 23 months

\begin{tabular}{|c|c|c|c|c|}
\hline Season & $\mathbf{N}$ & $\begin{array}{l}\text { Size of } \\
\text { impact }\end{array}$ & $\begin{array}{c}\text { 95\% confidence } \\
\text { interval }\end{array}$ & Interpretation \\
\hline \multicolumn{5}{|c|}{ Outcome: Minimum meal frequency (binary) } \\
\hline March & 3,380 & 0.0537 & $-0.022 ; 0.129$ & \multirow{3}{*}{$\begin{array}{l}\text { We cannot reject the hypothesis that PSNP-4 } \\
\text { had no impact on this outcome. The } \\
\text { estimated impact is not statistically different } \\
\text { from zero. }\end{array}$} \\
\hline August & 3,395 & 0.0164 & $-0.062 ; 0.095$ & \\
\hline March-August & 3,395 & 0.0269 & $-0.036 ; 0.089$ & \\
\hline \multicolumn{5}{|c|}{ Outcome: Meal frequency (count) } \\
\hline March & 3,380 & 0.1600 & $-0.096 ; 0.417$ & Same as above. \\
\hline August & 3,395 & 0.0385 & $-0.221 ; 0.298$ & Same as above. \\
\hline March-August & 3,395 & -0.0184 & $-0.228 ; 0.191$ & Same as above. \\
\hline
\end{tabular}

Source: Authors' analysis of data from surveys.

Note: The impact is estimated using a difference-in-difference approach combined with a kernel matching method. Confidence intervals and p-values are estimated using bootstrap methods with 500 repetitions. See Chapter 10 for more details on the impact evaluation methodology. Asterisks indicate statistical significance: ${ }^{* \star *}=p<0.001,{ }^{* *}=p<0.01$, and ${ }^{*}=p<0.05$.

Minimum acceptable diet (MAD) is a composite index of adequate complementary feeding obtaining a value of 1 if the child met both minimum dietary diversity and minimum meal frequency and 0 otherwise. As we noted in Chapter 6 , less than 5 percent of children in each round in PSNP households achieved MAD. The differences between PSNP and non-PSNP households were marginal, but we did document some improvements in MAD prevalence over time. In March 2017, only 1.4 percent of all children achieved MAD, but this rose to 5.4 percent in August 2019. The top part of Table 11.8 reports the impact estimates on this outcome. The impact estimate is statistically insignificant; we have no evidence that PSNP-4 increased the prevalence of children who received minimum acceptable diet.

The bottom part of the Table 11.8 reports PSNP-4's impact on the share of children who consumed animal source foods. As discussed in Chapter 6, the consumption by children of animal source foods is highly seasonal, low in March, possibly due to fasting during Lent, and considerably higher in August. However, we see no evidence that PSNP-4 had an impact on the prevalence of children consuming animal source foods in either season. The point estimates are small in magnitude and not statistically different from zero.

Table 11.8. Impact of PSNP-4 on minimum acceptable diet and consumption of animal sourced foods, children aged 6 to 23 months

\begin{tabular}{|c|c|c|c|c|}
\hline Season & $\mathbf{N}$ & $\begin{array}{l}\text { Size of } \\
\text { impact }\end{array}$ & $\begin{array}{l}\text { 95\% confidence } \\
\text { interval }\end{array}$ & Interpretation \\
\hline \multicolumn{5}{|c|}{ Outcome: Minimum acceptable diet (binary) } \\
\hline March & 3,380 & -0.0192 & $-0.0438 ; 0.0053$ & \multirow{3}{*}{$\begin{array}{l}\text { We cannot reject the hypothesis that PSNP-4 } \\
\text { had no impact on this outcome. The } \\
\text { estimated impact is not statistically different } \\
\text { from zero. }\end{array}$} \\
\hline August & 3,395 & 0.0122 & $-0.0200 ; 0.0444$ & \\
\hline March-August & 3,395 & 0.0095 & $-0.0224 ; 0.0413$ & \\
\hline \multicolumn{5}{|c|}{ Outcome: Consumption of animal source foods (binary) } \\
\hline March & 3,380 & -0.0391 & $-0.0860 ; 0.0079$ & Same as above. \\
\hline August & 3,395 & -0.0022 & $-0.0634 ; 0.0590$ & Same as above. \\
\hline March-August & 3,395 & 0.0135 & $-0.0337 ; 0.0606$ & Same as above. \\
\hline
\end{tabular}

Source: Authors' analysis of data from surveys.

Note: The impact is estimated using a difference-in-difference approach combined with a kernel matching method. Confidence intervals and $p$-values are estimated using bootstrap methods with 500 repetitions. See Chapter 10 for more details on the impact evaluation methodology. Asterisks indicate statistical significance: ${ }^{\star * *}=p<0.001,{ }^{* *}=p<0.01$, and ${ }^{*}=p<0.05$.

\subsubsection{Hygiene practices}

Access to safe sanitation as well as adherence to good hygiene practices reduce infection risks among young children (Headey and Hirvonen 2016; Headey et al. 2016; Headey and Palloni 2019). In Chapter 3, we reported on households' access to proper toilets, whether a pit latrine or a flush 
toilet; and overall hygiene practices and conditions in the home, including prevalence of handwashing with soap and the presence of fecal matter in the compound.

Table 11.9 reports PSNP-4's impact on these hygiene-related outcomes. As before, the impact estimates are small in magnitude and not statistically different from zero. Hence, we conclude that PSNP-4 had no impact on these outcomes.

\section{Table 11.9. Impact of PSNP-4 on hygiene practices in the household}

\begin{tabular}{|c|c|c|c|c|}
\hline Season & $\mathbf{N}$ & $\begin{array}{l}\text { Size of } \\
\text { impact }\end{array}$ & $\begin{array}{c}95 \% \text { confidence } \\
\text { interval }\end{array}$ & Interpretation \\
\hline \multicolumn{5}{|c|}{ Outcome: Household has a proper toilet (binary) } \\
\hline March & 4,648 & 0.0505 & $-0.0149 ; 0.1160$ & \multirow{2}{*}{$\begin{array}{l}\text { We cannot reject the hypothesis that PSNP-4 } \\
\text { had no impact on this outcome. The } \\
\text { estimated impact is not statistically different } \\
\text { from zero. }\end{array}$} \\
\hline August & 4,508 & 0.0072 & $-0.0629 ; 0.0773$ & \\
\hline \multicolumn{5}{|c|}{ Outcome: Household members washed hands yesterday (binary) } \\
\hline March & 4,648 & -0.0058 & $-0.0375 ; 0.0259$ & Same as above. \\
\hline August & 4,508 & -0.0062 & $-0.0297 ; 0.0172$ & Same as above. \\
\hline \multicolumn{5}{|c|}{ Outcome: Household members washed hands with soap yesterday (binary) } \\
\hline March & 4,648 & -0.0315 & $-0.0971 ; 0.0342$ & Same as above. \\
\hline August & 4,508 & -0.0002 & $-0.0655 ; 0.0651$ & Same as above. \\
\hline \multicolumn{5}{|c|}{ Outcome: There were human feces on the compound, enumerator observation (binary) } \\
\hline March & 4,551 & -0.0271 & $-0.0723 ; 0.0181$ & Same as above. \\
\hline August & 4,407 & -0.0019 & $-0.0493 ; 0.0454$ & Same as above. \\
\hline \multicolumn{5}{|c|}{ Outcome: There were animal feces on the compound, enumerator observation (binary) } \\
\hline March & 4,633 & -0.0271 & $-0.0954 ; 0.0413$ & Same as above. \\
\hline August & 4,478 & -0.0238 & $-0.0894 ; 0.0418$ & Same as above. \\
\hline
\end{tabular}

Source: Authors' analysis of data from 2019 surveys.

Note: The impact is estimated using a difference-in-difference approach combined with a kernel matching method. Confidence intervals and p-values are estimated using bootstrap methods with 500 repetitions. See Chapter 10 for more details on the impact evaluation methodology. Asterisks indicate statistical significance: ${ }^{* \star *}=p<0.001,{ }^{* \star}=p<0.01$, and ${ }^{*}=p<0.05$.

\subsection{Child anthropometry}

Trends in children's anthropometric outcomes were discussed in Chapter 5 . We found a clear seasonal pattern in acute child undernutrition (WLZ, wasting, MUAC) with these outcomes being generally worse in March than in August. For chronic undernutrition (LAZ, stunting), the story was more mixed. These outcomes improved steadily through March 2019, but decreased in August 2019 because of unusually fast growth faltering among younger children.

Table 11.10 reports PSNP-4's impact on chronic undernutrition in children ages 6 to 23 months. As before, the impact estimates are small in magnitude and not statistically different from zero. Hence, we conclude that PSNP-4 had no impact on these outcomes. The conclusion is the same if we look at measures of acute undernutrition (Table 11.11) or a composite measure of chronic and acute undernutrition (Table 11.12) based a child's weight-for-age. 
Table 11.10. Impact of PSNP-4 on chronic undernutrition, children 6 to 23 months of age

\begin{tabular}{lcccc}
\multicolumn{1}{c}{ Season } & N & $\begin{array}{c}\text { Size of } \\
\text { impact }\end{array}$ & $\begin{array}{c}95 \% \text { confidence } \\
\text { interval } \\
\text { Outcome: Stunting (binary) }\end{array}$ & Interpretation \\
March & 4,535 & -0.0233 & $-0.0867 ; 0.0401$ & We cannot reject the hypothesis that PSNP-4 \\
August & 4,455 & -0.0138 & $-0.0857 ; 0.0582$ & had no impact on this outcome. The \\
estimated impact is not statistically different \\
March-August & 4,455 & -0.0363 & $-0.0862 ; 0.0135$ & from zero. \\
& & Outcome: Length for age z-score (continuous) & Same as above. \\
March & 3,356 & 0.1090 & $-0.1400 ; 0.3580$ & Same as above. \\
August & 3,367 & 0.0889 & $-0.1180 ; 0.2960$ & Same as above. \\
March-August & 3,367 & 0.0654 & $-0.0141 ; 0.1450$ &
\end{tabular}

Source: Authors' analysis of data from surveys.

Note: The impact is estimated using a difference-in-difference approach combined with a kernel matching method. Confidence intervals and $p$-values are estimated using bootstrap methods with 500 repetitions. See Chapter 10 for more details on the impact evaluation methodology. Asterisks indicate statistical significance: ${ }^{* * *}=p<0.001,{ }^{* *}=p<0.01$, and ${ }^{*}=p<0.05$.

Table 11.11. Impact of PSNP-4 on acute undernutrition, children 6 to 23 months of age

\begin{tabular}{|c|c|c|c|c|}
\hline Season & $\mathbf{N}$ & $\begin{array}{l}\text { Size of } \\
\text { impact }\end{array}$ & $\begin{array}{l}95 \% \text { confidence } \\
\text { interval }\end{array}$ & Interpretation \\
\hline \multicolumn{5}{|c|}{ Outcome: Wasting (binary) } \\
\hline March & 4,446 & 0.0180 & $-0.027 ; 0.063$ & \multirow{3}{*}{$\begin{array}{l}\text { We cannot reject the hypothesis that PSNP-4 } \\
\text { had no impact on this outcome. The } \\
\text { estimated impact is not statistically different } \\
\text { from zero. }\end{array}$} \\
\hline August & 4,440 & -0.0112 & $-0.047 ; 0.025$ & \\
\hline March-August & 4,440 & -0.0015 & $-0.031 ; 0.028$ & \\
\hline \multicolumn{5}{|c|}{ Outcome: Weight for length z-score (continuous) } \\
\hline March & 3,322 & -0.0577 & $-0.293 ; 0.177$ & Same as above. \\
\hline August & 3,341 & -0.0548 & $-0.261 ; 0.151$ & Same as above. \\
\hline March-August & 3,341 & -0.0024 & $-0.127 ; 0.122$ & Same as above. \\
\hline \multicolumn{5}{|c|}{ Outcome: MUAC (continuous) } \\
\hline March & 3,366 & -0.0072 & $-0.205 ; 0.190$ & Same as above. \\
\hline August & 3,379 & -0.0432 & $-0.242 ; 0.156$ & Same as above. \\
\hline March-August & 3,379 & 0.0351 & $-0.068 ; 0.138$ & Same as above. \\
\hline
\end{tabular}

Source: Authors' analysis of data from surveys.

Note: The impact is estimated using a difference-in-difference approach combined with a kernel matching method. Confidence intervals and $p$-values are estimated using bootstrap methods with 500 repetitions. See Chapter 10 for more details on the impact evaluation methodology. Asterisks indicate statistical significance: ${ }^{* \star}=p<0.001,{ }^{* \star}=p<0.01$, and ${ }^{*}=p<0.05$.

\section{Table 11.12. Impact of PSNP-4 on weight for age and underweight prevalence,} children 6 to 23 months of age

\begin{tabular}{lcccc}
\multicolumn{1}{c}{ Season } & N & $\begin{array}{c}\text { Size of } \\
\text { impact } \\
\text { Outcome: Underweight (binary) }\end{array}$ & $\begin{array}{c}95 \% \text { confidence } \\
\text { interval }\end{array}$ \\
March & 4,542 & 0.0050 & $-0.0496 ; 0.0596$ & We cannot reject the hypothesis that PSNP-4 \\
August & 4,447 & -0.0091 & $-0.0705 ; 0.0523$ & had no impact on this outcome. The estimated \\
impact is not statistically different from zero.
\end{tabular}

Source: Authors' analysis of data from surveys.

Note: The impact is estimated using a difference-in-difference approach combined with a kernel matching method. Confidence intervals and $p$-values are estimated using bootstrap methods with 500 repetitions. See Chapter 10 for more details on the impact evaluation methodology. Asterisks indicate statistical significance: ${ }^{* \star}=p<0.001,{ }^{* \star}=p<0.01$, and ${ }^{*}=p<0.05$. 


\subsection{Heterogeneity in impact}

Some of the research questions listed in Table 1.1 ask whether the impacts vary by the sex of the household head (research question 9) or by PSNP transfer modality (research question 10). Unfortunately, the sample size does not allow us to explore the heterogeneity of impacts along these dimensions.

In assessing impact by the sex of the head of household, only about 10 percent of households in our sample are female-headed (Chapter 3). This is not surprising given the age-profile of these households and the fact that most households have a newborn child.

Only a few households in our sample received food-only payments. In 2017, less than 5 percent of PSNP households received food-only payments while in 2019, this was 6.1 percent. Moreover, as noted in Chapter 9, cash accounts for more than 70 percent of the value of all payments - in Amhara and SNNP, almost all payments are in cash. Considering this, we cannot assess how impacts vary by payment modality. We simply do not have enough households that received food payments and, even if we did, it would have been difficult to disentangle the contribution to any impacts between differences in payment modality and differences in geography, since payment modality is closely tied to regions.

\subsection{The impact of PSNP-4 on the level of nutrition outcomes}

Our impact evaluation design was based on the expectation that the nutrition-sensitive features of PSNP-4 would have been fully rolled out after our baseline in 2017 . The evidence reported in Chapters 6, 7, and 8, in particular, indicate that this was not the case. As the name implies, the 'difference-in-difference estimator' is designed to detect differences in changes (or trends) between the treated (PSNP) and non-treated (non-PSNP) households since the baseline survey round. In our case, the difference-in-difference estimator tests whether the nutrition-sensitive provisions in PSNP-4 had a positive impact on changes in nutrition outcomes between 2017 and 2019, over and above the core components, such as transfers received by beneficiary households.

It is reasonable to ask whether the PSNP transfer is sufficient to make a difference in nutritional outcomes. Our work during earlier phases of PSNP (Berhane, et al. 2015) and IFPRI's careful experimental work from Bangladesh (Ahmed, Hoddinott, and Roy 2019) suggests that this is not the case. Nevertheless, we can use these new data to test this in the context of PSNP-4. We do so by testing whether PSNP-4 had an impact on the level of nutrition outcomes by simply comparing the means between PSNP and non-PSNP households in 2019. Restricting the sample to 2019 households only, we applied the same matching estimator, but in a cross-sectional framework. Compared to the difference-in-difference matching estimator, this is a less convincing approach in terms of rigor. But as noted, these estimates tell us something about the level effect of PSNP on nutritional outcomes.

Table 11.13 reports the results. As before, irrespective of the agricultural season, all confidence intervals include zero, indicating that none of the impact estimates are statistically different from zero. This finding is in line with our previous work on PSNP and in Bangladesh:

Cash or food transfer programs alone are likely to have limited impacts on child nutritional status, but given their cost-effectiveness and scalability, are promising platforms through which to leverage improvements in child nutrition, particularly with the addition of nutrition specific complementary programming. Ahmed, et al. (2019) 
Table 11.13. Impact of PSNP-4 on levels of child and maternal nutrition outcomes, cross sectional estimates

\begin{tabular}{|c|c|c|c|c|}
\hline & $\mathbf{N}$ & Impact estimate & \multicolumn{2}{|c|}{ Confidence interval } \\
\hline \multicolumn{5}{|c|}{ Mother: body-mass index } \\
\hline March 2019 & 2,246 & -0.040 & -0.270 & 0.190 \\
\hline August 2019 & 2,111 & 0.006 & -0.208 & 0.220 \\
\hline \multicolumn{5}{|c|}{ Mother: MUAC } \\
\hline March 2019 & 2,311 & -0.054 & -0.277 & 0.169 \\
\hline August 2019 & 2,238 & 0.053 & -0.178 & 0.284 \\
\hline \multicolumn{5}{|c|}{ Mother: dietary diversity } \\
\hline March 2019 & 2,326 & 0.030 & -0.066 & 0.126 \\
\hline August 2019 & 2,255 & -0.020 & -0.124 & 0.084 \\
\hline \multicolumn{5}{|c|}{ Mother: complementary feeding knowledge score $(\max =12)$} \\
\hline March 2019 & 2,326 & -0.088 & -0.335 & 0.160 \\
\hline August 2019 & 2,255 & 0.195 & -0.040 & 0.430 \\
\hline \multicolumn{5}{|c|}{ Child: dietary diversity score } \\
\hline March 2019 & 1,694 & -0.004 & -0.130 & 0.121 \\
\hline August 2019 & 1,782 & -0.045 & -0.159 & 0.068 \\
\hline \multicolumn{5}{|c|}{ Child: meal frequency } \\
\hline March 2019 & 1,694 & 0.153 & -0.008 & 0.315 \\
\hline August 2019 & 1,782 & 0.098 & -0.065 & 0.262 \\
\hline \multicolumn{5}{|c|}{ Child: Length-for-age z-score } \\
\hline March 2019 & 1,683 & 0.018 & -0.134 & 0.171 \\
\hline August 2019 & 1,765 & -0.038 & -0.177 & 0.100 \\
\hline \multicolumn{5}{|c|}{ Child: Weight-for-length Z-score } \\
\hline March 2019 & 1,677 & -0.070 & -0.216 & 0.075 \\
\hline August 2019 & 1,761 & 0.000 & -0.142 & 0.142 \\
\hline \multicolumn{5}{|c|}{ Child: MUAC } \\
\hline March 2019 & 1,687 & -0.114 & -0.248 & 0.020 \\
\hline August 2019 & 1,770 & 0.040 & -0.086 & 0.166 \\
\hline \multicolumn{5}{|c|}{ Child: Weight-for-age z-score } \\
\hline March 2019 & 1,679 & -0.051 & -0.189 & 0.088 \\
\hline August 2019 & 1,765 & 0.005 & -0.127 & 0.136 \\
\hline
\end{tabular}

Source: Authors' analysis of data from 2019 surveys.

Note: The impact is estimated using a difference-in-difference approach combined with a kernel matching method. Confidence intervals and $p$-values are estimated using bootstrap methods with 500 repetitions. See Chapter 10 for more details on the impact evaluation methodology. Asterisks indicate statistical significance: ${ }^{* *}=p<0.001,{ }^{* *}=p<0.01$, and ${ }^{*}=p<0.05$.

In summary, we assessed in this chapter the impact of PSNP-4 on mothers' diet, anthropometry, workload and time use for their own activities and child care; maternal IYCF knowledge, attitudes, and practices; and child anthropometry. None of the impact estimates reported in this chapter were found to be statistically different from zero. These results indicate that PSNP-4 did not lead to improvements in nutrition outcomes. The next chapter, the concluding chapter, provides some reflections on what may explain these disappointing findings. 


\section{REFLECTIONS}

In this chapter, we offer some thoughts on the nutrition-sensitive dimensions of the fourth phase of Ethiopia's Productive Safety Net Programme (PSNP-4) and their implications for the design of the next phase of PSNP. We begin by noting that there were multiple components to these nutritionsensitive dimensions of PSNP. We highlight four:

- Integrating HEWs into PSNP planning and implementation structures, such as membership in Kebele Food Security Task Forces and Kebele Appeals Committees and working in coordination with Development Agents.

- Training of HEWs on PSNP implementation and on nutrition education.

- Increased contact of pregnant and lactating mothers with HEWs, particularly through the provision of nutrition behavior change communication activities.

- Protections for pregnant and lactating mothers through transitions from Public Works to temporary Direct Support.

As discussed elsewhere in this report, we summarize the implementation of these dimensions as follows:

- Considerable progress was made in integrating HEWs into PSNP structures. In most kebeles (73 percent in 2017; 78 percent in 2019), a HEW is a member of the Kebele Food Security Task Force, and the majority of Kebele Appeals Committees have a HEW as a member (57 percent in 2017; 69 percent in 2019). There are some regional variations in membership, with HEWs more likely to be members of these committees in Tigray and Amhara and somewhat less likely to be members in Oromia and SNNP. Most HEWs (94 percent) report meeting with the DAs in their kebele, most on at least a weekly basis (65 percent).

- There was a marked increase in the percentage of HEWs who have received training on PSNP, rising from 25 percent in 2017 to 62 percent in 2019. But while this increase occurred in all regions, differences across regions remain with 85 and 70 percent of HEWs in Tigray and Oromia, respectively, reporting having received training in the August 2019 survey, compared to 46 and 45 percent of HEWs in Amhara and SNNP, respectively. Training matters. Trained HEWs were much more likely to know how nutrition-related provisions of PSNP should be implemented, such as when lactating mothers should return to Public Works.

- While there was some increase in nutrition behavior change communication activities, such as food demonstrations or community conversations to discuss child feeding practices, coverage of these was low in 2019 at between 19 and 23 percent depending on survey round. Other forms of contact that could provide nutrition information, such as one-to-one conversations with HEWs or HDAs, was also low.

In our report, we also find that:

- Knowledge and practices of age-appropriate breastfeeding practices are high with more than 70 percent of children less than 6 months of age being exclusively breastfed.

- Knowledge of appropriate complementary feeding practices is poor with mothers answering only about 50 percent of questions on these topics correctly. The nutrition-sensitive component of PSNP did not increase maternal knowledge on these topics.

- Children's and mothers' dietary diversity is poor. In each survey round, less than 5 percent of children aged 6 to 23 months consumed a diet that is considered minimally acceptable by 
WHO standards. Child diets are extremely monotonous with the average child consuming from two or fewer food groups. Moreover, out of ten food groups, the average caregiver consumed from less than three food groups in 2019 and only about 6 percent met the minimum dietary diversity for women (MDD-W) of five food groups. The nutrition-sensitive component of PSNP did not improve child or maternal diets.

- Children's anthropometric status is poor. Depending on the survey round, between 39 and 45 percent of preschool children in PSNP households were categorized as short for their age (stunted). This is a considerably higher share than the national stunting prevalence of 33 percent for children in the same age range. Measures of acute undernutrition are also relatively high. The nutrition-sensitive component of PSNP did not improve child anthropometry.

- Compliance with requirements that women should shift from Public Works to Temporary Direct Support has improved, but there is still space for further improvement. Among those who were working on Public Works, 59 percent stopped working after they learned they were pregnant, an improvement from 31 percent at baseline. However, 12 percent continued to work until giving birth, although this was an improvement from 20 percent at baseline. More than half of pregnant women that stopped working under the Public Works component of PSNP were advised to do so by a health extension worker. This is quite an improvement from the 30 percent that were advised to do so at baseline. However, still 29 percent of women reported they were discouraged from stopping work by the Community Food Security Taskforce.

Based on this, we think that discussions about a nutrition-sensitive PSNP-5, should include the following design elements:

1. HEW involvement in PSNP planning and implementation structures at kebele-level - Kebele Food Security Task Forces and Kebele Appeals Committees - should continue. Their participation in these bodies ensures that the selection of PSNP beneficiaries is based on input from a wider set of actors with information on household food security and nutrition status.

2. The implementation of nutrition behavior change communication (BCC) activities needs to be re-thought. Given their many existing commitments, HEWs simply do not have the time to undertake these activities in addition to the many tasks for which they are already responsible. As we note, HEWs work nearly every day of the month for long hours each day and carry heavy client caseloads. This increasing workload may be adversely affecting their mental health. In 2019, 34 percent of HEWs showed signs of medium or high levels of emotional exhaustion. Continuing to add to their workload risks reducing HEW effectiveness, while failing to improve maternal knowledge of infant and young child nutrition.

Some elements of such a re-think should include the following:

a. Additional staff are needed to implement BCC activities. These staff will need to be trained properly if the BCC is to be delivered effectively.

b. The "intensity" of exposure needs to be re-considered. While we acknowledge that the existing literature provides too little guidance on the optimal amount of BCC that should be provided, we suspect that the amount envisaged under PSNP-4 was too small to be effective. This is an area where some experimentation in the intensity and frequency of BCC activities might be helpful by, for example, comparing the effects of monthly versus bi-monthly group meetings. 
c. There is a need to provide more information on complementary feeding. Unlike breastfeeding knowledge and practice, this is poorly understood in many areas where PSNP operates. This could be accomplished, in part, by developing and implementing a structured curriculum that covers key IYCF topics.

3. Our survey of health posts showed that more than half did not have a height board for measuring children's height and 13 percent did not have a scale for measuring children's weight. It would be helpful if PSNP were to coordinate with the Ministry of Health to ensure that health posts situated in kebeles where PSNP operates have the right equipment for nutrition monitoring.

4. As noted in this report and elsewhere, the high relative cost of non-staple foods makes them unaffordable for many PSNP households. So, even if mothers know what foods they should feed their children, such foods may be unavailable or unaffordable. Where agro-ecologically appropriate, an increased use of the PSNP livelihood component to encourage production of non-staple foods could contribute to rectifying this problem.

5. Discussions about how compliance with requirements that women should shift from Public Works to temporary Direct Support can be met. As noted, this has improved, but there is still space for further improvement. Training of HEWs on this topic is one, but not the only mechanism, by which this can achieved. It is unacceptable that nearly 30 percent of pregnant women reported they were discouraged from stopping work by members of the Community Food Security Taskforce. 


\section{REFERENCES}

Abadie, A., and G. W. Imbens. 2006. "Large sample properties of matching estimators for average treatment effects." Econometrica 74 (1):235-267.

Abay, K., and K. Hirvonen. 2017. "Does market access mitigate the impact of seasonality on child growth? Panel data evidence from North Ethiopia." Journal of Development Studies 53 (9):1414-1429.

Abebe, Z., G. D. Haki, and K. Baye. 2016. "Health Extension Workers' Knowledge and Knowledge-Sharing Effectiveness of Optimal Infant and Young Child Feeding Are Associated With Mothers' Knowledge and Child Stunting in Rural Ethiopia." Food and Nutrition Bulletin 37 (3):353 - 363.

Ahmed, A., J. Hoddinott, and S. Roy. 2019. Food transfers, cash transfers, behavior change communication and child nutrition: Evidence from Bangladesh. Vol. 1868: Intl Food Policy Res Inst.

Baye, K., and K. Hirvonen. 2020. "Seasonality: a missing link in preventing undernutrition." The Lancet. Child $\&$ adolescent health 4 (1):PE3.

Berhane, G., I. Birch, L. Cabral, D. Gilligan, K. Hirvonen, J. Hoddinott, B. Koru, N. Kumar, J. Lind, R. SabatesWheeler, A. S. Taffesse, F. Tadesse, M. Tefera, A. Weldegerima, I. Worku, F. Yimer, and Y. Yohannes. 2019. The Productive Safety Net Programme 4 Midline Survey 2018: Program Performance Report. Addis Ababa: The International Food Policy Research Institute and the Institute for Development Studies.

Berhane, G., S. Devereux, J. Hoddinott, J. Hoel, K. Roelen, K. Abay, M. Kimmel, N. Ledlie, and T. Woldu. 2015. Evaluation of the Social Cash Transfers Pilot Programme, Tigray Region, Ethiopia, Endline Report. Washington, DC, International Food Policy Research Institute.

Berhane, G., D. Gilligan, K. Hirvonen, J. Hoddinott, N. Kumar, and A. S. Taffesse. 2019. The Productive Safety Net Programme 4 Midline Survey 2018: Highland Outcomes Report. Washington D.C.: International Food Policy Research Institute.

Berhane, G., D. Gilligan, K. Hirvonen, J. Hoddinott, N. Kumar, A. S. Taffesse, K. Abay, F. Tadesse, Y. Yohannes, I. Worku, R. Sabates-Wheeler, J. Lind, I. Birch, and S. Kohnstamm. 2016a. The Productive Safety Nets Programme IV - Baseline Survey Report 2016: Outcomes (Highlands). Washington D.C.: International Food Policy Research Institute.

. 2016b. The Productive Safety Nets Programme IV - Baseline Survey Report 2016: Program Performance. Washington D.C.: International Food Policy Research Institute.

Berhane, G., D. O. Gilligan, J. Hoddinott, N. Kumar, and A. S. Taffesse. 2014. "Can Social Protection Work in Africa? The Impact of Ethiopia's Productive Safety Net Programme." Economic Development and Cultural Change 63 (1):1-26.

Berhane, G., K. Hirvonen, and J. Hoddinott. 2016. The Implementation of the Productive Safety Nets Programme, 2014: Highlands Outcomes Report (2015). Addis Ababa: Ethiopia Strategy Support Program, International Food Policy Research Institute.

Berhane, G., J. Hoddinott, N. Kumar, and A. Margolies. 2015. The impact of the Productive Safety Net Programme on the schooling and nutrition of children. edited by IFPRI and 3ie.

Block, S. A. 2004. "Maternal nutrition knowledge and the demand for micronutrient-rich foods: Evidence from Indonesia." Journal of Development Studies 40 (6):82-105. . 2007. "Maternal nutrition knowledge versus schooling as determinants of child micronutrient status." Oxford Economic Papers 59 (2):330-353.

Blundell, R., and M. C. Dias. 2009. "Alternative approaches to evaluation in empirical microeconomics." Journal of Human Resources 44 (3):565-640.

Blundell, R., M. C. Dias, C. Meghir, and J. Reenen. 2004. "Evaluating the employment impact of a mandatory job search program." Journal of the European Economic Association 2 (4):569-606.

Branca, F., G. Pastore, T. Demissie, and A. Ferro-Luzzi. 1993. "The nutritional impact of seasonality in children and adults of rural Ethiopia." European Journal of Clinical Nutrition 47 (12):840-850.

Central Statistical Agency [Ethiopia]. 2010. Population and Housing Census Report-Country - 2007. Addis Ababa: Central Statistical Agency.

Chotard, S., J. B. Mason, N. P. Oliphant, S. Mebrahtu, and P. Hailey. 2010. "Fluctuations in wasting in vulnerable child populations in the Greater Horn of Africa." Food \& Nutrition Bulletin 31 (Supplement 3):219S-233S.

Cleland, C. L., R. F. Hunter, F. Kee, M. E. Cupples, J. F. Sallis, and M. A. Tully. 2014. "Validity of the global physical activity questionnaire (GPAQ) in assessing levels and change in moderate-vigorous physical activity and sedentary behaviour." BMC public health 14 (1):1255. 
de Onis, M., A. W. Onyango, E. Borghi, A. Siyam, C. Nishida, and J. Siekmann. 2007. "Development of a WHO growth reference for school-aged children and adolescents." Bulletin of the World Health Organization 85 (9):660-7.

Egata, G., Y. Berhane, and A. Worku. 2013. "Seasonal variation in the prevalence of acute undernutrition among children under five years of age in east rural Ethiopia: a longitudinal study." BMC Public Health $13(1): 864$.

FAO, and FHI 360. 2016. Minimum Dietary Diversity for Women: A Guide to Measurement. Rome: Food and Agriculture Organization (FAO) of the United Nations and USAID's Food and Nutrition Technical Assistance III Project (FANTA), managed by FHI 360.

Ferro-Luzzi, A., S. S. Morris, S. Taffesse, T. Demissie, and M. D'Amato. 2001. Seasonal Undernutrition in Rural Ethiopia. In IFPRI Research Report. Washington, D.C., Rome and Addis Ababa: International Food Policy Research Institute and Istituto Nazionale della Nutrizione in collaboration with Ethiopian Health and Nutrition Research Institute.

GFDRE. 2014. Productive Safety Net Programme: Programme Implementation Manual. Addis Ababa: Government of the Federal Democratic Republic of Ethiopia (GFDRE).

Gilbert, C. L., L. Christiaensen, and J. Kaminski. 2017. "Food Price Seasonality in Africa: Measurement and Extent." Food Policy 67:119-132.

Gilligan, D. O., J. Hoddinott, and A. S. Taffesse. 2009. "The impact of Ethiopia's Productive Safety Net Programme and its linkages." The Journal of Development Studies 45 (10):1684-1706.

Glewwe, P. 1999. "Why does mother's schooling raise child health in developing countries? Evidence from Morocco." Journal of Human Resources:124-159.

Golan, J., D. Headey, K. Hirvonen, and J. Hoddinott. 2019. "Changes in child undernutrition rates in Ethiopia, 2000-16." In The Oxford Handbook of the Ethiopian Economy, edited by Christopher Cramer, Fantu Cheru and Arkebe Oqubay. Oxford: Oxford University Press.

Headey, D., and K. Hirvonen. 2016. "Is Exposure to Poultry Harmful to Child Nutrition? An Observational Analysis for Rural Ethiopia." PloS one 11 (8):e0160590.

Headey, D., K. Hirvonen, J. Hoddinott, and D. Stifel. 2019. "Rural food markets and child nutrition." American Journal of Agricultural Economics 101 (5):1311-1327.

Headey, D., P. Nguyen, S. Kim, R. Rawat, M. Ruel, and P. Menon. 2016. "Is Exposure to Animal Feces Harmful to Child Nutrition and Health Outcomes? A Multicountry Observational Analysis." The American Journal of Tropical Medicine and Hygiene:16-0270.

Headey, D., and G. Palloni. 2019. "Water, sanitation, and child health: evidence from subnational panel data in 59 countries." Demography 56 (2):729-752.

Heckman, J. J., H. Ichimura, and P. E. Todd. 1997. "Matching as an econometric evaluation estimator: Evidence from evaluating a job training programme." The Review of Economic Studies 64 (4):605-654. . 1998. "Matching as an econometric evaluation estimator." The Review of Economic Studies 65 (2):261-294.

Hirvonen, K., and D. Headey. 2018. "Can governments promote homestead gardening at scale? Evidence from Ethiopia." Global Food Security 19:40-47.

Hirvonen, K., J. Hoddinott, B. Minten, and D. Stifel. 2017. "Children's diets, nutrition knowledge and access to markets." World Development 95:303-315.

Hirvonen, K., A. S. Taffesse, and I. Worku. 2016. "Seasonality and household diets in Ethiopia." Public Health Nutrition 19 (10):1723-1730.

Imbens, G. W. 2015. "Matching methods in practice: Three examples." Journal of Human Resources 50 (2):373-419.

Kim, S. S., D. Ali, A. Kennedy, R. Tesfaye, A. W. Tadesse, T. H. Abrha, R. Rawat, and P. Menon. 2015. "Assessing implementation fidelity of a community-based infant and young child feeding intervention in Ethiopia identifies delivery challenges that limit reach to communities: a mixed-method process evaluation study." BMC public health 15 (1):316.

Kim, S. S., P. H. Nguyen, L. M. Tran, Y. Abebe, Y. Asrat, M. Tharaney, and P. Menon. 2018. "Maternal behavioural determinants and livestock ownership are associated with animal source food consumption among young children during fasting in rural Ethiopia." Maternal and Child Nutrition e12695.

Leroy, J. 2011. "ZSCORE06: Stata module to calculate anthropometric z-scores using the 2006 WHO child growth standards." Statistical Software Components.

Lindtjørn, B., and T. Alemu. 2002. "Year-to-year and seasonal variations in stunting among preschool children in Ethiopia." Journal of Health, Population and Nutrition:326-333. 
Maleta, K., S. Virtanen, M. Espo, T. Kulmala, and P. Ashorn. 2003. "Seasonality of growth and the relationship between weight and height gain in children under three years of age in rural Malawi." Acta Paediatrica 92 (4):491-497.

Roba, K. T., T. P. O'Connor, T. Belachew, and N. M. O'Brien. 2016. "Variations between post-and pre-harvest seasons in stunting, wasting, and Infant and Young Child Feeding (IYCF) practices among children 623 months of age in lowland and midland agro-ecological zones of rural Ethiopia." The Pan African Medical Journal 24.

Rosenbaum, P. R., and D. B. Rubin. 1983. "The central role of the propensity score in observational studies for causal effects." Biometrika 70 (1):41-55.

Smith, J. A., and P. E. Todd. 2005. "Does matching overcome LaLonde's critique of nonexperimental estimators?" Journal of Econometrics 125 (1):305-353.

Taffesse, A. S., P. Dorosh, and S. A. Gemessa. 2012. "Crop Production in Ethiopia." In Food and Agriculture in Ethiopia, edited by Paul Dorosh and Shahidur Rashid. Philadelphia: University of Pennsylvania Press.

Thomas, D., J. Strauss, and M.-H. Henriques. 1991. "How does mother's education affect child height?" Journal of Human Resources:183-211.

UNICEF. 2019. The State of the World's Children 2019: Children, food and nutrition Geneva: UNICEF.

Vaitla, B., S. Devereux, and S. H. Swan. 2009. "Seasonal hunger: a neglected problem with proven solutions." PLOS Med 6 (6).

Ververs, M.-t., A. Antierens, A. Sackl, N. Staderini, and V. Captier. 2013. "Which anthropometric indicators identify a pregnant woman as acutely malnourished and predict adverse birth outcomes in the humanitarian context?" PLOS Currents Disasters.

Victora, C. G., M. de Onis, P. C. Hallal, M. Blossner, and R. Shrimpton. 2010. "Worldwide timing of growth faltering: revisiting implications for interventions." Pediatrics 125 (3):e473-80.

Wamani, H., A. N. Åstrøm, S. Peterson, J. K. Tumwine, and T. Tylleskär. 2007. "Boys are more stunted than girls in sub-Saharan Africa: a meta-analysis of 16 demographic and health surveys." BMC Pediatrics 7 (1):17.

WHO. 2006. "WHO Child Growth Standards based on length/height, weight and age." Acta paediatrica Suppl 450:76-85.

. 2010. Monitoring the building blocks of health systems: a handbook of indicators and their measurement strategies. Geneva: World Health Organization (WHO).

—. 2012. Global physical activity questionnaire (GPAQ) analysis guide. Geneva: World Health Organization (WHO).

. 2013. Essential nutrition actions: improving maternal, newborn, infant and young child health and nutrition. Geneva: World Health Organization (WHO).

WHO, and UNICEF. 2009. "WHO child growth standards and the identification of severe acute malnutrition in infants and children: a joint statement by the World Health Organization and the United Nations Children's Fund." Geneva: World Health Organization \& UNICEF. 


\section{APPENDICES}

\section{Appendix A (Chapter 3)}

Table A1. Index child and household characteristics by region 2017 and 2019

\begin{tabular}{|c|c|c|c|c|c|c|c|c|}
\hline & \multicolumn{4}{|c|}{ March 2017} & \multicolumn{4}{|c|}{ March 2019} \\
\hline & Tigray & Amhara & Oromia & SNNP & Tigray & Amhara & Oromia & SNNP \\
\hline Index child is male & 0.48 & 0.51 & 0.51 & 0.50 & 0.50 & 0.50 & 0.56 & 0.50 \\
\hline Index child's age in months & 11.56 & 11.03 & 11.57 & 11.74 & 11.57 & 9.99 & 10.51 & 11.29 \\
\hline \multicolumn{9}{|l|}{ Age categories: } \\
\hline $0-6$ months $(\mathrm{N}=620)$ & 0.21 & 0.27 & 0.23 & 0.23 & 0.26 & 0.30 & 0.28 & 0.25 \\
\hline 6-11 months $(\mathrm{N}=690)$ & 0.27 & 0.22 & 0.31 & 0.25 & 0.25 & 0.28 & 0.31 & 0.27 \\
\hline $12-17$ months $(\mathrm{N}=728)$ & 0.29 & 0.27 & 0.26 & 0.29 & 0.23 & 0.27 & 0.22 & 0.26 \\
\hline $18-23$ months $(\mathrm{N}=589)$ & 0.23 & 0.24 & 0.20 & 0.23 & 0.27 & 0.15 & 0.17 & 0.22 \\
\hline 24 months $(\mathrm{N}=8)$ & 0.00 & 0.01 & 0.00 & 0.00 & 0.00 & 0.00 & 0.02 & 0.00 \\
\hline Mother's age (in years) & 28.89 & 27.63 & 29.52 & 29.25 & 29.56 & 27.34 & 29.28 & 29.67 \\
\hline Mother's education (in years) & 0.85 & 0.48 & 0.84 & 1.29 & 1.87 & 1.96 & 2.71 & 3.16 \\
\hline Mother has not gone to school & 0.84 & 0.89 & 0.81 & 0.79 & 0.65 & 0.58 & 0.46 & 0.50 \\
\hline Father's/caregiver's age (in years) & 38.44 & 35.33 & 36.67 & 38.03 & 38.73 & 34.55 & 36.67 & 39.83 \\
\hline Father's/caregiver's education (years) & 1.01 & 1.01 & 1.49 & 1.56 & 1.95 & 3.50 & 3.85 & 3.09 \\
\hline Father has not gone to school & 0.85 & 0.89 & 0.81 & 0.80 & 0.63 & 0.34 & 0.30 & 0.46 \\
\hline Household size & 5.38 & 6.06 & 6.09 & 5.56 & 5.45 & 6.00 & 5.91 & 5.55 \\
\hline
\end{tabular}

Source: Authors' analysis of data from March 2017 and March 2019 surveys.

Table A2. Hygiene conditions and practices by region and PSNP 2017

\begin{tabular}{lccccccc} 
& $\begin{array}{c}\text { Non- } \\
\text { PSNP }\end{array}$ & PSNP & Amhara & Oromia & SNNP & Tigray & All \\
Access to proper toilet & 58.4 & 50.9 & 45.0 & 51.6 & 85.7 & 39.3 & 55.4 \\
Human feces in the compound & 16.3 & 15.8 & 12.4 & 21.5 & 14.7 & 15.8 & 16.1 \\
Animal feces in the compound & 55.0 & 58.8 & 72.2 & 59.4 & 39.9 & 55.5 & 56.5 \\
Garbage in the compound & 63.1 & 67.4 & 76.8 & 65.1 & 62.2 & 55.8 & 64.8 \\
Mother washed hands yesterday & 95.1 & 96.6 & 99.4 & 93.4 & 92.3 & 97.9 & 95.7 \\
--- with soap & 40.4 & 38.5 & 32.0 & 31.5 & 53.3 & 41.4 & 39.7 \\
\hline
\end{tabular}

Source: Authors' analysis of data from 2017 surveys.

Table A3. Food gap in the last 6 months, by survey round and PSNP status, 2017

\begin{tabular}{lcccccc} 
& \multicolumn{3}{c}{ March 2017} & \multicolumn{3}{c}{ August 2017 } \\
& $\begin{array}{l}\text { Full } \\
\text { sample }\end{array}$ & PSNP & $\begin{array}{c}\text { Non- } \\
\text { PSNP }\end{array}$ & $\begin{array}{c}\text { Full } \\
\text { sample }\end{array}$ & $\begin{array}{c}\text { PSNP } \\
\text { PSNP }\end{array}$ \\
\hline Mean food gap & 2.1 & 2.1 & 2.0 & 1.8 & 1.9 & 1.7 \\
\hline $\begin{array}{l}\text { Distribution of food gap (\%): } \\
\text { Zero months }\end{array}$ & 18.0 & 18.0 & 18.0 & 39.0 & 36.3 & 40.8 \\
1 month & 26.0 & 24.6 & 27.0 & 11.8 & 12.5 & 11.4 \\
2 months & 27.8 & 27.1 & 28.3 & 18.2 & 18.9 & 17.7 \\
3 months & 11.5 & 12.1 & 11.1 & 14.1 & 14.0 & 14.2 \\
4 months & 4.0 & 5.0 & 3.4 & 6.0 & 6.6 & 5.7 \\
5 months & 2.0 & 1.7 & 2.2 & 2.2 & 1.9 & 2.4 \\
6 months & 10.8 & 11.7 & 10.2 & 8.7 & 9.9 & 7.9 \\
\hline Total & 100 & 100 & 100 & 100 & 100 & 100 \\
\hline
\end{tabular}

Source: Authors' analysis of data from 2017 surveys. 
Table A4. Mean Food gap (in months) in the last six months, by region and PSNP status

\begin{tabular}{lcccccc} 
& \multicolumn{3}{c}{ March 2017 } & \multicolumn{3}{c}{ August 2017 } \\
& $\begin{array}{c}\text { Full } \\
\text { sample }\end{array}$ & PSNP & $\begin{array}{c}\text { Non- } \\
\text { PSNP }\end{array}$ & $\begin{array}{c}\text { Full } \\
\text { sample }\end{array}$ & PSNP & $\begin{array}{c}\text { Non- } \\
\text { PSNP }\end{array}$ \\
Amhara & 1.57 & 1.67 & 1.49 & 1.22 & 1.38 & 1.09 \\
Oromia & 2.73 & 3.12 & 2.55 & 2.48 & 2.90 & 2.28 \\
SNNP & 2.08 & 2.29 & 1.93 & 2.95 & 3.29 & 2.77 \\
Tigray & 1.47 & 1.40 & 1.58 & 0.48 & 0.58 & 0.39 \\
\hline All & 2.07 & 2.13 & 2.02 & 1.78 & 1.87 & 1.71 \\
\hline
\end{tabular}

Source: Authors' analysis of data from 2017 surveys.

Table A5. Share of households with cereals in storage in March and August 2017, by region and PSNP status

\begin{tabular}{lcccccc} 
& \multicolumn{3}{c}{ March 2017 } & \multicolumn{3}{c}{ August 2017 } \\
& $\begin{array}{l}\text { Full } \\
\text { sample }\end{array}$ & PSNP & $\begin{array}{c}\text { Non- } \\
\text { PSNP }\end{array}$ & $\begin{array}{c}\text { Full } \\
\text { sample }\end{array}$ & PSNP & Non- \\
PSNP
\end{tabular}

Source: Authors' analysis of data from 2017 surveys.

Table A6. Share of households with pulses in storage in March and August, by region and PSNP status

\begin{tabular}{lcccccc} 
& \multicolumn{3}{c}{ March 2017 } & \multicolumn{3}{c}{ August 2017 } \\
& $\begin{array}{l}\text { Full } \\
\text { sample }\end{array}$ & PSNP & $\begin{array}{c}\text { Non- } \\
\text { PSNP }\end{array}$ & $\begin{array}{c}\text { Full } \\
\text { sample }\end{array}$ & PSNP & Non- \\
PSNP
\end{tabular}

Source: Authors' analysis of data from 2017 surveys.

Table A7. Mean amount (in kg) of cereals in storage in March and August, by region and PSNP status

\begin{tabular}{lcccccc} 
& \multicolumn{3}{c}{ March 2017 } & \multicolumn{3}{c}{ August 2017 } \\
& $\begin{array}{l}\text { Full } \\
\text { sample }\end{array}$ & PSNP & $\begin{array}{c}\text { Non- } \\
\text { PSNP }\end{array}$ & $\begin{array}{c}\text { Full } \\
\text { sample }\end{array}$ & PSNP & $\begin{array}{c}\text { Non- } \\
\text { PSNP }\end{array}$ \\
Amhara & 327 & 186 & 428 & 124 & 85 & 153 \\
Oromia & 59 & 47 & 65 & 75 & 22 & 101 \\
SNNP & 72 & 84 & 65 & 28 & 12 & 37 \\
Tigray & 238 & 185 & 291 & 81 & 50 & 112 \\
\hline All & 175 & 134 & 202 & 77 & 45 & 99 \\
\hline
\end{tabular}

Source: Authors' analysis of data from 2017 surveys. 
Table A8. Primary sources of food consumption by month and PSNP beneficiary status, 2017

\begin{tabular}{lccccc} 
& \multicolumn{2}{c}{ PSNP households (\%) } & Non-PSNP households (\%) \\
& $\begin{array}{c}\text { Own } \\
\text { production }\end{array}$ & PSNP & $\begin{array}{c}\text { Other } \\
\text { sources }\end{array}$ & $\begin{array}{c}\text { Own } \\
\text { production }\end{array}$ & $\begin{array}{c}\text { Other } \\
\text { Sources }\end{array}$ \\
\hline March 2017 & 52.9 & 22.7 & 24.5 & 69.9 & 30.1 \\
April 2017 & 47.1 & 26.9 & 26.1 & 66.2 & 33.9 \\
May 2017 & 38.9 & 31.8 & 29.3 & 58.2 & 41.9 \\
June 2017 & 35.8 & 31.3 & 32.8 & 54.2 & 45.9 \\
July 2017 & 34.8 & 26.4 & 38.9 & 53.3 & 49.8 \\
August 2017 & 35.1 & 19.5 & 45.4 & 52.0 & 48.0 \\
\hline
\end{tabular}

Source: Authors' analysis of data from 2017 surveys.

Note: PSNP transfers refers to transfers received through Public Works or Direct Support. Purchase captures non-PSNP related money which has been used to purchase consumption foods, which includes gifts and transfers from family, relatives and neighbors as well as transfers from governmental and non-governmental organizations. 


\section{Appendix B (Chapter 4)}

Table B1. Mothers' anthropometry, by region and round, 2017

\begin{tabular}{|c|c|c|c|c|c|c|c|c|c|c|}
\hline & \multicolumn{5}{|c|}{ March 2017} & \multicolumn{5}{|c|}{ August 2017} \\
\hline & Tigray & Amhara & Oromia & SNNP & $\begin{array}{l}\text { All } \\
\text { regions }\end{array}$ & Tigray & Amhara & Oromia & SNNP & $\begin{array}{l}\text { All } \\
\text { regions }\end{array}$ \\
\hline Number of observations & 473 & 499 & 498 & 518 & 1,988 & 469 & 494 & 501 & 514 & 1,978 \\
\hline Body mass index $\left(\mathrm{kg} / \mathrm{m}^{2}\right)$, mean & 19.7 & 19.7 & 20.3 & 19.0 & 19.7 & 19.9 & 19.7 & 20.2 & 19.7 & 19.7 \\
\hline \multicolumn{11}{|l|}{ BMI categories (percent): } \\
\hline Underweight $\left(<18.5 \mathrm{~kg} / \mathrm{m}^{2}\right)$ & 25.2 & 28.2 & 19.6 & 41.8 & 29.0 & 26.5 & 29.5 & 21.6 & 41.1 & 29.9 \\
\hline Normal weight $\left(18.5-25 \mathrm{~kg} / \mathrm{m}^{2}\right)$ & 74.0 & 70.5 & 77.4 & 57.8 & 69.6 & 72.4 & 68.9 & 76.1 & 58.3 & 68.7 \\
\hline Overweight (> $\left.25 \mathrm{~kg} / \mathrm{m}^{2}\right)$ & 0.9 & 1.3 & 3.0 & 0.4 & 1.4 & 1.1 & 1.6 & 2.4 & 0.6 & 1.4 \\
\hline Height (cm) & 156.4 & 158.3 & 157.6 & 157.1 & 157.4 & 155.9 & 157.9 & 157.4 & 157.0 & 157.1 \\
\hline $\begin{array}{l}\text { Mid-upper arm circumference } \\
(\mathrm{cm}) \text {, mean }\end{array}$ & 22.8 & 23.6 & 24.0 & 23.1 & 23.4 & 23.0 & 23.2 & 23.7 & 22.8 & 23.2 \\
\hline \multicolumn{11}{|l|}{ MUAC categories (percent): } \\
\hline Less than $21 \mathrm{~cm}$ & 13.6 & 8.6 & 4.6 & 13.0 & 9.9 & 12.6 & 10.7 & 10.4 & 16.4 & 12.6 \\
\hline Between 21 and $23 \mathrm{~cm}$ & 46.7 & 36.5 & 30.7 & 42.0 & 38.9 & 45.3 & 41.6 & 31.3 & 41.0 & 39.7 \\
\hline More than $23 \mathrm{~cm}$ & 39.7 & 55.0 & 64.8 & 45.0 & 51.2 & 42.1 & 47.7 & 58.3 & 42.6 & 47.7 \\
\hline
\end{tabular}

Source: Authors' analysis of data from 2017 surveys.

Note: BMI was not calculated for 109 pregnant mothers. MUAC = Mid-Upper Arm Circumference

Table B2. Mothers' anthropometry by PSNP beneficiary status and round, 2017

\begin{tabular}{lcccc} 
& \multicolumn{2}{c}{ March 2017} & \multicolumn{2}{c}{ August 2017} \\
& Non-PSNP & PSNP & Non-PSNP & PSNP \\
Number of observations & 1,195 & 793 & 1,187 & 791 \\
\hline Body mass index $\left(\mathrm{kg} / \mathrm{m}^{2}\right)$, mean & 19.7 & 19.7 & 19.7 & 19.5 \\
BMl categories (percent): & & & & \\
$\quad$ Underweight $\left(<18.5 \mathrm{~kg} / \mathrm{m}^{2}\right)$ & 28.5 & 29.7 & 29.3 & 30.8 \\
Normal weight $\left(18.5-25 \mathrm{~kg} / \mathrm{m}^{2}\right)$ & 69.8 & 69.4 & 69.2 & 68.0 \\
Overweight $\left(>25 \mathrm{~kg} / \mathrm{m}^{2}\right)$ & 1.7 & 0.9 & 1.5 & 1.2 \\
Height $(\mathrm{cm})$ & 157.5 & 157.2 & 157.1 & 157.1 \\
Mid-upper arm circumference $(\mathrm{cm})$, mean & 23.4 & 23.3 & 23.2 & 23.1 \\
MUAC categories (percent): & & & & \\
Less than 21 cm & 8.9 & 11.5 & 11.8 & 13.7 \\
Between 21 and 23 cm & 38.5 & 39.4 & 40.3 & 39.0 \\
More than 23 cm & 52.6 & 49.1 & 47.9 & 47.3 \\
\hline
\end{tabular}

Source: Authors' analysis of data from 2017 surveys.

Note: BMI was not calculated for 109 pregnant mothers. MUAC = Mid-Upper Arm Circumference 
Table B3. Mothers' dietary diversity by region and round, 2017

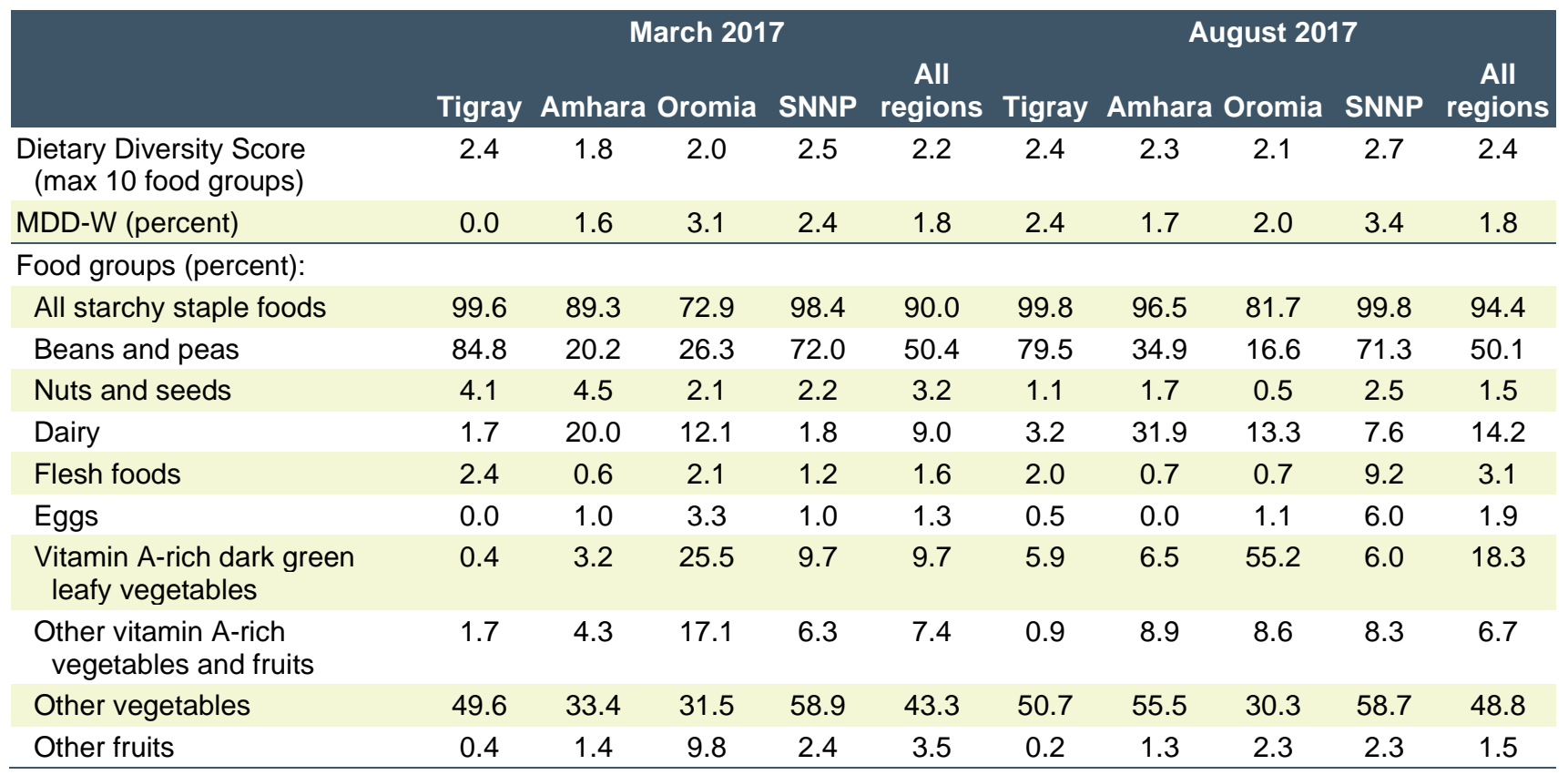

Source: Authors' analysis of data from 2017 surveys.

Note: MDD-W = Minimum Dietary Diversity-Women.

\section{Table B4. Mothers' dietary diversity by PSNP status, 2017}

\begin{tabular}{lcccc} 
& \multicolumn{2}{c}{ March 2017} & \multicolumn{2}{c}{ August 2017} \\
& Non-PSNP & PSNP & Non-PSNP & PSNP \\
Dietary Diversity Score (max 10 food groups) & 2.2 & 2.1 & 2.4 & 2.4 \\
MDD-W (percent) & 2.0 & 1.6 & 1.9 & 1.6 \\
\hline Food groups (percent): & & & & \\
All starchy staple foods & 90.2 & 89.7 & 93.5 & 95.9 \\
Beans and peas & 49.5 & 51.9 & 49.3 & 51.4 \\
Nuts and seeds & 3.3 & 3.1 & 1.6 & 1.2 \\
Dairy & 10.3 & 7.0 & 15.7 & 11.9 \\
Flesh foods & 1.9 & 1.1 & 3.0 & 3.2 \\
Eggs & 1.6 & 0.9 & 2.1 & 1.5 \\
Vitamin A-rich dark green leafy vegetables & 10.5 & 8.6 & 19.4 & 16.5 \\
Other vitamin A-rich vegetables and fruits & 7.1 & 7.8 & 7.5 & 5.4 \\
Other vegetables & 45.0 & 40.7 & 49.8 & 47.3 \\
Other fruits & 4.3 & 2.4 & 1.7 & 1.2 \\
\hline
\end{tabular}

Source: Authors' analysis of data from 2017 surveys.

Note: MDD-W = Minimum Dietary Diversity-Women. 


\section{Appendix C (Chapter 5)}

Table C1. Anthropometric indicators, children 6 to 23 months of age, by region

\begin{tabular}{|c|c|c|c|c|c|c|c|c|c|c|c|}
\hline & $\begin{array}{c}\text { LAZ } \\
\text { z-score }\end{array}$ & $\begin{array}{c}\text { Stunted } \\
\%\end{array}$ & $\begin{array}{c}\text { WLZ } \\
\text { z-score }\end{array}$ & $\begin{array}{c}\text { Wasted } \\
\%\end{array}$ & $\begin{array}{c}\text { WAZ } \\
\text { z-score }\end{array}$ & $\begin{array}{c}\text { Under- } \\
\text { weight } \\
\%\end{array}$ & $\begin{array}{c}\text { MUAC } \\
\mathrm{cm}\end{array}$ & $\begin{array}{c}\text { MUAC } \\
<11.5 \\
\mathrm{~cm} \\
\%\end{array}$ & $\begin{array}{c}\text { MUAC } \\
11.5- \\
12.5 \mathrm{~cm} \\
\%\end{array}$ & $\begin{array}{c}\text { MUAC } \\
>12.5 \\
\mathrm{~cm} \\
\%\end{array}$ & $\begin{array}{c}\text { Acute } \\
\text { malnutrition, } \\
\text { WHO } \\
\text { definition } \\
\%\end{array}$ \\
\hline \multicolumn{12}{|c|}{ March 2017} \\
\hline Tigray & -1.81 & 46.1 & -0.64 & 14.7 & -1.41 & 30.5 & 13.40 & 2.9 & 16.0 & 81.2 & 28.5 \\
\hline Amhara & -1.84 & 47.5 & -0.59 & 15.1 & -1.40 & 30.6 & 13.15 & 3.8 & 19.0 & 77.2 & 31.2 \\
\hline Oromia & -1.39 & 36.3 & -0.25 & 11.9 & -0.96 & 19.9 & 13.48 & 5.3 & 13.7 & 80.9 & 26.4 \\
\hline SNNP & -1.23 & 36.6 & -0.43 & 13.7 & -0.95 & 23.6 & 13.62 & 3.0 & 13.0 & 84.0 & 24.1 \\
\hline \multicolumn{12}{|c|}{ August 2017} \\
\hline Tigray & -1.72 & 40.6 & -0.76 & 14.1 & -1.40 & 27.5 & 13.36 & 3.4 & 16.0 & 80.6 & 25.7 \\
\hline Amhara & -1.92 & 50.8 & -0.38 & 5.2 & -1.27 & 23.7 & 13.49 & 2.6 & 14.6 & 82.9 & 19.1 \\
\hline Oromia & -1.36 & 34.8 & -0.43 & 6.8 & -1.00 & 18.7 & 13.70 & 1.6 & 8.6 & 89.8 & 14.3 \\
\hline SNNP & -1.22 & 31.1 & -0.04 & 5.0 & -0.66 & 12.5 & 13.91 & 2.1 & 8.9 & 89.1 & 13.8 \\
\hline \multicolumn{12}{|c|}{ March 2019} \\
\hline Tigray & -1.65 & 40.5 & -0.68 & 11.2 & -1.33 & 26.5 & 13.53 & 3.9 & 13.6 & 82.5 & 22.9 \\
\hline Amhara & -1.81 & 42.7 & -0.64 & 11.3 & -1.39 & 29.2 & 13.52 & 3.5 & 13.6 & 82.9 & 21.7 \\
\hline Oromia & -1.22 & 30.5 & -0.31 & 8.5 & -0.85 & 18.2 & 13.73 & 3.5 & 11.3 & 85.2 & 19.7 \\
\hline SNNP & -1.22 & 31.9 & -0.35 & 11.1 & -0.90 & 20.5 & 13.73 & 2.0 & 11.9 & 86.1 & 18.8 \\
\hline \multicolumn{12}{|c|}{ August 2019} \\
\hline Tigray & -1.77 & 43.1 & -0.48 & 6.2 & -1.24 & 22.9 & 13.58 & 1.6 & 11.9 & 86.5 & 16.2 \\
\hline Amhara & -2.01 & 51.6 & -0.61 & 11.3 & -1.47 & 31.0 & 13.66 & 2.5 & 7.8 & 89.7 & 16.9 \\
\hline Oromia & -1.47 & 36.8 & -0.37 & 10.7 & -1.03 & 21.3 & 13.74 & 3.3 & 7.5 & 89.2 & 16.9 \\
\hline SNNP & -1.44 & 35.1 & -0.07 & 7.3 & -0.80 & 16.1 & 14.05 & 1.4 & 8.6 & 90.0 & 13.5 \\
\hline
\end{tabular}

Source: Authors' analysis of data from surveys. LAZ = Length-for-age $z$-score. WAZ = Weight-for-age $z$-score. MUAC $=$ Mid-Upper Arm Circumference

Table C2. Fever, diarrhea and ARI prevalence, children 6 to 23 months of age, by region, percent

\begin{tabular}{|c|c|c|c|}
\hline \multicolumn{4}{|c|}{ March 2017} \\
\hline Tigray & 25.6 & 17.1 & 14.0 \\
\hline Amhara & 40.6 & 30.8 & 23.9 \\
\hline Oromia & 21.3 & 18.4 & 9.6 \\
\hline SNNP & 33.2 & 29.2 & 12.4 \\
\hline \multicolumn{4}{|c|}{ August 2017} \\
\hline Tigray & 21.0 & 15.2 & 6.4 \\
\hline Amhara & 31.1 & 28.9 & 13.7 \\
\hline Oromia & 30.2 & 24.1 & 17.5 \\
\hline SNNP & 36.9 & 25.1 & 10.1 \\
\hline \multicolumn{4}{|c|}{ March 2019} \\
\hline Tigray & 22.3 & 12.6 & 8.1 \\
\hline Amhara & 39.9 & 30.6 & 20.9 \\
\hline Oromia & 24.3 & 26.1 & 11.5 \\
\hline SNNP & 49.7 & 42.7 & 19.7 \\
\hline \multicolumn{4}{|c|}{ August 2019} \\
\hline Tigray & 19.2 & 14.0 & 5.7 \\
\hline Amhara & 34.6 & 31.5 & 10.4 \\
\hline Oromia & 24.0 & 23.7 & 7.9 \\
\hline SNNP & 40.9 & 28.2 & 14.9 \\
\hline
\end{tabular}

Source: Authors' analysis of data from surveys. ARI = Acute respiratory infection 


\section{Appendix D (Chapter 6)}

Table D1. WHO recommended core infant and young child feeding (IYCF) indicators

\begin{tabular}{|c|c|c|c|}
\hline Indicator name & Definition & Numerator & Denominator \\
\hline $\begin{array}{l}\text { Early initiation of } \\
\text { breastfeeding }\end{array}$ & $\begin{array}{l}\text { Proportion of children born in the } \\
\text { last } 24 \text { months who were put to } \\
\text { the breast within one hour of birth }\end{array}$ & $\begin{array}{l}\text { Children born in the last } 24 \text { months } \\
\text { who were put to the breast within } \\
\text { one hour of birth }\end{array}$ & $\begin{array}{l}\text { Children born in } \\
\text { the last } 24 \\
\text { months }\end{array}$ \\
\hline $\begin{array}{l}\text { Exclusive } \\
\text { breastfeeding } \\
\text { under } 6 \text { months }\end{array}$ & $\begin{array}{l}\text { Proportion of infants } 0 \text { to } 5 \text { months } \\
\text { of age who are fed exclusively } \\
\text { with breast milk }\end{array}$ & $\begin{array}{l}\text { Infants } 0 \text { to } 5 \text { months of age who } \\
\text { received only breast milk during } \\
\text { the previous day }\end{array}$ & $\begin{array}{l}\text { Infants } 0 \text { to } 5 \\
\text { months }\end{array}$ \\
\hline $\begin{array}{l}\text { Continued } \\
\text { breast-feeding } \\
\text { at one year }\end{array}$ & $\begin{array}{l}\text { Proportion of children } 12 \text { to } 15 \\
\text { months of age who are fed breast } \\
\text { milk }\end{array}$ & $\begin{array}{l}\text { Children } 12 \text { to } 15 \text { months who } \\
\text { received breast milk during the } \\
\text { previous day }\end{array}$ & $\begin{array}{l}\text { Children } 12 \text { to } \\
15 \text { months }\end{array}$ \\
\hline $\begin{array}{l}\text { Introduction of } \\
\text { solid, } \\
\text { semisolid, or } \\
\text { soft foods }\end{array}$ & $\begin{array}{l}\text { Proportion of infants } 6 \text { to } 8 \text { months } \\
\text { of age who receive solid, } \\
\text { semisolid, or soft foods }\end{array}$ & $\begin{array}{l}\text { Children } 6 \text { to } 8 \text { months of age who } \\
\text { received solid, semisolid, or soft } \\
\text { foods during the previous day }\end{array}$ & $\begin{array}{l}\text { Children } 6 \text { to } 8 \\
\text { months }\end{array}$ \\
\hline $\begin{array}{l}\text { Minimum dietary } \\
\text { diversity }(\geq 4 \\
\text { food groups) }\end{array}$ & $\begin{array}{l}\text { Proportion of children } 6 \text { to } 23 \\
\text { months of age who receive foods } \\
\text { from } 4 \text { or more food groups }\end{array}$ & $\begin{array}{l}\text { Children } 6 \text { to } 23 \text { months of age who } \\
\text { received foods from four or more } \\
\text { food groups during the previous } \\
\text { day }\end{array}$ & $\begin{array}{l}\text { Children } 6 \text { to } 23 \\
\text { months }\end{array}$ \\
\hline $\begin{array}{l}\text { Minimum meal } \\
\text { frequency }\end{array}$ & $\begin{array}{l}\text { Proportion of breastfed and non- } \\
\text { breastfed children } 6 \text { to } 23 \text { months } \\
\text { of age who receive solid, } \\
\text { semisolid, or soft foods (but also } \\
\text { including milk feeds for non- } \\
\text { breastfed children) the minimum } \\
\text { number of times or more }\end{array}$ & $\begin{array}{l}\text { Breastfed or non-breastfed children } \\
6 \text { to } 23 \text { months of age who } \\
\text { received solid, semisolid, or soft } \\
\text { foods the minimum number of } \\
\text { times or more during the previous } \\
\text { day }\end{array}$ & $\begin{array}{l}\text { Breastfed or } \\
\text { non-breastfed } \\
\text { children } 6 \text { to } 23 \\
\text { months of age }\end{array}$ \\
\hline \multirow[t]{2}{*}{$\begin{array}{l}\text { Minimum accept- } \\
\text { able diet }\end{array}$} & \multirow[t]{2}{*}{$\begin{array}{l}\text { Proportion of children } 6 \text { to } 23 \\
\text { months of age who receive a } \\
\text { minimum acceptable diet (apart } \\
\text { from breast milk) }\end{array}$} & $\begin{array}{l}\text { Breastfed children } 6 \text { to } 23 \text { months } \\
\text { who had at least the minimum } \\
\text { dietary diversity and the minimum } \\
\text { meal frequency during the } \\
\text { previous day }\end{array}$ & $\begin{array}{l}\text { Breastfed } \\
\text { children } 6 \text { to } 23 \\
\text { months of age }\end{array}$ \\
\hline & & $\begin{array}{l}\text { Non-breastfed children } 6 \text { to } 23 \\
\text { months of age who received at } \\
\text { least } 2 \text { milk feedings and had at } \\
\text { least the minimum dietary } \\
\text { diversity, not including milk feeds } \\
\text { and the minimum meal frequency } \\
\text { during the previous day }\end{array}$ & $\begin{array}{l}\text { Non-breastfed } \\
\text { children } 6 \text { to } 23 \\
\text { months of age }\end{array}$ \\
\hline $\begin{array}{l}\text { Consumption of } \\
\text { iron-rich or } \\
\text { iron-fortified } \\
\text { foods }\end{array}$ & $\begin{array}{l}\text { Proportion of children } 6 \text { to } 23 \\
\text { months of age who receive an } \\
\text { iron-rich food or iron-fortified food } \\
\text { that is especially designed for } \\
\text { infants and young children, or that } \\
\text { is fortified in the home }\end{array}$ & $\begin{array}{l}\text { Children } 6 \text { to } 23 \text { months of age who } \\
\text { received an iron-rich food or a food } \\
\text { that was especially designed for } \\
\text { infants and young children and } \\
\text { was fortified with iron during the } \\
\text { previous day }\end{array}$ & $\begin{array}{l}\text { Children } 6 \text { to } 23 \\
\text { months }\end{array}$ \\
\hline
\end{tabular}

Source: WHO (2010). 


\section{Appendix E (Chapter 9)}

Table E1. Whether the same Health Extension Worker was interviewed in both 2017 and 2019 , by region

\begin{tabular}{|c|c|c|c|c|c|}
\hline & Tigray & Amhara & Oromia & SNNP & All \\
\hline $\begin{array}{l}\text { Same HEW interviewed from } \\
\text { last round (percent) }\end{array}$ & 45.5 & 27.4 & 61.0 & 45.3 & 44.6 \\
\hline Common reason for absence & \multicolumn{5}{|c|}{$\begin{array}{l}\text { 1) HEW has moved to a different health post but continues to work as a HEW }(32 \%) \\
\text { 2) HEW still works at this health post but was not available for interview because she was } \\
\text { away for personal reasons }(29 \%) \\
\text { 3) HEW still works at this health post but was not available for interview because she was } \\
\text { away for work-related reasons }(18 \%)\end{array}$} \\
\hline
\end{tabular}

Source: HEW quantitative survey, August 2019.

Table E2. Health Extension Worker characteristics, by region, 2017

\begin{tabular}{|c|c|c|c|c|c|}
\hline & Tigray & Amhara & Oromia & SNNP & All regions \\
\hline Age (years, mean) & 28.1 & 26.5 & 25.6 & 27.3 & 26.9 \\
\hline \multicolumn{6}{|l|}{ Place of origin (percent): } \\
\hline This woreda and kebele & 46.2 & 23.3 & 25.0 & 51.6 & 37.0 \\
\hline This woreda, different kebele & 47.7 & 65.0 & 60.0 & 37.5 & 52.2 \\
\hline Another woreda & 6.1 & 11.7 & 15.0 & 10.9 & 10.8 \\
\hline \multicolumn{6}{|c|}{ Highest level of schooling completed (percent): } \\
\hline Primary & 0.0 & 0.0 & 0.0 & 10.9 & 2.8 \\
\hline Secondary & 15.4 & 6.7 & 10.0 & 26.6 & 14.9 \\
\hline Post-secondary: Technical or vocational & 64.6 & 75.0 & 83.3 & 48.4 & 67.5 \\
\hline Post-secondary: College or university & 20.0 & 18.3 & 6.7 & 14.1 & 14.8 \\
\hline
\end{tabular}

Source: HEW quantitative survey, August 2017. 
Table E3. Percent of Health Extension Workers reporting undertaking specific activity and their assessment of time spent on activity, by activity group

\begin{tabular}{|c|c|c|c|c|}
\hline & \multirow{2}{*}{$\begin{array}{c}\text { Undertook } \\
\text { this } \\
\text { activity }\end{array}$} & \multicolumn{3}{|c|}{$\begin{array}{l}\text { Self-assessment of time spent on } \\
\text { this activity }\end{array}$} \\
\hline & & $\begin{array}{l}\text { Consider- } \\
\text { able time }\end{array}$ & $\begin{array}{l}\text { Moderate } \\
\text { amount }\end{array}$ & Little time \\
\hline \multicolumn{5}{|l|}{ Pregnant and lactating mothers } \\
\hline Antenatal care & 95 & 27 & 50 & 22 \\
\hline Delivery care & 53 & 16 & 55 & 29 \\
\hline Postnatal care & 92 & 24 & 55 & 22 \\
\hline Breastfeeding counselling & 95 & 30 & 53 & 17 \\
\hline \multicolumn{5}{|l|}{ Children's nutrition } \\
\hline Neonatal care & 86 & 32 & 47 & 21 \\
\hline Vitamin A; iron supplementation & 84 & 26 & 47 & 28 \\
\hline Growth monitoring & 92 & 37 & 47 & 16 \\
\hline Complementary feeding & 97 & 34 & 50 & 16 \\
\hline Diarrhea treatment & 86 & 20 & 43 & 38 \\
\hline Management of Severe Acute Malnutrition (SAM) & 79 & 25 & 39 & 36 \\
\hline \multicolumn{5}{|l|}{ Health and illness } \\
\hline Family planning & 98 & 27 & 56 & 17 \\
\hline Immunization & 97 & 39 & 43 & 18 \\
\hline Deworming & 77 & 32 & 38 & 30 \\
\hline Referral of sick child & 52 & 7 & 28 & 65 \\
\hline HIVIAIDS counselling & 79 & 16 & 47 & 36 \\
\hline Pneumonia treatment & 63 & 9 & 35 & 56 \\
\hline Malaria treatment & 49 & 25 & 36 & 39 \\
\hline Providing/selling bed nets & 6 & 31 & 25 & 44 \\
\hline $\begin{array}{l}\text { Health or Water, Sanitation and Hygiene (WASH) } \\
\text { education }\end{array}$ & 97 & 54 & 34 & 12 \\
\hline \multicolumn{5}{|l|}{ Community outreach } \\
\hline Food demonstration & 55 & 12 & 43 & 46 \\
\hline \multicolumn{5}{|l|}{ Administration } \\
\hline Registering and recording & 96 & 37 & 42 & 21 \\
\hline Preparing reports & 97 & 30 & 37 & 33 \\
\hline Attending meetings & 79 & 10 & 38 & 52 \\
\hline Training & 59 & 7 & 30 & 63 \\
\hline Supervision & 82 & 23 & 48 & 29 \\
\hline
\end{tabular}

Source: HEW quantitative survey, August 2017. 
Table E4. Interactions of Health Extension Workers with HDAs, Development Agents, and social workers, 2017

\begin{tabular}{|c|c|c|c|c|c|}
\hline & Tigray & Amhara & Oromia & SNNP & All \\
\hline & \multicolumn{5}{|c|}{ Health Development Army } \\
\hline Are any Health Development Armies (HDA) active in this kebele? & 100.0 & 90.0 & 71.7 & 96.9 & 90.0 \\
\hline Are you responsible for supervising the HDA leaders? & 96.9 & 96.3 & 86.0 & 96.8 & 94.6 \\
\hline How many HDA leaders do you supervise? (number of HDAs/kebele) & 20 & 28 & 14 & 29 & 23 \\
\hline \multicolumn{6}{|l|}{ How often do you usually meet with the HDA leaders? } \\
\hline Every day or several times a week & 9.2 & 11.1 & 4.7 & 6.5 & 8.0 \\
\hline Weekly & 26.2 & 16.7 & 41.9 & 58.1 & 35.7 \\
\hline Monthly & 63.1 & 63.0 & 41.9 & 33.9 & 50.9 \\
\hline \multirow[t]{2}{*}{ Less than once a month } & 1.5 & 9.3 & 11.6 & 1.6 & 5.4 \\
\hline & \multicolumn{5}{|c|}{ Development Agents } \\
\hline $\begin{array}{l}\text { Do you ever meet with the agriculture Development Agents (DA) in } \\
\text { your kebele? }\end{array}$ & 86.2 & 98.3 & 88.3 & 92.2 & 91.2 \\
\hline \multicolumn{6}{|l|}{ How often do you usually meet with DAs? } \\
\hline Every day or several times a week & 5.4 & 28.8 & 34.0 & 30.5 & 24.7 \\
\hline Weekly & 39.3 & 49.2 & 30.2 & 55.9 & 44.1 \\
\hline Monthly & 51.8 & 15.3 & 20.8 & 11.9 & 24.7 \\
\hline Less than once a month & 3.6 & 6.8 & 15.1 & 1.7 & 6.6 \\
\hline \multicolumn{6}{|l|}{ When was the last time you met with DAs to talk about PSNP? } \\
\hline During last month & 85.7 & 54.2 & 34.0 & 49.2 & 55.9 \\
\hline 1-3 months ago & 7.1 & 25.4 & 11.3 & 10.2 & 13.7 \\
\hline 4-6 months ago & 1.8 & 3.4 & 3.8 & 3.4 & 3.1 \\
\hline 7 or more months ago & 0.0 & 1.7 & 13.2 & 1.7 & 4.0 \\
\hline \multirow[t]{2}{*}{ Never } & 5.4 & 15.3 & 37.7 & 35.6 & 23.3 \\
\hline & \multicolumn{5}{|c|}{ Social Workers } \\
\hline Is there a Social Worker deployed in this kebele? & 41.5 & 11.7 & 25.0 & 20.3 & 24.9 \\
\hline \multicolumn{6}{|l|}{ How often do you usually meet with the Social Worker? } \\
\hline Every day or several times a week & 0.0 & 14.3 & 0.0 & 7.7 & 3.2 \\
\hline Weekly & 14.8 & 71.4 & 40.0 & 30.8 & 30.6 \\
\hline Monthly & 70.4 & 14.3 & 40.0 & 46.2 & 51.6 \\
\hline Less than once a month & 14.8 & 0.0 & 20.0 & 15.4 & 14.5 \\
\hline \multicolumn{6}{|l|}{$\begin{array}{l}\text { When was the last time you met with the Social Worker to talk about } \\
\text { PSNP? }\end{array}$} \\
\hline During last month & 74.1 & 71.4 & 40.0 & 38.5 & 58.1 \\
\hline 1-3 months ago & 3.7 & 0.0 & 6.7 & 7.7 & 4.8 \\
\hline 4-6 months ago & 0.0 & 0.0 & 0.0 & 0.0 & 0.0 \\
\hline 7 or more months ago & 0.0 & 0.0 & 0.0 & 0.0 & 0.0 \\
\hline Never & 22.2 & 28.6 & 53.3 & 53.8 & 37.1 \\
\hline
\end{tabular}

Source: HEW quantitative survey, August 2017.

Table E5. Length of PSNP training for Health Extension Workers, by region, 2017, percent

\begin{tabular}{lccccc}
\multicolumn{1}{c}{ Days: } & $\mathbf{1}$ & $\mathbf{2}$ & $\mathbf{3}$ & $\mathbf{4 +}$ & Total \\
Amhara & 30 & 70 & 0 & 0 & 100 \\
Oromia & 0 & 0 & 80 & 20 & 100 \\
SNNP & 0 & 40 & 40 & 20 & 100 \\
Tigray & 53 & 35 & 6 & 6 & 100 \\
All regions & 39 & 39 & 15 & 7 & 100 \\
\hline
\end{tabular}

Source: HEW quantitative survey, August 2017.

Note: Sample consists of 54 HEWs who reported receiving training on PSNP in the last 12 months 
Table E6. Perceptions of change in workload of Health Extension Workers, 2017, by region

\begin{tabular}{|c|c|c|c|c|c|}
\hline & Tigray & Amhara & Oromia & SNNP & All \\
\hline \multicolumn{6}{|l|}{ Overall, how would you describe your workload } \\
\hline Too little & 0.0 & 0.0 & 3.4 & 4.8 & 2.2 \\
\hline Just right & 13.5 & 39.0 & 44.8 & 33.9 & 33.3 \\
\hline Too much & 86.5 & 61.0 & 51.7 & 61.3 & 64.5 \\
\hline \multicolumn{6}{|l|}{$\begin{array}{l}\text { In the past } 12 \text { months, would you say that your workload is } \\
\text { less, more, or the same as before? }\end{array}$} \\
\hline Less & 5.8 & 22.0 & 7.0 & 11.5 & 11.8 \\
\hline Same & 9.6 & 11.9 & 21.1 & 9.8 & 13.1 \\
\hline More & 84.6 & 66.1 & 71.9 & 78.7 & 75.1 \\
\hline \multicolumn{6}{|l|}{$\begin{array}{l}\text { If workload has increased, what are the reasons for this } \\
\text { (\% of HEWs who report this reason as either the first, } \\
\text { second, or third reason for higher workload) }\end{array}$} \\
\hline Increased number of people/patients & 18.3 & 19.0 & 19.2 & 23.8 & 20.4 \\
\hline Increased coverage areas & 4.3 & 19.0 & 12.1 & 9.8 & 10.9 \\
\hline Multiple sites of work (more villages and home visits) & 1.1 & 3.8 & 12.1 & 2.5 & 4.8 \\
\hline More government programs and services & 37.6 & 22.8 & 20.2 & 23.8 & 26.0 \\
\hline More activities from projects & 24.7 & 7.6 & 6.1 & 10.7 & 12.2 \\
\hline More supervision/inspection & 0.0 & 3.8 & 4.0 & 4.1 & 3.1 \\
\hline More training sessions & 0.0 & 1.3 & 2.0 & & 0.8 \\
\hline More paperwork & 0.0 & 1.3 & 1.0 & 7.4 & 2.8 \\
\hline More meetings & 1.1 & 1.3 & 4.0 & 4.9 & 3.1 \\
\hline Staff shortage/covering other's work & 11.8 & 16.5 & 13.1 & 10.7 & 12.7 \\
\hline \multicolumn{6}{|l|}{$\begin{array}{l}\text { In the past } 12 \text { months, has your workload become less, } \\
\text { more, or the same as before because of activities related } \\
\text { to infant and young child feeding (such as giving } \\
\text { messages and food demonstrations)? }\end{array}$} \\
\hline Less & 1.9 & 30.5 & 32.8 & 16.1 & 20.8 \\
\hline Same & 28.8 & 32.2 & 29.3 & 29.0 & 29.9 \\
\hline More & 69.2 & 37.3 & 37.9 & 54.8 & 49.4 \\
\hline \multicolumn{6}{|l|}{$\begin{array}{l}\text { In the last } 12 \text { months have you spent time beyond your } \\
\text { usual work hours to keep up with your workload? }\end{array}$} \\
\hline Yes & 96.2 & 78.0 & 67.2 & 80.6 & 80.1 \\
\hline No & 3.8 & 22.0 & 32.8 & 19.4 & 19.9 \\
\hline \multicolumn{6}{|l|}{ If Yes, how much additional time } \\
\hline Less than 30 minutes & 0.0 & 2.2 & 0.0 & 8.0 & 2.7 \\
\hline 30-60 minutes & 16.0 & 13.0 & 28.2 & 6.0 & 15.1 \\
\hline 1-2 hours & 68.0 & 60.9 & 51.3 & 36.0 & 54.1 \\
\hline 3-4 hours & 12.0 & 19.6 & 12.8 & 12.0 & 14.1 \\
\hline More than 4 hours & 4.0 & 4.3 & 7.7 & 38.0 & 14.1 \\
\hline
\end{tabular}

Source: HEW quantitative survey, August 2017. 
Table E7. Frequencies in the experience of 22 feelings related to occupation burnout among all Health Extension Workers across the four regions, 2017, percent

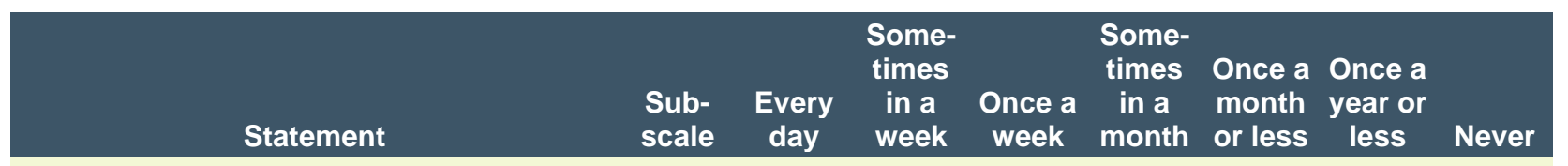

\begin{tabular}{|c|c|c|c|c|c|c|c|c|}
\hline \multicolumn{9}{|l|}{ Depersonalization } \\
\hline Worry that job is hardening emotionally & $\mathrm{D}$ & 17 & 4 & 4 & 10 & 6 & 13 & 44 \\
\hline Treat patients as impersonal "objects" & $\mathrm{D}$ & 8 & 3 & 3 & 5 & 2 & 3 & 76 \\
\hline Become more callous toward people & $\mathrm{D}$ & 6 & 2 & 2 & 2 & 2 & 3 & 83 \\
\hline Don't really care what happens to patients & $\mathrm{D}$ & 6 & 1 & 1 & 3 & 1 & 3 & 84 \\
\hline Feel patients blame for their problems & $\mathrm{D}$ & 24 & 6 & 4 & 9 & 7 & 10 & 39 \\
\hline \multicolumn{9}{|l|}{ Emotional Exhaustion } \\
\hline Feel emotionally drained from work & $\mathrm{EE}$ & 10 & 2 & 6 & 6 & 10 & 19 & 48 \\
\hline Feel used up at the end of the workday & $\mathrm{EE}$ & 6 & 3 & 7 & 5 & 9 & 19 & 50 \\
\hline Feel fatigued I get up in the morning & EE & 8 & 4 & 10 & 10 & 13 & 12 & 41 \\
\hline Feel frustrated by my job & $\mathrm{EE}$ & 5 & 2 & 4 & 9 & 14 & 17 & 49 \\
\hline Working with people puts too much stress & $\mathrm{EE}$ & 13 & 3 & 9 & 10 & 12 & 11 & 42 \\
\hline Working with patients is a strain & EE & 8 & 4 & 5 & 4 & 8 & 10 & 61 \\
\hline Feel I'm working too hard on my job & $\mathrm{EE}$ & 49 & 9 & 6 & 7 & 6 & 9 & 14 \\
\hline Feel like I'm at the end of my rope & EE & 10 & 3 & 7 & 9 & 6 & 11 & 55 \\
\hline Feel burned out from my work & $\mathrm{EE}$ & 10 & 3 & 4 & 7 & 6 & 9 & 62 \\
\hline \multicolumn{9}{|l|}{ Personal Accomplishment } \\
\hline Feel very energetic & PA & 65 & 7 & 2 & 6 & 4 & 7 & 9 \\
\hline Can easily create a relaxed atmosphere & PA & 60 & 10 & 6 & 2 & 7 & 6 & 8 \\
\hline Have accomplished worthwhile things in job & PA & 59 & 10 & 8 & 5 & 6 & 8 & 4 \\
\hline Feel positively influencing people's lives & PA & 53 & 8 & 7 & 3 & 6 & 4 & 18 \\
\hline Deal with emotional problems calmly & PA & 57 & 10 & 8 & 3 & 7 & 6 & 9 \\
\hline Can easily understand patients' feelings & PA & 66 & 6 & 7 & 5 & 4 & 4 & 7 \\
\hline Deal effectively with the patients' problems & PA & 75 & 4 & 8 & 4 & 2 & 2 & 5 \\
\hline Feel exhilarated after working with patients & PA & 77 & 6 & 6 & 3 & 3 & 2 & 3 \\
\hline
\end{tabular}

Source: HEW quantitative survey, August 2017.

Note: Sample size is 249. EE = Emotional Exhaustion; PA = Personal Accomplishment; $D=$ Depersonalization. 
Table E8. Frequencies in the experience of 22 feelings related to occupation burnout among all Health Extension Workers across the four regions, 2019, percent

\begin{tabular}{|c|c|c|c|c|c|c|c|c|}
\hline Statement & $\begin{array}{l}\text { Sub- } \\
\text { scale }\end{array}$ & $\begin{array}{c}\text { Every } \\
\text { day }\end{array}$ & $\begin{array}{c}\text { Some- } \\
\text { times } \\
\text { in a } \\
\text { week }\end{array}$ & $\begin{array}{c}\text { Once a } \\
\text { week }\end{array}$ & $\begin{array}{l}\text { Some- } \\
\text { times } \\
\text { in a } \\
\text { month }\end{array}$ & $\begin{array}{l}\text { Once a } \\
\text { month } \\
\text { or less }\end{array}$ & $\begin{array}{c}\text { Once a } \\
\text { year or } \\
\text { less }\end{array}$ & Never \\
\hline \multicolumn{9}{|l|}{ Depersonalization } \\
\hline Worry that job is hardening emotionally & $\mathrm{D}$ & 14 & 7 & 7 & 10 & 5 & 11 & 46 \\
\hline Treat patients as impersonal "objects" & $\mathrm{D}$ & 9 & 4 & 5 & 4 & 4 & 5 & 68 \\
\hline Become more callous toward people & $\mathrm{D}$ & 3 & 3 & 2 & 2 & 4 & 3 & 84 \\
\hline Don't really care what happens to patients & $\mathrm{D}$ & 8 & 1 & 1 & 4 & 2 & 3 & 81 \\
\hline Feel patients blame for their problems & $\mathrm{D}$ & 19 & 4 & 6 & 8 & 5 & 18 & 40 \\
\hline \multicolumn{9}{|l|}{ Emotional Exhaustion } \\
\hline Feel emotionally drained from work & EE & 12 & 3 & 3 & 7 & 9 & 18 & 48 \\
\hline Feel used up at the end of the workday & EE & 10 & 4 & 4 & 7 & 7 & 10 & 57 \\
\hline Feel fatigued I get up in the morning & EE & 10 & 8 & 3 & 5 & 8 & 16 & 50 \\
\hline Feel frustrated by my job & EE & 8 & 4 & 3 & 3 & 6 & 16 & 60 \\
\hline Working with people puts too much stress & EE & 9 & 3 & 6 & 10 & 12 & 14 & 47 \\
\hline Working with patients is a strain & EE & 11 & 5 & 3 & 5 & 6 & 8 & 63 \\
\hline Feel I'm working too hard on my job & EE & 45 & 11 & 4 & 4 & 8 & 8 & 20 \\
\hline Feel like I'm at the end of my rope & EE & 10 & 4 & 5 & 4 & 7 & 13 & 56 \\
\hline Feel burned out from my work & EE & 13 & 3 & 3 & 7 & 5 & 12 & 57 \\
\hline \multicolumn{9}{|l|}{ Personal Accomplishment } \\
\hline Feel very energetic & PA & 63 & 7 & 2 & 5 & 5 & 8 & 10 \\
\hline Can easily create a relaxed atmosphere & PA & 49 & 10 & 6 & 10 & 11 & 6 & 7 \\
\hline Have accomplished worthwhile things in job & PA & 61 & 10 & 6 & 6 & 6 & 5 & 6 \\
\hline Feel positively influencing people's lives & PA & 41 & 8 & 7 & 4 & 8 & 7 & 25 \\
\hline Deal with emotional problems calmly & PA & 51 & 11 & 8 & 7 & 4 & 6 & 13 \\
\hline Can easily understand patients' feelings & PA & 62 & 7 & 8 & 5 & 6 & 5 & 7 \\
\hline Deal effectively with the patients' problems & PA & 64 & 12 & 6 & 4 & 6 & 3 & 6 \\
\hline Feel exhilarated after working with patients & PA & 74 & 5 & 4 & 4 & 5 & 3 & 5 \\
\hline
\end{tabular}

Source: HEW quantitative survey, August 2019.

Note: Sample size is 250. EE = Emotional Exhaustion; PA = Personal Accomplishment; $D=$ Depersonalization. 


\section{ABOUT THE AUTHORS}

Guush Berhane is a Research Fellow in the Development Strategy and Governance Division (DSGD) of the International Food Policy Research Institute (IFPRI), based in Addis Ababa. Jenna Golan is a Doctoral candidate in the Program in International Nutrition in the Division of Nutritional Sciences at Cornell University, Ithaca, NY, USA. Kalle Hirvonen is a Senior Research Fellow in DSGD of IFPRI, based in Addis Ababa. John Hoddinott is Professor of Food and Nutrition Economics and Policy at Cornell University, Ithaca, NY, USA, Sunny Kim is a Research Fellow in the Poverty, Health, and Nutrition Division of IFPRI, based in Washington, DC. Alemayehu Seyoum Taffesse is a Senior Research Fellow in DSGD of IFPRI, based in Addis Ababa. Kibrewossen Abay was a Research Officer in the Ethiopia Strategy Support Program (ESSP) of IFPRI at the time this research was conducted and is now a consultant at the World Bank, based in Addis Ababa. Thomas Assefa was a Research Officer in ESSP at the time this research was conducted and is now a Doctoral candidate at the University of Georgia, Athens, GA, USA. Yetmwork Habte is a Research Officer in ESSP of IFPRI, based in Addis Ababa. Mehari Hiluf Abay was a Research Officer in ESSP at the time of this research was conducted and is now a researcher at the Tigray Institute of Policy Studies. Bethelem Koru is a Research Officer in ESSP of IFPRI, based in Addis Ababa. Fanaye Tadesse was a Research Officer in ESSP at the time of this research was conducted and is now with UNICEF, based in Addis Ababa. Haleluya Tesfaye is a Research Officer with DSGD of IFPRI, based in Addis Ababa. Abdulazize Wolle is a Research Officer with DSGD of IFPRI, based in Addis Ababa. Feiruz Yimer was a Research Officer in ESSP at the time of this research was conducted and is now pursuing at Master's degree in Public Administration in International Development at the Kennedy School of Government, Harvard University, Cambridge, MA, USA.

\section{ACKNOWLEDGEMENTS}

This work has been funded by the Bill and Melinda Gates Foundation (Award No. OPP1162182). We are grateful to Raphael Mekonnen, Rahul Rawat, and Amsale Mengistu of the Bill and Melinda Gates Foundation for their support throughout the project.

We also thank the Ethiopian Central Statistical Agency for their support during the fieldwork. We acknowledge the staff at BST Survey Solutions for the critical role they played during the fieldwork, ensuring that all work was undertaken to a high standard. The hard work by the 88 Central Statistical Agency enumerators and 22 BST supervisors, who spent several weeks travelling and living in PSNP localities, often in very challenging conditions, is also greatly acknowledged.

We are grateful for the administrative support provided by the International Food Policy Research Institute's (IFPRI) Ethiopian Strategic Support Program, particularly from Mahlet Mekuria and Nahume Yadene.

We have benefitted from conversations with many people on aspects of the nutrition-sensitive components of the Food Security Program. In the preparation of this report, discussions with Anne Bossuyt (formerly UNICEF-Ethiopia), Ato Tewodros Hailemariam from the Ministry of Agriculture, and Haregewien Admassu from the World Bank have been particularly valuable. This report has also benefited from participants at the 'Progress in the implementation of nutrition-sensitive PSNP-4' seminar organized at UNICEF, Addis Ababa, on 24 December 2019. Moreover, we are indebted to UNICEF-Ethiopia for providing us with the MUAC measurement kits used in the surveys. 
Finally, none of this work would have been possible without the openness and hospitality of the 2,635 households and more than 220 health workers who sat with us through the interviews answering our questions about themselves. We thank them all sincerely.

The authors of this report are solely responsible for its content.

INTERNATIONAL FOOD POLICY RESEARCH INSTITUTE

1201 Eye St, NW | Washington, DC 20005 USA

T. +1-202-862-5600 | F. +1-202-862-5606

Email: ifpri@cgiar.org | www.ifpri.org | www.ifpri.info

IFPRI-ESSP ADDIS ABABA

P.O. Box 5689, Addis Ababa, Ethiopia

T. +251-11-617-2000 | F. +251-11-667-6923

Email: ifpri-essp@cgiar.org | http://essp.ifpri.info
POLICY STUDIES INSTITUTE

P.O. Box 2479, Addis Ababa, Ethiopia

T. +251.11-550-6066; +251-11-553-8633 | F. +251-11-550-5588 http://psi.gov.et/

The Ethiopia Strategy Support Program (ESSP) is managed by the International Food Policy Research Institute (IFPRI); is jointly implemented with the Policy Studies Institute (PSI); and is financially supported by the United States Agency for International Development (USAID), the Department for International Development (DFID) of the government of the United Kingdom, and the European Union (EU).

This publication has been prepared as an output of ESSP and has not been independently peer reviewed. Any opinions expressed here belong to the author(s) and are not necessarily representative of or endorsed by IFPRI, PSI, USAID, DFID, or EU.

(c) 2020, Copyright remains with the author(s). This publication is licensed for use under a Creative Commons Attribution 4.0 International License (CC BY 4.0). To view this license, visit https://creativecommons.org/licenses/by/4.0. 